\title{
Ontogeny of the Hapuka (Polyprion oxygeneios) Immune System
}

\author{
BY
}

SIMON PARKER

A thesis submitted to the Victoria University of Wellington

in fulfilment of the requirements for the degree of Master of Science

Victoria University of Wellington

2013 


\begin{abstract}
In this study the ontogeny of the hapuka (Polyprion oxygeneios) immune system was studied during larval development. In teleost fish, the head kidney, thymus, and spleen are generally regarded as important immune organs. The head kidney was observed at 4 days post hatch (dph), the spleen at $16 \mathrm{dph}$ and lastly the thymus at $20 \mathrm{dph}$ and all 3 lymphoid organs were relatively well developed by $45 \mathrm{dph}$. The immune genes CSF1R, C3, MHCII $\alpha$, TCR $\alpha$, TCR $\beta$, RAG1, IgM and IgZ were examined by RT-PCR to investigate the leucocyte development. Macrophages appear to be present from hatch with both CSF1R and MHCII $\alpha$ expression from $1 \mathrm{dph}$, while IgM is expressed at $9 \mathrm{dph}$. T-cells appear later in hapuka with TCR $\beta$ expression first detected at $32 \mathrm{dph}$ whereas TCR $\alpha$ was not expressed until after $63 \mathrm{dph}$. Immunostaining using a monoclonal antibody against fish IgM detected IgM in the head kidney at $12 \mathrm{dph}$, the spleen at $32 \mathrm{dph}$, the intestinal tract at $45 \mathrm{dph}$ and lastly the thymus at $50 \mathrm{dph}$. Comparison of the leucocyte populations in juveniles and adults indicated that innate cell populations are late to develop, while the adaptive cells mature earlier in hapuka than expected. Finnally, the maternal transfer of immunity was examined and while lysozyme and IgM appear to be transferred, complement does not. Overall this study provides insight into the developmental sequence of immune organs and cells and will be useful in understanding the timing of immune competence in juveniles and adult hapuka.
\end{abstract}




\section{Acknowledgements}

First and foremost, I would like to thank Dr. Irene Salinas for her continuous support of my study and research, her patience and immense knowledge. Her guidance during my research and writing of this thesis was paramount.

In addition to my immediate supervisor, I would like to thank Prof. Anne la Flamme, for her awesome guidance, affable nature and keen insight.

I would also like to thank Jane Anderson from the Otago School of medicine for her epic contribution with preparing the tissues for histological analysis.

Lastly I would like to thank my golden girl Melissa Francis for her advice, her warmth and her all round aura of awesomeness. 


\section{Table of contents}

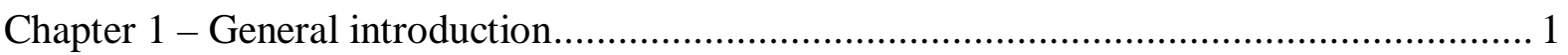

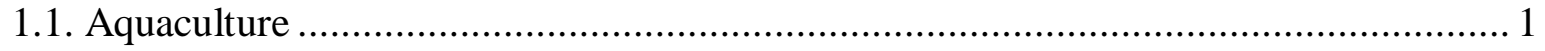

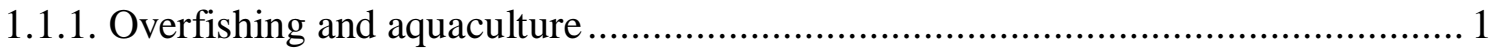

1.1.2. New Zealand groper "hapuka” (Polyprion oxygeneios) ..................................... 2

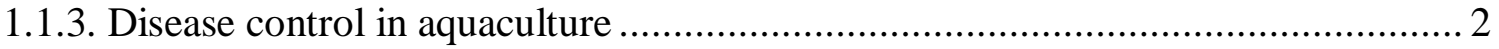

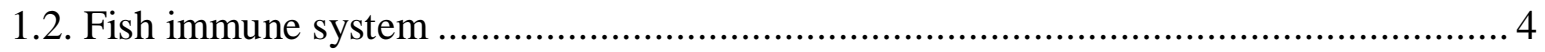

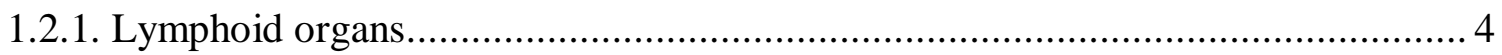

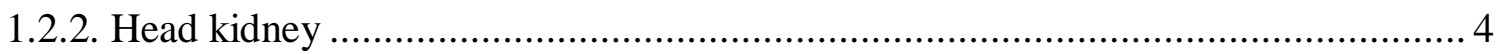

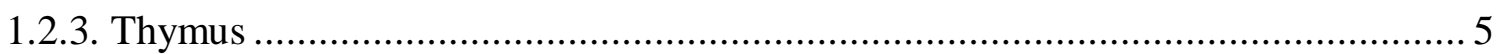

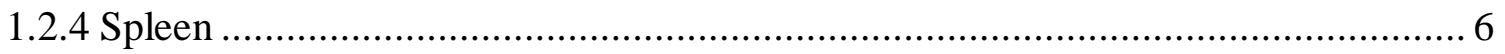

1.2.5. Mucosal-associated lymphoid tissues (MALT) ............................................... 7

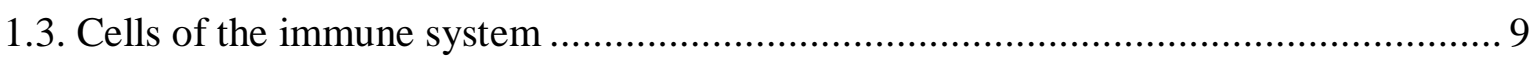

1.3.1. Cellular components of the teleost immune system...................................... 9

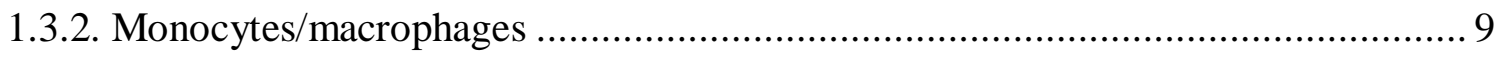

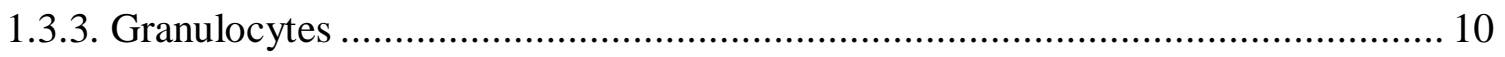

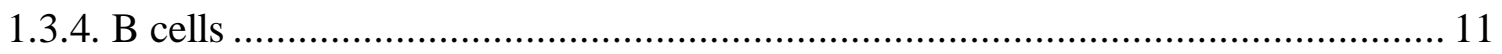

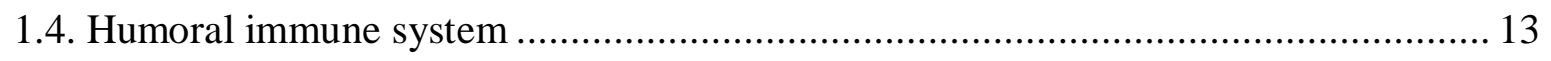

1.4.1. Components of the humoral immune system................................................. 13

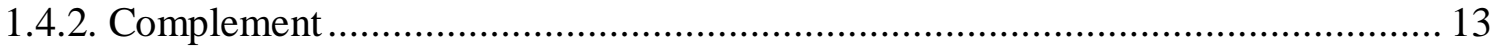

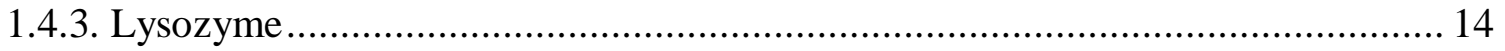

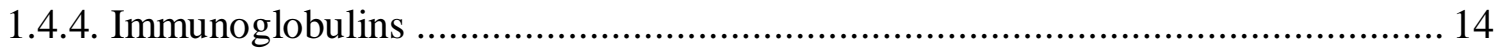

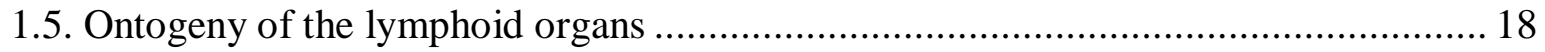

1.5.1. Light microscopy for studying lymphoid organ ontogeny ................................ 18

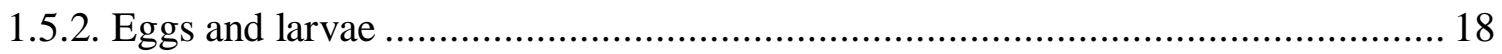


1.5.3. Ontogeny of the head kidney

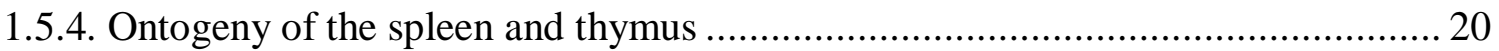

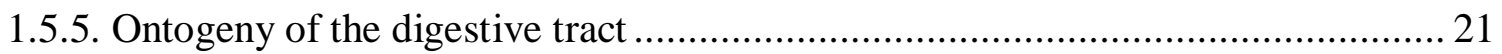

1.6. Ontogeny of the cellular and humoral immune system ........................................ 24

1.6.1. Ontogeny of the cellular immune system using cell markers .............................. 24

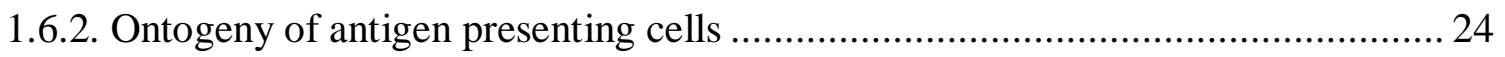

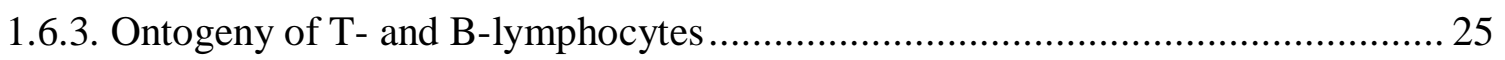

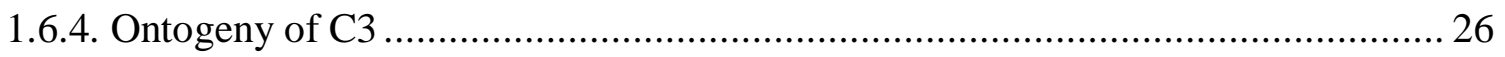

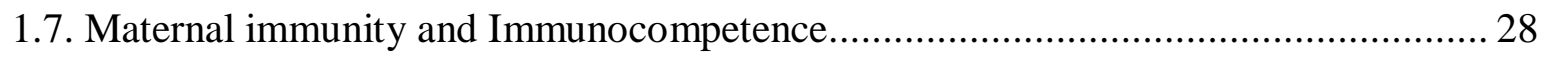

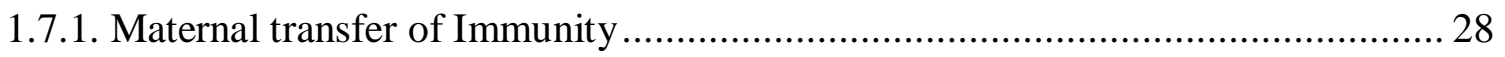

1.7.2. Factors affecting maternal immunity ..................................................... 30

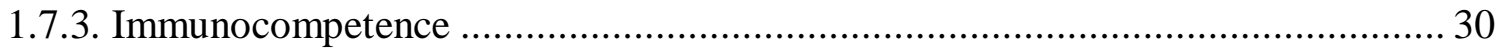

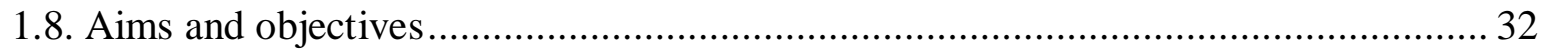

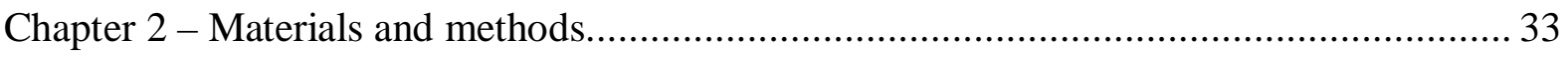

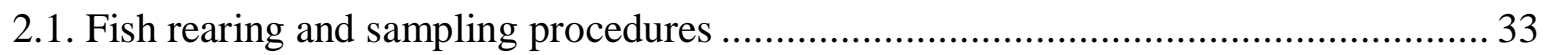

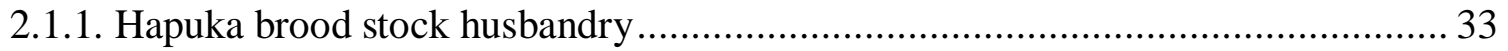

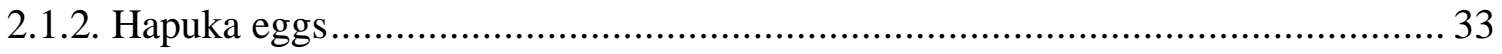

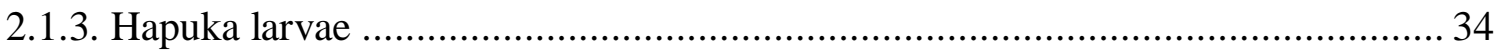

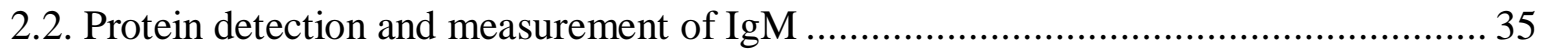

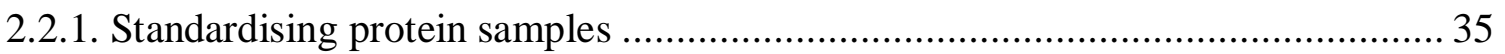

2.2.2. Enzyme-linked immunosorbent assays (ELISA) ........................................... 35

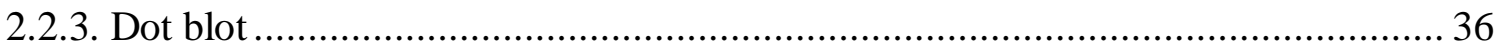

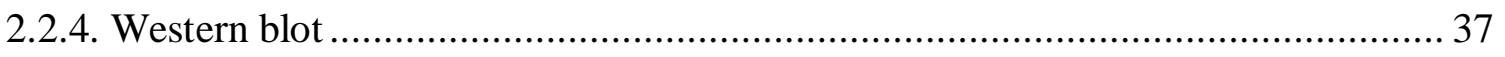

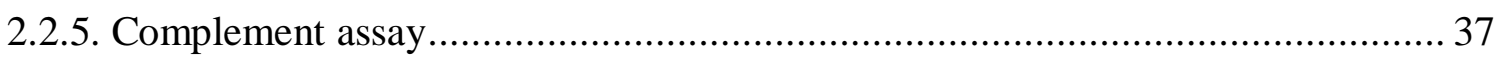

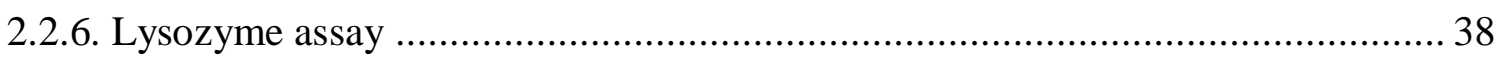


2.3. Gene expression studies .....

2.3.1. Total RNA and cDNA preparation for reverse transcription polymerase chain

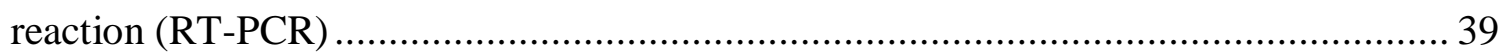

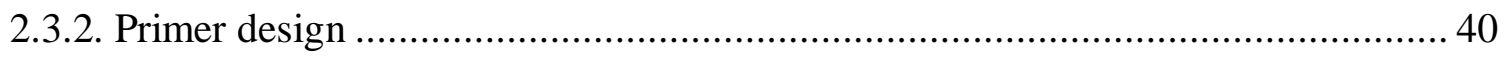

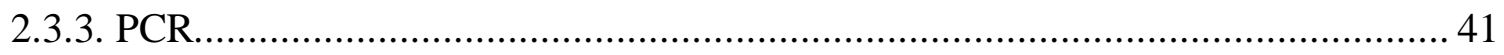

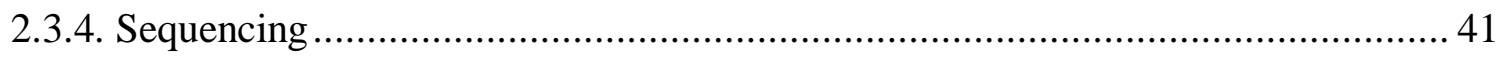

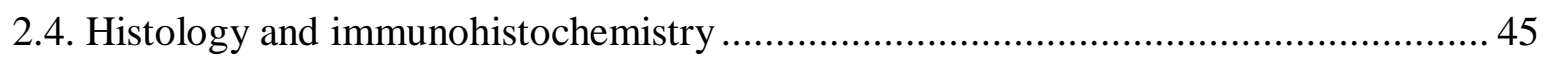

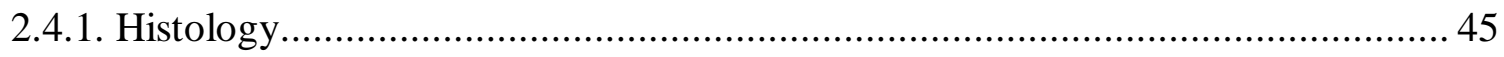

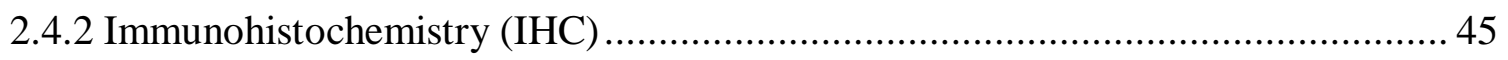

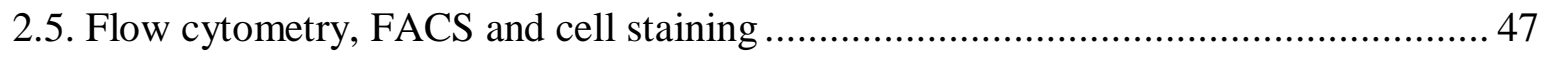

2.5.1. Flow cytometry and fluorescence-activated cell sorting ............................... 47

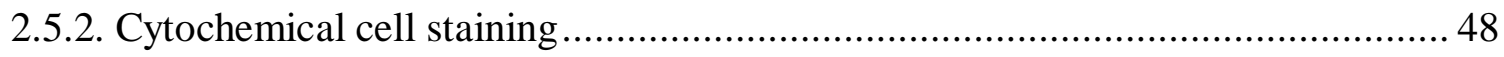

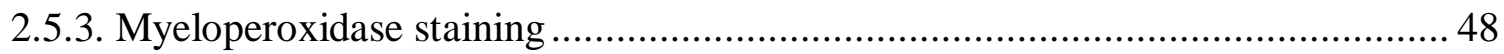

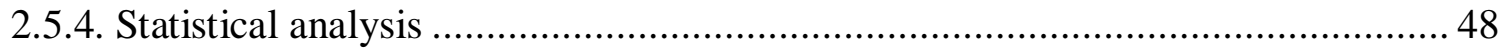

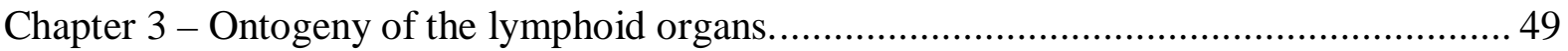

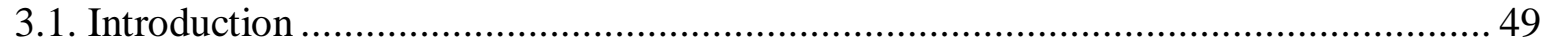

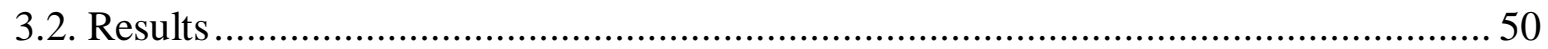

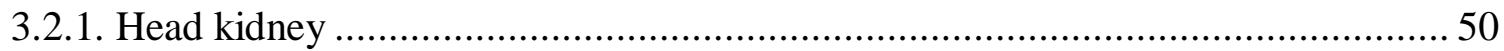

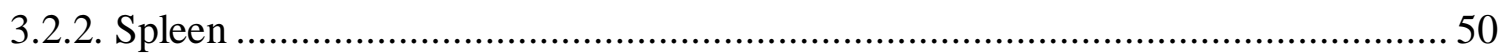

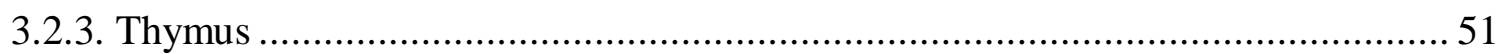

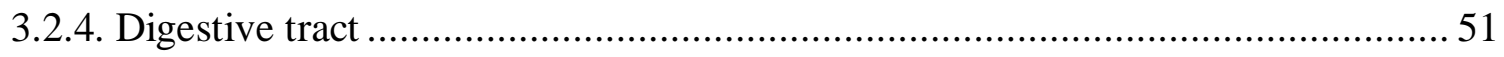

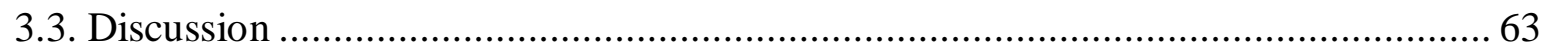

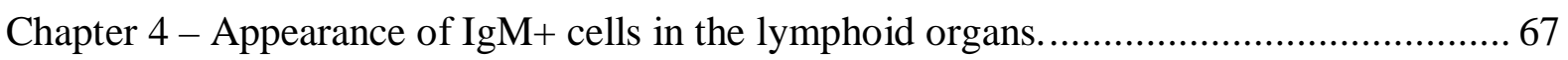

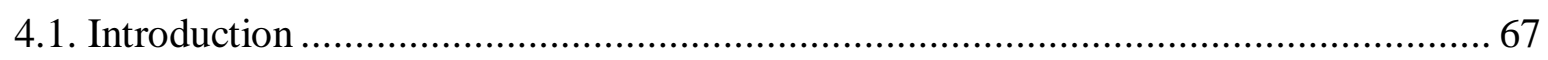

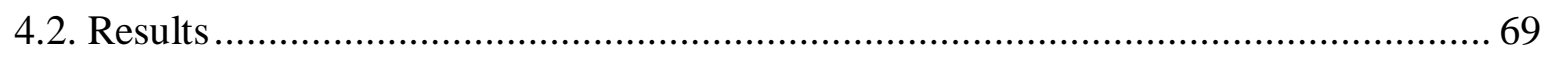




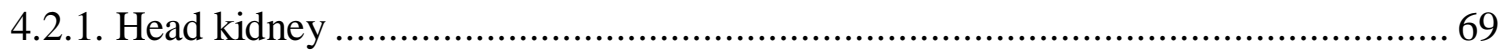

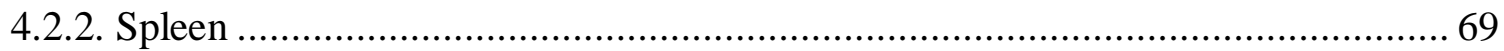

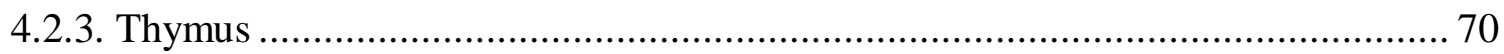

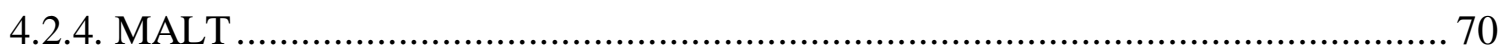

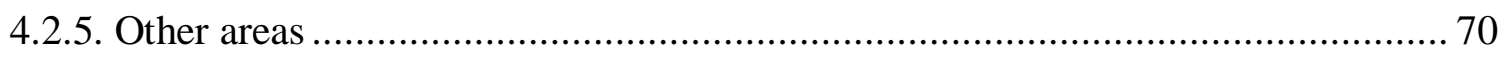

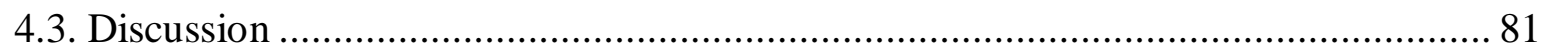

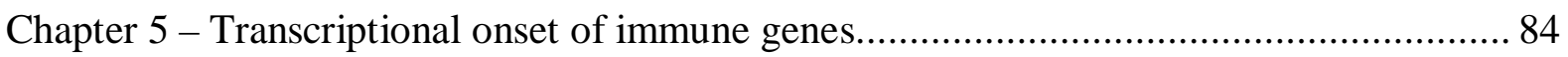

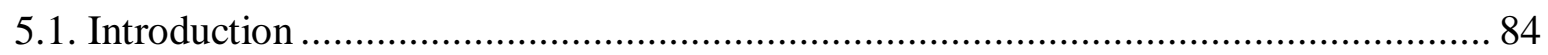

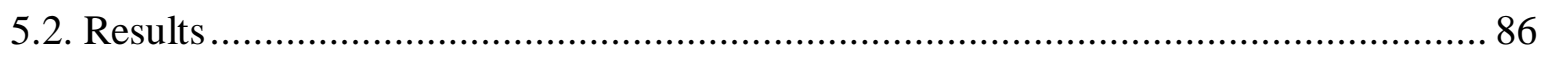

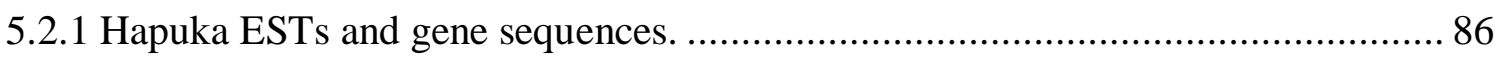

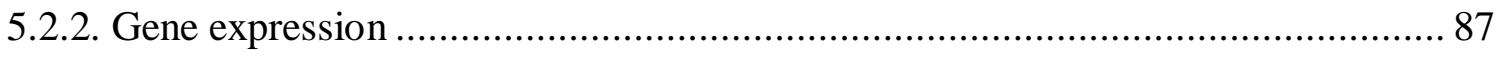

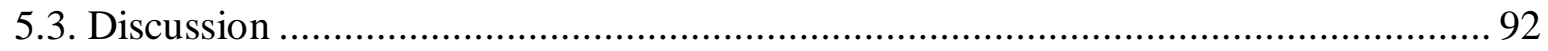

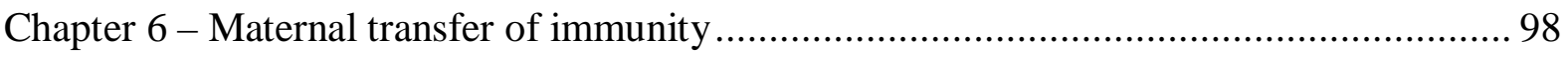

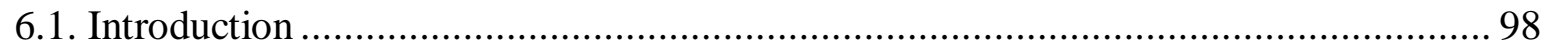

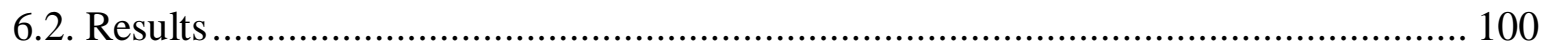

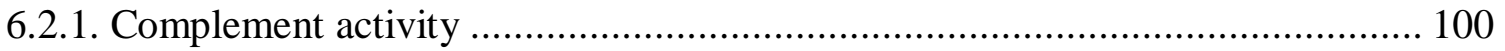

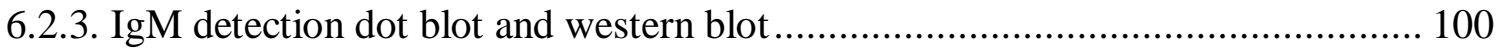

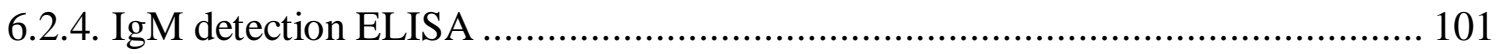

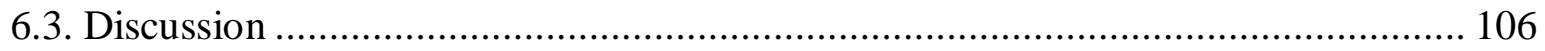

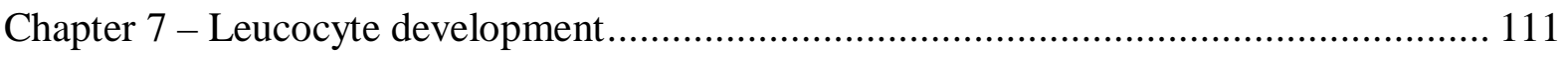

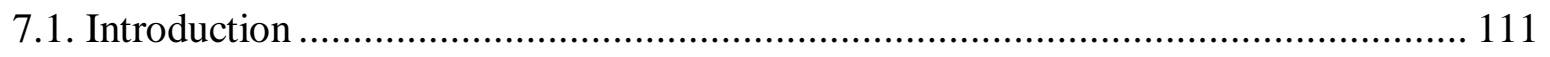

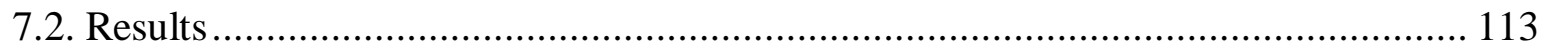

7.2.1 Morphology of adult and juvenile hapuka leucocytes.................................... 113

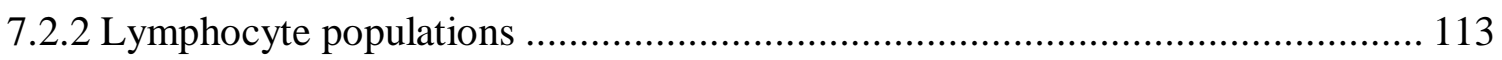

7.2.3. Morphology of adult and juvenile hapuka leucocytes................................... 113 


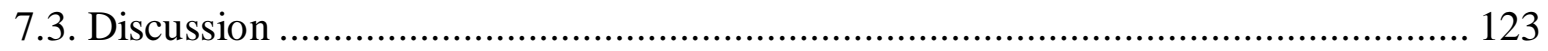

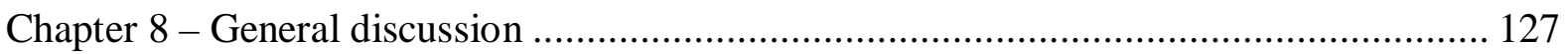

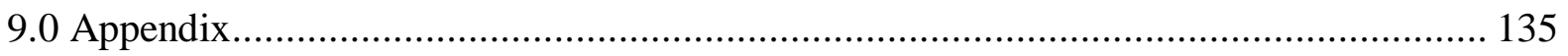

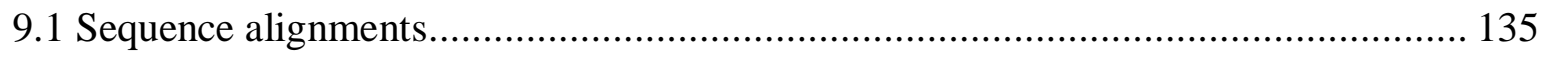

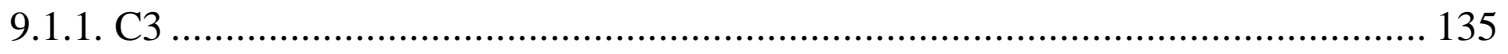

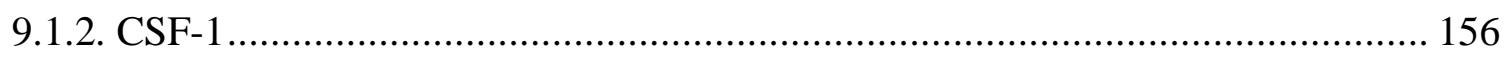

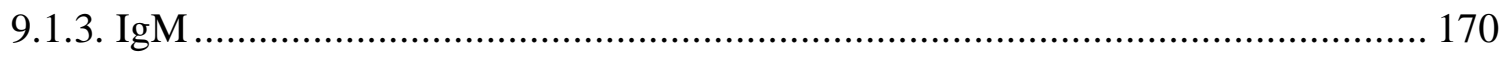

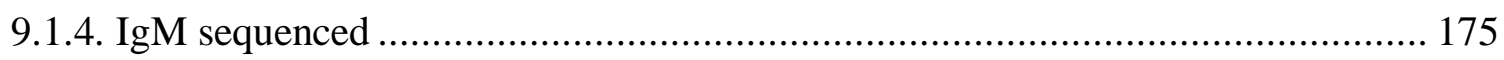

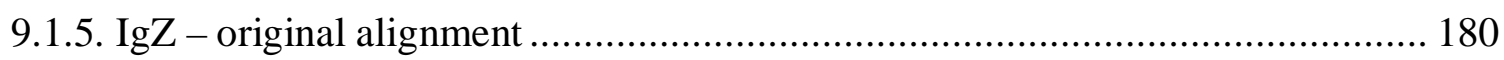

9.1.6. Obtained IgZ sequence for hapuka.......................................................... 186

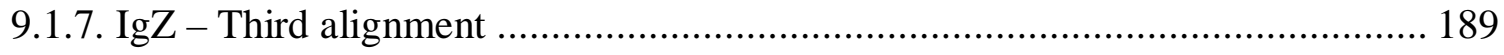

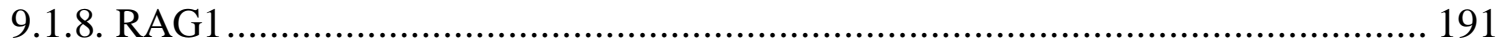

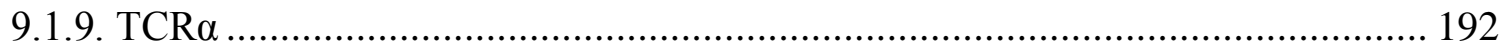

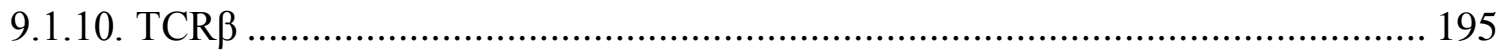

9.1.11. MHCII

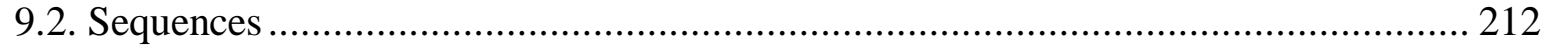

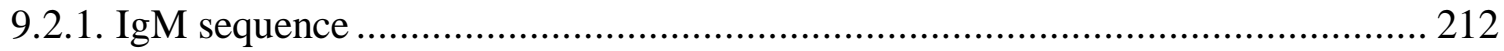

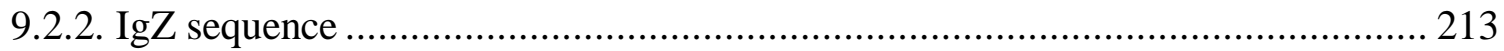

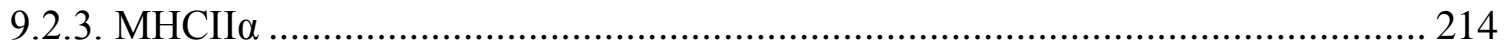

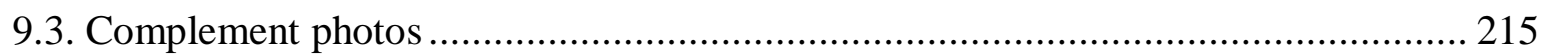

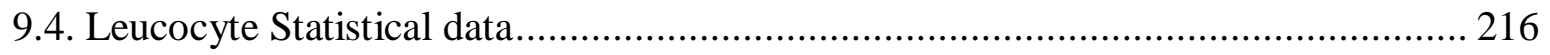




\section{Table of figures}

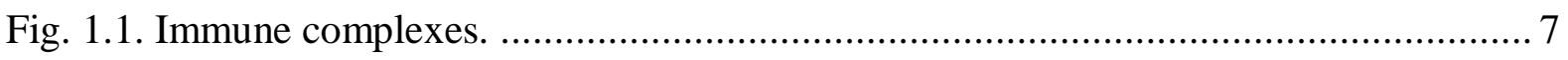

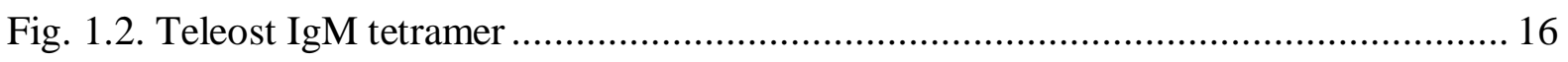

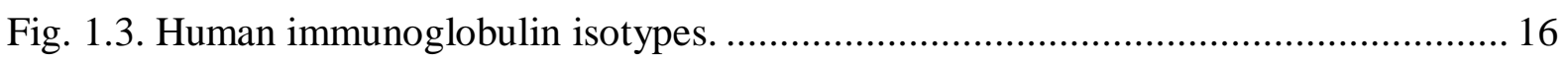

Fig. 3.1. Sagittal cut sections showing morphological development of the kidney of hapuka at 4-7 dph. 52

Fig. 3.2. Sagittal cut sections showing morphological development of the kidney of hapuka at 8-16 dph. 54

Fig. 3.3. Sagittal cut sections showing morphological development of the kidney of hapuka at 20-63 dph. 57

Fig. 3.4. Sagittal cut sections showing morphological development of the spleen of hapuka.59 Fig. 3.5. Sagittal cut sections showing morphological development of the thymus of hapuka.

Fig. 3.6. Sagittal cut sections showing morphological development of the gut of hapuka..... 62

Fig. 4.1. The appearance of $\operatorname{IgM}^{+}$cells in the head kidney of hapuka larvae. ...................... 73

Fig. 4.2. The appearance of $\operatorname{IgM}^{+}$cells in the spleen of hapuka larvae. .............................. 74

Fig. 4.3. The appearance of $\operatorname{IgM}^{+}$cells in the thymus of hapuka larvae............................... 76

Fig. 4.4. The appearance of $\operatorname{IgM}^{+}$cells in the intestine of hapuka larvae. ............................ 78

Fig. 4.5. The appearance of $\operatorname{IgM}^{+}$cells in other areas of hapuka larvae. ............................. 80

Fig. 5.1. Neighbour-joining phylogenetic tree based on MHC class IIa sequences from perciformes fish, using the Tamura-Nei model. 88

Fig. 5.2. Neighbour-joining phylogenetic tree based on IgM heavy chain sequences from perciformes fish, using the Tamura-Nei model.

Fig. 5.3. Gene expression profiles for selected immune genes and corresponding $\beta$-actin amplification in hapuka larvae at various days post hatch. 91 
Fig. 6.1. Photograph of a 96 well plate showing no red blood cell lysis by complement

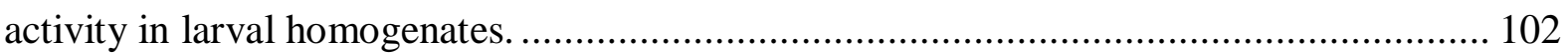

Fig. 6.2. Lysozyme activity is present in hapuka eggs.................................................. 103

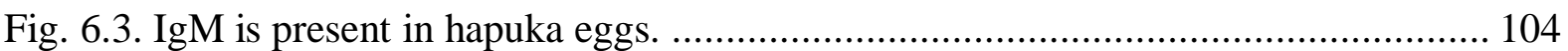

Fig. 6.4. IgM is present in the eggs and decreases until endogenous production................. 105

Fig. 7.1. Flow cytometric analysis of juvenile and adult head kidney leucocyte populations.

Fig. 7.2. Flow cytometric analysis of juvenile and adult peripheral blood leucocyte populations 116

Fig. 7.3. Flow cytometric analysis of hapuka lymphocyte populations between adult and juveniles after being incubated with an IgM labelling antibody. 117

Fig. 7.4. Morphological and cytochemical appearance of adult hapuka leucocytes by light microscopy.

Fig. 7.5. Morphological and cytochemical appearance of juvenile hapuka leucocytes by light microscopy 


\section{Table of tables}

Table 1.1 Timing in dph and hpf of the major lymphoid organs in several perciformes species including the cyprinid zebrafish. 23

Table 2.1. Oligonucleotide primers used for amplification of hapuka cDNA target genes for PCR expression studies. 42

Table 2.2. Oligonucleotide primers used for amplification of hapuka IgM, IgZ and MHCII sequences.

Table 3.1. The first appearance of the lymphoid organs in perciform fish, including the cyprinid zebrafish. 66

Table 8.1. Important ontogenic events of the hapuka immune system. 134 


\section{Abbreviations/Glossary}

Anlage: the initial clustering of embryonic cells that serves as a foundation from which an organ develops

C3: complement factor 3

CSF1R: colony stimulating factor 1 receptor

Dpf: days post fertilisation

Dph: days post hatch

Ellipsoid: terminations of arterioles and are closely associated with reticular cells and macrophages

GALT: Gut-associated lymphoid tissue

Hpf: hours post fertilisation

Ig: immunoglobulin

Immunocompetence: when an organism's immune system is mature

MALT: mucosal-associated lymphoid tissue

MHCII $\alpha$ : major histocompatibility complex Class II

MMC: melanomacrophage center

MPO: myeloperoxidase

RAG1: recombinase activating gene 1

Sinusoid: specialised blood vessel

Teleost: (bony fish) one of three infraclasses in class Actinopterygii

TCR: T cell receptor 


\section{Chapter 1 - General introduction}

\subsection{Aquaculture}

\subsubsection{Overfishing and aquaculture}

Overfishing has become a big problem over the last few decades with many fish stocks over exploited. During the early 1990s Atlantic cod stocks collapsed, declining to less than 95\% of their maximum historical biomass and have yet to recover (Frank et al., 2005). Several other important commercial fish populations have decreased to the point where their survival is threatened and it is predicted that stocks of all fished species will collapse by mid century. Sustainable alternatives to commercial fishing such as aquaculture are continuing to rise as a better alternative.

Aquaculture is the farming of aquatic organisms including fish, molluscs, crustaceans and aquatic plants. Aquaculture has become the fastest growing food producing sector in the world, with an average annual growth rate of 8.9\% since 1970 (Bondad-Reantaso et al., 2005). Aquaculture in New Zealand started around the late 1960s and is dominated by the green-lipped mussel (Perna canaliculus), the pacific oyster (Crassostrea gigas) and the king salmon (Onchorhynchus tshawytscha). Recently New Zealand has put forward an ambitious goal with a target of increasing its aquaculture industry to be worth an annual one billion NZ dollars by the year 2025. With potential for the industry to diversify and the marine finfish farming continuously looking for new specices suitable for aquaculture, one such candidate of interest is the New Zealand groper or hapuka (Polyprion oxygeneios (Schneider \& Forester, 1801)). 


\subsubsection{New Zealand groper “hapuka” (Polyprion oxygeneios)}

Hapuka (P. oxygeneios) is a species of wreckfish (Polyprionidae family) found in waters around New Zealand, southern Australia, southern Chile and a number of Southern Ocean islands. Belonging to the Perciformes order of fish, the wreckfish family includes 6 species of fish belonging to 2 genera, Stereolepis and Polyprion. Stereolepis consists of S. doederleini and S. gigas, whereas Polyprion consists of P. americanus, P. moeone, P. yanezi and P. oxygeneios (hapuka). Hapuka live predominately in temperate mid-shelf to upper slope waters in depths ranging from 20 meters $(\mathrm{m})$ to a maximum recorded depth of $854 \mathrm{~m}$ and are associated strongly with floating objects (Roberts, 1996). Small juvenile hapuka have a unique life strategy involving an extended pelagic stage of up to 4 years in oceanic waters, obtaining sizes of up to 670 millimeters (mm) total length (Roberts, 1996). At about $500 \mathrm{~mm}$ in length and an estimated 3-4 years of age, they become demersal in depths of 50-600 m and become vulnerable to bottom trawlers (Beentjes and Francis, 1999). Hapuka are large, longlived fish with reports of specimens being more than $1700 \mathrm{~mm}$ in length and 70 kilograms (kg) in weight, and living longer than 60 years (Wakefield et al., 2010). Although hapuka are slow growing and long lived, growth in size of $2 \mathrm{~kg}$ within 12 months for juveniles is considered rapid, making them an ideal candidate for aquaculture. Furthermore hapuka are valued highly by recreational and commercial fishers, because of their flesh quality and texture (Beentjes and Francis, 1999). Knowledge of larval development and immune system ontogeny for wild and captive hapuka will be crucial for the development of an effective aquaculture programme.

\subsubsection{Disease control in aquaculture}

Aquaculture operations aim to produce large numbers of healthy fish for consumption under intensive conditions by means that are biologically and economically efficient. However, the intensive farming practices of aquaculture can have negative effects on the fish, causing stress and rendering them more prone to disease. It is becoming increasingly apparent that disease outbreaks significantly inhibit aquaculture production and trade, affecting the economic development of the sector in many countries (Balcazar et al., 2006). There can be many different sources of stress in fish culture conditions and among them crowding is the most common, along with handling procedures such as confinement or capture (Rotllant et al., 1997). Additionally, studies have shown that high stocking densities may have effects on 
feeding behaviour (Kentouri et al., 1994), growth rate (Pickering and Stewart, 1984), disease resistance (Mazur and Iwama, 1993) and even the skin colour of fish (Van der Salma et al., 2004). Most importantly, a decreased immune function means that fish become more susceptible to disease resulting in mortalities and economic losses (Bakopoulos et al., 1997). Furthermore, fish eggs are released and embryos hatch into a pathogenically hostile environment, at a time when the embryo's immunological capacity is still extremely limited (Mulero et al, 2007). Because of this limitation, high mortality rates in the early larval stages are common in the aquaculture industry for many fish species (Seppola et al., 2009). Mortalities have also been recorded in early attempts to rear hapuka due to protozoan parasites (personal communication, Salinas, I.). Immunostimulation and vaccination can provide fish protection from potential pathogens. However, the effectiveness of immunostimulation and vaccination methods used on cultured fish largely depends on the level of maturity of their immune system (Mulero et al., 2007b). Yet nothing is known about the immune system of hapuka or when their larvae become immunocompetent. For successful aquaculture of marine finfish, understanding and knowledge of their immune system is essential. 


\subsection{Fish immune system}

\subsubsection{Lymphoid organs}

Fish are a very heterogeneous group of animals that include the agnathans (lampreys and myxines), chondrichthyes (sharks and rays) and teleosteans "teleosts” (bony fish) (Tort et al., 2003), to which hapuka belong. Like their mammalian counterparts, the immune system of teleost fish is composed of both cellular and humoral components and displays an innate and adaptive immune response. Fish possess central or primary lymphoid organs which govern the immune response as their main function. In addition to these, fish have a series of secondary lymphoid organs, known as the mucosal associated lymphoid tissues (MALT). In this section the main components of the adult teleost immune organs will be described.

\subsubsection{Head kidney}

Although fish and mammals share many similarities regarding their immune functions, there are obvious differences. Anatomically, major differences include the lack of lymph nodes and bone marrow in fish (Whyte, 2007). Instead of bone marrow, fish hematopoiesis occurs in the anterior portion of the kidney, called the head kidney and is one of the 3 main lymphoid organs along with the spleen and thymus (Fänge, 1986). This portion of the kidney lacks excretory tissue such as renal tubules and is predominantly lympho-myeloid in nature. The fish kidney is a Y shaped organ located behind the head and spreads along parallel to the vertebral column with only the posterior end carrying out renal function. The parenchyma of the head kidney is dispersed between large networks of sinusoids (specialised blood vessels) supported by the stroma of the kidney. The stroma can be referred to as a reticulo-endothelial stroma which is made up of endothelial cells that line the sinusoids, the adventitial cells which cover the abluminal surface of the endothelial cells, and lastly the reticular cells which are involved in phagocytosis (Meseguer et al., 1995).

The hematopoietic tissue of the head kidney is supported by the stroma, which also has an important role in non specific immunity and the clearance of debris and damaged cells. Thus the renal portal system acts like a filtration bed with the sinusoidal macrophages and endothelial cells trapping and removing particles from the bloodstream (Dannevig et al., 1994; Press et al., 1994; Espenes et al., 1995). Unlike higher vertebrates the kidney is the 
principal immune organ responsible for phagocytosis (Dannevig et al., 1994), antigen processing (Brattgjerd and Evensen, 1996) and generation of adaptive immune responses (Herraez and Zapata, 1986). The head kidney is a major producer of B cells and thus antibody and the melanomacrophage accumulations of the parenchyma are able to retain antigens for long periods of time after administration or vaccination (Herraez and Zapata, 1986; Press et al., 1996) possibly being involved with immunological memory (Press et al., 1996). The melanomacrophage accumulations or centers (MMCs) are are distinctive groupings of pigment-containing cells usually found within the hematopoietic tissues (Agius and Roberts, 2003). Their functions are many but include acting as metabolic dumps for the relocation of debris such as red blood cells, while also participating in antigen capture and presentation (Agius and Roberts, 2003). The head kidney is also an important endocrine organ, homologous to mammalian adrenal glands; releasing various hormones (Tort et al., 2003). Thus, the teleost head kidney is an organ with key hematopoietic and regulatory functions, as well as being central for immune and endocrine interactions.

\subsubsection{Thymus}

The thymus, another key lymphoid organ in teleosts, is a paired organ situated in the dorsolateral region of the gill chamber, near the opercular cavity. The first morphological sign of the thymus anlage (initial clustering of cells) is present as early as 24 hours after fertilisation in the Tilapia species (Fishelson, 1995) or late in species such as in Atlantic halibut (Hippoglossus hippoglossus L.), first detected at 33 dph (Patel et al., 2009). The thymus lies on a connective tissue layer and is covered by the modified stratified epithelium of the gill chamber. In the thymus, an outer layer (cortex) and an inner layer (medulla) can usually be distinguished, and is composed of epithelial cells and thymocytes (Press and Evensen, 1999). The cortex usually contains a higher density of thymocytes than the medulla and relatively few epithelial cells, which when present are characterised by long and slender cellular projections. The medulla is less densely populated with cells but the epithelial cells are more prominent and form a supporting meshwork (Press and Evensen, 1999). This zonation of the thymus is observed in some species such as turbot (Scophthalmus maximus L.), sea bream (Sparus aurata) and Atlantic halibut (Jósefsson and Tatner, 1993; Padros and Crespo, 1996; Patel et al., 2009); while in other species such as the salmon (Salmo salar L.) and olive flounder (Paralichthys olivaceus) no zonation is observed (Ellis, 1977a; Liu et al., 
2004). The thymus is primarily responsible for maturation of $T$ lymphocytes, which are fundamental mediators of the adaptive immune response and are involved in cellular killing of infected cells (Bowden et al., 2005).

\subsubsection{Spleen}

The last major lymphoid organ is the spleen, although the spleen of teleost fish is considered a secondary lymphoid organ. The absence of lymph nodes in fish suggests a pivotal role for the spleen in antigen presentation and the initiation of adaptive immune responses (ChavesPozo et al., 2005). The spleen has a fibrous capsule with small trabeculae extending into the parenchyma, which is usually divided into a red and white pulp. The red pulp consists of a reticular cell network supporting blood-filled sinusoids that hold diverse cell populations including macrophages and lymphocytes (Press and Evensen, 1999).

In teleosts, splenic lymphoid tissue (white pulp) is usually poorly developed, but prevalent layers of lymphoid tissue may surround arteries, ellipsoids and melanomacrophage centres and lymphocytes can be seen scattered throughout the parenchyma (Fänge and Nilsson, 1985). The ellipsoids are terminations of arterioles and are closely associated with reticular cells and macrophages. Ellipsoids have been shown to have a specialised function involving the filtration of plasma and trapping blood borne substances such as immune-complexes (Fig. 1.1) (Espenes et al., 1995). Melanomacrophage centres are special pigment-containing nodules that occur in the lymphohemopoietic tissues of most teleostean fishes (Fänge and Nilsson, 1985) and are major sites of erythrocyte destruction. Additionally interactions observed between melanomacrophage centres and lymphoid tissue indicate that the centres are involved in immune responses (Fänge and Nilsson, 1985). Melanomacrophage centres have also shown the remarkable ablitiy to retain antigens for long periods of time, possibly in the form of immune-complexes, drawing a comparison with the germinal centres in higher vertebrates (Ferguson, 1976; Agius, 1980). 


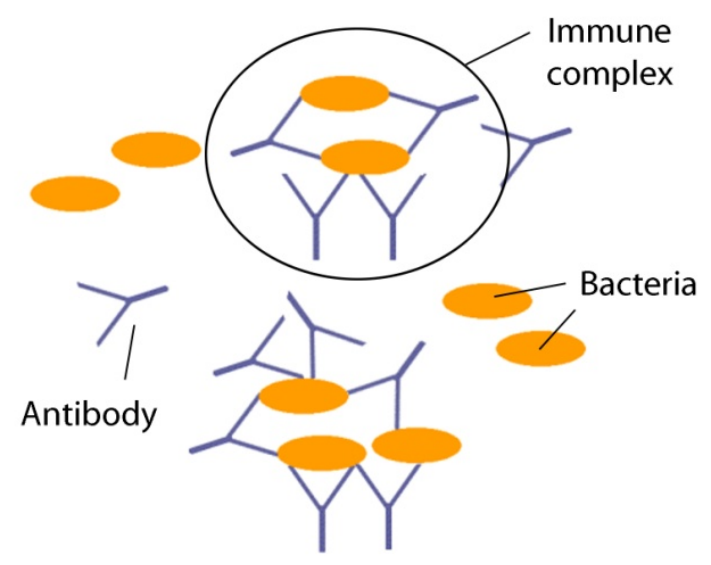

Fig. 1.1. Immune complexes.

\subsubsection{Mucosal-associated lymphoid tissues (MALT)}

Mucosal surfaces are physical barriers that separate and protect all animals from the surrounding environment. In addition to being physical barriers, mucosal surfaces also act as active immunological sites prepared with cellular and humoral defences (Press and Evensen, 1999). The mucosal surfaces are common pathogen entry sites because these surfaces act as an interface between animal and environment. Peyer's patches, IgA and $\mathrm{M}$ cells are not reported in teleost fish (Rombout et al., 2010). In teleost fish, the presence of immunoglobulins in mucosal secretions was first reported in plaice (Pleuronectes platessa) (Fletcher and Grant, 1969) and until recently it was believed IgM was the only functional immunoglobulin in teleosts, both in systemic and mucosal compartments (Salinas et al., 2011). However, the recent discovery of new immunoglobulin classes such as IgD (Yuko and Flajnik, 2006) and IgT/IgZ in different fish species has proven that paradigm wrong (Danilova et al., 2005; Hansen et al., 2005). Additionally a recent study reported that rainbow trout IgT specialized in gut mucosal immune responses, while IgM appears to be specialized in systemic immunity (Zhang et al., 2010; Zhang et al., 2011).

There are obvious physiological, anatomical and histological differences between terrestrial and aquatic vertebrates and so the presence of MALT in fish is distinct from their mammalian counterparts. In teleost fisht there are three main mucosal immune compartments including: the gut associated lymphoid tissue (GALT) with the lamina propria (LP) and intraepithelial lymphocyte (IEL) compartments; the skin-associated lymphoid tissue (SALT) and the gill- 
associated lymphoid tissue which includes the gills and the interbranchial immune tissue (ILT) (Salinas et al., 2011). Herbivorous, detritivorous, omnivorous and carnivorous fish species differ from each other in terms of the presence or absence of a stomach, the length of the intestine and the presence and number of pyloric caeca, intestinal loops and valves (Evans, 1998). Teleosts have a more diffuse GALT, which is morphological and functional different from the mammalian GALT, lacking organisation and containing no Peyer's patches or mesenteric lymph nodes. However, the LP and IEL compartments have been identified and lymphoid cells are present in a scattered manner along the alimentary canal (Salinas et al., 2011). The teleost LP houses many types of immune cells such as macrophages, granulocytes, lymphocytes and plasma cells, whereas the IEL compartment is mainly composed of $\mathrm{T}$ cells and few B cells. However, a lack of suitable antibodies makes the distinction of subpopulations within the GALT difficult (Rombout et al., 2010).

Immunological differences also exist along the different segments of the fish gastrointestinal tract with different uptake of particles occurring in the anterior gut (foregut) compared to the posterior gut (hindgut) (Rombout et al., 2010). Ig $^{+}$cells are present in the intestinal mucosa of many fish such as salmonids, cyprinids and the sea bass, however, the amount varies between species (Rombout et al., 1993; Abelli et al., 1997). In addition to $\operatorname{~gg}^{+}$cells, $\mathrm{T}$ cells have been detected in the guts of fish including carp and sea bass, using monoclonal antibodies specific for T cells or T cell subpopulations (Rombout et al., 1993; Abelli et al., 1997). In both carp and sea bass, $\mathrm{T}$ cells were abundant in both the lamina propria and epithelium. Gut macrophages have been morphologically described in many teleost species (Rombout et al., 1986; Inami et al., 2009). These macrophages are strongly $\mathrm{Ig}^{+}$due to their Ig-binding capacity and these characteristics combined with the abundant presence of $\mathrm{B}$ and $\mathrm{T}$ cells strongly suggest that local immune responses can be evoked (Rombout et al., 2010). 


\subsection{Cells of the immune system}

\subsubsection{Cellular components of the teleost immune system}

Fish possess both an innate and adaptive immune system which mount non-specific and specific immune responses respectively. In general, fish have myeloid and lymphoid lineages, however, there are important differences compared to those present in higher vertebrates. The nomenclature used to classify leucocytes in human hematology is based on their affinities for acid or basic dyes, which may not necessarily reflect functional diversity when applied to the granulocytes of teleosts (Ellis, 1977b). Additionally, it should be noted that the erythrocytes of fish are nucleated. A broad selection of key cell types are involved in the innate or nonspecific cellular defense responses of teleost fish including the monocytes/macrophages, the granulocytes and the non-specific cytotoxic cells (Secombes, 1996). Additionally, fish also have functional equivalents of mammalian $\mathrm{T}$ and $\mathrm{B}$ lymphocytes, involved in their adaptive immune response. However the lymphoid system is organised differently, for example the lack of lymph nodes, Peyer's patches and bone marrow (Tort et al., 2003). A number of morphological, physical and functional characteristics can be used to distinguish cells involved in non-specific immunity. Although many reagents and markers are still lacking, over the years some progress has been made towards establishing fish leucocyte cell lines (Secombes, 1996). Although other cell types such as dendritic cells and thrombocytes are present in teleost fish, they will not be discussed because this study is not concerned with their function.

\subsubsection{Monocytes/macrophages}

Macrophages are mononucleated tissue cells derived from circulating monocytes and are characterised by their high capacity for phagocytosis, while their ability to adhere to glass and plastic makes them easy to isolate (Ellis, 1977b). The primary hematopoietic organ in the fish is the kidney, with the spleen providing a site of more specific macrophage/monocyte maturation (Hanington et al., 2009b). Macrophages have an important role as scavengers of dead and foreign material such as invading pathogens and are regularly recruited to sites of imflammation (Mathias et al., 2009). Macrophages have been shown to play a central part in host defense, with roles in both the innate and adaptive immune responses (Mosser and 
Edwards, 2008). Macrophages can engulf bacteria and kill them principally by production of reactive oxygen species (ROS) during the so-called respiratory burst. These products include the superoxide anion $\left(\mathrm{O}_{2}^{-}\right), \mathrm{H}_{2} \mathrm{O}_{2}$ and the hydroxyl free radical $\left(\mathrm{OH}^{*}\right)$ which have potent bactericidal activity (Ellis, 1999).

Morphologically, fish macrophages are characterised by their prominent, eccentric, kidney shaped or bilobed nucleus, with their cytoplasm staining light blue-gray with Giemsa stain (Lopez-Ruiz et al., 1992; Esteban et al., 2000). Addtionally they have an undulating membrane with irregular extending pseudopodia and at high magnifications lysosomes and other vesicles can be observed (Lopez-Ruiz et al., 1992). Monocytes/macrophages have been reported in many fish (Lopez-Ruiz et al., 1992; Roca et al., 2006; Hanington et al., 2009b; Mathias et al., 2009), however, ultrastructural differences exist between species and confusion exists among the literature on monocytes, with some reporting their abscence or denying their existence in teleost fish (Ellis, 1977b; Lopez-Ruiz et al., 1992).

\subsubsection{Granulocytes}

Generally fish have two granulocyte lineages which in the zoological literature are usually called heterophil or neutrophil granulocytes (presumed to be functionally orthologous with the mammalian neutrophil) and eosinophil granulocytes (Lieschke et al., 2001). Teleost basophil granulocytes are also described in some species (Bielek, 1981). Studies of the leucocyte response to tissue damage and/or infection have shown that neutrophils are the first to respond (Dale et al., 2008). Although fish neutrophils are generally thought of as being highly mobile and phagocytic by the production of reactive oxygen species, their bactericidal activity is often relatively poor compared with that of macrophages (Secombes, 1996). Never-the-less, neutrophils, like macrophages, engulf and kill bacteria via the production of $\mathrm{O}_{2}^{-}, \mathrm{H}_{2} \mathrm{O}_{2}$ and $\mathrm{OH}^{-}$(Ellis, 1999). In addition, neutrophils contain myeloperoxidase (MPO) in their cytoplasmic granules (Afonso et al., 1997) which, when in the presence of halide ions and $\mathrm{H}_{2} \mathrm{O}_{2}$, can kill bacteria by halogenations of the bacterial cell walls as well as production of bactericidal hypohalite ions (Ellis, 1999). 
Morphologically teleost neutrophils have a pale cytoplasm to most dyes (hence neutrophilic) and present a characteristic multilobulated segmented nucleus (Lopez-Ruiz et al., 1992; Esteban et al., 2000; Lieschke et al., 2001). On the other hand, the eosinophilic granulocyte cytoplasm is filled with many granules that stain pink/red with Giemsa stain and their nuclei appear peripheral and nonsegmented (Lopez-Ruiz et al., 1992; Esteban et al., 2000; Lieschke et al., 2001). Although the role of the eosinophil in teleosts varies, in the sea bream they are involved in active phagocytosis and these granulocytes are the most numerous type of phagocyte detected in all tissues (Lopez-Ruiz et al., 1992).

\subsubsection{B cells}

B lymphocytes (B cells) are essential antibody-producing cells of the adaptive immune system. During the development of progenitor B cells to mature B cells, the cells undergo selection at several checkpoints, which ensures that a diverse antibody repertoire is generated. Once the progenitors have matured they express a membrane-bound antibody, the $\mathrm{B}$ cell receptor (BCR), which in teleost fish is transmembrane IgM (Martensson et al., 2010). In teleost fish, the head kidney is considered the primary lymphoid tissue and a major source of B cells (Fänge, 1986). B cells are activated in response to antigenic stimulation and interactions with MHC class II molecules signalling them to differentiate into plasma cells, capable of secreting large quantities of antibody. Teleost B cells can be differentiated into plasmablasts which are characterised as replicating, low antibody secretors that bear minimal amounts of the B cell receptor and plasma cells which are characterised as non-replicating, terminally differentiated, bearing no B cell receptors (Bromage et al., 2004). Plasma cells can be further sorted into two distinct populations; the short-lived plasma cells and the long-lived plasma cells (Bromage et al., 2004). These distinct plasma cell populations possess different life spans, antigen affinity and life histories in regards to where they originated, and where they will eventually reside (regionality).

IgM is used as a marker for B cells and the appearance of $\operatorname{IgM}^{+}$cells in fish larvae is an indicator of immune system function (Tian et al., 2009b). Because sites such as Peyers patches and lymph nodes have not been described, it has been proposed that in fish such as trout the kidney and spleen act as sites of B cell differentiation (Bromage et al., 2004). B cell differentiation in fish does not involve class switching, however other loci have been 
identified; IgD in catfish (Bengtén et al., 2006), IgT in trout (Hansen et al., 2005), and IgZ in zebrafish (Danilova et al., 2005). To date though only IgM has been shown to be involved in protective immunity in fish. Lastly plasma cells located in the head kidney can serve as a source of serum IgM antibodies and humoral memory (Bromage et al., 2004).

\subsection{5. $T$ cells}

The $\mathrm{T}$ cells are another fundamental mediator of the adaptive immune response and can be divided in two major subsets based on the expression of the co-receptors CD4 (helper T cells) and CD8 (cytotoxic T cells) (Castro et al., 2010). In humans and mice, CD4 ${ }^{+} \mathrm{T}$ cells play a central role in initiating and maintaining diverse immune responses by recruitment and activation of cellular immunity, including $\mathrm{CD}^{+} \mathrm{T}$ cells, $\mathrm{B}$ cells, macrophages, and granulocytes, using MHC class II. In contrast $\mathrm{CD}^{+}$marks cytotoxic T cells that recognize antigenic peptides associated with the MHC class I present on most cells and function directly in the killing of target cells (Castro et al., 2010). T cells bind to the MHC complex on other cells using the T cell receptor (TCR) a common T cell marker, which is a heterodimer made up of an $\alpha$ - and a $\beta$-chain (although $\gamma \delta$ T-cells also exist).

The diversity of TCR $\alpha \beta$ is generated by the assembly of V, D and, for $\beta$-chain, J genes (Castro et al., 2010). Recombination signal sequences and recombination activating genes (RAGs) are required for rearrangement of the TCR genes (Marchanlonis et al., 2002). The TCR $\beta$-chain is rearranged and expressed on thymocytes before the TCR $\alpha$-chain, which is only expressed after thymocytes have gone through a double negative and double positive phase expressing CD4 and CD8; before they go through positive and negative selection (Øvergård et al., 2011). Similarly fish CD4 receptors have been cloned in many fish (Picchietti et al., 2009; Øvergård et al., 2011), however the sequences show differences to those of higher vertebrates, but features such as gene organization, splicing pattern, binding motifs and key residues are clearly conserved, and gene syntenic relationships are also found among vertebrates (Castro et al., 2010). 


\subsection{Humoral immune system}

\subsubsection{Components of the humoral immune system}

Like other vertebrates, fish activate their immune system after recognition of pathogen associated molecular patterns (PAMPs) through specific receptors. The innate immune system, characterised by being fast acting, non-specific and therefore not dependent on previous recognition of a pathogen, is considered essential, both in lower and higher vertebrates. It seems that lower vertebrates such as teleosts possess a powerful innate immunity and rely on their innate immunity even more than their mammalian counterparts (Tort et al., 2003). Additionally it is believed that the teleost adaptive immune responses are less effective and not as efficient as those of higher vertebrates. Given the very potent innate immunity of fish, selective pressure to fine tune the adaptive immune system may not have been very high (Trede et al., 2004). The adaptive immune system is relatively new in evolution, first appearing only 500 million years ago in a common ancestor to all vertebrates (Flajnik and Kasahara, 2010). It is characterised by its slower, later appearance, its specificity and its ability to recognise antigens previously encountered. The fish humoral immune system is similar to that in mammals and includes lysozyme, agglutinin, precipitins (lectins, opsonins), antibacterial lytic enzymes, transferrin (iron binding protein), as well as components of the complement system, interferons and immunoglobulins (Swain and Nayak, 2009). However, discussion will focus on humoral components relative to this study.

\subsubsection{Complement}

The complement system operates through the classical, alternative and lectin pathways and is one of the most important components of the innate immune system (Nonaka and Smith, 2000). Consisting of approximately 35 plasma and membrane bound proteins, the complement system acts as one of the first lines of defence against the invading pathogens (Wang et al., 2008). The alternative pathway which is antibody independent has very high activity in fish serum compared with mammalian serum (Yano, 1996), suggesting this pathway is more important in fish than mammals (Ellis, 1999). In teleosts, the complement system interacts with the adaptive immune response (Morgan et al., 2005) helping with chemotaxis, opsonization, phagocytosis and degradation of pathogens (Boshra et al., 2006). Complement factor 3 (C3) is central subsequent to activation of all pathways of the 
complement system and hepatocytes represent the major source of C3 (Løvoll et al., 2007). Unlike the one C3 isoform seen in mammals, fish express several functionally active C3 isoforms, from three in rainbow trout and medaka (Sunyer et al., 1996; Kuroda et al., 2000), to up to five in seabream and carp (Sunyer et al., 1997; Nakao et al., 2000). Teleost C3 shares the two-chain structure, yet shows changes in the catalytic residues of the protein; they have an altered affinity for several substrates suggesting they are products of several polymorphic genes (Slierendecht et al., 1999). Similar in the way that mammals have Ig variability which gives more efficiency in binding immunogens, it is possible that fish may have developed complement varability in regards to the complement response (Sunyer et al., 1996). Additionally these C3 isoforms in fish show higher hemolytic and bacteriolytic activity than in mammals, also justifying the preference for the alternative pathway response in fish (Sunyer and Tort, 1995).

\subsubsection{Lysozyme}

Lysozyme is another important innate defence parameter and is one of the most studied innate responses in fish (Tort et al., 2003). Produced by phagocytic cells such as neutrophils and macrophages, lysozyme acts on the peptidoglycan layer of bacterial cell walls resulting in the lysis of the bacteria and its functional role in fighting against infectious diseases of fish has been recorded (Fänge et al., 1976). The lysozyme response has been found to be variable in its potency depending on the species and the tissue location but is present in all species studied (Fänge et al., 1976; Murray and Fletcher, 1976). Additionally lysozyme often works simultaneously with other mechanisms of the nonspecific immune system, such as complement (Glynn, 1969; Wang et al., 2008; Wang and Zhang, 2010) Wang \& Zhang, 2010). It appears that the lysozyme response in fish may be induced very rapidly and may not only be related to bacterial presence but also to other alarm situations such as after stress (Demers et al., 1988; Demers and Bayne, 1997).

\subsubsection{Immunoglobulins}

The immunoglobulin (Ig) is the primary humoral component of the adaptive immune system and acts by recognising and binding to a unique part of the foreign target, termed the antigen (Magnadottir et al., 2005). Immunoglobulins are mainly produced by plasmablasts and plasma cells, and are found secreted into body fluids (including serum and mucosal 
secretions) as antibodies (soluble form), or on the surface of B cells in the form of a BCR (membrane-bound form) (Martensson et al., 2010). Immunoglobulins operate in three ways; neutralising pathogens by binding to them, preventing them from entering or damaging cells, opsonising the pathogen promoting phagocytosis by macrophages or other cells and by activating complement which helps with opsonisation and lyses some pathogens (Schroder and Cavacini, 2010). Some Igs also act as "natural antibodies" which are produced at tightly regulated levels in the complete absence of exogenous antigenic stimulation (Boes, 2000). They provide immediate, early and broad protection against pathogens, classifying them as an important part of the innate humoral immune system.

The Ig structure isolated from teleost fishes is a tetrameric IgM of approximately $600-800$ kilodaltons ( $\mathrm{kDa}$ ) (Fig. 1.2). The tetramer structure of fish Ig is composed of four monomeric units, two identical heavy chains $(\mathrm{H})$ and two light chains $(\mathrm{L})$ of approximately $70 \mathrm{kDa}$ and $25 \mathrm{kDa}$ respectively. Each subunit is either fully linked by covalent bonding or by a combination of covalent and noncovalent attachment (Morrison and Nowak, 2002). Additionally there is a carboxyl-terminal constant (C) domain, which together with the $\mathrm{H}$ chain, define effector functions of the immunoglobulin (Zhang et al., 2011). Based on the nature of the $\mathrm{C}$ domains of their $\mathrm{H}$ chains, immunoglobulins can be classified into different isotypes (classes) and subtypes (subclasses) (Zhang et al., 2011). In mammals, five Ig isotypes, IgM, IgD, IgG, IgE, and IgA, (Fig. 1.3.) have been identified, each possessing specific effector functions in humoral and cellular immune responses (Flajnik and Kasahara, 2010). 


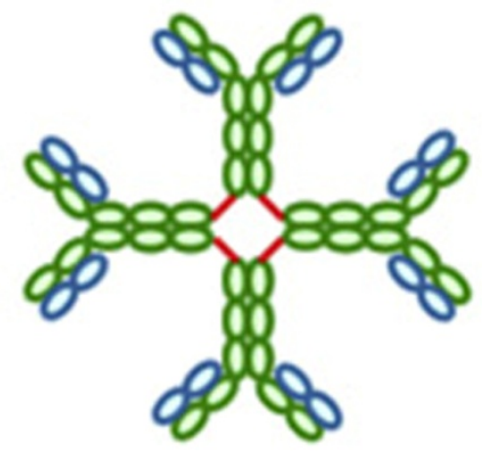

Heavy chain

Light chain

Covalent bond

Fig. 1.2. Teleost IgM tetramer

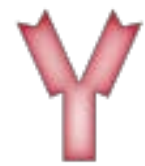

\section{Monomer}

$\lg D, \lg E, \lg G$

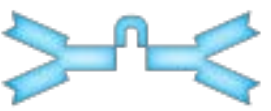

Dimer

$\lg \mathrm{A}$

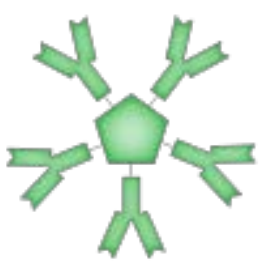

Pentamer

IgM

Fig. 1.3. Human immunoglobulin isotypes.

IgM is the only isotype functionally conserved in all jawed vertebrates (Zhang et al., 2011) and is the chief Ig isotype in fish, as well as being the most studied. The heavy chain locus for IgM, known as the IGHM gene, encodes four $\mathrm{C}$ domain-coding exons and two transmembrane (TM) exons in two physical forms: secreted (soluble) and transmembrane isoforms. The IGHM transcript of the secreted form in all teleosts consists of four $\mathrm{C} \mu$ domains (C $\mu 1-4)$, while the membrane form contains three $\mathrm{C} \mu$ domains and a TM domain connected to the end of $\mathrm{C} \mu 3$, with the C $\mu 4$ exon spliced out (Bengtén et al., 1991; Hordvik et al., 1992; Wilson and Warr, 1992). A unique feature of teleost IgM is the fact that these molecules are not secreted as uniformly disulfide bonded oligomers; but instead various redox forms exist, giving rise to multiple IgM isomers (Kaattari et al., 1998). For example in salmonids it has 
been shown that the basic covalent subunit is a monomer but the final combination for the tetramer may be a fully crosslinked tetramer or combinations of monomers, dimers or trimers (Evans et al., 1998).

Untill recently the evaluation of mucosal antibody responses in fish has always been limited to IgM (Rombout et al., 2010). However, a new novel Ig molecule was discovered in zebrafish and trout in 2005, named IgZ (Danilova et al., 2005) and IgT respectively (Hansen et al, 2005). Using antibodies raised against trout IgT the identification and characterisation of a new lineage of B cells (IgT ${ }^{+}$) was achieved (Zhang et al., 2011). These IgT ${ }^{+}$cells make up only a small portion of the B cells in the systemic lymphoid organs, but are found in greater numbers than $\operatorname{IgM}^{+} \mathrm{B}$ cells in the gut (over 50\% of B cells) (Zhang et al., 2011). From recent studies it is now believed that IgT specialises in teleost mucosal immunity (Zhang et al., 2010) and IgZ/IgT has been reported in many fish (Danilova et al., 2005; Hansen et al., 2005; Gambon-Deza et al., 2010; Tadiso et al., 2011). The gene region of IgZ is sandwiched between two D and J clusters located upstream of $\mu$ region. This variation to the "translocon" type of Ig genomic arrangement in fish makes it unique (Ryo et al., 2010). The prototypic gene structure of the IgZ gene from trout and zebrafish consists of four constant domains similar to the IgM gene (Fig 1.1). In contrast, the fugu homolog has only two constant domains bridged with a hinge-like region joining these domains (Savan et al., 2005). Unlike the tetrameric IgM, IgZ is predicted to exist as a monomer (Zhang et al., 2011). 


\subsection{Ontogeny of the lymphoid organs}

\subsubsection{Light microscopy for studying lymphoid organ ontogeny}

With the exception of zebrafish, studies have exclusively used light and/or electron microscopy to investigate the ontogeny of the main lymphoid organs of teleosts; the thymus, spleen and head kidney (Mulero et al., 2007b). Although the basic developmental mechanisms of teleosts are similar, there are differences in regards to the timing of developmental events (Table 1.1). These differences exist partly because of the widely varying duration of the embryonic period and larva development between teleost species, but also because development is affected by culture conditions, such as temperature, photoperiod and salinity (Falk-Petersen, 2005). Marine fish larvae, which typically weigh less than fresh water fish at hatch, can be shown to experience high mortality rates, have higher metabolic requirements, and have longer larval stage durations than do freshwater fish larvae. The difference in body size between typically small marine and typically large freshwater fish larvae is an important factor which affects their dynamics and energetics (Houde, 1993). Mortalities from starvation are more likely to occur with marine larvae, primarily due to their small body size, associated high metabolic demands, and possibly higher ingestion requirements (Houde, 1993). The onset of exogenous feeding is a crucial moment in developing fish larvae and this stage has been associated with massive mortalities. Additionally this stage is the first time larvae will come into contact with many new antigens present in the food. This influx of new antigens and possible pathogens has a big impact on the development of the gut (Yufera and Darias, 2007) and possibly the immune system.

\subsubsection{Eggs and larvae}

In general the development of fish eggs and larvae follows a similar pattern, however large differences exist between species in regards to egg size, yolk composition, developmental rates and egg incubation time (Blaxter, 1988; Howell et al., 1998). These contributing factors influence differences in regards to size at hatch, developmental status at hatch and thus the timing of development and maturity of various organs and organ systems (Blaxter, 1988; Kjørsvik et al., 2004). Additionally as mentioned, development is further affected by culture conditions, such as temperature, photoperiod and salinity (Falk-Petersen, 2005). Many marine fish cultivated in Europe such as Atlantic cod (Gadus morhua), turbot (Scophthalmus 
maximus), sea bream (Sparus aurata) and sea bass (Dicentrarchus labrax) spawn from small, pelagic eggs (0.8 - $3 \mathrm{~mm}$ ) and have an extended larval stage (Falk-Petersen, 2005); while others such as the Atlantic wolffish (Anarhichas lupus) spawn from large demersal eggs (5 $6 \mathrm{~mm}$ ) at a relatively more advanced larval stage (Falk-Petersen and Hansen, 2003). Hapuka hatch from small $2 \mathrm{~mm}$ pelagic eggs with one or multiple oil droplets and rely on the yolksac until $11 \mathrm{dph}$ when yolk sac reabsorption is almost complete. In general, the yolk sac provides the growing embryo with nutrition until the onset of exogenous feeding and contains maternally transferred factors essential for the protection of the growing fish (Swain and Nayak, 2009).

\subsubsection{Ontogeny of the head kidney}

Generally lymphoid organs develop earlier in fresh water species than in marine species (Willett et al., 1999). The kidney, thought to be the most important major lymphoid organ, is present at 4 days post fertilisation (dpf) in the zebrafish a fresh water species and contains hematopoietic cells such as developing erythrocytes and granulocytes. The amount of renal hematopoietic tissue increases rapidly; however, lymphocytes are not present until 3 wph (Willett et al., 1999). Similarily the head kidney is already observed and lymphoid before hatching in the rainbow trout (Razquin et al., 1990). In the marine fish species that have been studied, the lymphoid organs usually have not developed at the time of hatching. The kidney is present at hatch in some marine fish species such as Atlantic cod and turbot (Morrison, 1993; Schrøder et al., 1998). In the turbot, the kidney anlage at hatch consisted of two rudimentary pronephric ducts running below the notochord with undifferentiated stem cells appearing between the pronephric ducts. In the kelp grouper (Epinephelus bruneus) the excretory part of the kidney was present at $1 \mathrm{dph}$ consisting of tubules between the yolk sac and notochord (Kato et al., 2004) and within 2 days blast like cells appeared between the tubules. In Atlantic halibut, the excretory part of the anterior kidney was present at hatching, and consisted of two parallel tubuli located dorsally between the intestine anlage and the notochord (Patel et al., 2009). However, no hematopoietic cells or tissue were present at hatch. Similarly in the common dentex (Dentex dentex), the excretory part of the kidney was present at hatch but hematopoietic cells first appeared 2 days later (Santamaria et al., 2004). The head kidney of the sea bass first appeared at $10 \mathrm{dph}$, with the hemopoietic and lymphoid components of the tissue merged together, showing no evidence of regionalisation until later 
juvenile stages (Abelli et al., 1996). Kidney tubules are present at hatch in the sea bream, but the first signs of hematopoietic tissue only appeared at $5 \mathrm{dph}$, in the form of apparent hematopoietic stem cells (Jósefsson and Tatner, 1993).

\subsubsection{Ontogeny of the spleen and thymus}

The spleen and thymus appear after the kidney in most marine teleosts; in turbot the spleen is seen at the end of the yolk sac stage as a small cluster of mesenchymal cells and blood capillaries (Padros and Crespo, 1996). However, in halibut, the spleen could not be observed during the yolk sac stage, instead appearing at 59 dph after the thymus, where it consisted of a small encapsulated organ consisting of a small cluster of erythrocytes, primitive reticular cells and primitive sinusoids (Patel et al., 2009). Lymphoid cells and connective tissue were present at $66 \mathrm{dph}$ as the organ started to differentiate into red and white pulp. The kelp grouper spleen appears much earlier, at $6 \mathrm{dph}$ appearing close to the gut as a group of blast like cells, but rapidly progressing with a distinct capsule and reticular cells at 8dph (Kato et al., 2004). The spleen of sea bream first appeared at $12 \mathrm{dph}$, consisting of a 'bag' of fibroblasts and fibrocytes next to the pancreas (Jósefsson and Tatner, 1993). The anlage of the spleen was first seen in sea bass at $17 \mathrm{dph}$ in the anterior portion of the intestine, with only scarce lymphoid elements detected at 44 dph (Abelli et al., 1996). The thymus, the last lymphoid organ to appear in marine fish; appears as a paired organ in sea bream at $29 \mathrm{dph}$, in the branchial cavity on each side of the fish (Jósefsson and Tatner, 1993). In sea bass the thymic anlage appears lymphoid at $27 \mathrm{dph}$ and starts becoming regionalised soon after, with numerous lymphoid cells filling the outer region (Abelli et al., 1996). In zebrafish the thymus appears during the embryo stage at 60 hours post fertilisation (hpf) and by 65 hpf it is colonised by immature lymphoblasts (Willett et al., 1999). The thymus first appears before the spleen in halibut, at $33 \mathrm{dph}$ located near the gill arches at the dorsal part of the pharyngeal cavity, consisting of a collection of lymphoblast like cells surrounded by a single epithelial layer (Patel et al., 2009). However in the kelp grouper, a distinct thymus was observed at 12 dph consisting of blast like cells with large pale nuclei (Kato et al., 2004). 


\subsubsection{Ontogeny of the digestive tract}

In most marine teleosts, the oesophagus starts to differentiate soon after hatching, usually just before the mouth first opens for the start of exogenous feeding (Zambonio-Infante et al., 2008). The oesophagus at this stage is a short, narrow duct, lined with stratified or pseudostratified epithelium and connects the buccopharyngeal cavity with the intestine or stomach anlagen. The first functional goblet cells appear scattered among the epithelial cells of the oesophagus and the timing varies amongst species. In the yellow tail flounder (Limanda ferruginea) these cells are present at the time of exogenous feeding while in the gilhead seabream and European sea bass, they are present during later stages (Sarasquete et al., 1995; Garcia-Hernandez et al., 2001). These goblet cells are involved in the transport, absorption and protection processes of the gut (Zambonio-Infante et al., 2008).

In many species a basic stomach is distinguishable soon after hatching between the oesophagus and the intestine. The stomach is the last organ of the digestive system to differentiate, although, not all types of fish have stomachs (Zambonio-Infante et al., 2008). As larvae grow, the mucosa of the stomach develops forming folds and within these folds form gastric pits. Gastric glands differentiate within these gastric pits and the stomach is considered developed at this stage (Zambonio-Infante et al., 2008). The pancreas is involved in producing hormones such as insulin and glucagon as well as screting digestive enzymes (Hoehne-Reitan and Kjørsvik, 2004). An anlage is usually present at hatch and the exocrine cells differentiate soon after. The appearance of excretory ducts and blood vessels usually occur before the opening of the mouth (Zambonio-Infante et al., 2008). The liver which is involved in nutrient metabolism, production of bile and lipid storage develops from a ventral budding of the gut close to the yolk sac (Hoehne-Reitan and Kjørsvik, 2004). In cold water species such as haddock (Hamlin et al., 2000), the liver is already differentiated at hatch, whereas in temperate water species such as the common dentex (Santamaria et al., 2004) and gilthead seabream (Sarasquete et al., 1995) the liver is absent at hatch. The intestine which is the longest portion of the digestive tract is present at hatch in larvae as a rudiment forming an intestinal valve at 5 dph in seabass, 4-5 dph in common dentex and 4-6 dph in sea bream (Sarasquete et al., 1995; Garcia-Hernandez et al., 2001; Santamaria et al., 2004). During larval development, the intestine coils forming loops as it increases in size. As these folds increase, the goblet cells begin to differentiate in the epithelium. The pyloric caeca is 
involved in nutrient digestion and absorption and begins development as the last morphological change in intestinal development in some species such as haddock (Hamlin et al., 2000). The development of the pyloric caeca in the intestine, together with gastric glands in the stomach, shows maturation of the digestive system similar to the adult determining the transformation from larva to juvenile (Bisbal and Bengtson, 1995). 
Table 1.1 Timing in dph and hpf of the major lymphoid organs in several perciformes species including the cyprinid zebrafish.

\begin{tabular}{|c|c|c|c|c|c|c|c|}
\hline Species & Family & $\begin{array}{l}\text { Temperature } \\
{ }^{\circ} \mathrm{C}\end{array}$ & Method & Head kidney & Spleen & Thymus & Reference \\
\hline Atlantic halibut & Pleuronectidae & $6^{\circ} \mathrm{C}$ & $\begin{array}{c}\text { Light microscopy } \\
\text { and IHC }\end{array}$ & $\begin{array}{c}\text { Tubules present at hatch. } \\
\text { Hematopoietic tissue at } 40 \\
-45 \mathrm{dph}\end{array}$ & $59 \mathrm{dph}$ & $33 \mathrm{dph}$ & (Patel et al., 2009) \\
\hline European sea bass & Moronidae & $16{ }^{\circ} \mathrm{C}$ & $\begin{array}{l}\text { Light \& electron } \\
\text { microscopy }\end{array}$ & $10 \mathrm{dph}$ & $17 \mathrm{dph}$ & $27 \mathrm{dph}$ & (Abelli et al., 1996) \\
\hline Gilthead sea bream & Sparidae & $19-20^{\circ} \mathrm{C}$ & Light microscopy & $\begin{array}{c}\text { Tubules present at hatch. } \\
\text { Hematopoietic cells at } 5 \\
\text { dph }\end{array}$ & $12 \mathrm{dph}$ & $29 \mathrm{dph}$ & $\begin{array}{c}\text { (Jósefsson and } \\
\text { Tatner, 1993) }\end{array}$ \\
\hline Zebrafish & Cyprinidae & $28^{\circ} \mathrm{C}$ & $\begin{array}{l}\text { Light \& electron } \\
\text { microscopy }\end{array}$ & $96 \mathrm{hpf}$ & N/A & $60 \mathrm{hpf}$ & $\begin{array}{c}\text { (Willett et al., } \\
\text { 1999) }\end{array}$ \\
\hline Common dentex & Sparidae & $18^{\circ} \mathrm{C}$ & Light microscopy & $3 \mathrm{dph}$ & $5 \mathrm{dph}$ & $16 \mathrm{dph}$ & $\begin{array}{c}\text { (Santamaria et al., } \\
\text { 2004) }\end{array}$ \\
\hline Kelp grouper & Serranidae & $25{ }^{\circ} \mathrm{C}$ & Light microscopy & $\begin{array}{c}\text { Tubules present at } 1 \mathrm{dph} \text {. } \\
\text { Hematopoietic cells at } 3 \\
\text { dph }\end{array}$ & $6 \mathrm{dph}$ & $12 \mathrm{dph}$ & (Kato et al., 2004) \\
\hline
\end{tabular}




\subsection{Ontogeny of the cellular and humoral immune system}

\subsubsection{Ontogeny of the cellular immune system using cell markers}

In fish development, embryonic and definitive hematopoiesis are separate and different processes, which is similar to what is described in mammals (Galloway and Zon, 2003). In teleosts, three models of primitive hematopoiesis have been documented. In species such as angelfish, the initial hematopoiesis is limited to the yolk sac blood islands (Al-Adhami and Kunz, 1976). But in other species such as zebrafish, during embryogenesis, the first and only hematopoietic site is the intraembryonic cell mass (Willett et al., 1999). Further still, in species such as the trout, early hematopoiesis occurs at both locations (Iuchi and Yamamoto, 1983). Unlike mammals, bone marrow is absent in fish and instead the head kidney assumes hematopoietic function. Hematopoietic stem cells of the fish head kidney give rise to the multipotent myeloid-erythroid progenitors (MMP) and the bipotent lymphoid progenitors (BLP). The MMPs are the precursors for the erythrocytes and thrombocytes, as well as the innate immune cells such as the granulocytes and monocytes/macrophages (Rombout et al., 2005). BLPs give rise to the lymphocytes; the $B$ and $T$ cells which are responsible for the adaptive immune response. Until recently an absence of cell markers has impaired efforts for studying teleost cellular and humoral ontogeny (Mulero et al., 2007b), however, the zebrafish has proven to be a powerful vertebrate model for the study of developmental immunity (Trede et al., 2004). Lastly, comparison of data between fish species can be difficult due to the different detection techniques used such as flow cytometry, immuno- or in situ histology, PCR, ELISA or western blotting of tissue homogenates (Magnadottir et al., 2005).

\subsubsection{Ontogeny of antigen presenting cells}

Macrophages have been shown to play an essential role in host defense, with roles in both the innate and adaptive immune responses (Gordon, 2007; Mosser and Edwards, 2008). Colonystimulating factor (CSF1) is the principal regulator of the survival, proliferation, and differentiation of macrophages and their precursors (Fixe and Praloran, 1997). The macrophage CSF1 receptor (CSF1R) has become an accepted marker of macrophages, due to its co-expression with L-plastin but not with myeloperoxidase (MPO) (Clay and Ramakrishnan, 2005; Meijer et al., 2008). The expression of CSF1R has been used to detect 
the development of macrophages in fish species (Roca et al., 2006; Hanington et al., 2009a; Mathias et al., 2009). Interestingly macrophages can be present at very early stages, seen at 1 dpf in zebrafish embryo and originating from hematopoietic areas preceeding the head kidney. These macrophages were involved with phagocytosis of cell corpses and showed antibacterial ability even during the embryonic stage of the fish (Herbomel et al., 1999). Other described methods to identify macrophages require phagocytosis of fluorescent bacteria or the dye Neutral Red (Clay and Ramakrishnan, 2005; Clay et al., 2007).

MHC molecules are vital to proper function of the immune system and are involved in both innate and adaptive immunity with a chief role in antigen presentation and recognition of non-self (Bjorkman et al., 1987; Brown et al., 1993). In mammalian immunology, MHC class I molecules are widely expressed on all nucleated cells and present processed peptides from endogenously produced antigens to $\mathrm{CD}^{+} \mathrm{T}$ cells. On the other hand, MHC class II molecules present peptides from exogenously produced antigens to $\mathrm{CD}^{+}$cells, and are almost exclusively restricted to professional antigen presenting cells (APC), such as the monocyte/macrophage, dendritic and B cell lineages making MHC class II a professional APC marker (Margulies and McCluskey, 2003). MHC has been reported in many fish species including the channel catfish, sea bass, common carp, rainbow trout, and zebrafish (Rodrigues et al., 1995; Fischer et al., 2005; Buonocore et al., 2007; Moulana et al., 2008).

\subsubsection{Ontogeny of $T$ - and B-lymphocytes}

Only a few $\mathrm{T}$ cell markers are available for fish and as a result of this there are a limited number of studies on T-cell ontogeny (Zapata et al., 2006). Usually morphological evidence combined with T cell markers such as TCR $\alpha$ and TCR $\beta$ are used to confirm the appearance of T cells in the thymus (Willett et al., 1999; Trede et al., 2004). The TCR $\beta$-chain is the first chain to be rearranged. It is expressed on the surface of the thymocytes as a part of a pre-TCR complex, consisting of TCR $\beta$, a pre-T $\alpha$ chain, and the CD3 chains followed by the expression of the TCR $\alpha$ (Øvergård et al., 2011). However, many researchers only use the TCR $\alpha$ as a marker of mature T cells. In zebrafish the TCR $\alpha$ chain expression first begins in the thymus at $4 \mathrm{dpf}$ (Danilova et al., 2004), two days after the appearance of the first lymphoid cells in the organ. In the sea bass, immunohistochemical detection of assumed T cells (DLT-15 positive cells) occurs in the thymus 3 days after the first lymphoblasts appeared (Scapigliati 
et al., 2002). However, it is shown that lymphoid progenitors that colonize the early thymic primordium only differentiate into immunocompetent $\mathrm{T}$ cells after the thymic stroma has matured (Castillo et al., 1990). These progenitors are believed to originate from the head kidney which will be discussed later.

In most teleosts that have been studied, the B-lymphocytes have been suggested to originate and differentiate in the kidney (Hansen and Zapata, 1998), although the origin and time of appearance of B-lymphocytes in teleosts is a matter of discussion (Zapata et al., 2006). For example in one study on zebrafish they were unable to demonstrate RAG1 expression in the kidney by whole mount in situ hybridization (WISH), suggesting that the RAG probe was either unable to sufficiently penetrate the fish body or that there was a lack of lymphoid progenitors in the embryonic kidney. Other authors using the same WISH technique, demonstrated RAG1 expression interestingly in the zebrafish pancreas by 4 dpf followed by the expression of IgM at $10 \mathrm{dpf}$ (Danilova and Steiner, 2002). On the other hand, IgM has been detected as early as $3 \mathrm{dpf}$ by RT-PCR in zebrafish (Lam et al., 2004) and generally in zebrafish a few IgH chain positive cells first appear around 1-2 weeks post fertilisation (Zapata et al., 2006). In the gadoid haddock (Melanogrammus aeglefinus) using RT-PCR, although levels of IgM were detected relatively early between 12-16 dph, a large increase in IgM expression was first detected at $40 \mathrm{dph}$, after a large increase in RAG1 expression at 33 dph (Corripio-Miyar et al., 2007).

\subsubsection{Ontogeny of C3}

Ontogenic studies of fish complement components are limited and the studies have focused on larvae development mostly after hatching. Immunohistochemical techniques have been used to study the ontogeny of C3 at various developmental stages in Atlantic cod and Atlantic halibut (Lange et al., 2004a; Lange et al., 2004b). In Atlantic halibut, C3 has been detected in several tissues and cells at developmental stages from 5 to 99 dph. Five dph C3 was found in the skeletal muscle fibres and the yolk sac. By 15 dph C3 was detected in liver hepatocytes and endothelial cells. Fifty dph showed C3 being detected for the first time in the myocardial cells of the heart as well as the gut and the mucosal cells of the skin. Only by 57 dph was C3 observed in the lymphomyeloid cells of the kidney (Lange et al., 2004a). Using RT-PCR C3 products were first detected in the spotted wolffish at 49 dpf, which is still during the 
embryonic period in wolffish (Ellingsen et al., 2005). Lastly using RT-PCR in Atlantic salmon it was shown that C3 was first expressed at 14 dph (Løvoll et al., 2007). 


\subsection{Maternal immunity and Immunocompetence}

\subsubsection{Maternal transfer of Immunity}

Maternal immunity transmission is defined as the transfer of immune factors by an immunocompetent female to an immunologically naive neonate transplacentally or through colostrum, milk or yolk (Grindstaff et al., 2003). In teleosts both innate and adaptive immune factors such as Ig, complement factors, lysozyme, serum amyloid A and other lectins are commonly transmitted to offspring (Hanif et al., 2004). These transferred maternal factors provide larvae with a limited period of immunity, which gives young fish a chance to survive against deadly pathogens while their own immune system develops (Swain and Nayak, 2009). Because of the delayed maturation of lymphoid organs and acquisition of an autologous immune system in fish, maternal immunity is essential for survival during the early life stages. Possibly the most important of factors to be transferred are the maternal immunoglobulins, specifically IgM. Like reptiles and birds, IgM is transferred through yolk in fish. During the early stage of vitellogenesis, the maternal IgM is transferred through the yolk, to the immature ovaries possessing early yolk globule stage oocytes. This is followed by its transfer in a sequential manner to reproductively active mature ovaries, eggs and finally yolk sac larvae (Kanlis et al., 1995). Although the mechanism of IgM uptake and its storage within the eggs is yet to be established, the transport of IgM to eggs is believed to occur by transcytosis across the follicle cells (Swain and Nayak, 2009). The transfer process of IgM could be from the blood to the follicle which is dependent on the variation of the circulating Ig concentration. A significant increase in serum Ig concentration during the reproductive period in multiple fishes supports this impression (Kanlis et al., 1995; Picchitti et al., 2001). Similarly, mouth bearers can transfer some immunity to larvae through the mucus secreted from the mouth cavity (Sin et al., 1994).

These maternally transferred Ig's may be of great importance for early defence against pathogens in the eggs containing developing embryos and the growing larvae, especially because of the relatively late appearance of autologous humoral IgM in fish juveniles (Magnadottir et al., 2005). Because the persistence of maternal Ig in offspring circulation depends on body size and metabolic rate, in teleosts maternally derived IgM usually persists for limited duration, becoming nearly exhausted within the completion of the yolk absorption 
process, and completely disappear during larval stages. For the most part maternally derived IgM of eggs is tetrameric and structurally and antigenically identical to the maternal serum IgM and shows the same total and heavy and light chain sizes (Swain and Nayak, 2009). However, the transfer of monomeric and dimeric forms has also been demonstrated (Lobb and Clem, 1981; Evans et al., 1998; Kaattari et al., 1998). Studies on many species of fish have shown that maternal Ig's are transferred to the offspring including the sea bream, sea bass and tilapia (Takemura and Takano, 1997; Hanif et al., 2004; Picchietti et al., 2004). Transfer of not only the Ig protein but also the mRNA transcripts to the oocytes has been documented (Picchietti et al., 2006), and is thought to be translated during the early stages of development when maternal Ig is slowly depleted. Additionally, antibodies that have been raised in the maternal circulation after immunisation can be incorporated into vitellogenic oocytes in the ovary and then transferred from the larval yolk sac into the larval circulation. These transferred antibodies degrade gradually due to metabolism, but maintain their ability to bind antigens and give the larval offspring relatively good survival (Sin et al., 1994; Hanif et al., 2005). Although immunisation can provide transferred protection to offspring in some species of fish, in other species offspring are not protected. Because of this a different or additional role could be attributed to maternal IgM, such as a nutritional yolk protein (Magnadottir et al., 2005). Whether IgD and IgT/IgZ have a role in maternal immunity is yet to be discovered.

In addition to antibodies, many complement components such as C3, C4, C5, C7, factor B and D have been reported to be transferred to eggs and larvae in rainbow trout (Løvoll et al., 2006), sea bream (Hanif et al., 2004), zebrafish (Wang et al., 2008; Wang and Zhang, 2010) and spotted wolfish (Ellingsen et al., 2005), suggesting a key role for complement in fish maternal immunity. The powerful innate antibacterial enzyme lysozyme is also commonly transferred and has been found in the ova, embryos and eggs of coho salmon, sea bass and zebrafish eggs (Yousif et al., 1991; Cecchini et al., 2000; Wang et al., 2008; Wang and Zhang, 2010). Furthermore, it was proved that the purified lysozyme from the eggs of coho salmon had antibacterial activity, which played a role to prevent the vertical transmission of some bacteria from mother to progeny (Yousif et al., 1991). Similar findings of antibacterial activity were seen in the eggs of zebrafish (Wang and Zhang, 2010). However, few functional studies concerning lysozymes role in defending the early embryos and larvae against exotic pathogens have been carried out thus far. 


\subsubsection{Factors affecting maternal immunity}

In order to create large and healthy yields of fish for aquaculture the health of the brood fish needs to be taken into account. The overall health and immunity of brood fish is affected by different environmental, seasonal and nutritional conditions (Swain and Nayak, 2009). Seasonal cycles can affect certain biological activities such as feeding, behaviour, metabolism and reproduction in fishes (Sumpter, 1997; Cerda-Reverter et al., 1998). It is well known that the relationship between the fish gonad development and plasma level of gonadal steroids is affected by seasonal changes (Lambert et al., 1978). One of the key environmental factors is temperature variation, which can disturb the homeostasis of living animals and affect the growth and metabolism of fish (Das and Ratha, 1996; Person-Le Ruyet et al., 2004). In many fishes, decreased immunity is often recorded during cold seasons such as autumn and winter; as well as a reduction in immunocompetence (Bly and Clem, 1991). Depressed innate immunity and susceptibility to microbial infections have been reported more in the winter, due to the lower water temperatures (Swain et al., 2007). Brood fish also show seasonal variations of many immune parameters such as the circulation levels of many different blood cells including erythrocytes and leucocytes (Akmirza and Tepecik, 2007).

Likewise, nutrition plays an important role in the growth, immunity, reproduction and overall health status of any organism. Maternal nutrition, around the time of conception is very crucial for ensuring the birth of full-term viable and healthy offspring (Williams, 1994) and the role of nutritions impact on immunity and disease resistance in fish has been reported (Blazer, 1992). Poor nutrition during early larval stages can restrict a fishes developmental potential and delay the first maturation age (Swain et al., 2007). Additionally, a restricted food supply during oocyte differentiation in females reduces the number of eggs (Swain and Nayak, 2009). Generally a good balance of macro and micronutrients such as amino acids, vitamins, polyunsaturated fatty acids, trace elements and enzyme co-factors are essential for not only normal growth and development of the fish but also for development and function of the immune system (Swain and Nayak, 2009).

\subsubsection{Immunocompetence}

Immunostimulation and vaccination can provide fish protection from potential pathogens. However, the effectiveness of immunostimulation and vaccination methods used on cultured 
fish largely depends on the level of maturity of their immune system (Mulero et al., 2007b). Emergence of the immune organs followed by their active immune cells such as $\operatorname{IgM}^{+}$cells can be a gauge of immunocompetence, when an organism's immune system has reached maturity. Because vaccination of fish larvae at too young an age can lead to undesired effects such as immunosuppression or tolerance (Mulero et al., 2007b), research must be done to discover the timing of immunocompetence so vaccination trials can be effective. For carp and gilthead seabream, 2 month old fish appear to be suitable for oral vaccination (Joosten et al., 1995). Yet nothing is known about the immune system of hapuka or when their larvae become immunocompent. For successful aquaculture of marine fin fish, understanding and knowledge of their immune system is essential. 


\subsection{Aims and objectives}

The overall aim of this study is to investigate the development of the hapuka immune system from the egg through the larval stage to the adult. Developmental aspects will be compared with known data from closely related fish species such as members of the perciform order of fish and in particular focusing on species important in the aquaculture industry.

Specific aims will include:

Study the ontogeny of the major lymphoid organs in hapuka; the head kidney, spleen and thymus.

Determine when and where $\operatorname{IgM}^{+}$cells appear during larval development.

Identify the onset of transcription for immune related genes.

Determine whether the maternal transfer of immune factors occurs in hapuka eggs.

Establish the level of maturity of the juvenile leucocyte populations comparing them with adults. Describe the morphology and distribution of the hapuka leucocytes.

Hypothesis: This thesis will address the hypothesis that the development of the hapuka immune system will closely resemble other marine dwelling perciform fish. The kidney will be the first lymphoid organ to develop followed by the spleen and thymus. Components of the innate immune system should develop earlier than the adaptive immune system and cells of the innate immune system should be present and mature before cells of the adaptive have developed. 


\section{Chapter 2 - Materials and methods}

\subsection{Fish rearing and sampling procedures}

Hapuka were reared at the National Institute of Water and Atmospheric research's (NIWA) Bream Bay Aquaculture Park, Bream Bay, Northland, New Zealand.

\subsubsection{Hapuka brood stock husbandry}

The population of broodstock consisted of 37 hapuka of wild origin (19 females, 17 males and 1 unknown sex) with an average weight of $19.5 \mathrm{~kg}$ (average fork length $100 \mathrm{~cm}$ ). Broodstock were caught from the East Coast of Northern New Zealand between 2003 and 2006 using hook and line and then transported to NIWA's Bream Bay Aquaculture Park in insulated oxygenated containers. The fish were reared in two $70 \mathrm{~m}^{3}$ circular rearing tanks and were kept on a naturally simulated photoperiod except from May to November when day length was kept constant at 9h 45 min light. Sea water temperature ranged from 11.5 to 21.0 ${ }^{\circ} \mathrm{C}$ and during spawning (August to November) was maintained between 12.3 and $14.9^{\circ} \mathrm{C}$. Incoming water was sand filtered and ultraviolet light treated. Broodstock were hand fed three times a week to satiation on a diet of New Zealand arrow squid (Nototodarus sloanii) and pilchards (Sardinops neopilchardus) enriched with vitamins and oils (Nutra-brood nutrition supplement). Serum was taken from three random adult hapuka for use as a control.

\subsubsection{Hapuka eggs}

The broodstock in both tanks were allowed to spawn naturally. Eggs from 3 different clutches were collected using an external surface egg collector which involved the floating eggs passively moving into a net. Egg collectors were checked a minimum of 3 times daily and all eggs present were collected. Collected eggs were allowed to settle for 5 minutes to allow the negatively buoyant eggs to sink and the total batch volume plus the floating and sinking egg volumes were calculated. The negatively buoyant eggs were discarded preceding incubation and were also excluded from further sampling. Samples of approximately 200 eggs were taken at $0,1,2,3,4$ and $5 \mathrm{dpf}$ from the 3 clutches. 


\subsubsection{Hapuka larvae}

The remaining collected eggs were rinsed and added to a 400L incubator tanks for hatching. Upwelling water current was maintained $\left(8 \mathrm{~L} \mathrm{~min}^{-1}\right)$ and the incubator tank was oxygenated with 2 air stones. Hatched larvae were reared for 11 days in the 400L incubators under fluorescent lights set to 10 hours light: 14 hours dark photoperiod, at $13-14^{\circ} \mathrm{C}$ after which they were transferred to a new tank for the remainder of the sampling. This tank was maintained at a temperature ranging from $15-19^{\circ} \mathrm{C}$ with dissolved oxygen (DO) \% ranging from 7.6 to 11.4mg/L. The larvae were fed rotifers from $11 \mathrm{dph}$ to $22 \mathrm{dph}$ (12 days) and then artemia from 22 dph to 56 dph (34 days). Dry pellet feed commenced at $40 \mathrm{dph}$, and continued until the end of sampling. Larval samples from the 3 clutches were taken at 1, 2, 3, 4, 5, 6, 7, 8, 9, $10,11,12,16,20,24,32,45,50,63,72,80$ and 90 dph. Five to 10 larvae were collected on $1,2,3,4,5,6,7,8,9,10,11,12,16,20$ and 24 dph. Three juveniles were collected on 32, 45, 50, 63, 72, 80 and $90 \mathrm{dph}$. 


\subsection{Protein detection and measurement of IgM}

\subsubsection{Standardising protein samples}

Egg samples for $0,1,2,3,4$ and 5 dpf were prepared for each of the three clutches by pooling together 60 hapuka eggs each. Egg samples were homogenised with $350 \mu \mathrm{l}$ of $10 \mathrm{mM}$ phosphate-buffered saline (PBS) pH 7.2 containing Complete Protease Inhibitor Cocktail (Roche) (according to manufacturers instructions). Larval samples for 1, 2, 3, 4, 5, 6, 7, 8, 9, $10,11,12,16,20,32,45$ and 50 dph were prepared for each of the three clutches by pooling together 3 larvae/juveniles each. Larval samples were homogenised with an approximately equal volume of $10 \mathrm{mM}$ PBS pH 7.2 containing Complete Protease Inhibitor Cocktail (Roche). Each homogenised sample was centrifuged at $14,500 \mathrm{~g}$ for $10 \mathrm{~min}$ at $4^{\circ} \mathrm{C}$ and the supernatant collected. Total protein content from the supernatants was measured by Bradford reagent (Sigma) protein assay. All protein samples were adjusted to $100 \mu \mathrm{g} / \mathrm{ml}$ total protein in PBS, and stored at $-80^{\circ} \mathrm{C}$ until required.

\subsubsection{Enzyme-linked immunosorbent assays (ELISA)}

Flat-bottom 96 well plates were coated with serial dilutions (ranging from 1:4 to 1:1024) of the egg and larval protein samples (previously adjusted to $100 \mu \mathrm{g} / \mathrm{ml}$ total protein) in coating buffer (50mM sodium carbonate $\left.\left(\mathrm{Na}_{2} \mathrm{CO}_{3}\right) \mathrm{pH} 9.6\right)$, and left overnight at $4^{\circ} \mathrm{C}$. Positive controls consisted of serial dilutions (ranging from 1:4 to 1:1024) of adult groper serum. Preliminary experiments using the complete series of dilutions indicated the optimal amount of sample required to measure IgM levels. Thus, plates were coated with $2.5 \mu$ g total protein from each sample. Plates were washed three times with $200 \mu \mathrm{l}$ of PBT (10mM PBS with 0.05\% Tween 20), then blocked with $200 \mu \mathrm{l}$ of 3\% bovine serum albumin (BSA) in PBT for $1 \mathrm{~h}$ at room temperature. The plates were then washed twice with $200 \mu \mathrm{lBT}$ and incubated with $100 \mu \mathrm{l}$ of the primary antibody F06 (a mouse anti-giant gourami (Osphronemus goramy) IgM monoclonal antibody (Aquatic Diagnostics Ltd, Institute of Aquaculture, University of Stirling, Stirling) at $400 \mathrm{ng} / \mathrm{ml}$ concentration in 10mM PBS/PBT (1:2)) for $1 \mathrm{~h}$ at room temperature. The reactivity of primary antibody F06 against groper serum was tested by ELISA, dot blots and western blots during preliminary experiments (Irene Salinas, personal communication, 2011). Additionally, flow cytometry analysis of adult groper peripheral 
blood leucocytes (PBLs) revealed that only one population of lymphocytes was stained by primary antibody F06 (Irene Salinas, personal communication, 2011). After washing 3x with $200 \mu \mathrm{l}$ PBT, $100 \mu \mathrm{l}$ of a HRP-conjugated goat anti-mouse IgG (Jackson Immunoresearch, USA) at $1.5 \mu \mathrm{g} / \mathrm{ml}$ (in 10mM PBS/PBT (1:2)) was added to each well and incubated for $1 \mathrm{~h}$ at room temperature in the dark. After washing 3x with $200 \mu$ l PBT the peroxidase activity was measured by adding $100 \mu \mathrm{l}$ of 3,3',5,5'-tetramethylbenzidine (TMB) (Sigma-Aldrich) solution containing $3 \% \mathrm{H}_{2} \mathrm{O}_{2}$ to each well. The plates were incubated in the dark at room temperature for 1-10 minutes and the enzyme reaction was stopped by adding $50 \mu l$ sulphuric acid solution (2M) to each well. The optical density of each sample was measured at $450 \mathrm{~nm}$ using a Versamax Funable microplate reader (Molecular Devices), to give absorbance/2.5 $\mu \mathrm{g}$ of total protein; absorbance/2.5 $\mu \mathrm{g}$ of total protein is directly proportional to IgM concentration.

\subsubsection{Dot blot}

A PDVF membrane was activated by placing it in methanol for 10 seconds and then in sterile water for 5 minutes. The membrane was then kept in PBT (10mM PBS with $0.15 \%$ Tween 20) until samples were loaded. Four $\mu$ l samples of eggs from 2 different batches $(0,1,2,3,4$ and $5 \mathrm{dpf}$ ) were pipetted onto the membrane and left until the membrane appeared dry. The membrane was placed in methanol for 1 second and then back into PBT, before being placed into $20 \mathrm{ml}$ of blocking buffer (5\% non fat milk powder in PBT) for 1.5 hours on a shaker. The milk was drained and the membrane incubated with $7 \mathrm{ml}$ of the primary antibody F06 (Aquatic Diagnostics Ltd) in PBT, at a concentration of $1 \mu \mathrm{g} / \mathrm{ml}$ for 1.5 hours on a shaker at room temperature. The primary antibody was poured out and the membrane washed 5 times with PBT for 5 minutes each wash. The membrane was incubated with the seconday antibody a goat anti-mouse IgG, Cy3 conjugate (Jackson Immunoresearch) at $1.4 \mu \mathrm{g} / \mathrm{ml}$ for 1 hour on a shaker in the dark at room temperature. The secondary antibody was tipped out and the membrane washed 5 times with PBT for 5 minutes each wash in the dark. The membrane was scanned in a fluorescent image analyser (Fujifilm FIA-5100 (Alphatech Systems)) 


\subsubsection{Western blot}

Twelve $\mu \mathrm{l}$ of the egg protein samples (previously adjusted to $100 \mu \mathrm{g} / \mathrm{ml}$ total protein) and adult serum control samples were prepared with $4 \mu \mathrm{l}$ of $4 \mathrm{x}$ Laemmli Buffer to give a final concentration of $1 \mathrm{x}$. Samples were heated for $5 \mathrm{~min}$ at $97^{\circ} \mathrm{C}$ and loaded into a precast polyacrylamide gel (Thermo Scientific), then run for approximately $1 \mathrm{~h}$ at 120 volts (V). The gels were assembled with PVDF membranes (Amersham Hybond, GE Healthcare) that had been activated in methanol for $10 \mathrm{~s}$ and transferred for 17 hours at $20 \mathrm{~V}$. Membranes were incubated in blocking buffer made from 5\% non fat milk powder in PBT (10mM PBS with 0.15\% Tween 20) then rinsed briefly with PBT. After rinsing (no wash) the membranes were incubated with primary antibody F06 at $400 \mathrm{ng} / \mathrm{ml}$ concentration in 10mM PBS/PBT (1:2) for 1.5 hours at room temperature with gentle shaking. Membranes were washed 5 times with PBT for 5 minutes, then incubated with the secondary antibody FITC-donkey anti mouse IgG (Jackson Scientific) at a concentration of $700 \mathrm{ng} / \mathrm{ml}$ in 10mM PBS/PBT (1:2) for 1.5 hours at room temperature with gentle shaking. Membranes were washed 5 times for 5 minutes in PBT and then scanned in a fluorescent image analyser (Fujifilm FIA-5100 (Alphatech Systems)).

\subsubsection{Complement assay}

A red blood cell suspension was made by adding $12 \mathrm{ml}$ of fresh defibrinated sheep blood to a $50 \mathrm{ml}$ tube containing $35 \mathrm{ml}$ Hanks buffer (no calcium) with $\mathrm{Mg}^{2+}(10 \mathrm{mM})$ and ethylene glycol tetraacetic acid (EGTA) (10 mM). The tube was mixed gently and centrifuged at $400 \mathrm{~g}$ for $10 \mathrm{~min}$ with no brake or rapid deacceleration to avoid cell lysis. The supernatant was removed and a wash performed using Hanks buffer. An additional $50 \mathrm{ml}$ of Hanks buffer was added to resuspend the pellet. The tube was centrifuged at $400 \mathrm{~g}$ for $10 \mathrm{~min}$ after which no redness was observed in the red blood cell suspension. Into 96 well plates, $40 \mu \mathrm{l}$ of egg $(0,1$, 2, 3, 4 and 5 dpf) and larval (1, 2, 3, 4, 5, 6, 7, 8, 9, 10, 11, 12, 16, 20, 24, 32, 45, 50 and 63 dph) protein samples (previously adjusted to $100 \mu \mathrm{g} / \mathrm{ml}$ total protein) were pipetted. Forty $\mu \mathrm{l}$ of adult hapuka serum was used as a positive control and $40 \mu \mathrm{l}$ of PBS (10 mM) was used as a negative control. Sixty $\mu$ l of Hanks buffer was added to each well. Seven serial dilutions were made for each sample, decreasing in concentration by $50 \%$ each time. One hundred $\mu \mathrm{l}$ of the red blood cell suspension was added to each well and the plates incubated at room temperature for $1 \mathrm{~h} 30 \mathrm{~min}$ with gentle agitation. The plates were centrifuged at $400 \mathrm{~g}$ for 10 
min and the resulting supernatants pipetted into clean 96 well plates. Supernatant absorbances were measured at $550 \mathrm{~nm}$ in a Versamax microplate reader (Molecular Devices).

\subsubsection{Lysozyme assay}

A series of lysozyme standards from chicken egg white (Sigma) in phosphate/citrate (0.1 M) buffer containing $0.09 \% \mathrm{NaCl}$, pH 5.8 were made ranging from 0 to $40 \mu \mathrm{g} / \mathrm{ml} ; 25 \mu \mathrm{l}$ of these lysozyme standards were pipetted into a 96 well plate. Twentyfive $\mu$ l of hapuka egg ( $0 \mathrm{dpf}$ ) and juvenile larvae (90 dph) protein samples (previously adjusted to $100 \mu \mathrm{g} / \mathrm{ml}$ total protein) were pipetted in triplicate into the flat bottom 96 well plate. Twentyfive $\mu l$ of adult hapuka serum was used as a positive control and $25 \mu \mathrm{l}$ of PBS (10 mM) was used as a negative control. To each well, $175 \mu \mathrm{l}$ of Micrococcus lysodeiketicus (Sigma) at $0.75 \mathrm{mg} / \mathrm{ml}$ in phosphate/citrate $(0.1 \mathrm{M})$ buffer containing $0.09 \% \mathrm{NaCl}$, pH 5.8 was added. The plate was immediately placed in a Versamax microplate reader (Molecular Devices). After 10 seconds of initial shaking, the absorbance at $450 \mathrm{~nm}$ was read in negative kinetics mode at 15 second intervals over 5 minutes. Sample values were calculated using a standard curve of Vmax rate (OD/min) from the known standards and the resulting activity was expressed in lysozyme units. 


\subsection{Gene expression studies}

2.3.1. Total RNA and $c D N A$ preparation for reverse transcription polymerase chain reaction (RT-PCR)

RT-PCR techniques were carried out in order to obtain larval cDNA for ontogenic mRNA expression analysis (IgM, IgZ, CSF1R, C3, Il-12, MHCII $\alpha$, TCR $\alpha$, TCR $\beta$, RAG1 and Bactin) and hapuka gene sequences (IgM, IgZ and MHCII $\alpha$ ). Larval samples for 1, 2, 3, 6, 9, $12,20,24,32,45,50$ and $63 \mathrm{dph}$ were prepared for each of the three clutches by pooling together 5 larvae/juveniles each. Larvae sampled for gene expression studies were rinsed with sterile $10 \mathrm{mM}$ PBS then placed in RNA Later (Ambion) and stored at $-20^{\circ} \mathrm{C}$ until use. Total RNA was isolated using a High Pure RNA Tissue Kit (Roche) according to manufacturer's instructions. Tissue fragments were homogenised in tubes containing autoclaved glass beads and lysed using a ribolyser (Hybaid) under conditions to avoid overheating. Head kidneys from adult hapuka were used as controls using the method described. Total RNA was stored at $-80^{\circ} \mathrm{C}$ until use. The concentration of total RNA was assessed with a Qubit Fluorometer (Invitrogen). Total cDNA was obtained by reverse transcription using Transcriptor First Strand cDNA Synthesis Kit (Roche) according to manufacturer's instructions. The reaction volume was $20 \mu \mathrm{l}$ and contained 19 ng of total RNA. Non-template control was performed for a selection of samples to verify the absence of genomic DNA. The cDNA was stored at $20^{\circ} \mathrm{C}$ until use. 


\subsubsection{Primer design}

Primers were designed from conserved regions of the gene sequences of related fish species that were downloaded from national zcentre for biotechnology information (NCBI) GenBank and aligned using Geneious v5.3.6. For the IgM heavy chain gene, available sequences from rainbow trout (Onchorhyncus mykiss) (U04615), zebra fish (Danio rerio) (AF281479), fugu (Takifugu rubripes) (AB217621) and medaka (Oryzias latipes) (AB274729) were aligned to create degenerate primers for hapuka. The degenerate primers used for initial IgM detection in hapuka are shown in table 2 and the sequenced hapuka IgM primers are listed in table 1. The pair IGMFW1 and IGMRV2 yielded a single band of 920 bp. The PCR product was sequenced and the acquired IgM sequence was analyzed and compared using the BLAST program (Altschul, 1990), and a phylogenetic tree created using Geneious v5.3.6. For the IgZ gene, available sequences from orange-spotted grouper (Epinephelus coioides) (GU182366.1), mandarin fish (Siniperca chuatsi) (DQ016660.1), grass carp (Ctenopharyngodon idella) (EU243240.1) and zebrafish (AY646282.1, (AY646281.1), were aligned to create degenerate primers for hapuka. The degenerate primers used for initial IgZ detection in hapuka are shown in table 3. The pair IGZFW2 and IGZRV2 yielded a single band of 858 bp. The degenerate primers used for initial IgZ detection in hapuka are shown in table 2 and the sequenced hapuka IgZ primers are listed in table 1.

For MHC class II available sequences from Sea bass (DQ821108.1), Rainbow trout (AJ251431.1), zebrafish (L19451.1) and tilapia (AF212855.1) were aligned for primer design. The degenerate primers used for initial MHC-II detection in hapuka are shown in table 4 and the sequenced hapuka MHC-II primers are listed in table 1. For RAG1 available sequences from striped trumpeter (Latris lineata) (FJ864718.1), California sheephead (Semicossyphus pulcher) (FJ616726.1), hogfish (Lachnolaimus maximus) (FJ616724.1) and bicolor damselfish (Stegastes partitus) (FJ616717.1) were aligned for primer design. For the TCR $\alpha$ gene, available sequences from channel catfish (Ictalurus punctatus) (U58505.1), zebrafish (AY476726.1), Japanese flounder (AB053406.1), rainbow trout (U50991.1), sea bass (AY831387.1), Atlantic cod (AJ133847.1), carp (AB120623.1), and bicolor damselfish (AY198370.1) were aligned for primer design. For the TCR $\beta$ gene, available sequences from Atlantic cod (AJ133850.1), fugu (Takifugu rubripes) (AB222424.1), bicolor damselfish (AF324823.1), Japanese flounder (Paralichthys olivaceus) (AB053443.1), rainbow trout 
(AF329700.1) gilt-head sea bream (Sparus aurata) (AM490437.1) and sea bass (AJ493441.1) were aligned for primer design. For CSF-1 available sequences from zebrafish (NM_131672), sea bream (AM050293) and rainbow trout (NM_001124738) were aligned for primer design.

\subsection{3. $P C R$}

PCR was performed using larval cDNA samples for ontogenic mRNA expression analysis. FastStart Taq DNA Polymerase, dNTPack (Roche) was used according to manufacturer's instructions; each reaction mixture included $2 \mathrm{U}$ of FastStart Taq DNA Polymerase. One $\mu 1$ of cDNA was used in a $50 \mu \mathrm{l}$ final volume reaction for each sample. Forward and reverse primers were used at a final concentration of $200 \mathrm{nM}$ to amplify the target gene regions: IgM, IgZ, CSF1R, C3, Il-12, MHCII $\alpha$, TCR $\alpha$, TCR $\beta$, RAG1 and B-actin (primers given in Table 2). A 2720 thermal cycler (Applied Biosystems) was used for amplification and the conditions were as follows: preliminary denaturation at $95{ }^{\circ} \mathrm{C}$ for 4 minutes, followed by 40 cycles of denaturation at $95{ }^{\circ} \mathrm{C}$ for 30 seconds, annealing for 30 seconds and extension at 72 ${ }^{\circ} \mathrm{C}$ for 1 minute. Annealing temperatures are given for their respective primers in Table 2 . Final extension was at $72{ }^{\circ} \mathrm{C}$ for 7 minutes. An aliquot of each PCR product $(4 \mu \mathrm{l})$ was electrophoresed on a $1 \%$ agarose gel made with 0.5X TBE (Tris/Borate/EDTA) in a buffer of $0.5 X$ TBE. The gel contained $4 \mu \mathrm{l}$ of $10 \mathrm{mg} / \mathrm{ml}$ ethidium bromide (Bio-Rad) and was viewed under ultraviolet light to detect the presence of cDNA products.

\subsubsection{Sequencing}

Additional PCR experiements using the same protocol were carried out to obtain PCR products for IgM, IgZ and MHC-II. The PCR products were extracted from their respective gels and purified using a QuickClean II PCR Extraction kit according to manufacturer's instructions. Sequencing was carried out by the Massey Genome Service (Massey University, New Zealand). 
Table 2.1. Oligonucleotide primers used for amplification of hapuka cDNA target genes for PCR expression studies.

\begin{tabular}{|c|c|c|c|}
\hline Gene & Primer name & Sequence (5’ - 3’) & $\begin{array}{l}\text { Annealing } \\
\text { temperature }{ }^{\circ} \mathrm{C}\end{array}$ \\
\hline \multirow{2}{*}{ B-actin } & BactinFW & ATGGAWGAKGAAATCGC & \multirow{2}{*}{50} \\
\hline & BactinRV & TGCCAGATCTTCTCCAT & \\
\hline \multirow{2}{*}{ CSF-1 } & CSFW & CWYGGCGACCTBCTGAACTTCC & \multirow{2}{*}{55} \\
\hline & CSFRV & СТСТСТGGAGCСАТССАСТТСАС & \\
\hline \multirow{2}{*}{ IgM heavy chain } & IgMFW0 & GAGGCTTCСТTCTCСТGCT & \multirow{2}{*}{60} \\
\hline & JoMRV0 & СССТTGСТССАТTСGTСAT & \\
\hline \multirow{2}{*}{ C3 } & C3FW2 & TTCATCCAGACTGACAAGA & 50 \\
\hline & C3RV1 & СТСТGССТYАССАТYТСАС & \\
\hline \multirow{2}{*}{ MHC-II } & MHCFW0 & CCTGAAAGTGGATCTCCA & \multirow{2}{*}{57} \\
\hline & MHCRV0 & GCTGAGTCTTCTCCACAT & \\
\hline \multirow{4}{*}{ RAG1 } & RAG1FW & CCAGTTTGAATGGCAGCC & 55 \\
\hline & RAG1RV & GGCTTACAGGACAGTTCT & \\
\hline & TCRaRV2 & CCACAGYCGHAGVGTCA & \\
\hline & TCRbRV2 & CCTGAAGCTTCCACRCCA & \\
\hline \multirow{3}{*}{ TCR- $\alpha$} & TCRaFW1 & CTGCTGCKGTYWCAGACTC & \multirow{3}{*}{50} \\
\hline & & & \\
\hline & TCRaRV2 & CCACAGYCGHAGVGTCA & \\
\hline
\end{tabular}




\begin{tabular}{|l|l|l|l|}
\hline \multirow{2}{*}{ TCR- $\beta$} & TCRbFW & GTGCAGTWTATTTCTGTGCTG & \multirow{2}{*}{54} \\
\cline { 2 - 3 } & TCRbRV2 & CCTGAAGCTTCCACRCCA & \\
\hline \multirow{2}{*}{ IgZ } & IGZFW0 & CTTTCCAGTGGACCGA & \multirow{2}{*}{54} \\
\cline { 2 - 3 } & IGZRV0 & GGAGCTTTYGAGGCC & \\
\hline
\end{tabular}


Table 2.2. Oligonucleotide primers used for amplification of hapuka IgM, IgZ and MHCII sequences.

\begin{tabular}{|c|c|c|c|}
\hline Gene & Primer name & Sequence $\left(5^{\prime}-3^{\prime}\right)$ & $\begin{array}{l}\text { Annealing } \\
\text { temperature }{ }^{\circ} \mathrm{C}\end{array}$ \\
\hline \multirow{7}{*}{ IgM heavy chain } & IGMFW1 & TGCYTBGCCACMGGCTTCACACC & \multirow{7}{*}{60} \\
\hline & IGMFW2 & GAYTTYRTRCAGTACCC & \\
\hline & IGMFW3 & CTCAAAAGATGTCCAGACCACG & \\
\hline & IGMFW4 & GCCATCACATWTCAWGAATGG & \\
\hline & IGMRV1 & TCRTCATYRACAAGCC & \\
\hline & IGMRV2 & CYAGHGWTAACTGGCCATAAGC & \\
\hline & IGMRV3 & AYCTAWTGGGCCTTGC & \\
\hline \multirow{4}{*}{ IgZ } & IGZFW1 & GCTCTGGAGTGGATTGGGT & \multirow{4}{*}{54} \\
\hline & IGZFW2 & CTYACTTTCCAGTGGACC & \\
\hline & IGZRV1 & GGKTCAGTGTCACTGTGA & \\
\hline & IGZRV2 & ACACACCAGAGTGACCTC & \\
\hline \multirow{2}{*}{ MHC-II } & MHCFW & GGTGAAGWGWWGTGGTACGC & \multirow{2}{*}{57} \\
\hline & MHCRV2 & CAGMCCCASAGTCAGACCC & \\
\hline
\end{tabular}




\subsection{Histology and immunohistochemistry}

\subsubsection{Histology}

Sectioning and processing was carried out by Jane Anderson at the Otago School of Medicine in Wellington. Five larvae were sampled at days 1, 2, 3, 4, 5, 6, 7, 8, 9, 10, 11, 12, 16, 20, and 24 dph. At 32, 45, 50 and 63 dph 4 larvae were sampled. Larvae were fixed in 4\% paraformaldehyde (PFA) at $4^{\circ} \mathrm{C}$ overnight. Next larvae were gently rinsed in $70 \%$ ethanol to remove PFA residues and transferred to 70\% ethanol. Samples were processed through an alcohol series of $70 \%, 90 \%$ and $100 \%$ before a xylol step according to Sakura Tissue-Tek VIP. Samples were embedded in paraffin wax cassettes, and sections $4 \mu \mathrm{m}$-thick were cut in the transverse and sagittal plane using a Jung Biocut 2035 microtome (Leica) then mounted onto slides and left to dry at $37{ }^{\circ} \mathrm{C}$ overnight. Lastly the samples were stained with hematoxylin and eosin (H\&E) according to standard procedures. Observations were based on multiple samples at each time point.

\subsubsection{Immunohistochemistry (IHC)}

For IHC, 5 whole larvae were sampled at 1, 2, 3, 6, 9, 12, 16, 20, and 24 dph. For 45, 50 and $63 \mathrm{dph} 4$ whole larvae were sampled. Larvae samples were fixed over night at $4^{\circ} \mathrm{C}$ in $\mathrm{BT}$ fix (4\% PFA and 1.25x fix buffer consisting of Sucrose, $\mathrm{CaCl} 2$ and $\mathrm{PO} 4$ buffer, $\mathrm{pH}$ 7.3) then transferred to $30 \%$ sucrose solution and left to sink overnight at $4^{\circ} \mathrm{C}$. Samples were placed in cryomolds, covered with O.C.T (Tissue-Tek, Sakura) and frozen for 2 min or until O.C.T became solid. Freezing was conducted by pre-cooling a metal stage inside a box containing a bath of liquid nitrogen. Cryoblocks were immediately stored at $-80^{\circ} \mathrm{C}$ until being sectioned in a cryostat. Five $\mu \mathrm{m}$-thick longitudinal sections were cut and mounted onto Superfrost Plus slides (Menzel-Glaser), then air dried and stored at $-80^{\circ} \mathrm{C}$ until use. A $2 \mathrm{~mm}$ PAP pen (SigmaAldrich) was used to draw a circle around the tissue sample on the slide and the sample kept hydrated at all times with $10 \mathrm{mM}$ PBS. Samples were incubated in a $0.1 \mathrm{M}$ Glycine-HCL solution ( $\mathrm{pH}$ 2.3) for $10 \mathrm{~min}$ at room temperature in order to reduce background fluorescence. This solution was then removed and the slides rinsed with 10mM PBS twice for $5 \mathrm{~min}$, before pipetting a small volume of StartingBlock Blocking Buffer (Thermo Scientific) with 10mM PBS onto each slide for $15 \mathrm{~min}$ at room temperature. After removal of the protein blocker, 
slides were incubated with primary antibody F06 at $800 \mathrm{ng} / \mathrm{ml}$ concentration in PBT (10mM PBS with $0.05 \%$ tween 20 ) overnight in a humid chamber at $4{ }^{\circ} \mathrm{C}$. After incubation with the primary antibody, the slides were washed twice with 10mM PBS for 5 minutes, then incubated with the secondary antibody, goat anti-mouse IgG, Cy3 conjugate (Jackson Immunoresearch) at $5 \mu \mathrm{g} / \mathrm{ml}$ concentration for 2 hours in the dark at room temperature. After incubation with the secondary antibody, the slides were washed twice with 10mM PBS and then placed into tap water. To visualise tissue structure cell nuclei were stained by dipping slides for 40 seconds in a 1:10000 concentration Hoechst 33342 solution (Molecular Probes) in tap water. Slides were transferred into clean tap water to wash off excess Hoechst and then mounted immediately with fluorescent microscopy mounting solution. Negative controls included cyrosections incubated with no primary antibody or an isotype control (IgG1). 


\subsection{Flow cytometry, FACS and cell staining}

\subsubsection{Flow cytometry and fluorescence-activated cell sorting}

Blood was collected using a syringe from the caudal vein of 4 hapuka juveniles (127 dph) into Microcentrifuge Tubes (Eppendorf) containing RPMI medium (Gibco Invitrogen) with $10 \mathrm{IU} / \mathrm{ml}$ heparin. Additonally the head kidneys of the 4 hapuka juveniles were removed with forceps after an incision and the tissue crushed through a cell strainer (BD Falcon) into $10 \mathrm{ml}$ tubes with approximately $5 \mathrm{ml}$ of RPMI medium containing heparin at $10 \mathrm{IU} / \mathrm{ml}$ to acquire the blood cells. The size of the spleen was not large enough to produce significant cell numbers after Percoll separation so was not included. These blood and head kidney samples in media were then carefully pipetted into $10 \mathrm{ml}$ tubes containing a Percoll gradient of 51\% and 34\% then spun in a centrifuge at $400 \mathrm{xg}$ for 30 minutes with no brakes/acceleration at $4^{\circ} \mathrm{C}$. After centrifugation, the top layer was discarded to avoid red blood cell contamination and the white blood cell layer carefully pipetted into new tubes containing $5 \mathrm{ml}$ RPMI medium with antibiotics Penicillin-Streptomycin (10,000 U/mL) (Gibco Invitrogen) at 1:100 dilution. Samples were then centrifuged at $400 \mathrm{xg}$ this time with brakes/acceleration for 10 minutes at $4{ }^{\circ} \mathrm{C}$. The supernatant was discarded and the pellet resuspended in $5 \mathrm{ml}$ of RPMI media and Penicillin-Streptomycin (10,000 U/mL) (Gibco Invitrogen) at 1:100 dilution. Samples were centrifuged again at $400 \mathrm{xg}$ for 10 minutes at $4{ }^{\circ} \mathrm{C}$ and the supernatant discarded. Samples for leucocyte population FACS analysis were resuspended in $3 \mathrm{ml} 10 \mathrm{mM}$ PBS and kept at $4{ }^{\circ} \mathrm{C}$ until being read in the FACScan flow cytometer (Becton Dickinson). Samples for microscopy were resuspended in $3 \mathrm{ml} 10 \mathrm{mM}$ PBS and kept at $4{ }^{\circ} \mathrm{C}$ until being mounted

Samples for $\operatorname{IgM}^{+}$(IgM positive) lymphocyte FACS analysis were resuspended in $1 \mathrm{ml}$ $10 \mathrm{mM}$ PBS including $5 \%$ hapuka serum (2.5 $\mathrm{ml}$ in $50 \mathrm{ml} 10 \mathrm{mM}$ PBS) and cell counts performed. Samples were adjusted to $1 \times 10^{6}$ cells per $200 \mu \mathrm{l}$ of $10 \mathrm{mM}$ PBS, including $5 \%$ hapuka serum, and the primary antibody F06 at a final concentration of $400 \mathrm{ng} / \mathrm{ml}$. The samples were incubated with F06 for 45 minutes on ice. Samples were washed twice using 3 $\mathrm{ml} 10 \mathrm{mM}$ PBS including 5\% hapuka serum and centrifuged for 8 minutes at $400 \mathrm{xg}$ at $4{ }^{\circ} \mathrm{C}$. The supernatant was discarded after each wash. The samples were incubated with the secondary antibody FITC-donkey anti mouse IgG (Jackson Immunoresearch) at a final 
concentration of $1.5 \mu \mathrm{g} / \mathrm{ml}$ in $200 \mu 110 \mathrm{mM}$ PBS including 5\% hapuka serum. The incubation was performed for 35 minutes on ice in the dark. The samples were washed 3 times using 3 $\mathrm{ml}$ 10mM PBS including 5\% hapuka serum and the lymphocyte populations separated using the FACS machine with 20000 events. Lymphocyte populations were analysed by flow cytometry on the basis of their size (FSC) and granularity (SSC) using Flowjo version 7.6.4.

\subsubsection{Cytochemical cell staining}

Cytospins from head kidneys and blood of adult and juvenile hapuka were mounted on slides. Slides were dipped in 100\% methanol for 60 seconds at room temperature and left to air dry. A 1 in 10 dilution of Giemsa in tap water was used to stain the slides for 30 minutes in the dark. Slides were rinsed carefully under tap water, air dried and mounted with DPX mounting media (Sigma Aldrich).

\subsubsection{Myeloperoxidase staining}

Cytospins from head kidneys and blood of adults and juveniles were mounted on slides and fixed for 60 seconds in 10\% paraformaldehyde solution in ethanol. Slides were washed for 30 seconds in water and incubated for 30 seconds in a staining solution containing $30 \%$ ethanol with $3 \mathrm{mg} / \mathrm{ml}$ benzidine dihydrochloride [B-3383; Sigma], 1.32mM ZnSO4, 0.123M sodium acetate, $0.0146 \mathrm{M}$ sodium hydroxide and $0.02 \% \mathrm{H} 2 \mathrm{O} 2$. Slides were briefly washed in water, air-dried and mounted.

\subsubsection{Statistical analysis}

For determining significance of head kidney (127 dph) and peripheral blood leucocytes (PBL) (134 dph) leucocyte populations between juveniles and adults, 2 tailed $\mathrm{T}$ tests were performed. Additionally 2 tailed T tests were performed for determining significance between $\operatorname{IgM}^{+}$cell populations between adults and juveniles (117 dph). 


\section{Chapter 3 - Ontogeny of the lymphoid organs.}

\subsection{Introduction}

Studying the appearance and structure of lymphoid organs in developing fish larvae is one method of assessing maturation and possible immunocompetence and has been done for many fish species, reviewed by Mulero (2007). However, nothing is known about the ontogeny of the hapuka lymphoid organs, and to date no immunological studies have been carried out on any members for the perciformes family Polyprionidae, to which hapuka belongs. This family includes 2 genera Stereolepis and Polyprion and these genera contain a total of 6 species, Stereolepis consists of S. doederleini and S. gigas, whereas Polyprion consists of P. americanus, P. moeone, P. yanezi and P. oxygeneios (hapuka). Knowledge of organ development is necessary for the understanding of both specific and non-specific immunocompetence mechanisms in hapuka, and will be useful to design therapeutic and immunoprophylactic measures when rearing hapuka. With regards to other species of fish important to aquaculture, most studies have exclusively used light and/or electron microscopy to investigate the ontogeny of the main lymphoid organs; the thymus, spleen and head kidney (Mulero et al., 2007b). This is primarily because of the lack of appropriate markers available for specific cell populations. In contrast, the zebrafish (Danio rerio) is an exception, with many cell markers available and the entire genome sequenced due to its use as a model organism (Willett et al., 1999; Trede et al., 2004). Because there are no available reagents or cell markers for hapuka, the study of their lymphoid organs was carried out using light microscopy. Finally, although the development of lymphoid organs does not necessarily correspond to the maturation of immune functions, learning the timing of organ development in hapuka will help improve the understanding in other areas of their immune system and provide information for future studies.

Aims: This chapter aims to describe the development of the lymphoid organs including the head kidney, spleen, thymus and digestive tract in hapuka larvae with respect to other fish species important to aquaculture. Descriptions will start from the first appearance of each respective organ, determining key developmental events. 


\subsection{Results}

\subsubsection{Head kidney}

The excretory part of the hapuka kidney was present at 4 dph (Fig 3.1A and B) and consisted of two renal tubuli located ventrally to the notochord and anterior to the developing intestine. At this stage there was no sign of hematopoietic tissue. At 5 dph (Fig 3.1C and D) cells could be seen migrating to this site; possibly erythropoietic cells. During the next 5 days the number of tubules and migrating cells increased (Fig 3.1E and F, 3.2A, B and C) as the yolk sac was fully absorbed. On the day after first feeding, 12 dph (Fig 3.2D) the organ tissue appears hematopoietic and lymphoid progenitor cells are visible with their high nucleus to cytoplasm ratio. At 16 dph (Fig 3.2E) the kidney organ appears formed; however the anterior kidney is not yet distinct from the posterior kidney. Hematopoietic tissue continues to grow and develop (Fig 3.2F) and many lymphoid looking cells are scattered throughout the tissue. At $20 \mathrm{dph}$ (Fig 3.3A) the morphology remained similar. Tubules can be seen forming further towards the posterior end of the kidney at 24 dph after live artemia feeding had commenced (22 dph). At this stage sinusoids are beginning to form within the tissue (Fig 3.3B). The kidney continued to increase in size and volume at 32 dph (Fig 3.3C) and many lymphoid cells can be seen within the tissue. By 45 dph (Fig 3.3D) the head kidney has formed into a distinct organ from the excretory posterior kidney and erythrocytes can be seen in the developing sinusoids (Fig 3.3E). It is at this stage that the first melanomacrophage centres (MMCs) can be seen. The bi-lobed nature of the head kidney can be seen (Fig 3.3F) at $50 \mathrm{dph}$ as it continues to increase in size and complexity. At 63 dph (Fig 3.3G) the head kidney is a sea of hematopoietic and lymphoid tissue, with leucocytes spread amongst the parenchyma and sinusoids invigorating the tissue (Fig 3.3H).

\subsubsection{Spleen}

In hapuka larvae the spleen anlage was first observed at $16 \mathrm{dph}$ in the peritoneal cavity next to the liver and developing pancreas (Fig 3.4A). The characteristic capsule of the spleen was still forming and the organ itself consisted mostly of interstitial space and contained small clusters of erythrocytes and primitive reticular cells (Fig 3.4B). Later, at $24 \mathrm{dph}$, the spleens capsule consisting of squamous epithelium, appears intact (Fig 3.4C) and its connection to 
the basement membrane has thickened. Additionally the interstitial space within the organ has been replaced with connective tissue (Fig 3.4D). At 32 dph (Fig 3.4E) the spleen has increased in size and complexity, and primitive sinusoids can be seen forming amongst the developing tissue (Fig 3.4F). By 45 dph the organ has achieved its distinct oval shape (Fig 3.4G) and appears populated with various leucocytes. Furthermore trabeculae can be seen infiltrating the tissue (Fig 3.4H) and MMCs are visible, especially around the sinusoids. At this stage the spleen appears mostly differentiated.

\subsubsection{Thymus}

The thymic anlage first appeared in the pharyngeal cavity at 20dph, as a thickening of the pharyngeal epithelium next to the gill arches (Fig 3.5A). At this stage the thymus consisted of undifferentiated darkly stained cells, seemingly lymphoblasts and thymocytes (Fig 3.5B); which were separated from the connective tissue by an epithelial layer. At 32 dph (Fig 3.5C) the thymus had increased in size, however the tissue morphology was similar to that at day 20 and appeared immature in nature (Fig 3.5D). By $50 \mathrm{dph}$ (Fig 3.5E) the number of cells with thymocyte morphology had increased greatly and blood sinusoids could be seen invigorating the tissue (Fig 3.5F). Later at 63 dph the thymus has achieved its typical wedge shape and appears differentiated with trabeculae extending into the parenchyma; now rich in thymocytes and lymphocytes.

\subsubsection{Digestive tract}

The gut rudiment was present at hatch (data not shown) and began differentiating soon after. At 9 dph (Fig 3.6A) an intestinal lumen is visible but the mucosa appears undifferentiated. At $10 \mathrm{dph}$ (Fig 3.6B), the lumen has increased in size as the length of the digestive tract increases and by 16 dph the gastric folds are beginning to form (Fig 3.6C). Addtionally at this stage, goblet cells can be seen appearing within the mucosa. The gut appears more differentiated at $32 \mathrm{dph}$ (Fig 3.6D) with many gastric folds and a lamina propria visable. The guts surface area increases at days 50 and 63 (Fig 3.6E and F) with the mucosa and serosa appearing differentiated. 


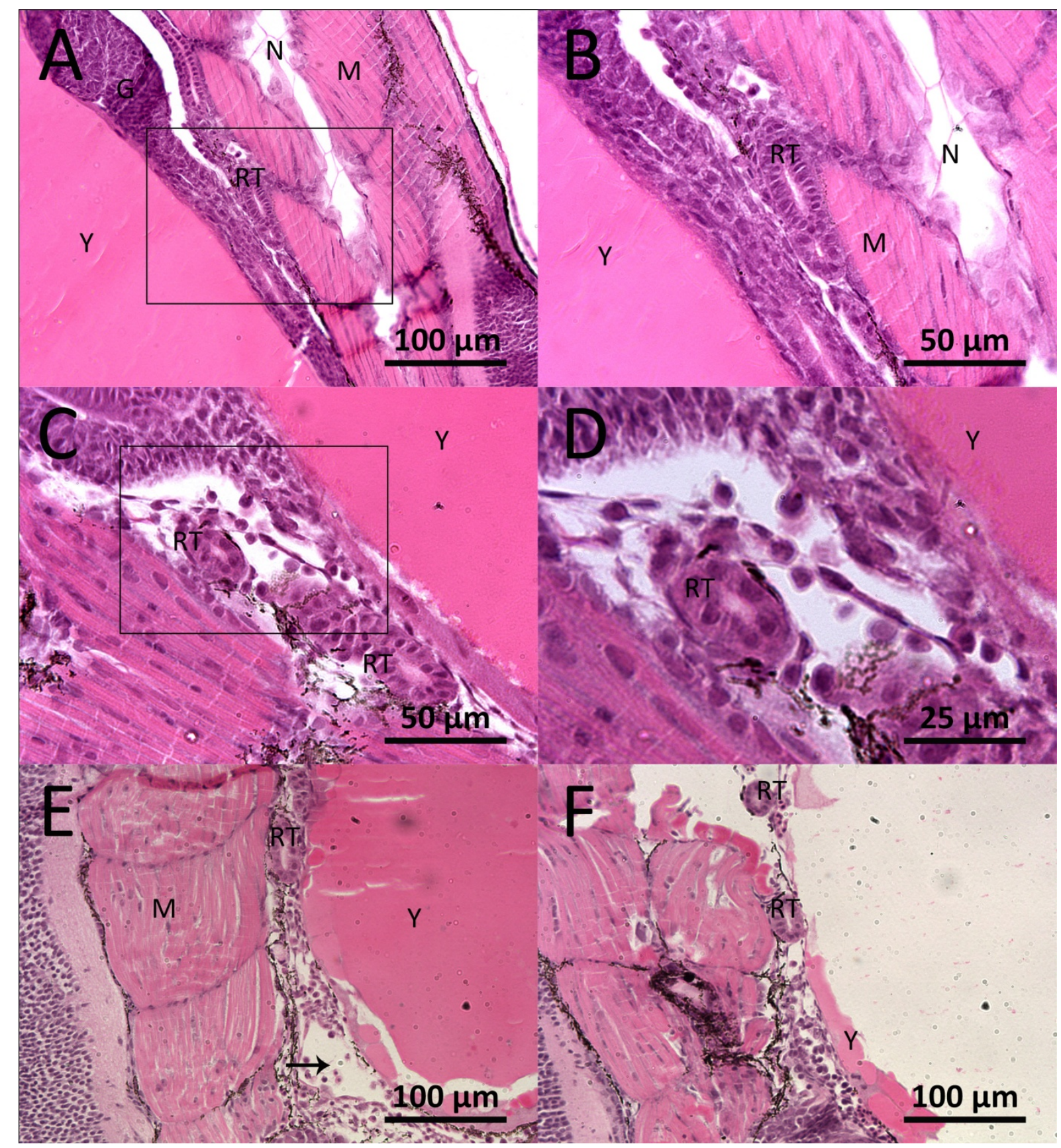

Fig. 3.1. Sagittal cut sections showing morphological development of the kidney of hapuka at 4-7 dph. $4 \mu \mathrm{m}$ sections of tissue were stained with H\&E. (A) Section at 4 dph showing the developing kidneys proximity to the gut anlage and yolk sac. (B) Higher magnification at 4 dph showing a single visible tubule. (C) Five dph section showing second tubule and (D) migrating lymphoid progenitor cells. (E) 6 dph section showing continued cell migration (arrow) and expansion. (F) More cells are seen migrating to the posterior region of the kidney 
at 7 dph. Abbreviations: Renal tuble (RT), Yolk sac (Y), skeletal muscle (M), gut (G), notochord $(\mathrm{N})$. 


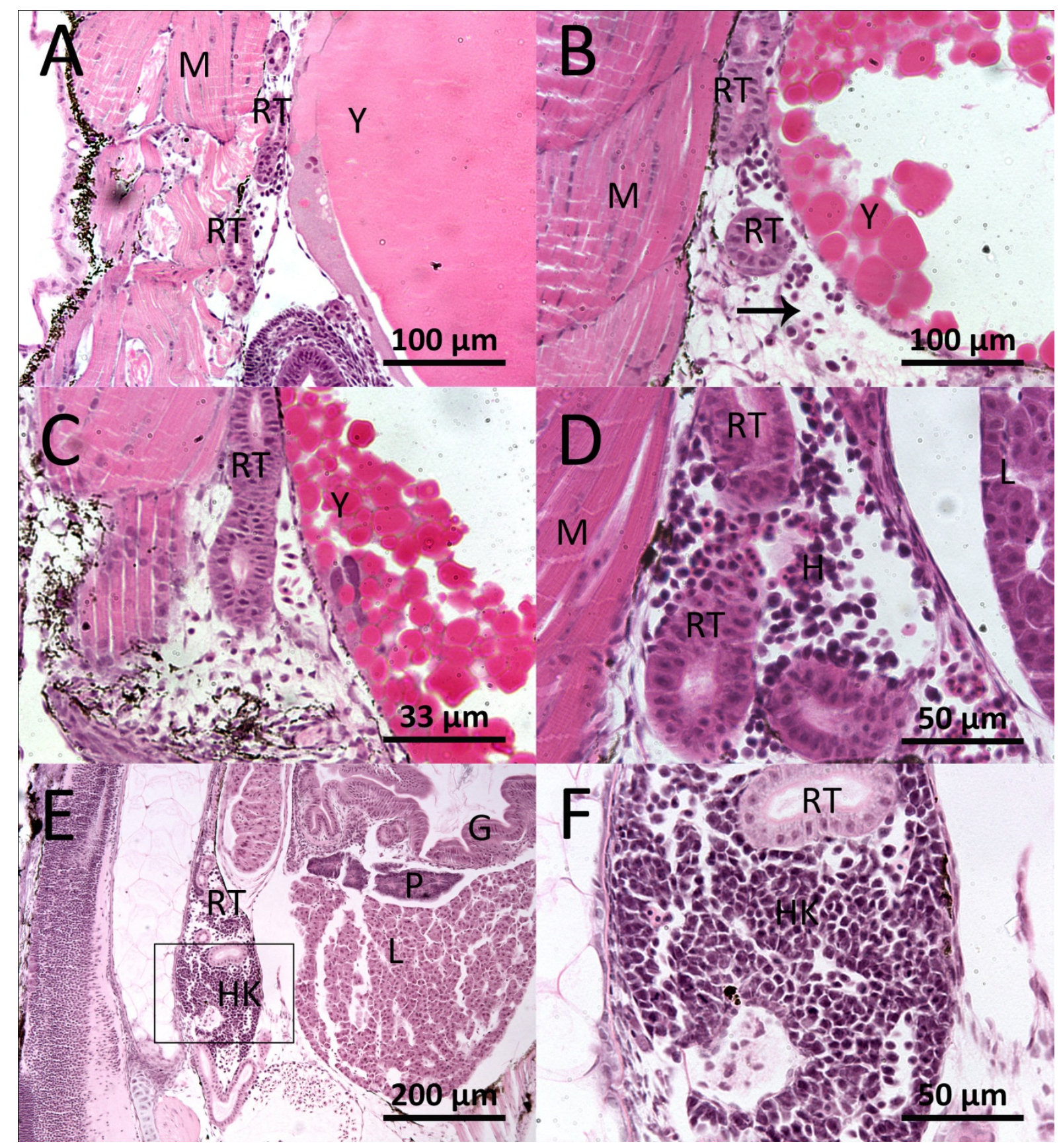

Fig. 3.2. Sagittal cut sections showing morphological development of the kidney of hapuka at 8-16 dph. $4 \mu \mathrm{m}$ sections of tissue were stained with H\&E. (A) 8dph section showing increased growth of kidney. (B) Kidney at 9 dph, showing more migrating cells (arrow) towards posterior end. (C) Remnants of the yolk sac beside the kidney at $10 \mathrm{dph}$. (D) $12 \mathrm{dph}$ kidney with hematopoietic stem cells forming accumulating. (E) Increased structural definition of kidney at $16 \mathrm{dph}$ (F) 16 dph kidney parenchyma. Abbreviations: Renal tubule 
(RT), skeletal muscle (M), yolk sac (Y), head kidney (HK), liver (L), Hematopoietic cells (H). 


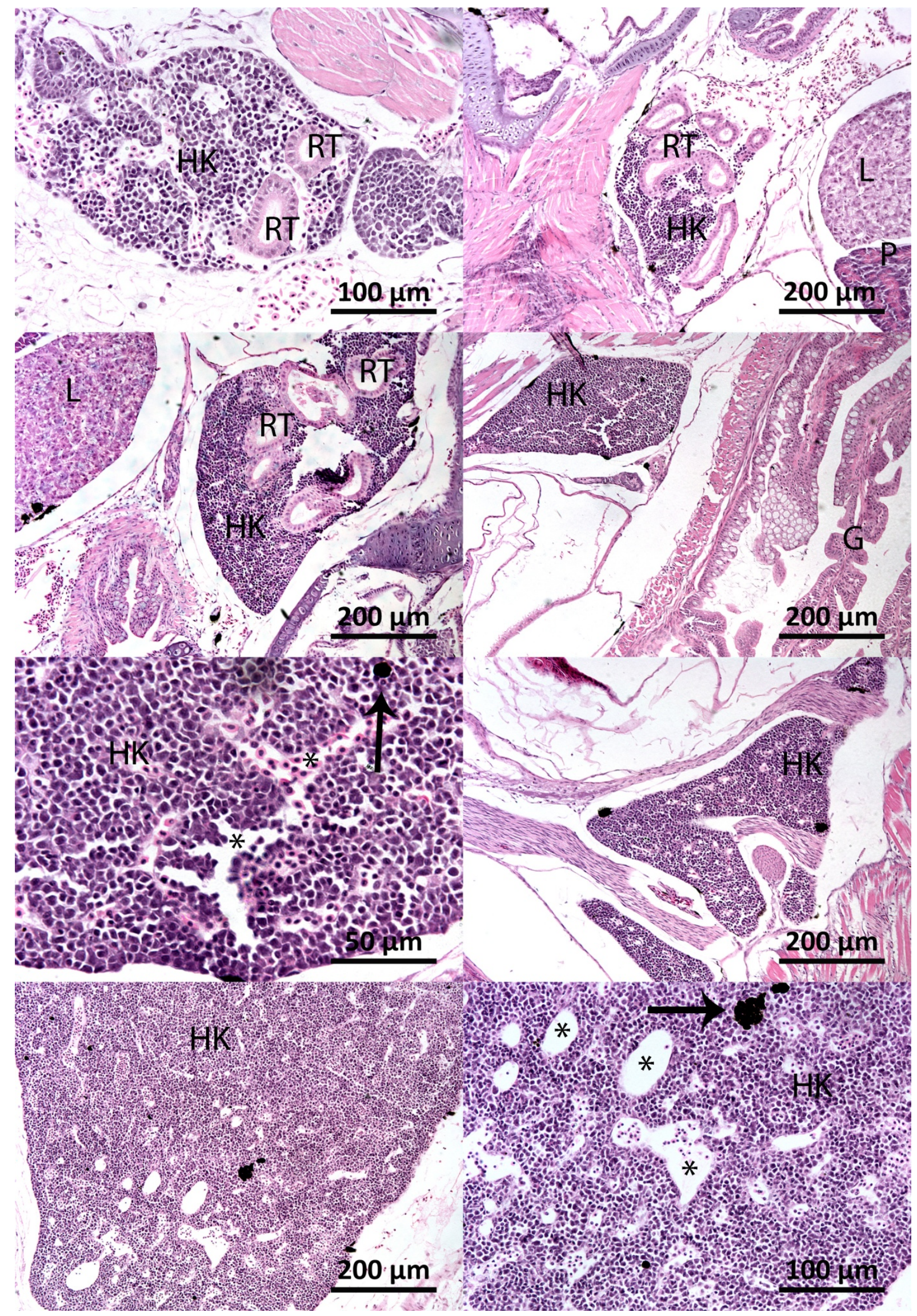


Fig. 3.3. Sagittal cut sections showing morphological development of the kidney of hapuka at 20-63 dph. $4 \mu \mathrm{m}$ sections of tissue were stained with H\&E. (A) 20 dph. (B) Tubules are seen more towards the posterior end of the kidney at $24 \mathrm{dph}$. (C) Many lymphoid cells seen in the HK tissue at $32 \mathrm{dph}$. (D) Head kidney is distinct from anterior kidney at $45 \mathrm{dph}$. (E) Sinusoid development at 45 dph. (F) Head kidney at 50 dph. (G) Head kidney at 63 dph (H) Head kidney at 63 dph with melanomacrophages (arrow) and sinusoids (*). Abbreviations: Head kidney (HK), renal tubule (RT), pancreas (P), gut (G), liver (L). 


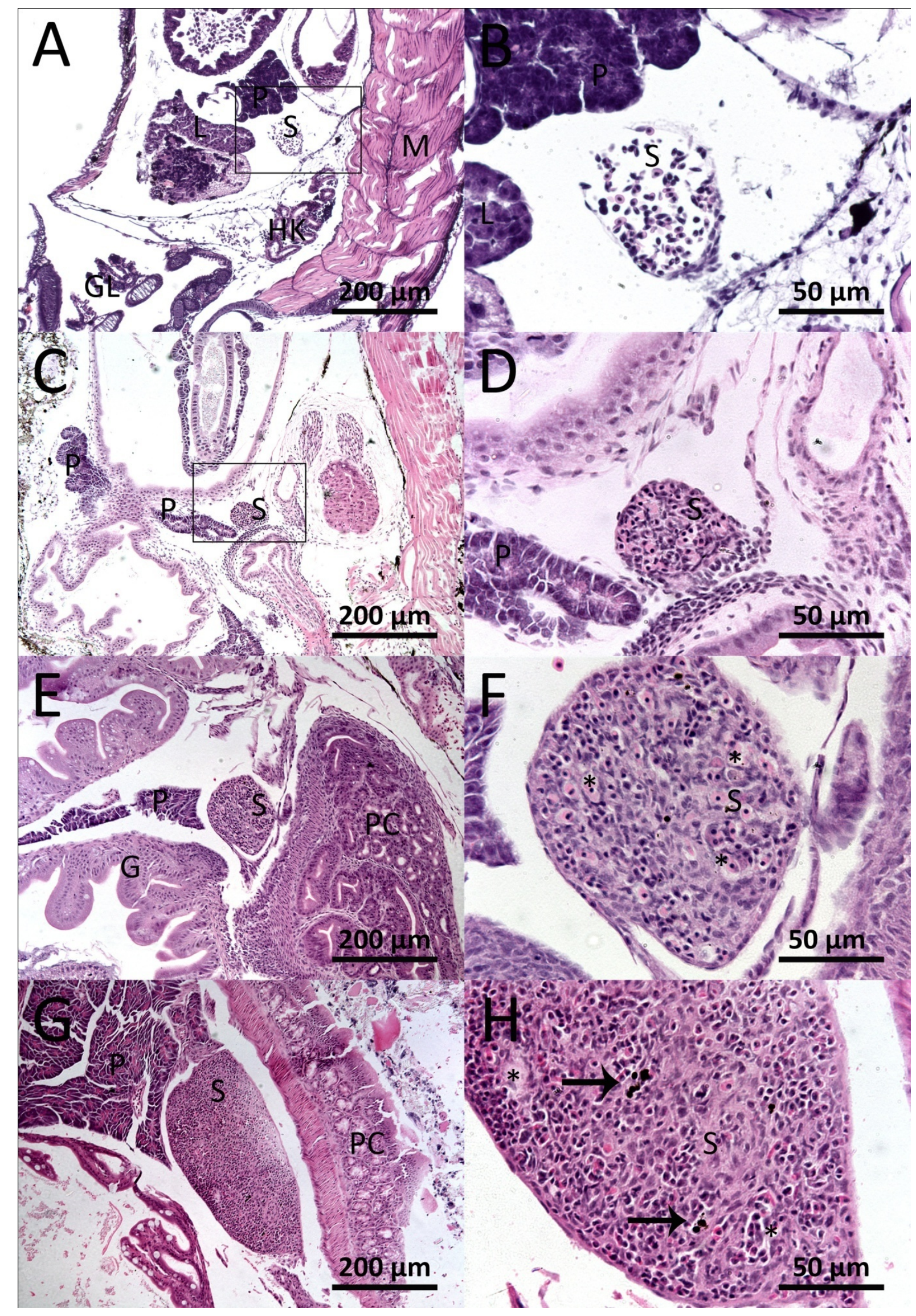


Fig. 3.4. Sagittal cut sections showing morphological development of the spleen of hapuka. 4 $\mu \mathrm{m}$ sections of tissue were stained with H\&E. (A) First appearance of spleen at $16 \mathrm{dph}$ in the peritoneal cavity. (B) High magnification of $16 \mathrm{dph}$ spleen, showing capsule formation (arrow). (C) 24 dph. (D) High magnification of 24 dph showing finished capsule. (E) 32 dph. (F) 32 dph spleen showing sinusoid formation. (G) 45 dph. (H) 45 dph spleen, showing MMCs (arrows) and sinusoids (*). Abbreviations: (S) Spleen, (P) pancreas, (PC) pyloric caeca, (G) gut, (GL) gill lamellae, (HK) head kidney, (M) skeletal muscle. 


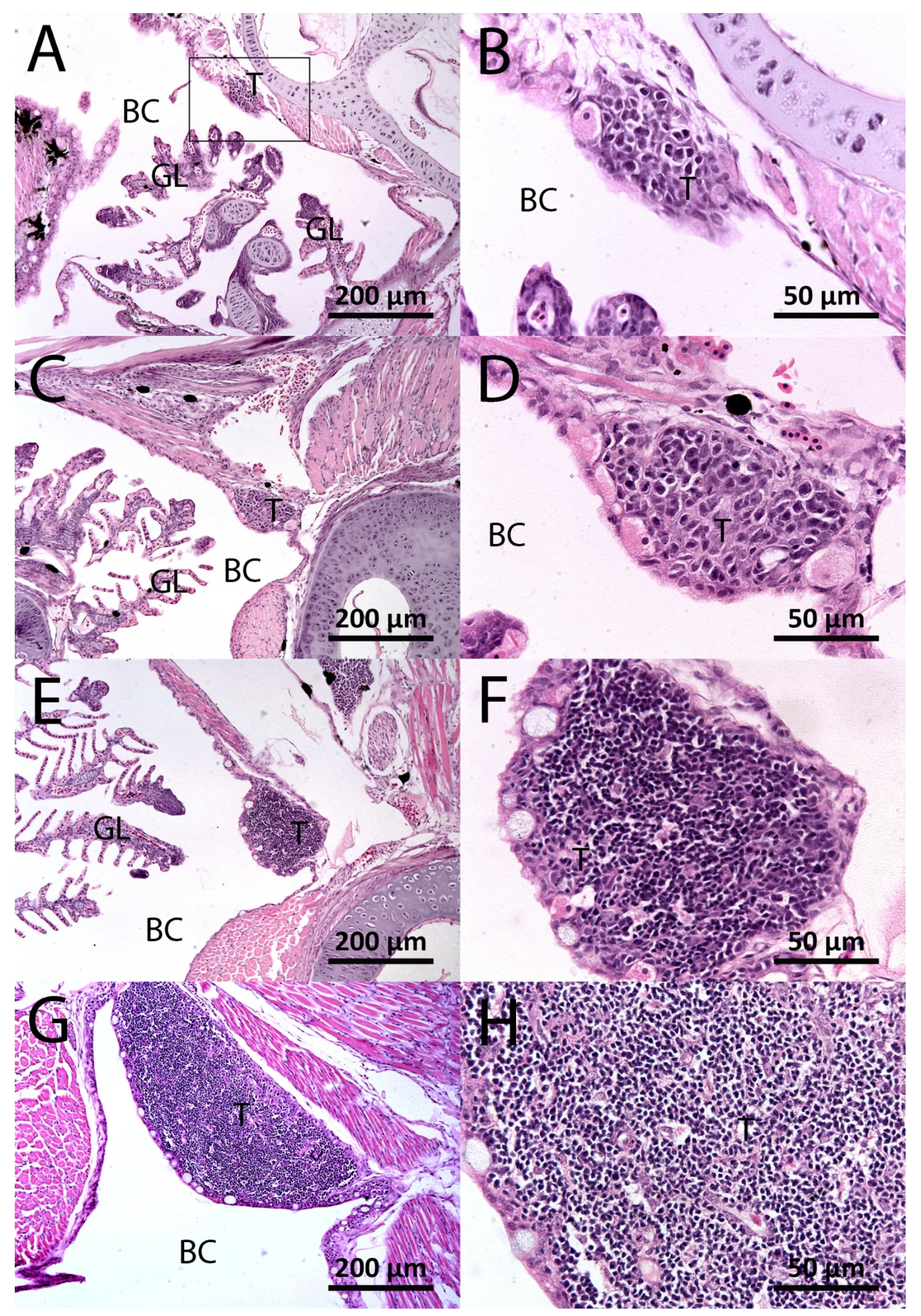


Fig. 3.5. Sagittal cut sections showing morphological development of the thymus of hapuka. $4 \mu \mathrm{m}$ sections of tissue were stained with H\&E. (A) Thymus anlage at $20 \mathrm{dph}$. (B) High magnification of early thymus $20 \mathrm{dph}$. (C) 32 dph thymus relative to the gill lamellae. (D) High magnification of 32 dph thymus. (E) 45 dph. (F) High magnification of 45 dph showing thymocytes. (G) 63 dph. (H) High magnification of 63 dph thymus showing tissue architecture. Abbreviations: branchial cavity (BC), gill lamina (LP), thymus (T). 


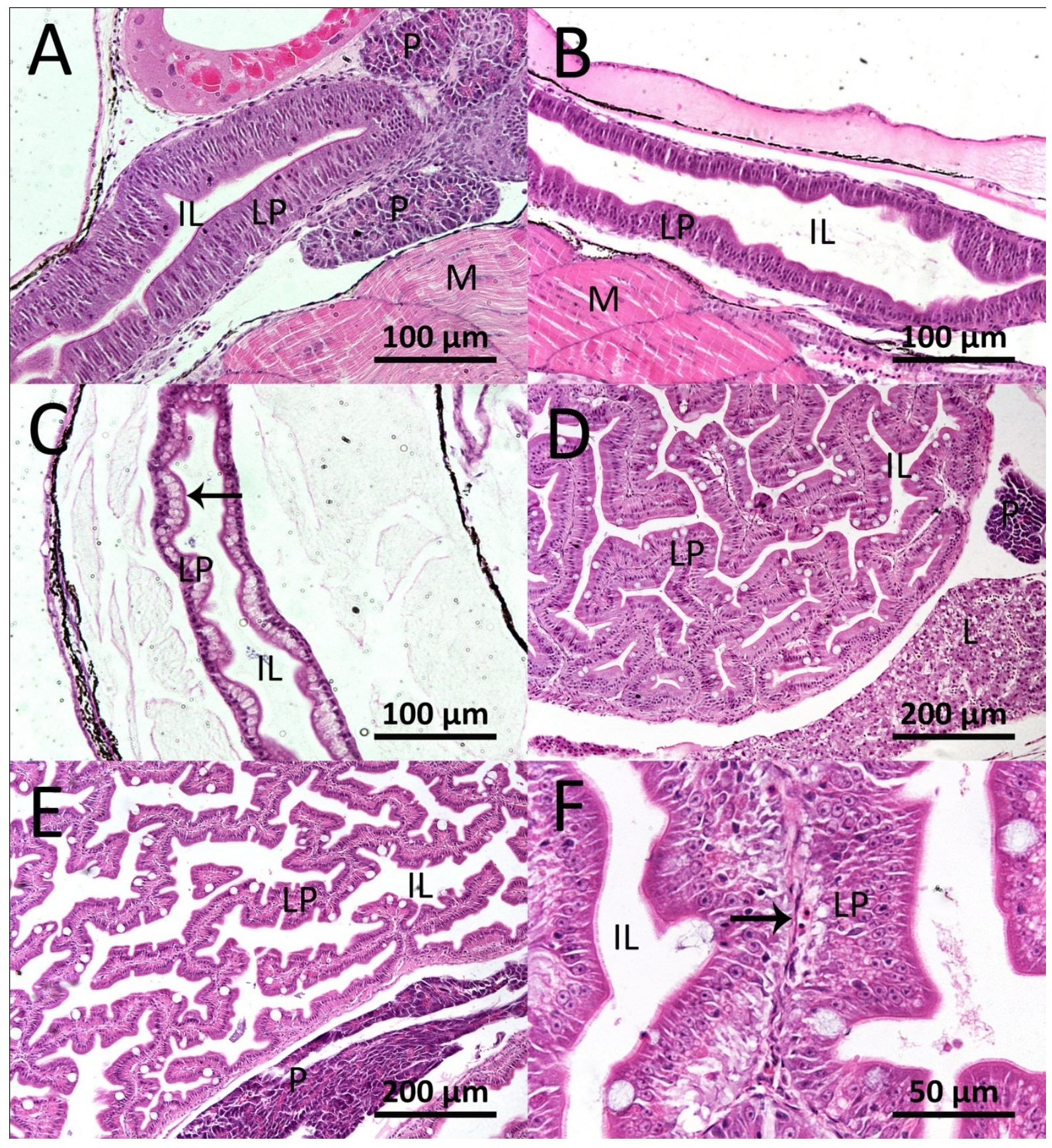

Fig. 3.6. Sagittal cut sections showing morphological development of the gut of hapuka. $4 \mu \mathrm{m}$ sections of tissue were stained with H\&E. (A) Developing gut at 9 dph. (B) Increase in size of the gut lumen at $10 \mathrm{dph}$. (C) Goblet cells (arrow) are seen at $16 \mathrm{dph}$. (D) Gut appears differentiated at 32 dph with lamina propria obvious. (E) 50 dph. (F) Lamina propria at 63 dph showing erythrocytes within. Abbreviations: Lamina propria (LP), intestinal lumen (IL), muscle (M), pancreas (P), liver (L). 


\subsection{Discussion}

This chapter aims to describe the appearance of lymphoid organs in hapuka. No immune studies to date have been carried out with any member of the Polyprionidae family, including hapuka. The appearance of the lymphoid organs were studied using light microscopy, (no electron microscopy was used). The results demonstrated that the kidney is the first lymphoid organ to develop in hapuka, first appearing at $12 \mathrm{dph}$. The spleen developed next at $16 \mathrm{dph}$ with the thymus a few days later, both after the start of first feeding.

This sequence resembled the normal order of development seen in most marine fish species (Falk-Petersen, 2005). This developmental order is seen in species such as Atlantic cod, turbot, sea bream, sea bass and Japanese flounder (Jósefsson and Tatner, 1993; Abelli et al., 1996; Padros and Crespo, 1996; Schrøder et al., 1998; Liu et al., 2004). However, this is a different order of development to species such as Atlantic halibut, where the head kidney developed first, followed by the thymus and lastly the spleen (Patel et al., 2009). Differences in size at hatch and the length of several developmental stages can explain some of the variation observed between lymphoid organ developmental timings in different species. However, the reason for the variations seen in the first appearance of multiple organs between fish species is not yet explained. Because of variations in the methods employed to study development, direct comparison between some species can be difficult.

Acting as the equivalent of mammalian bone marrow, the teleost head kidney plays an important role in immune function, serving as the site for B-cell maturation and antigen capturing, while the posterior part of the kidney possesses an excretory role (Zapata, 1979). The hapuka kidney appeared at $4 \mathrm{dph}$ and grew only slightly until $12 \mathrm{dph}$, after which it developed rapidly acquiring much hematopoietic tissue and by $16 \mathrm{dph}$ appearing as a distinct organ. It should be noted that kidney development accelerated after exogenous feeding had begun at $11 \mathrm{dph}$. This early growth pattern is similar to the kelp groper whose hematopoietic tissue growth becomes distinct at around $15 \mathrm{dph}$, however exogenous feeding in the kelp groper starts much earlier at $3 \mathrm{dph}$ (Kato et al., 2004). The head kidney of hapuka becomes distinct from the excretory kidney by $45 \mathrm{dph}$ and looks mature in nature, with sinusoids invigorating the tissue. In comparison the halibut kidney was slow to develop hematopoietic tissue, yet could be divided into an anterior, mid and posterior kidney by $49 \mathrm{dph}$ (Patel et al., 
2009). At around 36 dph in common dentex (Dentex dentex) the head kidney had become distinct from the excretory tail kidney (Santamaria et al., 2004).

The teleost spleen is similar in structure to its mammalian counterpart, containing blood vessels, ellipsoids, red pulp, lymphoid tissue (white pulp) and macrophages. The spleen's function includes antibody responses and erythrocyte destruction (Fänge and Nilsson, 1985). The hapuka spleen first appeared at $16 \mathrm{dph}$ as a capsule forming around an area of mostly interstitial space containing small clusters of erythrocytes and primitive reticular cells. The hapuka's spleen develops relatively later than that of other important marine fish species such as the turbot (10 dph), Japanese flounder ( $8 \mathrm{dph})$, Atlantic cod (5 dph) and sea bream (12 dph), yet before the sea bass (18 dph) (Jósefsson and Tatner, 1993; Padros and Crespo, 1996; Schrøder et al., 1998; Liu et al., 2004; Mulero et al., 2007a). The hapuka has a closer relation to the sea bass (family Moronidae) and bream (family Sparidae) than to the other fish mentioned, and indeed its spleen appearance coincides with this. The hapuka spleen started developing 5 days after exogenous feeding began, a time when the gut receives much antigen exposure and may act as a signal for development of this lymphoid organ. This certainly could not be the case for fish species where the spleen has already begun development during the yolk sac stage and before the mouth has opened. MMCs appeared in hapuka by 45 dph in the spleen, when the organs wedge shape became apparent. In the sea bream, MMCs were not present even at $77 \mathrm{dph}$ and the the organ was not yet lymphoid; nor had it divided into red and white pulp (Jósefsson and Tatner, 1993). Although the spleen's development in Atlantic halibut was very late, appearing only at $59 \mathrm{dph}$, it quickly matured differentiating into red and white pulp by 66 dph with lymphoid cells present at this stage (Patel et al., 2009). The spleen in halibut was completely differentiated by $80 \mathrm{dph}$ and melanomacrophages were present from $94 \mathrm{dph}$.

The thymus first appeared in hapuka at 20 dph, 4 days after the spleen was first seen. This is similar when compared with previously mentioned fish species, eg turbot (20-30 dph), Japanese flounder (15 dph), Atlantic cod (28 dph), sea bream (29 dph), sea bass (21 dph), common dentex (16 dph) and Atlantic halibut (33 dph) (Jósefsson and Tatner, 1993; Padros and Crespo, 1996; Schrøder et al., 1998; Liu et al., 2004; Mulero et al., 2007a; Patel et al., 2009); however very different from the non perciform species such as common carp (2 dph). By 45 dph the thymus was already populated with thymocytes and lymphocytes 25 days after 
it had first formed. However, an adequate section containing a thymus at $32 \mathrm{dph}$ was not observed. Atlantic halibut took 14 days after the thymus anlage was first formed to become populated with thymocytes (Patel et al., 2009) and in the kelp groper lymphocytes were seen in the developing thymus at $21 \mathrm{dph}, 9$ days after it first appeared (Kato et al., 2004). In the closer related sea bream, the thymus first appeared at $29 \mathrm{dph}$ and acquired mature lymphocytes 18 days later at 47 dph (Jósefsson and Tatner, 1993).

The increase in hematopoietic tissue of the kidney in hapuka coincided with the initial development of the thymus and although the kidney is usually the first lymphoid organ to develop in fish, the thymus is usually the first to become lymphoid (Chilmonczyk, 1992). However the development and maturation of the thymus varies amongst species and in many species it does not differentiate into a medulla and cortex. Additionally, many studies do not sample long enough for some maturation processes to be observed, such as the differentiation of the cortex and medulla of the thymus. The thymus of Atlantic halibut, turbot and sea bream differentiates into a visible medulla and cortex, while the Japanese flounder's thymus does not differentiate into separate regions (Jósefsson and Tatner, 1993; Padros and Crespo, 1996; Liu et al., 2004; Patel et al., 2009). Because of the thymus's close proximity to the head kidney, it has been thought that lymphoid stem cells in the thymus originate in the growing head kidney. Hemopoietic blast cells in the kidney prior to differentiation of lymphocytes in the thymus have been observed in many fish and it is believed that the thymus anlage is initially populated by stem cells from the head kidney (Ellis, 1998). Cell "bridges” between the kidney and thymus have been described in some fish species such as the turbot and sea bream (Jósefsson and Tatner, 1993; Padros and Crespo, 1996).

It is possible different rearing temperatures have an effect on the timing of lymphoid organ development. Although studies using zebrafish have examined the effects of temperature on embryos (Schirone and Gross, 1968), the effects of temperature on lymphoid organs is unknown. The order in which the lymphoid organs developed in hapuka; the kidney, spleen and thymus, was the same as is seen in other teleost species. The timing of appearance was most similar to the European sea bass and the gilthead sea bream, families Moronidae and Sparidae respectively (Table 3.1). Knowledge on the development of the lymphoid organs lays down the foundation for future research into the immune system of hapuka. Because 
arrival of the lymphoid organs does not necessarily correlate with immune function, studies into the appearance of specific cell populations within them will be important.

\begin{tabular}{|c|c|c|c|c|c|}
\hline Species and family & Method & $\begin{array}{l}\text { Head } \\
\text { Kidney }\end{array}$ & Spleen & Thymus & Reference \\
\hline $\begin{array}{l}\text { European sea bass, } \\
\text { Moronidae }\end{array}$ & $\begin{array}{l}\text { Light \& electron } \\
\text { microscopy - } 16 \\
{ }^{\circ} \mathrm{C}\end{array}$ & $10 \mathrm{dph}$ & $17 \mathrm{dph}$ & $27 \mathrm{dph}$ & $\begin{array}{l}\text { (Abelli et al., } \\
\text { 1996) }\end{array}$ \\
\hline $\begin{array}{l}\text { Gilthead sea bream, } \\
\text { Sparidae }\end{array}$ & $\begin{array}{l}\text { Light microscopy } \\
-19-20{ }^{\circ} \mathrm{C}\end{array}$ & $5 \mathrm{dph}$ & $12 \mathrm{dph}$ & $29 \mathrm{dph}$ & $\begin{array}{l}\text { (Jósefsson and } \\
\text { Tatner, 1993) }\end{array}$ \\
\hline $\begin{array}{l}\text { Zebrafish, } \\
\text { Cyprinidae }\end{array}$ & $\begin{array}{l}\text { Light \& electron } \\
\text { microscopy }-28 \\
{ }^{\circ} \mathrm{C}\end{array}$ & $96 \mathrm{hpf}$ & N/A & $60 \mathrm{hpf}$ & $\begin{array}{l}\text { (Willett et al., } \\
\text { 1999) }\end{array}$ \\
\hline $\begin{array}{l}\text { Common dentex, } \\
\text { Sparidae }\end{array}$ & $\begin{array}{l}\text { Light microscopy } \\
-18^{\circ} \mathrm{C}\end{array}$ & $3 \mathrm{dph}$ & $5 \mathrm{dph}$ & $16 \mathrm{dph}$ & $\begin{array}{l}\text { (Santamaria et al., } \\
\text { 2004) }\end{array}$ \\
\hline $\begin{array}{l}\text { Kelp Groper, } \\
\text { Serranidae }\end{array}$ & $\begin{array}{l}\text { Light microscopy } \\
-25^{\circ} \mathrm{C}\end{array}$ & $1 \mathrm{dph}$ & $6 \mathrm{dph}$ & $12 \mathrm{dph}$ & (Kato et al., 2004) \\
\hline $\begin{array}{l}\text { Halibut, } \\
\text { Pleuronectidae }\end{array}$ & $\begin{array}{l}\text { Light microscopy } \\
-6{ }^{\circ} \mathrm{C}\end{array}$ & $\begin{array}{l}\text { Excretory at } \\
\text { hatch }\end{array}$ & $49 \mathrm{dph}$ & $33 \mathrm{dph}$ & (Patel et al., 2009) \\
\hline $\begin{array}{l}\text { Hapuka, } \\
\text { Polyprionidae }\end{array}$ & $\begin{array}{l}\text { Light microscopy } \\
-13-19{ }^{\circ} \mathrm{C}\end{array}$ & $4 \mathrm{dph}$ & $16 \mathrm{dph}$ & $20 \mathrm{dph}$ & (This text) \\
\hline
\end{tabular}

Table 3.1. The first appearance of the lymphoid organs in perciform fish, including the cyprinid zebrafish. 


\section{Chapter 4 - Appearance of IgM+ cells in the lymphoid organs.}

\subsection{Introduction}

Fish hatch immature and vulnerable to pathogens, with their protective immune organs only just starting to develop. The arrival of the lymphoid organs is an important first step in the process of developing an autologous immune system. However, the morphological maturation of the lymphoid organs, as well as the lymphoid cells in them does not necessarily correspond with the presence of immune function in fish (Tian et al., 2009b). For example immature B cells are not able to respond to antigenic stimulation or to produce antibodies (Martensson et al., 2010). Instead the appearance of Ig-producing cells (IgM+ cells) may better indicate the functional maturity of the immune system than lymphoid organ development (Tian et al., 2009b) because expression and production of IgM determines the time at which larvae or juveniles can mount a specific immune response, at least at the systemic level.

The first appearance of cytoplasmic and surface IgM in lymphocytes varies considerably in different fish species. Additionally due to the wide range of methods used to detect IgM, such as immuno- or in situ histology, flow cytometry, ELISA or Western blotting of tissue homogenates, comparison of published data can be difficult (Magnadottir et al., 2005). In general, the first appearance of $\operatorname{IgM}^{+}$cells is late in marine species compared to fresh water species (Chantanachookhin et al., 1991). The head kidney is usually the first lymphoid organ to show $\operatorname{IgM}^{+}$cells, followed by the spleen then thymus (Koumans-Van Diepen et al., 1994; Dos Santos et al., 2000; Lam et al., 2004; Patel et al., 2009; Tian et al., 2009b). However, the thymus is normally the first organ to become lymphoid (T-cells), although the head kidney can contain hematopoietic progenitors earlier but not lymphocytes (Hansen and Zapata, 1998; Zapata et al., 2006). Because there are no immunological studies involving members of the Polyprionidae family to which hapuka belongs, this study will be the first one to shed light onto this important aspect of immunocompetence. Knowledge of $\operatorname{IgM}^{+}$cell appearance in hapuka is needed when considering immunoprophylactic measures for hapuka aquaculture.

Aims: To determine the first arrival of $\operatorname{IgM}^{+}$cells in the main lymphoid organs and MALT and to describe and compare the patterns of appearance with other fish species. Ultimately 
knowing when $\operatorname{IgM}^{+}$cells appear in the tissues will provide insight into the development of immunocompentence in hapuka larvae. 


\subsection{Results}

\subsubsection{Head kidney}

The first $\operatorname{IgM}^{+}$cells appeared in the head kidney. There was no $\operatorname{IgM}^{+}$cells present in the newly hatched larvae or the $6 \mathrm{dph}$ larvae (Fig 4.1A). IgM $^{+}$cells first appeared in the head kidney at 12 dph (Fig 4.1B) and were spread along the length of the organ. The staining was localised to the cell surface or cytoplasm and no exogenous IgM was detected. At $32 \mathrm{dph}$ the number of positive cells increased and they formed small clusters mostly in the head kidney region (Fig 4.1C). By 45 dph the $\operatorname{IgM}^{+}$cells appeared fewer in number and were scattered mainly in the hematopoietic region of the head kidney (Fig 4.1D), however, clusters of $\operatorname{IgM}^{+}$ cells were found in the tail region of the head kidney next to the renal tubules (Fig 4.1E). Some non specific staining was seen in the renal tubules of these sections and was believed to be due to auto-fluorescence. This auto-fluorescence was also present in other areas of the larvae such as the gill lamellae and was present in the negative controls. From $63 \mathrm{dph}$ and onwards into the juvenile stages, the $\operatorname{IgM}^{+}$cells were abundant throughout the entire head kidney tissue and small clusters of cells were common (Fig 4.1 F, G and H).

\subsubsection{Spleen}

The hapuka spleen began to form at $16 \mathrm{dph}$ in the peritoneal cavity next to the intestine, liver and pancreas. No $\operatorname{IgM}^{+}$cells were found in the spleen before $32 \mathrm{dph}$ (data not shown) and only a few positive cells were found in the spleen at $32 \mathrm{dph}$ (Fig $4.2 \mathrm{~A}$ and B). Some autofluorescence was found on the edge of the spleen (Fig 4.2B) and was likely due to the thickness of the sections. At $45 \mathrm{dph}$ (Fig 4.2C) when the spleen shape was starting to elongate, there was an increase in the number of $\operatorname{IgM}^{+}$cells. At $63 \mathrm{dph}$ (Fig 4.2D), the number of $\operatorname{IgM}^{+}$cells further increased, but the positive cells appeared to be mostly confined to the inner zone of the spleen, localised mostly around the sinusoids (Fig 4.2E). By $90 \mathrm{dph}$ (Fig 4.2F) during the juvenile stage of hapuka, there were only a moderate number of $\operatorname{IgM}^{+}$ cells in the developed tissue of the spleen, but again some clusters existed around sinusoids. 


\subsubsection{Thymus}

The hapuka thymus was located in the branchial cavity, next to the gill lamellae at $40 \mathrm{dph}$ (Fig 4.3A). There were no signs of $\operatorname{IgM}^{+}$cells in the thymus at this stage (Fig 4.3B). The first $\operatorname{IgM}^{+}$cells appeared in the thymus at $50 \mathrm{dph}$, but were less in number and the signal was not as strong as seen in the head kidney or spleen (Fig 4.3C). The number of $\operatorname{IgM}^{+}$cells remained low even at $63 \mathrm{dph}$ (Fig 4.3D), but these cells were now found in clusters within the tissue. At 90 dph (Fig 4.3E), the juvenile hapuka thymus contained more $\operatorname{IgM}^{+}$cells scattered throughout the tissue. In contrast, a 63 dph thymus section (Fig 4.3F) stained with the monoclonal antibody G7 (isotype control) showed no positive staining indicating specific detection of $\operatorname{IgM}^{+}$cells in the thymus.

\subsection{4. $M A L T$}

In teleosts, the intestinal tract is composed of four layers, namely lamina epithelialis, lamina propria, lamina muscularis and serosa. The gut of hapuka showed no $\operatorname{IgM}^{+}$cells from hatch to $32 \mathrm{dph}$ (Fig 4.4A). The first $\operatorname{IgM}^{+}$cells were seen scattered scarcely in the pyloric caeca of 45 dph hapuka (Fig 4.4B). By 50 dph (Fig 4.4C), a few IgM positive cells were seen in groups in the lamina propria of the gut, and this area was increasingly more populated at $63 \mathrm{dph}$ (Fig 4.4D). Juvenile hapuka at $90 \mathrm{dph}$ showed many $\operatorname{IgM}^{+}$cells present in the lamina propria of the gut (Fig 4.4F). No IgM ${ }^{+}$cells were observed intraepithelially. From 45 dph onwards, hapuka also showed groups of $\operatorname{IgM}^{+}$cells in the hepatic vein of the liver, however, these cells were not found in the liver tissue (Fig 4.4E). The gill lamellae displayed some autofluorescence and making it difficult to draw any solid conclusions from this MALT. Skin harboured no $\operatorname{IgM}^{+}$cells, including the $90 \mathrm{dph}$ juveniles (data not shown). These results indicate that the lamina propria of the gut contains the highest number of $\operatorname{IgM}^{+}$cells which appear starting from $50 \mathrm{dph}$.

\subsubsection{Other areas}

$\operatorname{IgM}^{+}$cells were also found in other locations of the hapuka body such as the olfactory organ and jaw. A group of $\operatorname{IgM}^{+}$cells were seen in the olfactory region of 12 dph larvae (Fig. 4.5A), the same day that positive cells first appeared in the head kidney. Again at $32 \mathrm{dph} \mathrm{IgM}^{+}$cells were seen in the olfactory organ of larvae, but only a few scattered cells were detected (Fig. 
4.5B). Additionally at $32 \mathrm{dph}$ a large group of cells were observed in the mouth region, inside the epithelium (Fig. 4.5C), and a group of $\operatorname{IgM}^{+}$cells were also seen in the lower jaw of 50 dph larvae under the epithelial cell layer (Fig 4.5D). 
A

\section{B}

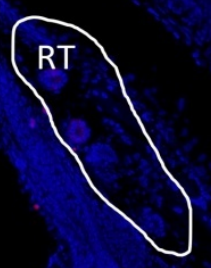

HT

$200 \mu \mathrm{m}$

$200 \mu \mathrm{m}$

D

HT

HT

$100 \mu \mathrm{m}$

$200 \mu \mathrm{m}$

E

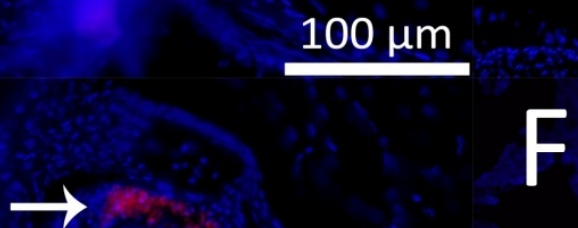

RT

HT

$100 \mu \mathrm{m}$

$200 \mu \mathrm{m}$

G

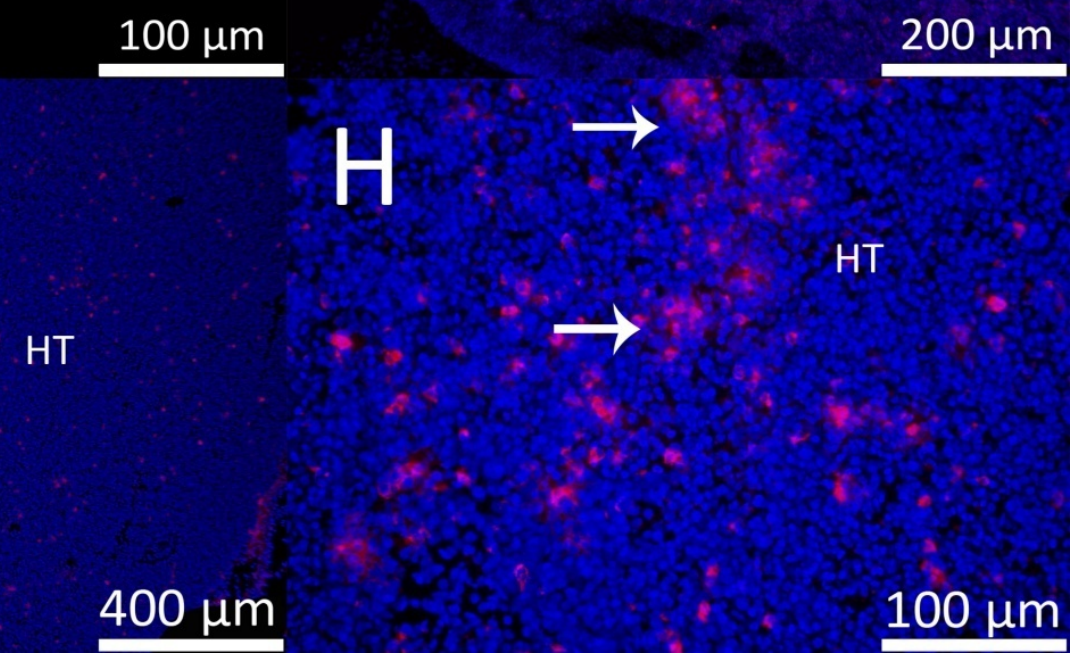


Fig. 4.1. The appearance of $\operatorname{IgM}^{+}$cells in the head kidney of hapuka larvae. Five $\mu \mathrm{m}$ sections of tissue were labled with a primary anti-giant gourami IgM monoclonal antibody (F06) and a secondary Mouse IgG conjugated to cy3 and then stained with Hoechst. (A) Kidney at 6 dph (circled), with no IgM ${ }^{+}$cells present. (B) Kidney at $12 \mathrm{dph}$ with the first appearance of $\operatorname{IgM}^{+}$ cells. (C) Increased numbers of $\operatorname{IgM}^{+}$cells in the head kidney at $32 \mathrm{dph}$. (D) Kidney at 45 dph, showing few $\operatorname{IgM}^{+}$cells located near the renal tubules, but many in the hematopoietic head kidney portion of the tissue. (E) Clusters of $\operatorname{IgM}^{+}$cells located in the tail portion of the kidney near the renal tubules at $45 \mathrm{dph}$ (arrows). (F) $\operatorname{IgM}^{+}$cells scattered throughout the head kidney at $63 \mathrm{dph}$. IgM ${ }^{+}$cells in juvenile hapuka at $90 \mathrm{dph}$ scattered throughout the tissue (G) and in small clusters (arrows) (H). Abbreviations: Hematopoietic tissue (HT), renal tubules (RT), 


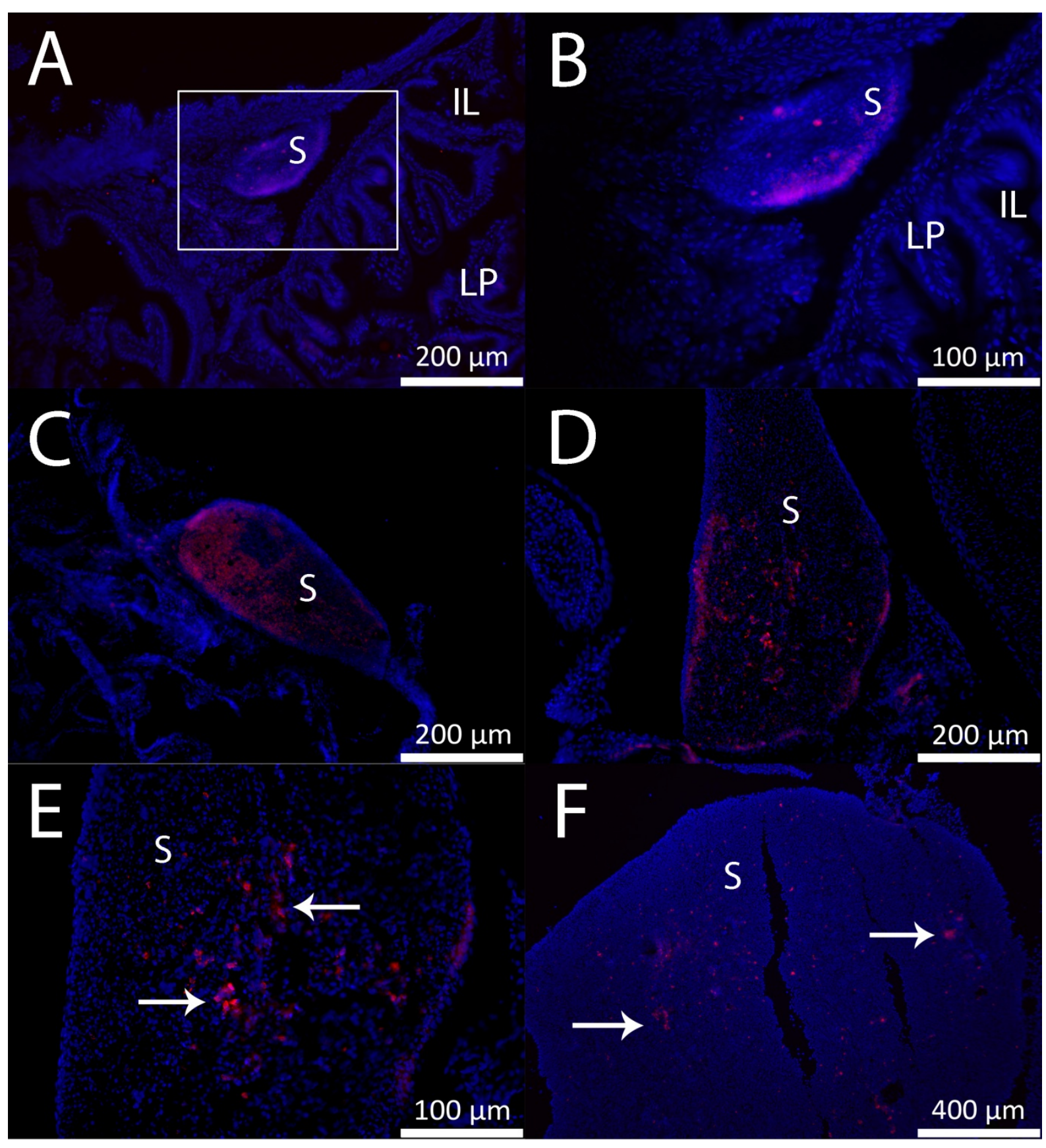

Fig. 4.2. The appearance of $\operatorname{IgM}^{+}$cells in the spleen of hapuka larvae. Five $\mu \mathrm{m}$ sections of tissue were labled with a primary anti-giant gourami IgM monoclonal antibody (F06) and a secondary Mouse IgG conjugated to cy3 and then stained with Hoechst. (A) The spleens location relative to the stomach at $32 \mathrm{dph}$. (B) A few $\operatorname{IgM}^{+}$cells first observed in the spleen at $32 \mathrm{dph}$. (C) Spleen at $45 \mathrm{dph}$ showing many $\operatorname{IgM}^{+}$cells present in the tissue. (D) Spleen at 63 dph, with many IgM ${ }^{+}$cells, (E) located mostly clustered around the sinusoids (arrows). (F) 
$\operatorname{IgM}^{+}$cells in juvenile hapuka at $90 \mathrm{dph}$, spread through the tissue and clustered around sinusoids (arrows). Abbreviations: spleen (S), intestinal lumen (IL), lamina propria (LP). 


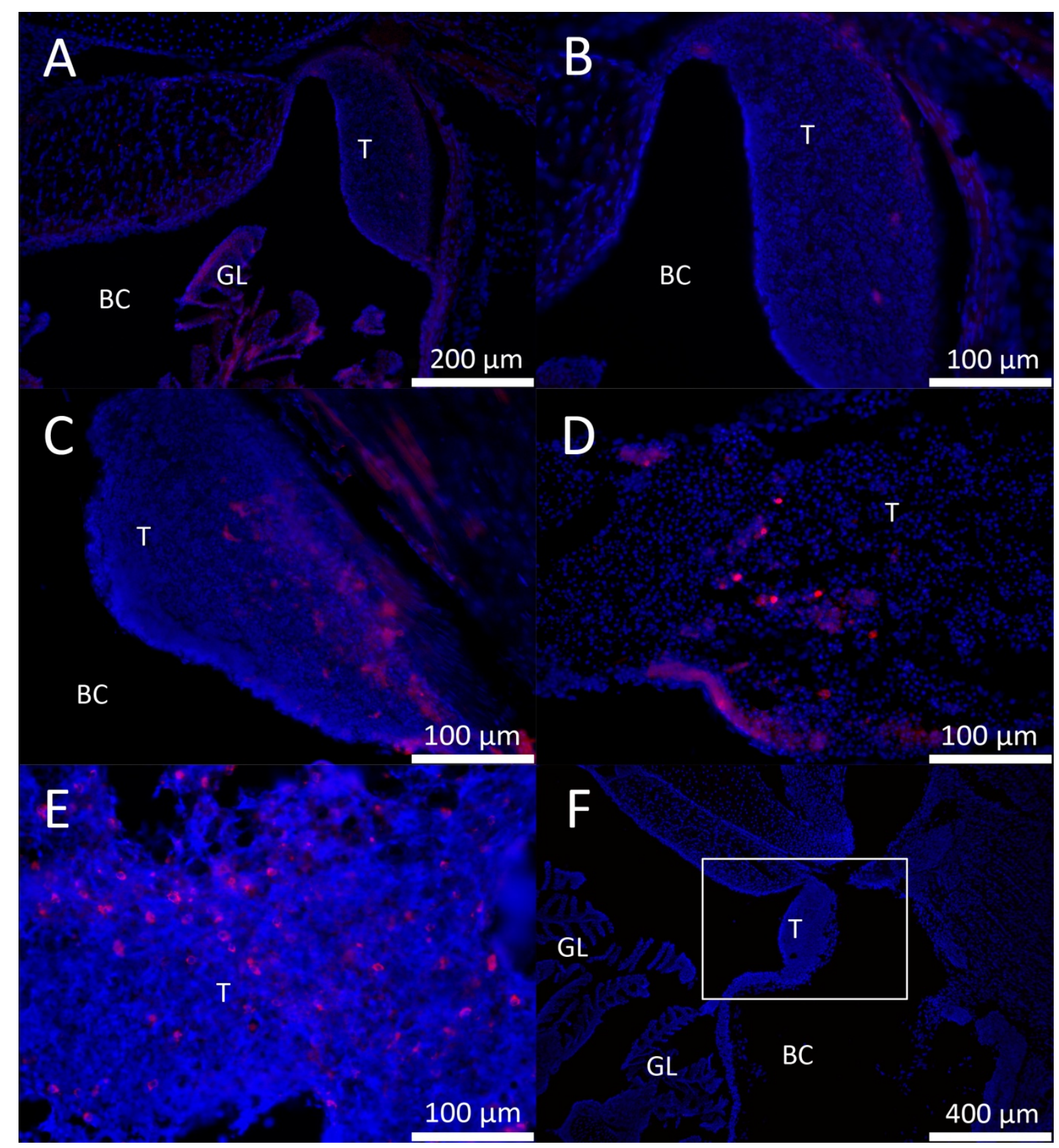

Fig. 4.3. The appearance of $\operatorname{IgM}^{+}$cells in the thymus of hapuka larvae. Five $\mu \mathrm{m}$ sections of tissue were labled with a primary anti-giant gourami IgM monoclonal antibody (F06) and a secondary Mouse IgG conjugated to cy3 and then stained with Hoechst. The negative control was stained with the monoclonal antibody G7 (A) The thymus's location at 40 dph next to the gill lamellae.(B) no IgM ${ }^{+}$cells present at $40 \mathrm{dph}$. (C) The thymus at $50 \mathrm{dph}$ with some IgM $^{+}$ cells present near the connective tissue layer. (D) Few $\operatorname{IgM}^{+}$cells, but some small clusters in the thymus at $63 \mathrm{dph}$. (E) $\operatorname{IgM}^{+}$cells scattered throughout the thymus of juvenile hapuka at 
90 dph. (F) Negative control showing G7 stained thymus with no positive cells (square). Abbreviations: Thymus (T), branchial cavity (BC), gill lamelle (GL). 


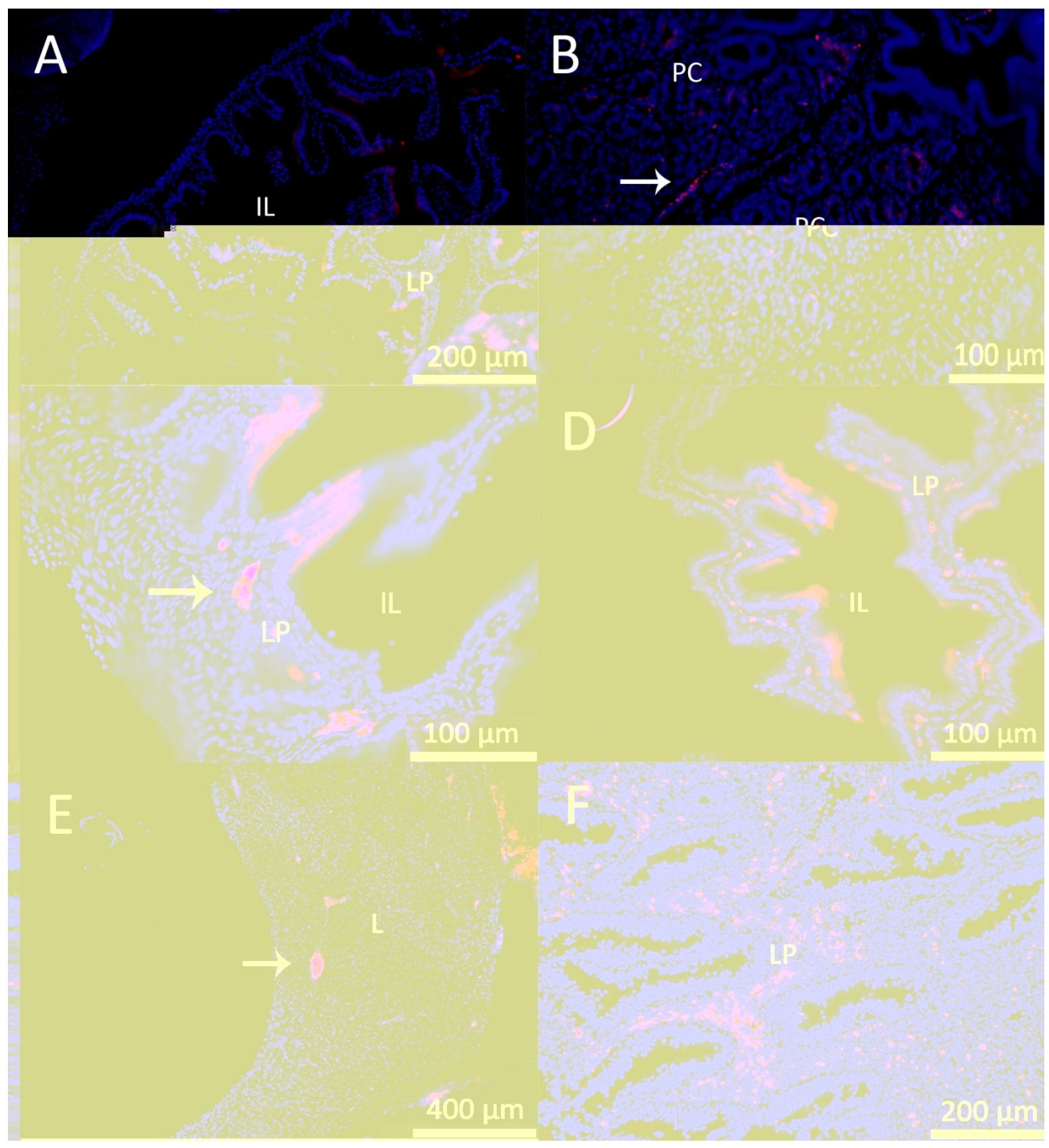

Fig. 4.4. The appearance of $\operatorname{IgM}^{+}$cells in the intestine of hapuka larvae. Five $\mu \mathrm{m}$ sections of tissue were labled with a primary anti-giant gourami IgM monoclonal antibody (F06) and a secondary Mouse IgG conjugated to cy3 and then stained with Hoechst. (A) The hapuka gut at $32 \mathrm{dph}$, with no $\operatorname{IgM}^{+}$cells present. (B) The pyloric caeca at 45 dph showing the first appearance of $\operatorname{IgM}^{+}$cells in the gut region (arrows). (C) $\operatorname{IgM}^{+}$cells present in the lamina propria at $50 \mathrm{dph}$ (arrow). (D) $\operatorname{IgM}^{+}$cells in the lamina propria of the gut at $63 \mathrm{dph}$. (E) The liver at 45 dph showing $\operatorname{IgM}^{+}$cells in the hepatic vein (arrow). (F) The gut of hapuka 
juveniles at 90 dph showing $\operatorname{IgM}^{+}$cells spread throughout the lamina propria. Abbreviations: intestinal lumen (IL), lamina propria (LP), pyloric caeca (PC), liver (L). 


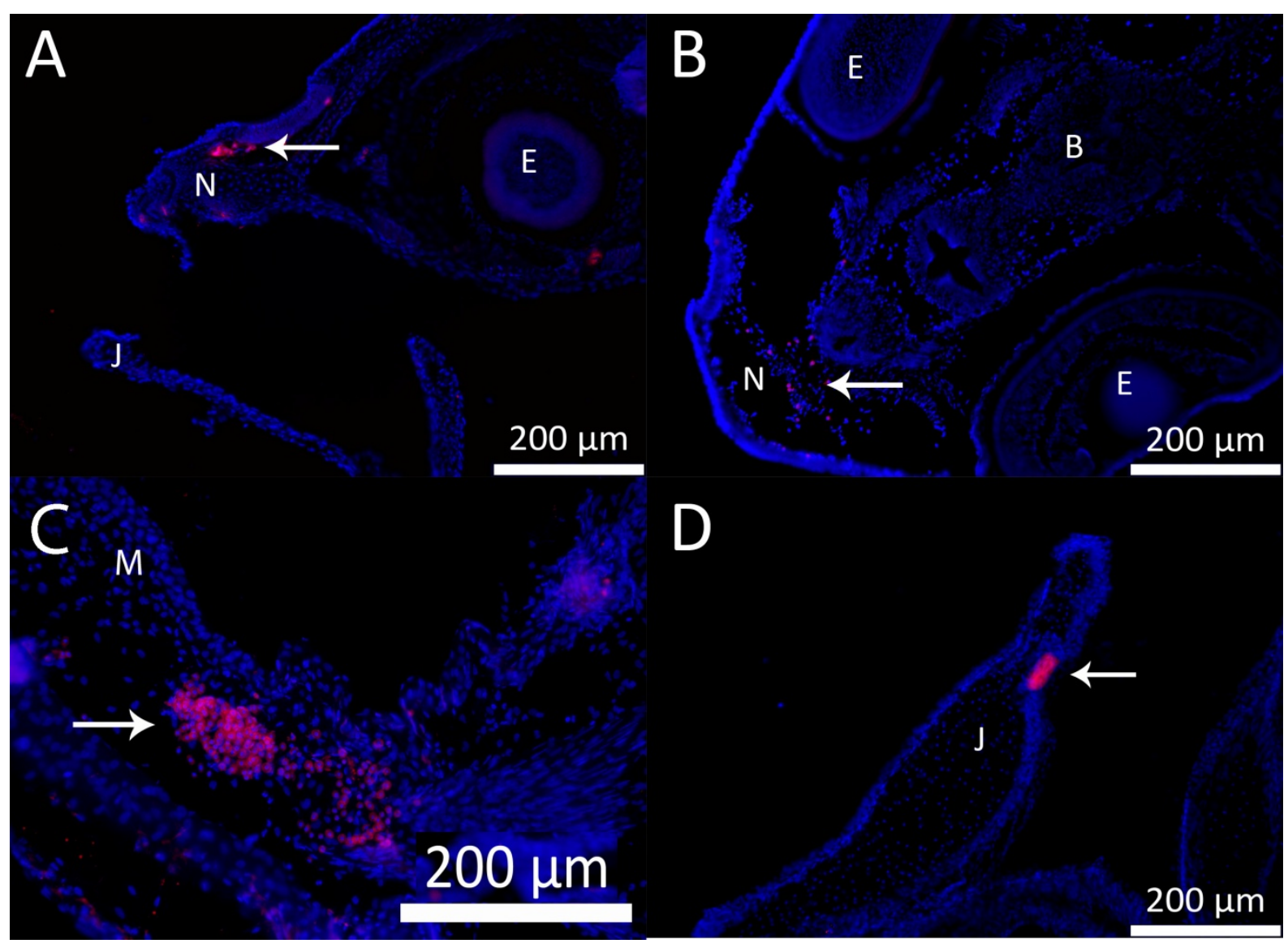

Fig. 4.5. The appearance of $\operatorname{IgM}^{+}$cells in other areas of hapuka larvae. Five $\mu \mathrm{m}$ sections of tissue were labled with primary antibody F06 conjugated to cy3 and then stained with Hoechst. (A) The nose of hapuka larvae at 12 dph showing a group of $\operatorname{IgM}^{+}$cells (arrow). (B) A coronal cut of a larval nose region at 32 dph showing scattered $\operatorname{IgM}^{+}$cells (arrow). (C) A large group of $\operatorname{IgM}^{+}$cells in epithelial tissue of the mouth at $32 \mathrm{dph}$ (arrow). (D) A group of $\operatorname{IgM}^{+}$cells in the jaw of hapuka larvae at 50 dph (arrow). Abbreviations: nose $(\mathrm{N})$, eye $(\mathrm{E})$, jaw (J), brain (B), mouth (M). 


\subsection{Discussion}

This chapter investigated for the first time, the appearance of IgM-bearing cells $\left(\operatorname{IgM}^{+}\right)$in lymphoid-related organs and tissues of the developing hapuka (from hatch to 90dph), including the head kidney, spleen, thymus and MALT. Because the primary antibody F06 used recognises the IgM heavy chain molecule (possibly at the Fc region), surface and cytoplasmic as well as reduced and non-reduced forms of the IgM molecule have been detected in this study. $\operatorname{IgM}^{+}$cells were detected in all the examined organs/tissues of hapuka and among these organs/tissues, $\operatorname{IgM}^{+}$cells were first detected in the kidney at $12 \mathrm{dph}$.

The first IgM ${ }^{+}$lymphocytes were observed in hapuka head kidney at $12 \mathrm{dph}$. This made sense with the head kidney acting as the equivalent to mammalian bone marrow (Razquin et al., 1990; Meseguer et al., 1995). $\operatorname{IgM}^{+}$cells were next seen in the spleen at $32 \mathrm{dph}$, the intestine at $45 \mathrm{dph}$ and lastly the thymus at $50 \mathrm{dph}$. The thymus is generally the first organ to become lymphoid in teleosts such as in Atlantic cod, sea bass, zebrafish and carp (Schroder et al, 1998; Breuil et al, 1997; Willett et al, 1999; Secombes et al, 1983); determined by observation of mature lymphocytes (T cells) in the tissue. The head kidney on the other hand contains hematopoietic lymphoid progenitors earlier and is the first organ to become populated with $\operatorname{IgM}^{+}$cells (B-cells), as seen in the turbot, mandarin fish, rainbow trout and Atlantic halibut (Razquin et al., 1990; Padros and Crespo, 1996; Patel et al., 2009; Tian et al., 2009b).

In the mandarin fish, using in situ hybridisation, $\operatorname{IgM}^{+}$cells appeared early in the head kidney at $20 \mathrm{dph}$. The number of positive cells increased as the fish aged, with many $\operatorname{IgM}^{+}$cells found scattered throughout the hematopoietic tissue and in small clusters by $67 \mathrm{dph}$. Clusters were more commonly found around blood sinusoids. In the spleen $\operatorname{IgM}^{+}$cells were initially detected at $26 \mathrm{dph}$, with an increase at $102 \mathrm{dph}$. However, in the thymus numbers of $\operatorname{IgM}^{+}$ were very low at the time of first appearance at $39 \mathrm{dph}$ and only increased at $78 \mathrm{dph}$ distributed mainly in the outer zone. Additionally $\operatorname{IgM}^{+}$cells appeared in the lamina propria of the intestine at $87 \mathrm{dph}$, but were not found in groups like in the other organs (Tian et al., 2009b).

This pattern of development is very similar to what was seen in hapuka, with the early appearance of a few $\operatorname{IgM}^{+}$cells in the head kidney at $12 \mathrm{dph}$, followed by an increase of cells 
as the fish aged. The cells were scattered throughout the organ mostly in the hematopoietic tissue with only some found near the renal tubules. A few clusters of $\operatorname{IgM}^{+}$cells were present at $45 \mathrm{dph}$, but became more common by $63 \mathrm{dph}$, especially around sinusoids. A similar pattern was seen in the hapuka spleen with $\operatorname{IgM}^{+}$appearing relatively early on at $32 \mathrm{dph}$, but with much lower numbers than the head kidney. The $\operatorname{IgM}^{+}$cells increased noticeably at 63 dph and cells were found mostly in the inner zone forming clusters. The thymus was the last lymphoid organ in hapuka to acquire $\operatorname{IgM}^{+}$cells and they first appeared in this organ at 50 dph, 30 days after the organ had formed. Only a few detectable cells were present at this stage and the number of $\operatorname{IgM}^{+}$cells did not appear to increase until the juvenile stages, where the cells were observed scattered throughout the tissue. $\operatorname{IgM}^{+}$cells were also detected in the pyloric caeca and lamina propria of gut at $45 \mathrm{dph}$ and $50 \mathrm{dph}$ respectively, probably having a role in mucosal immunity. $\operatorname{IgM}^{+}$cells were also detected in the olfactory region (nose) and jaw; however, we can only speculate to these findings due to the lack of data of IgM in these regions.

Interestingly in species such as the Atlantic halibut, the spleen was the last lymphoid organ to develop, but still contained IgM+ ${ }^{+}$cells earlier than the thymus (Patel et al., 2009). In Atlantic cod, hematopoietic stem cells seem to be present in the head kidney at hatching, confirming that the head kidney is the primary lymphoid organ in this species and that the thymic rudiment is colonised by stem cells originating from the head kidney. As previously mentioned hemopoietic blast cells in the kidney prior to differentiation of lymphocytes in the thymus have been observed in many fish and it is believed that the thymus anlage is initially populated by stem cells from the head kidney (Padros and Crespo, 1996; Ellis, 1998). However, these authors did not consider the existence of other sites of hematopoiesis earlier than the pronephros (Willett et al., 1999). Finally, the distribution of a relatively large amount of $\operatorname{IgM}^{+}$cells in the kidney at the early time points of 12 and 32 dph suggests that the head kidney is the earliest and most important source of B lymphocytes in hapuka. The first appearance of $\operatorname{IgM}^{+}$cells in the head kidney (12 dph) coincided with first feeding, which began at $11 \mathrm{dph}$, and thus, it is possible these early $\operatorname{IgM}^{+}$cells in hapuka were the very first signs of lymphopoietic activity in the developing head kidney. Likewise it has been suggested that the appearance of autogenous IgM coincides with the onset of feeding in salmonids (Ellis, 1977b) and a strong increase in IgM is seen after first feeding in sea bass and Atlantic cod (Breuil et al., 1997; Schrøder et al., 1998). 
However, the first detection of $\operatorname{IgM}^{+}$cells does not necessarily correlate with the ability to develop an antibody response to infection. A delay has been observed between the detection of $\operatorname{IgM}^{+}$cells and functional immunocompetence in both fresh water and marine fish species (Petrie-Hanson and Ainsworth, 1999; Dos Santos et al., 2000). For example, in carp it was revealed that although surface $\operatorname{IgM}^{+} \mathrm{B}$ cells were detectable in 2 week old fish, carp were not able to produce plasma cells until 1 month of age (Botham and Manning, 1981). On the other hand grafting experiments in carp indicate that lymphocytes are capable of effective allograft rejection even at 16 dph (Botham and Manning, 1981) and this coincides with the first detection of IgM $^{+}$positive cells (Koumans-Van Diepen et al., 1994). In salmon the mixed lymphocyte reaction and the presence of IgM on lymphocytes appear simultaneously about 34 dph (Ellis, 1977b). However in Atlantic cod using in situ hybridization to detect IgH transcripts as well as immunostaining to detect protein, plasma cells and B cells appeared together at $58 \mathrm{dph}$ (Schrøder et al., 1998). Although it is possible their methods only detected plasma cells and not unstimulated $\operatorname{IgM}^{+}$B cells, which contain a low copy number of IgH mRNA. Because detection of IgH in the current study was not carried out, it is difficult to say whether some of the $\operatorname{IgM}^{+}$cells stained were plasma cells or when plasma cells first appear in hapuka; indeed no exogenous IgM was detected. As mentioned previously, it has been speculated that the relatively late appearance of autologous humoral IgM in teleosts may be compensated, to some extent, by maternally-derived immunoglobulins (Swain and Nayak, 2009).

The present results show that $\operatorname{IgM}^{+}$cells first appear at $12 \mathrm{dph}$ and have colonised all the immune organs by 50 dph in hapuka larvae. However, at this time none of the organs appear fully developed except possibly the head kidney. Because expression and production of IgM determines the time at which larvae or juveniles can mount a specific immune response, hapuka larvae are probably competent for antibody production around $50 \mathrm{dph}$, after dry feed has commenced. Clinical observations have shown that hapuka larvae are highly sensitive to microbial diseases during this period and that vaccination or immunoprophylactic measures at this stage could provide protection. Similar studies of other immune cell populations in the future will contribute to and expand our understanding of this area of immunity. 


\section{Chapter 5 - Transcriptional onset of immune genes.}

\subsection{Introduction}

Studying the immune system ontogeny of fish species used in aquaculture is useful because it will reveal when different components of the immune system begin to develop and thus, when fish are able to respond to vaccines or immunoprophylactics. To date, most studies have used light and electron microscopy to study the immune system, focusing on the development of the lymphoid organs (Jósefsson and Tatner, 1993; Padros and Crespo, 1996; Willett et al., 1999; Petrie-Hanson and Ainsworth, 2001). Immunohistochemical techniques are also commonly used for detecting specific target proteins and thus identifying a particular cell type in a tissue section (Castillo et al., 1993; Breuil et al., 1997; Schrøder et al., 1998; Patel et al., 2009). Another method for studying the immune system development is gene expression assays and in particular, reverse-trascriptase polymerase chain reaction (RT-PCR). RT-PCR involves reverse transcribing mRNA isolated from a location of interest such as the head kidney or the entire fish into complementary DNA (cDNA). The expression of specific transcripts (now cDNA) are then amplified by PCR and quantified. One of the problems with gene expression studies is that the gene sequences must be known in order to design the primers, and until relatively recently, known sequences were few in number. However, over the past decade many fish species have had their entire genomes sequenced such as the fugu (Takifugu rubripes), green spotted puffer (Tetraodon nigroviridis), three-spined stickleback (Gasterosteus aculeatus), elephant shark (Callorhinchus milii) and zebrafish, contributing the to growing wealth of genetic information (Aparicio et al., 2002; Jaillon et al., 2004; Venkatesh et al., 2007).

Conserved synteny, which is the occurrence of synteny of orthologous genes between two different species, allows the use of datamining techniques to identify conserved motifs within genes of interest. These conserved motifs are areas of DNA that are highly similar among even distantly related species. Expressed sequence tags (EST) and gene sequences containing conserved motifs can be found in gene databases and aligned between different fish species to design probes for in situ hybridization and primers for PCR. Additionally sequence alignments can also be used for phylogenetic analysis between species and the creation of antibodies for experiments. These molecular techniques are being used more and more in fish 
immunology and the sequencing of entire fish genomes has made database mining and genetic studies in fish even easier. The expression of immune relevant genes has been studied in many fish species such as the common carp, channel catfish, zebrafish, trout, sea bass and sea bream (Rodrigues et al, 1995; Moulana et al, 2008; Danilova et al, 2005; Hansen et al, 2005; Buonocore et al, 2007; Lopez-Castejon et al, 2007) and the ontogenic expression of immune genes in hapuka is of great interest. This study has selected a range of immune genes from cell markers for different leucocytes to molecules that are important in innate, adaptive and inflammatory responses. These cell markers include TCR $\alpha$, TCR $\beta, \operatorname{IgM}, \operatorname{IgZ}, \mathrm{MHCII} \alpha$, RAG1, CSF-1 and the complement protein C3.

Aims: Detect the onset of expression of immune (relevant) genes used as markers for specific immune cells and immune maturation processes.

Detect expression of the immune genes TCR $\alpha$, TCR $\beta$, IgM, IgZ, MHCII $\alpha$, RAG1, CSF- 1 and C3.

Compare hapuka gene sequences for IgM, MHCII $\alpha$ and IgZ phylogenetically. 


\subsection{Results}

\subsubsection{Hapuka ESTs and gene sequences.}

Alignments with other fish species were used to generate initial primers for the genes MHCII $\alpha$, IgM and IgZ. The ESTs obtained from the PCR reactions were sequenced and the newly obtained sequences (data not shown) were used to design new hapuka specific primers for following gene expression studies. The sequences for MHCII $\alpha$ IgM and IgZ were also BLAST searched to find comparable sequences in other fish species. Sequences containing relatively high maximum identity and query coverage were used to create phylogenetic trees for each respective gene (Fig 1-2). Only one entry per unique species was included. IgZ only yielded matches within a conserved region, probably due to the lack of IgZ sequences available and thus no tree was constructed.

BLAST results for the sequenced hapuka MHCII $\alpha$ EST revealed identity matches with the sea bass, striped bass (Morone saxatilis), mi-iuy croaker (Miichthys miiuy), large yellow croaker (Larimichthys crocea), orange spotted groper (Epinephelus coioides), walleye (Sander vitreus) and gilthead sea bream (Sparus aurata) MHCII (Fig 5.1). Alignment and phylogenetic analysis of MHCII $\alpha$ in teleost fish was performed to reveal the relationship of hapuka MHCII $\alpha$ with other fish species with the most closely related MHCII $\alpha$. Of the species aligned, the tree revealed that the sea bass and striped bass were the two most closely related by MHCII $\alpha$, while the sea bream appeared the least.

BLAST results for the sequenced hapuka IgM heavy chain EST revealed identity matches with the mandarin fish, striped trumpeter (Latris lineata), thornfish (Bovichtus diacanthus), humphead snapper (Lutjanus sanguineus), orange-spotted grouper, longtooth grouper (Epinephelus bruneus), spotted wolffish (Anarhichas minor), large yellow croaker and snakehead (Channa argus) IgM heavy chains (Fig 5.2). Alignment and phylogenetic analysis of the IgM heavy chain in teleost fish was performed to reveal the relationship between the hapuka IgM heavy chain and other fish species. The mandarin fish and striped trumpeter had the closest matching IgM heavy chains to hapuka while the snakehead had the least. BLAST results for the sequenced hapuka IgZ EST revealed little, most likely due to the lack of sequenced marine teleost IgZ sequences. Instead the gene was translated and an xBLAST carried out revealing conserved sequence identity with trout IgZ (AAW66979.1), 


\subsubsection{Gene expression}

B-actin was used as a loading control (Fig 5.3A). The expression of C3 and CSF1R were assessed to investigate the timing of innate immune development. The complement protein C3 was present from $1 \mathrm{dph}$ as indicated by the $600 \mathrm{bp}$ band (Fig 5.3C). Similarly CSF1R was detected from 1 dph with a 400 bp band (Fig 5.3G) suggesting these innate components are active early.

The expression of genes associated with $\mathrm{T}$ and B cell development were also assessed. RAG1 expression was first found at $50 \mathrm{dph}$ with the appearance of a $390 \mathrm{bp}$ band (Fig 5.3B). TCR $\alpha$ expression could not be detected in hapuka larvae at any time point sampled (Fig 5.3D); however, the TCR $\beta$ was detected from $32 \mathrm{dph}$ onwards with expression of a $500 \mathrm{bp}$ band (Fig 5.3E). MHCII $\alpha$ expression was detected as early as $1 \mathrm{dph}$ in hapuka larvae with a band of 370 bp (Fig 5.3F). The first detection of IgM expression appeared to be 9 dph, showing a 513 bp band (Fig 5.3H), while the first $\operatorname{IgM}^{+}$cells appeared at $12 \mathrm{dph}$. IgZ expression was variable appearing in 1 out of 2 time points from 45 dph onwards with a 480 bp band (Fig 5.3I). 


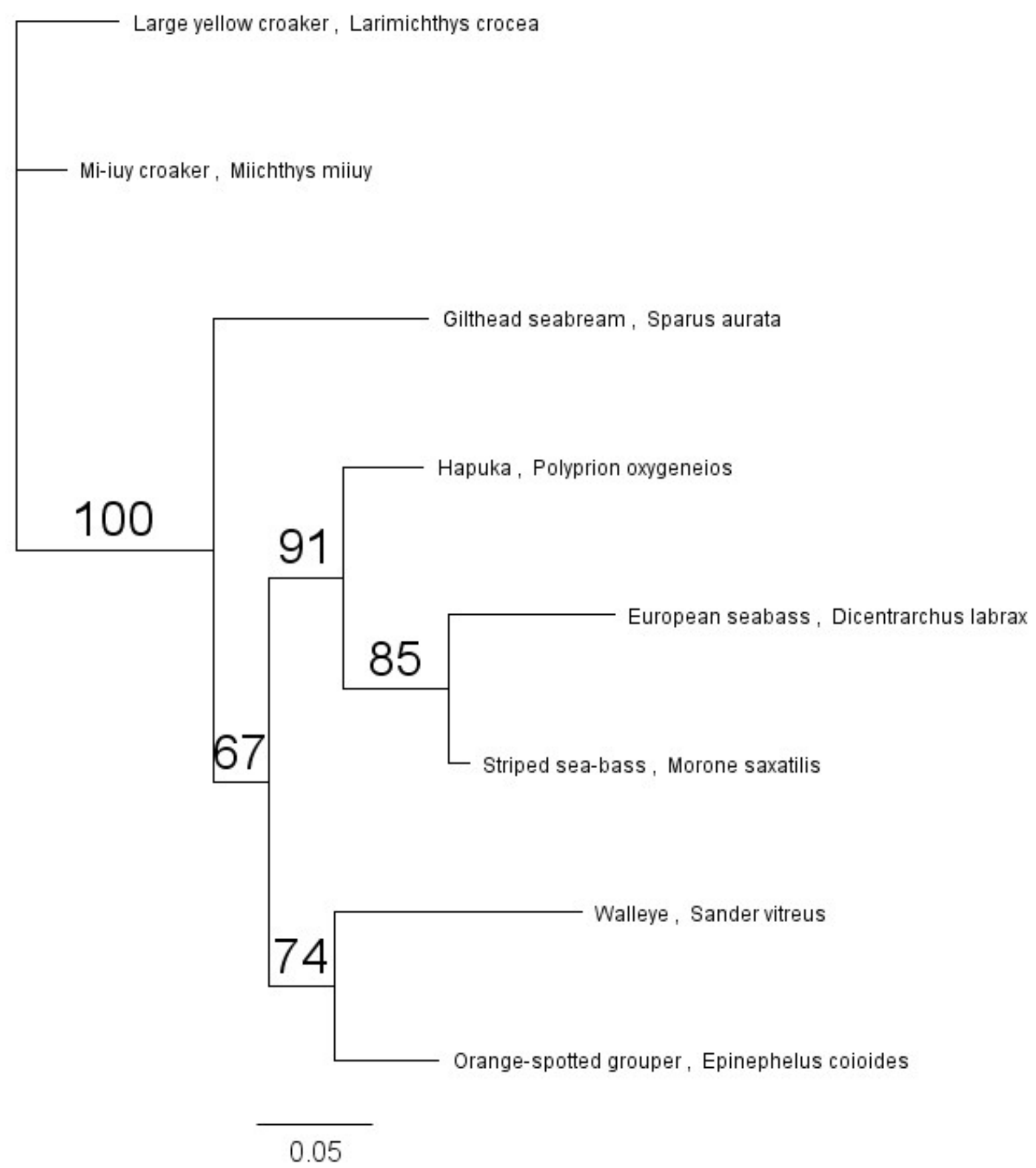

Fig. 5.1. Neighbour-joining phylogenetic tree based on MHC class IIa sequences from perciformes fish, using the Tamura-Nei model. Bootstrap values are shown for nodes supported by $>50 \%$ of 100 replicates. Scale bar represents 0.05 substitutions per site. The GenBank accession numbers are as follows: EF681861 (large yellow croaker), GU936787 (mi-iuy croaker), DQ019411 (gilthead seabream), DQ821108 (European seabass), L35062 (striped seabass), AY158872 (walleye), GU992887 (orange-spotted grouper). 


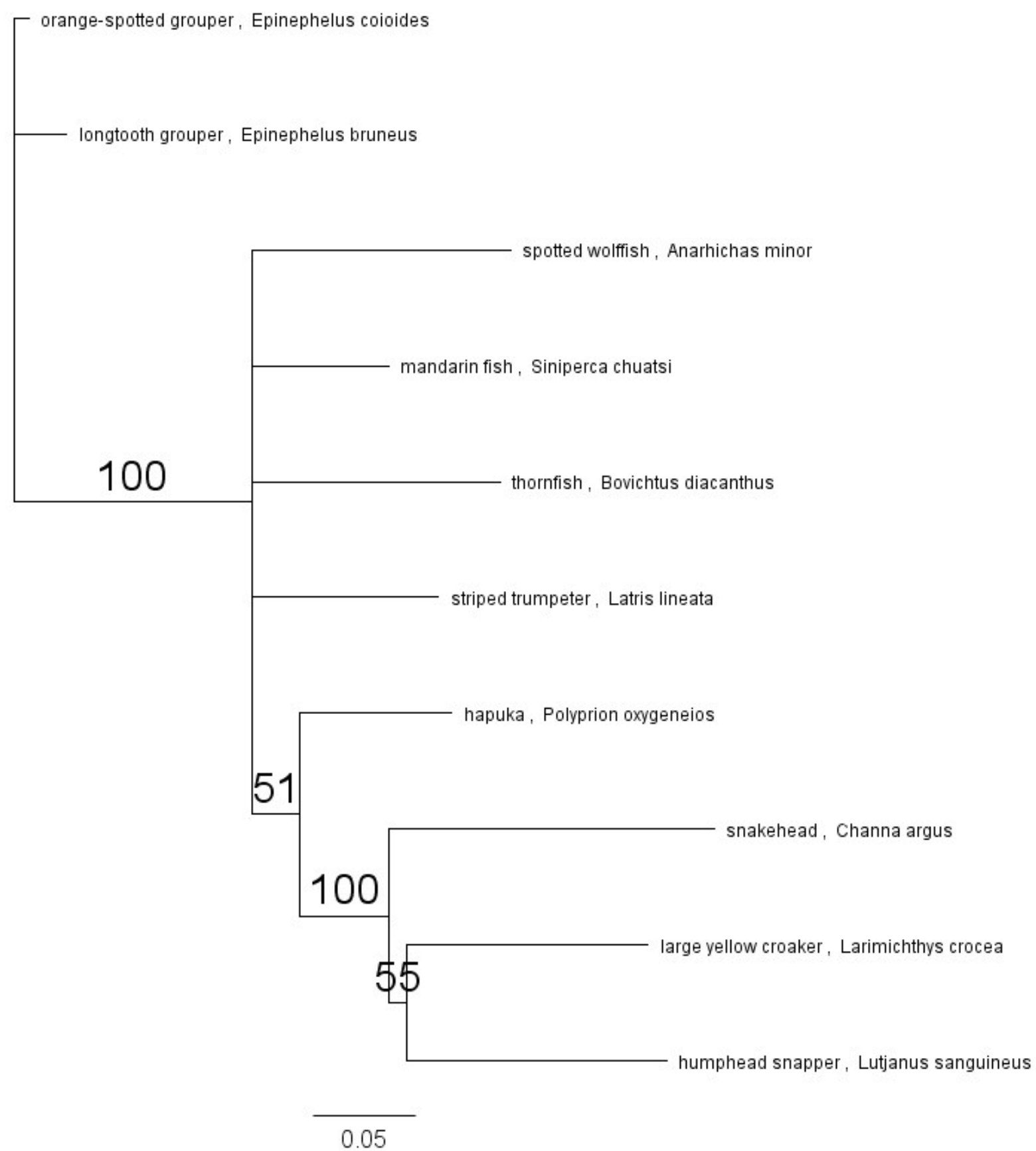

Fig. 5.2. Neighbour-joining phylogenetic tree based on IgM heavy chain sequences from perciformes fish, using the Tamura-Nei model. Bootstrap values are shown for nodes supported by $>50 \%$ of 100 replicates. Scale bar represents 0.05 substitutions per site. The GenBank accession numbers are as follows: AY885709 (orange spotted grouper), JF430683 (longtooth grouper), AF138958 (spotted wolffish), AF327364 (mandarin fish), EU884292 
(thornfish), FJ864717(stripped trumpeter), EU822510 (snakehead), EU627008 (large yellow croaker), HQ322494 (humphead snapper). 


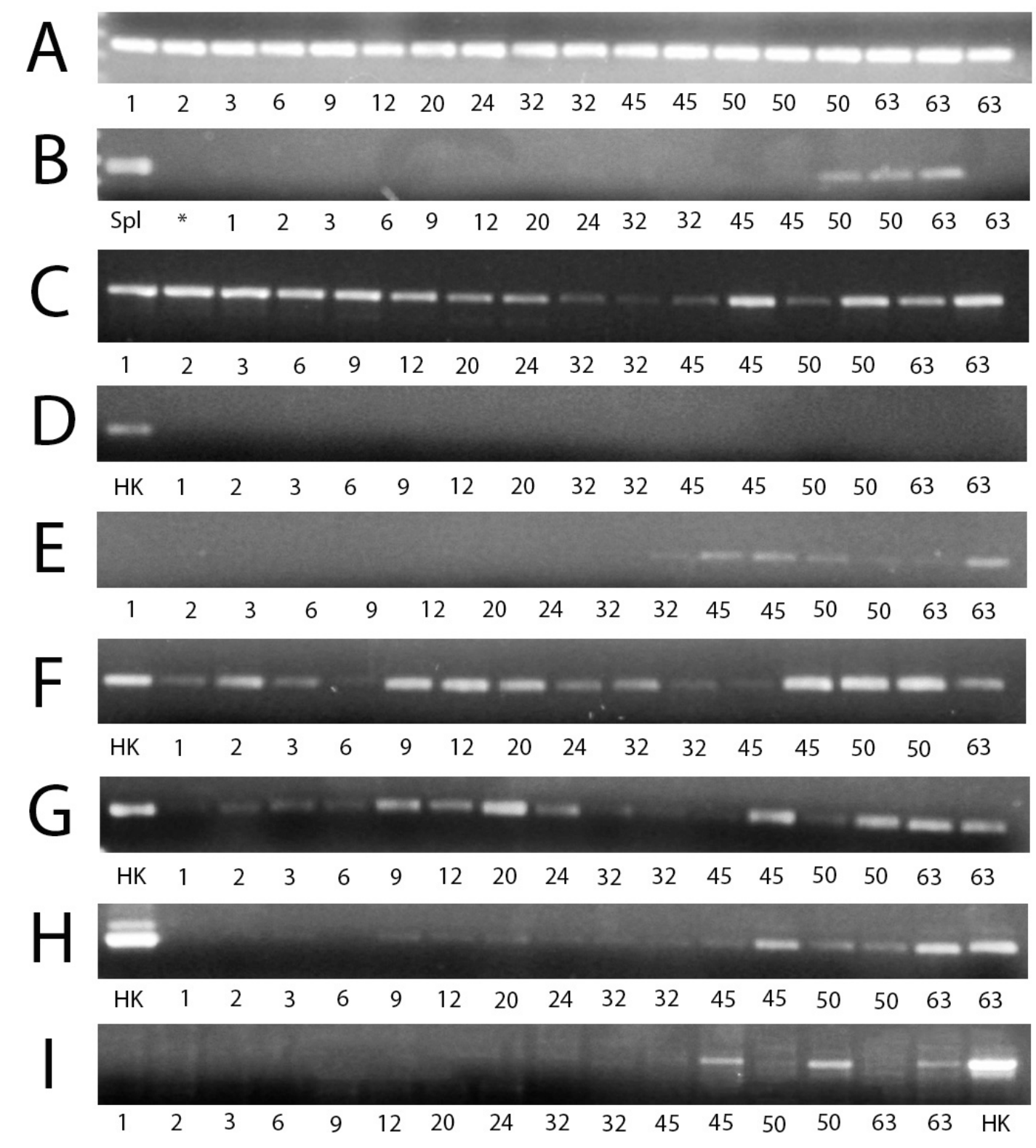

Fig. 5.3. Gene expression profiles for selected immune genes and corresponding $\beta$-actin amplification in hapuka larvae at various days post hatch. mRNA from whole fish homogenates was used for cDNA creation. (A) $\beta$-actin. (B) RAG1. (C) C3. (D) TCR $\alpha$. (E) TCRß. (F) MHCII . (G) CSF1R. (H) IgM heavy chain. (I) IgZ. Abbreviations: Adult spleen control cDNA (Spl), infected adult control cDNA(*), adult head kidney control cDNA (HK). 


\subsection{Discussion}

Microscopy can reveal a great deal of information about the ontogeny of the lymphoid organs. However, observation of the cell populations within them does not necessarily correlate with immune function. Instead to study the ontogeny of immune cells, examining the expression of genes can accurately detect their presence and help infer important information about their maturity. No information was available on the hapuka immune system and the expression of immune-related genes was unknown. Thus, this was the first study to investigate the expression of the immune-related genes CSF1R, C3, MHCII $\alpha$, IgM, IgZ, RAG1, TCR $\alpha$ and TCR $\beta$ in hapuka larvae starting from $1 \mathrm{dph}$. This information will help distinguish the state of lymphopoiesis and maturation of the immune system during larval ontogeny. In this study, RT-PCR of whole fish homogenates was used for detection of gene expression.

The activation of the vertebrate complement system results in the initiation of many biological processes, including phagocytosis, lysis, inflammation and regulation of the adaptive immune response (Magnadottir, 2006). The innate protein C3 plays a central role in the activation of complement system and its activation is required for both classical and alternative complement activation pathways (Sunyer and Lambris, 1998). In hapuka, C3 was expressed at all developmental stages from $1 \mathrm{dph}$ and showed no specific expression pattern. In Atlantic salmon, RT-PCR studies showed C3 expression present in the embryo stage even before hatching with mRNA levels steadily increasing throughout the study period (Løvoll et al., 2007). In the spotted wolf fish C3 was also detected in the embryo by RT-PCR at $49 \mathrm{dpf}$, with levels increasing towards hatch (Ellingsen et al., 2005). Immunohistochemical techniques on Atlantic cod and Atlantic halibut have also been carried out to study the ontogeny of C3 in these fish species (Lange et al., 2004b; Lange et al., 2004a). In Atlantic cod C3 was present in the yolk sac membrane at $1 \mathrm{dph}$ and in the liver, brain, kidney and muscle from 2 dph (Lange et al., 2004b). C3 was first detected in the Atlantic halibut at 5 dph in the skeletal muscle fibres and later for the first time in the hepatocytes and the sinus endothelial cells of the liver; however, this study did not take samples at earlier time points before 5 dph (Lange et al., 2004a). The early expression of C3 in hapuka further suggests the importance of complement in this species. 
Antigen presenting cells (APCs) are important phagocytic cells that present foreign antigens to T cells. The ontogeny of APCs in hapuka larvae was examined using the general APC marker MHCII $\alpha$ and the macrophage specific marker CSF1R. MHCII $\alpha$ and CSF1R were both expressed from $1 \mathrm{dph}$ in hapuka larvae, CSF1R showing greater amount of products between $9 \mathrm{dph}$ and $24 \mathrm{dph}$ and then again after $45 \mathrm{dph}$. The expression of these APC cell markers before the formation of the head kidney, the main site of hematopoiesis in fish (Chaves-Pozo et al., 2005), suggests either they originated from a hematopoietic location preceding the head kidney, or they were of maternal origin. In zebrafish, cells expressing CSF1R by in situ hybridization were able to be recruited to wounds in the tailfins of $2 \mathrm{dpf}$ embryos (Mathias et al., 2009), while the head kidney only appears in zebra fish at 4 dpf (Willett et al., 1999). These macrophages were distinguished from neutrophils by immunolabeling of L-plastin without MPO co-expression (Mathias et al., 2009).

Another study on zebrafish showed the appearance of macrophages at a very early stage, first in the yolksac at $1 \mathrm{dpf}$ and then in the mesenchyme of the head and in the blood. It was found that these early macrophages do not arise from the well-known caudal embryonic blood island that gives rise to erythroblasts and endothelial cells; instead they arose from the ventrolateral mesoderm of the head just anterior to the cardiac field (Herbomel et al., 1999). Additionally these early macrophages from the yolksac appeared before any other type of leucocyte in the embryo. As well as phagocytosing apoptotic corpses, these macrophages showed the ability to engulf and destroy large amounts of bacteria injected intravenously (Herbomel et al., 1999). Our data suggests macrophages are present from $1 \mathrm{dph}$; however, to more accurately conclude that the CSF1R/MHCII expressing cells are macrophages, as well as attributing any immune function, will require further studies. Although the use of CSF1R as a marker for macrophages is generally accepted, it may be somewhat limited due to expression in neural crest cells (Parichy et al., 2000). Because of this it is necessary to use multiple markers or techniques for accurate detection.

Studies into the ontogeny of $\mathrm{T}$ lymphocytes in teleost fish have been limited due to the limited number of markers available (Zapata et al., 2006). Nevertheless morphological evidence combined with expression of $\mathrm{T}$ cell markers such as TCR $\alpha / \mathrm{TCR} \beta$ can confirm the appearance of T cells in the thymus (Willett et al., 1999; Trede et al., 2004). Generally the expression of RAG genes precedes the expression of TCR $\alpha / \mathrm{TCR} \beta$ because RAG genes are 
involved in the genetic recombination process. In contrast the first expression of TCR $\beta$ in hapuka larvae occurred at $32 \mathrm{dph}$ with detectable expression of RAG1 at $50 \mathrm{dph}$. Additionally TCR $\alpha$ expression was not detected in any larval timepoint sampled. In the halibut, the expression of TCR $\alpha$ mRNA is delayed occurring after the expression of RAG1 and TCR $\beta$ (Øvergård et al., 2011). In zebrafish the RAG1 expression at 3dpf is followed by TCR $\alpha$ chain expression in the thymus at 4 dpf (Danilova et al., 2004), two days after the appearance of the first lymphoid cells in the organ, while in the sea bass, immunohistochemical detection of assumed T cells (DLT-15 positive cells) occurs in the thymus 3 days after the first lymphoblasts appeared (Scapigliati et al., 2002). Additionally lymphoid progenitors that colonize the early thymic primordium only differentiate into immunocompetent $\mathrm{T}$ cells after the thymic stroma has matured (Castillo et al., 1990). Interestlingly the thymic stroma of hapuka did appear mature at 63 dph (Chapter 3), with many thymocytes visible, although medulla and cortex could not be distinguished; however, not all fish species develop zonation of their thymus (Press and Evensen, 1999) and so this may not reflect a lack of maturity. In mammals the surface expression of the co-receptors CD4 and CD8 should appear at the same time as the TCR $\alpha$-chain is rearranged replacing the pre-T $\alpha$ chain within the TCR complex and this is precisely what is seen in halibut (Øvergård et al., 2011). For further studies in hapuka, examining the expression of CD4/CD8 combined with TCR $\alpha$ at later larval timepoints should more accurately identify timing of T lymphocyte maturation.

In most teleosts that have been studied, the B lymphocytes have been suggested to originate and differentiate in the kidney (Hansen and Zapata, 1998). The IgM heavy chain gene encodes for the isotype determining portion of antibody in fish. Primers targeting the heavy chain gene of the IgM molecule were developed. Expression of IgM was first detected at 9 dph in hapuka larvae with increased expression correlating with the growth and maturation of the headkidney. The relatively early expression of IgM in hapuka at 9 dph also coincides with the appearance of $\operatorname{IgM}^{+}$cells in the head kidney 3 days later and suggests that B cells develop and mature in the head kidney.

However, in contrast to this, in a zebrafish study they were unable to demonstrate RAG1 expression in the head kidney by whole mount in situ hybridization (WISH), suggesting that the Rag probe was either unable to sufficiently penetrate the fish body or that there was a lack 
of lymphoid progenitors in the embryonic head kidney (Trede et al., 2004). However, other authors using the same WISH technique, demonstrated RAG1 expression in the zebrafish pancreas by $4 \mathrm{dpf}$ followed by the expression of IgM at $10 \mathrm{dpf}$ (Danilova and Steiner, 2002). Never-the-less another study showed weak expression of Ig L isotypes by RT-PCR at 3 dph but their expression, which was evaluated by in situ hybridisation on head kidney sections, began at 3 weeks post fertilisation (Lam et al., 2004). In the haddock, using RT-PCR although levels of IgM were detected relatively early between 12-16 dph, a large increase in IgM expression is first detected at $40 \mathrm{dph}$, after a large increase in RAG1 expression at 33 dph (Corripio-Miyar et al., 2007).

The lack of RAG1 expression in hapuka larvae before the onset of IgM expression (and the TCR $\alpha / T C R \beta$ ) could be due to very low level quantities of RAG1 mRNA. It is known that RAG expression is down regulated as lymphocytes mature, as seen in the haddock where a high peak of RAG1 at $33 \mathrm{dph}$ is followed by decreased RAG1 levels and a large increase in IgM expression a few days later (Corripio-Miyar et al., 2007). It is possible the RAG1 levels stayed low in hapuka until the head kidney and thymus reached a more mature stage (50 dph) when larger amounts cell maturation took place. Overall, the head kidney appears to be the first organ that produces B-lymphocytes in hapuka.

The functional properties of IgZ are still relatively unknown aside from its possible involvement in the mucosal immune environment (Zhang et al., 2010). Although it has now been reported in many fish species (Danilova et al., 2005; Tian et al., 2009a; Ryo et al., 2010), ontogenic studies into IgZ (also called IgT) are lacking. In hapuka, IgZ was first expressed at 45 dph with a peculiar expression pattern, being present one out of two samples tested. In ontogeny studies conducted in fugu and trout, expression of IgZ was first detected at $4 \mathrm{dpf}$, while the secretory form was expressed 1 dpf (Hansen et al., 2005; Savan et al., 2005). In these studies, IgM and IgZ were expressed during the same stage of development, although in zebrafish IgZ was detected first (Danilova et al., 2005). It has been revealed that in rainbow trout, IgZ and IgM are mutually exclusive on B-cells (Li et al., 2006).

The expression of hapuka IgZ appeared at the same time the TCR $\beta$ gene first started expression and at a time when the lymphoid organs started appearing mature. The expression of IgZ in one out of two samples for the time points of 45, 50 and $63 \mathrm{dph}$ is strange, however, because this is the first time IgZ has been detected in hapuka, it is hard to speculate why. The 
late detection of IgZ relative to IgM in hapuka could be accounted for by the technique used. Because IgZ has been found at such low levels in the lymphoid organs previously (Danilova et al., 2005), RT-PCR may have not been sensitive enough as given that whole larvae were homogenized rather than specific organs or tissues. Rapid Amplification of cDNA Ends (RACE) experiments were attempted to sequence the hapuka IgZ gene; however, these experiments were not successful and so further studies are needed to shed light on hapuka IgZ.

Phylogenetic analysis of MHCIIa revealed that every fish showing a high match with hapuka was a member of the perciform order of fish to which hapuka belongs. The closest related species to hapuka by MHCIIa was the European sea bass and the striped bass, both marine species and members of the Moronidae family of fish, which are considered closely related to the wreckfish (Polyprionidae) family to which hapuka belong. Similarly, phylogenetic anaylsis of IgM revealed a comparable pattern in that all fish, which showed a relationship with hapuka IgM, were members of the Perciformes order. Hapuka IgM appeared most closely matched with the mandarin fish followed by the striped trumpeter IgM heavy chains. This was interesting because while the mandarin fish belongs to the temperate perch family (Percichthyidae), and is closely related to the Moronidae family, it is a freshwater species native to China. It should be noted that no relationships were found with other members of the Polyprionidae family; however, this is due to the lack of immunologic studies conducted on the wreckfish species. Lastly the hapuka IgZ EST sequence only yielded similarity with other sequences when translated, and only the conserved Ig domain. A trout sequence showed the closest similarity, which would be considered strange, because trout is not a member of the perciformes order; however, this is probably due to the lack of teleost IgZ sequences available.

In conclusion, the APC marker MHCII $\alpha$ and the macrophage specific cell markers CSF1R were present from hatch, as was the complement component C3, similar to what has been seen in other teleosts (Lieschke et al., 2001; Ellingsen et al., 2005). Interestingly the expression of the lymphocyte development marker RAG1 did not appear to correlate with the expression of the B and T cell markers IgM and TCR $\alpha$ or TCR $\beta$ respectively. IgM was expressed relatively early (9 dph) and correlated with the immunohistochemical detection of $\operatorname{IgM}^{+}$cells in the headkidney at $12 \mathrm{dph}$ (Chapter 4). TCR $\beta$ gene was expressed at $45 \mathrm{dph}$ 
before the expression of TCR $\alpha$ as expected. Generally TCR $\alpha$ is expressed soon after the TCR $\beta$ gene in other teleosts (Øvergård et al., 2011), however, TCR $\alpha$ was not detected in larvae sampled. Mechanisms for the absence of this expression remain speculative and further studies are needed. IgZ was first expressed at $45 \mathrm{dph}$ and showed a perculiar expression pattern being present in one out of two samples tested. The knowledge of these immune genes will help establish the ontogeny of the hapuka immunity and give insight into the development of immunocompetence. Of further interest is whether some of the important immune factors expressed here are also maternally transferred to the eggs of hapuka such as C3 or humoral IgM. 


\section{Chapter 6 - Maternal transfer of immunity}

\subsection{Introduction}

Fish eggs are released and embryos hatch into a hostile environment, at a time when the embryo’s immunological capacity is still extremely limited (Mulero et al., 2007b). Because of this limitation, high mortality rates in the early larval stages are common in the aquaculture industry for many fish species (Seppola et al., 2009). These mortalities are usually due to opportunistic pathogens present naturally in the water such as bacteria, protozoa and viruses and can cause serious economic losses (Bakopoulos et al., 1997). Rearing of hapuka has seen similar problems, with high mortalities recorded in young larvae (personal communication, Salinas, I.). However, it has been reported that the maternal transfer of immunity occurs in many fish species (Takemura and Takano, 1997; Hanif et al., 2004; Seppola et al., 2009). Maternal immunity transmission is defined as the transfer of immune factors by an immunocompetent female to an immunologically naive neonate transplacentally or through colostrum, milk or yolk (Grindstaff et al., 2003). Both innate and adaptive immune factors can be transferred (Hanif et al., 2004), providing larvae with a limited period of immunity. These factors can be in the form of protein, mRNA or both and include complement components, immunoglobulins, lysozyme and types of lectins, such as agglutinins and serum amyloid A (Anstee et al., 1973; Yousif et al., 1991; Hanif et al., 2004; Huttenhuis et al., 2006; Løvoll et al., 2006). Currently, it is unknown whether maternal transfer of immunity occurs in hapuka and if so, what form it takes. This study was conducted in order to obtain evidence on the transfer of maternal humoral immune parameters of hapuka to their offspring and will focus on IgM, complement and lysozyme.

Aims: The overall aim of this chapter is to determine whether maternal immune factors are transferred to hapuka eggs/larvae. The maternal transfer of immunity in hapuka is of great interest due to the relatively late arrival of immunocompetence in most fish species. Additionally, this information may shed light on other areas of the hapuka immune system such as the timing of organ ontogeny and onset of immune gene transcription.

Detect the transfer of complement in the eggs of hapuka by measuring hemolytic activity.

Determine if lysozyme is transferred to hapuka eggs by measuring lysozyme activity. 
Detect maternal transfer of the key adaptive immune factor IgM, by immunoblotting and ELISA. 


\subsection{Results}

\subsubsection{Complement activity}

If complement were present, lysis of the sheep red blood cells would cause a change in absorbance. No change in absorbance was detected in wells containing hapuka eggs or larvae at any time point with all samples showing values of approximately 0 (data not shown). In contrast, adult hapuka serum showed clear lysis of sheep red blood cells compared to egg and larval samples (Fig. 6.1) confirming that adult hapuka serum but not egg or larval samples contains active complement factors detectable by this assay. The complement plate containing larvae (Fig. 6.1) is shown instead of the egg plate because it contained the controls.

\subsubsection{Lysozyme activity}

Egg homogenate gave a value of 0.08 lysozyme units (U) (One unit will produce a $\Delta \mathrm{A} 450$ of 0.001 per minute at $\mathrm{pH} 6.24$ at $25^{\circ} \mathrm{C}$, using a suspension of Micrococcus lysodeikticus as substrate, in a $2.6 \mathrm{~mL}$ reaction mixture (1 cm light path) showing that hapuka eggs contain lysozyme (Fig. 6.2). Additionally, serum from 90 dph juveniles showed 4 times more lysozyme activity per $\mu \mathrm{g}$ of protein (0.32 U) than seen in the eggs (Fig. 6.2).

\subsubsection{IgM detection dot blot and western blot}

To identify whether or not IgM was present in eggs of hapuka, a simple dot blot was performed on whole egg homogenates from 0 dpf (Fig. 6.3A). To verify the molecular weight of the identified proteins, the $\operatorname{IgM}^{+}$bands were compared using western blot analysis and different sized bands were observed (Fig. 6.3B). In adult hapuka serum under non reducing conditions (lane 4) two bands of over $250 \mathrm{KDa}$ were detected but absolute size could not be measured using the protein ladder used. Reducing conditions for the adult serum yielded a single band on approximately $75 \mathrm{kDa}$ whereas in egg homogenates, under both reducing and non reducing conditions a single band of $75 \mathrm{KDa}$ was detected. 


\subsubsection{IgM detection ELISA}

The IgM levels in whole egg and larval homogenates were also measured by ELISA to provide a more quantitative assessment. Samples were standardised to $100 \mu \mathrm{g} / \mathrm{ml}$ of protein in order to compare the different tissue samples. Because an IgM standard was not used, the absolute amount of IgM could not be calculated; the neglection of an IgM standard was due to funding restraints. Instead, the absorbance at $450 \mathrm{~nm}$ indicated the relative amount of IgM present and is presented as absorbance per $2.5 \mu \mathrm{g}$ of total protein. The results indicated the presence of IgM in both the eggs and larvae when compared with PBS controls (Fig. 6.4). An initial absorbance value of 0.128 was seen at $0 \mathrm{dpf}$ and the IgM levels appeared to decrease to 0.05 by $16 \mathrm{dpf}$ in accordance with its possible degradation (Fig. 6.4). The IgM levels then increased to 0.067 by $18 \mathrm{dpf}$. By $56 \mathrm{dpf}$ the IgM levels had increased to an absorbance value over 0.148; higher than the initial detection levels in the eggs at $0 \mathrm{dpf}$. 


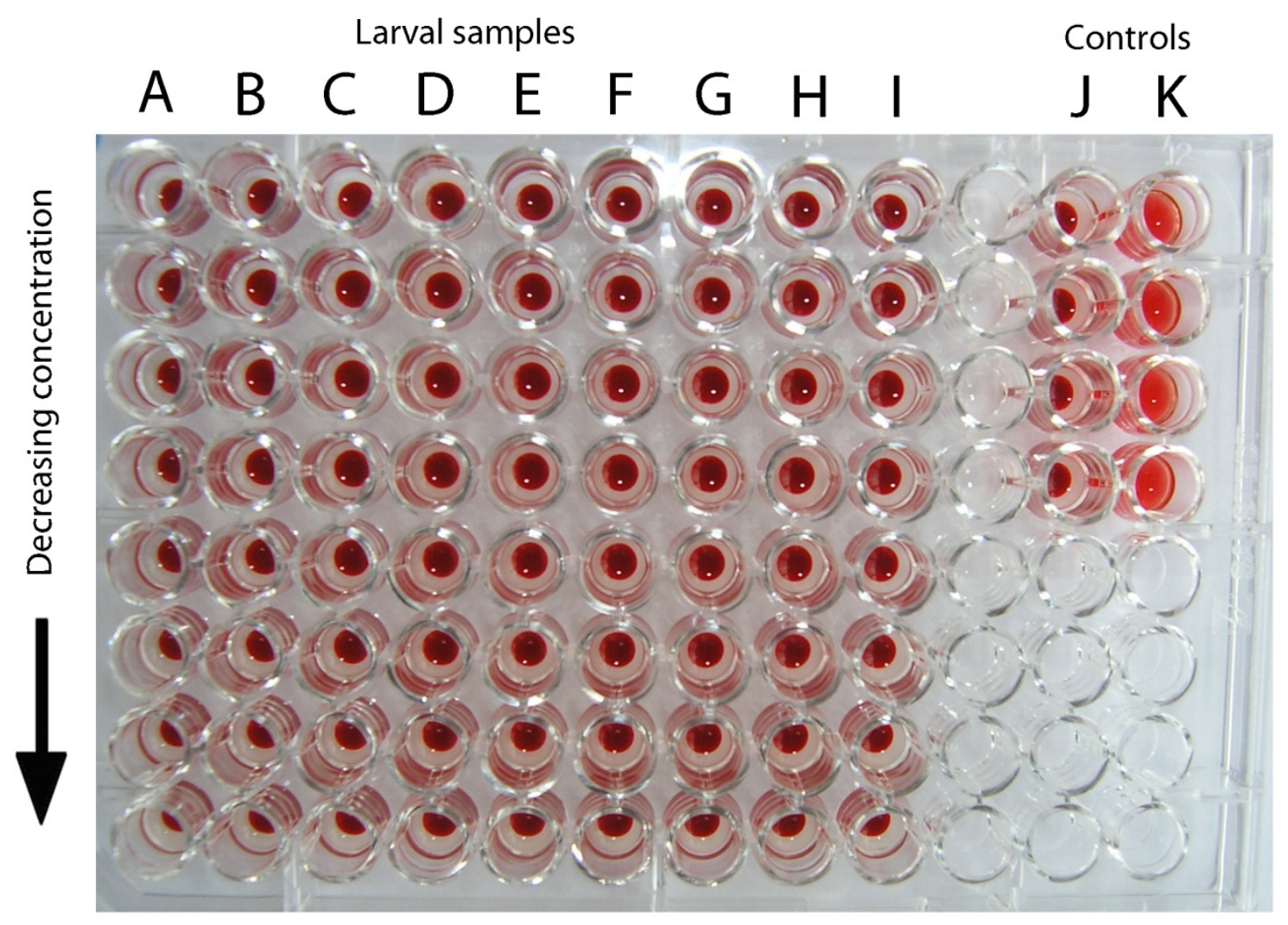

Fig. 6.1. Photograph of a 96 well plate showing no red blood cell lysis by complement activity in larval homogenates. No complement activity was detected in any egg or larval sample. Lanes are arranged in serial dilutions from top to bottom. (A) $12 \mathrm{dph} \# 1$. (B) $12 \mathrm{dph}$ \#2. (C) 16 dph \#1. (D) 16 dph \#2. (E) 20 dph \#1. (F) 20 dph \#2. (G) 24 dph \#1. (H) 24 dph \#2. (I) 32 dph. (J) 10mM PBS. (K) Adult hapuka serum. 


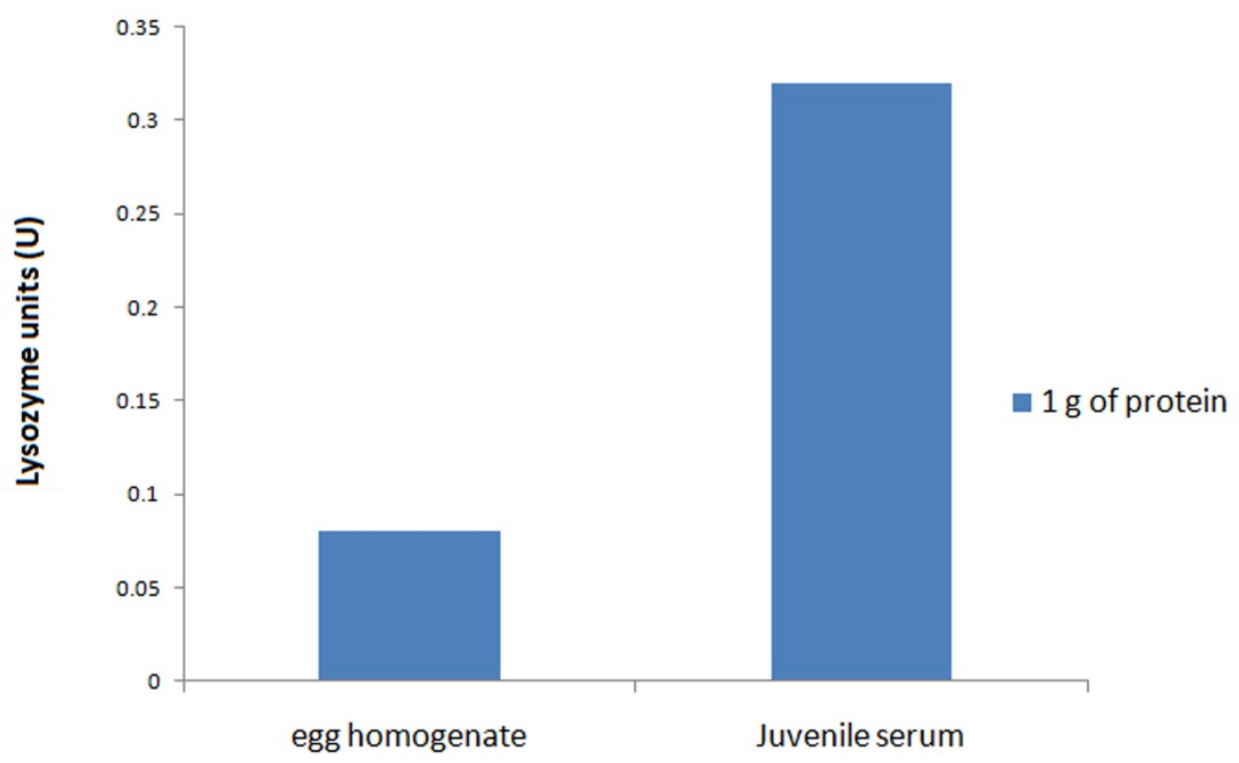

Fig. 6.2. Lysozyme activity is present in hapuka eggs. One lysozyme unit will produce a $\Delta \mathrm{A} 450$ of 0.001 per $\min$ at $\mathrm{pH} 6.24$ at $25{ }^{\circ} \mathrm{C}$, using a suspension of Micrococcus lysodeikticus as substrate, in a $2.6 \mathrm{~mL}$ reaction mixture $(1 \mathrm{~cm}$ light path). Lysozyme activity in hapuka eggs and juveniles was measured by activity with a chicken egg white lysozyme standard. 

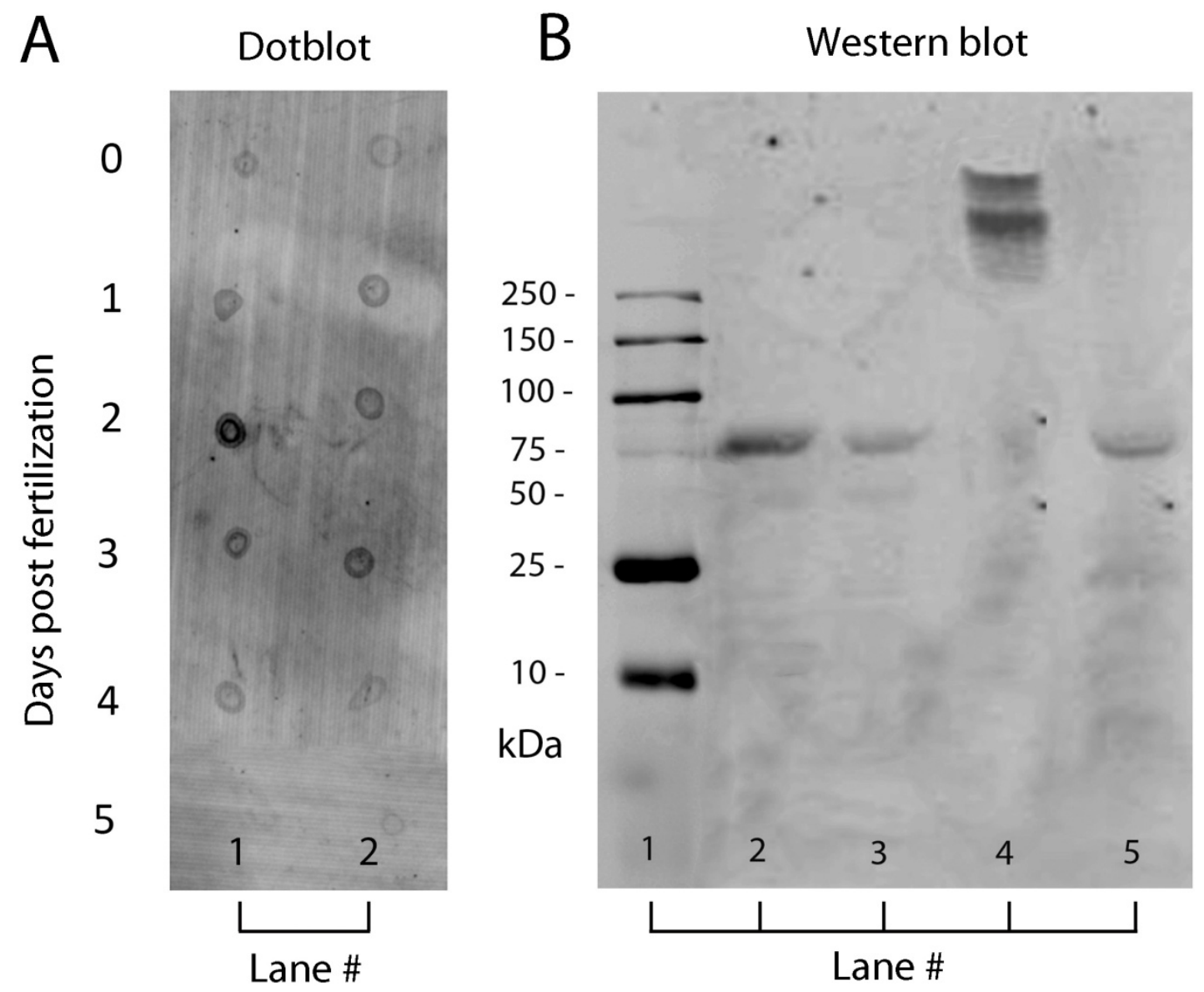

Fig. 6.3. IgM is present in hapuka eggs. (A) Dot blot analysis used for the detection of IgM in egg homogenates for two different batches of eggs. (B) Western blot analysis for the verification of transferred IgM molecular weight in egg homogenates and adult serum; Lane 1, Precision Plus Protein dual colour standards (Bio-Rad); lane 2, non-reduced egg homogenate; lane 3, reduced egg homogenate (10\% 2-ME); lane 4, non-reduced adult serum; lane 5, reduced adult serum (10\% 2-ME). 


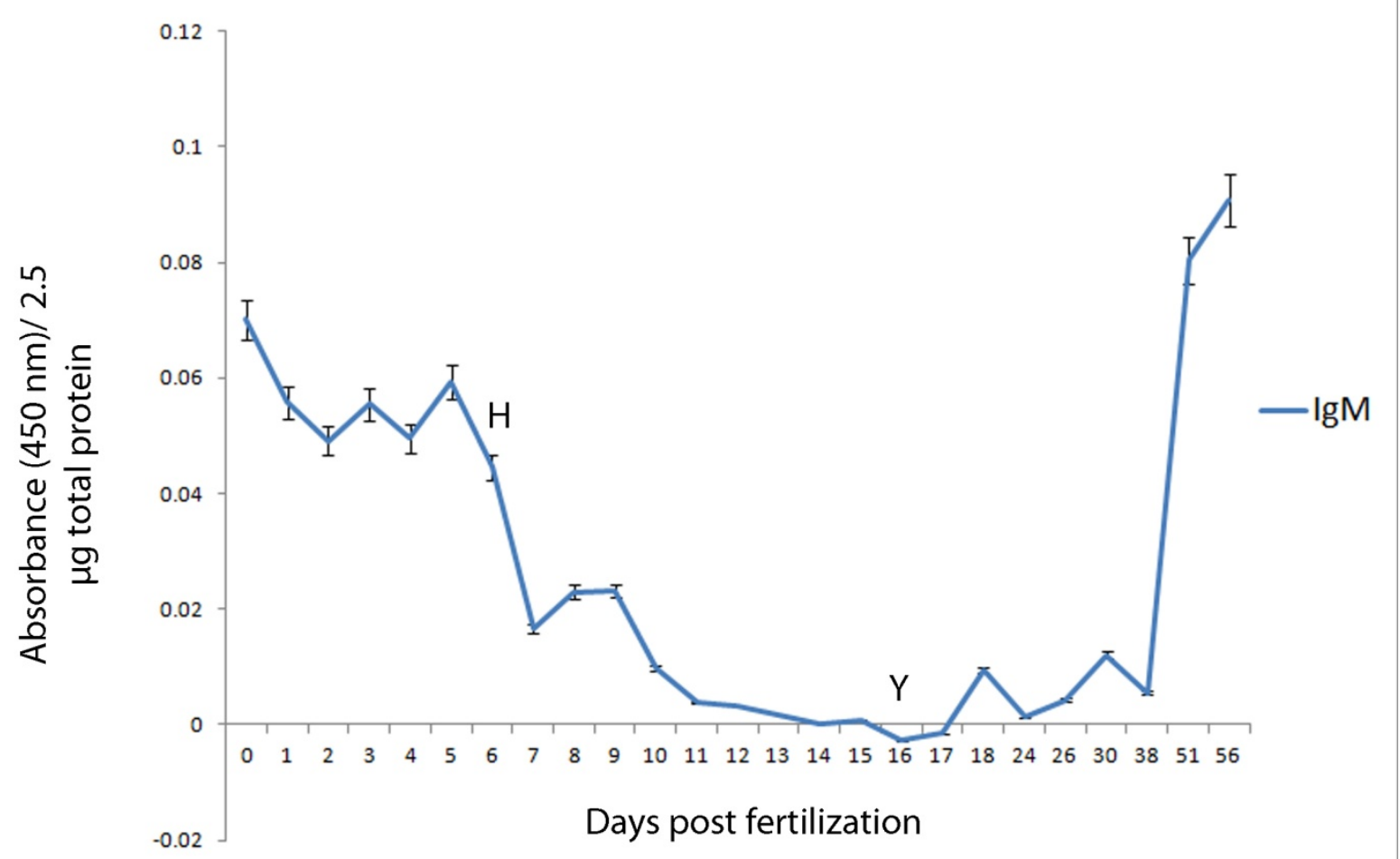

Fig. 6.4. IgM is present in the eggs and decreases until endogenous production. Figure shows the changes in IgM measured by ELISA at $450 \mathrm{~nm}$ in hapuku egg and larval homogenates. Note that the absorbance only shows the relative IgM level. $(\mathrm{H})$ refers to the time of hatch and $(\mathrm{Y})$ refers to the time of yolk sack absorption and the beginning of rotifer feeding. Bars represent percentage errors of the means. $(\mathrm{N}=3)$. 


\subsection{Discussion}

The teleost immune system is not fully developed during early embryonic stages and the immunological capacity is thus assumed to be limited. This study was performed to give insight into the maternal transfer of some of the key immune molecules in hapuka including complement, lysozyme and IgM. Currently it is not known if these factors are important in the maternal transfer of immunity to hapuka eggs or larvae. The results of this study showed that IgM and lysozyme were present in the eggs of hapuka, however, complement was not.

Complement is one of the most important components of the innate immune system, especially in fish (Ellis, 1999). Even with no antibody present, the complement system can act to lyse foreign cells with a membrane attack complex via the alternative pathway (Nonaka and Smith, 2000). To detect the presence of complement, the lysis of sheep red blood cells by complement was measured in eggs and larvae. Results showed no complement-mediated lysis of red blood cells in any egg sample or even the larval samples up to $63 \mathrm{dph}$, whereas the adult serum showed clear lysis. While this result suggests that no C3 was present in the egg and larval samples, it is possible that complement proteins were present but unable to form membrane attack complexes and thus lyse cells. The lack of one of the many complement proteins required to form the membrane attack complex would prevent lysis in our assay (Løvoll et al., 2006) and while the end result of complement activation was assessed, the presence of specific complement proteins was not examined.

The expression of the complement protein C3 was present from hatch in hapuka (Fig. 5.3C) which suggests at least some components of complement are present in the early stages. Even if a lytic pathway is not active until later stages in hapuka larvae, C3 degradation products can still function as opsonins and anaphylatoxins. These opsonins promote phagocytosis and thus require the presence of phagocytic cells (Løvoll et al., 2007). On the other hand, the head kidney, the main hematopoietic organ in teleosts first appears at $4 \mathrm{dph}$ in hapuka. The transfer of complement to eggs has been reported in other fish species. Studies on the spotted wolf fish showed that maternal C3 was transferred to the eggs and detected by immunohistochemical experiments; however, functional properties such as cell lysis were not determined (Ellingsen et al., 2005). Studies on Atlantic salmon showed the presence of the C3 protein in the unfertilised eggs, with C3 mRNA not detected in the larvae until $14 \mathrm{dpf}$ suggesting the maternal transfer of C3 (Løvoll et al., 2007). It would appear that although 
hapuka larvae express the complement protein C3 early, any components that are transferred from the mother are not able to form a membrane attack complex.

Lysozyme is another important innate defence parameter and acts on the peptidoglycan layer of bacterial cell walls resulting in the lysis of the bacteria. The maternal transfer of lysozyme in hapuka was studied by examining the presence of lysozyme in the eggs and juveniles, and the results showed that both hapuka eggs and juveniles contained significant lysozyme activity. It is believed that lysozyme in eggs may prevent vertical (mother to progeny) transmission of some bacterial pathogens (Yousif et al., 1994), however, it remains unknown if the lysozymes in hapuka eggs have any direct anti-bacterial activity. Atlantic cod showed maternal transfer of lysozyme to the eggs, while during the gastrula period (118 hpf) the transcript level of lysozyme increased slightly indicating that from this stage the embryo independently produces its own transcripts and the use of maternally derived lysozyme may be of less importance (Seppola et al., 2009). Because the gene expression of lysozyme was not examined in hapuka, similar conclusions cannot be made.

In coho salmon (Oncorhynchus kisutch), lysozyme activity has been found in unfertilised eggs (Yousif et al., 1991) and this lysozyme, when purified, showed antibacterial activity against several fish pathogenic bacteria (Yousif et al., 1994). Lysozyme has also been found in the eggs of zebrafish along with complement proteins, both demonstrating antibacterial activity (Wang and Zhang, 2010). Additionally it was suggested that the lysozyme-mediated bacteriolysis depended on the complement, and the complement-mediated bactericidal activity can be stimulated by the lysozyme activity (Wang \& Zhang, 2010); showing a synergistic role of these maternally-transferred proteins. The presence of lysozyme activity in hapuka eggs may indicate a role in the prevention of bacterial entry into the eggs and embryos. Thus, transfer of lysozyme to the egg may represent a maternal adaptation to increase offspring viability and improve overall egg quality (Seppola et al., 2009).

As well as innate factors, the transfer of the adaptive immune protein IgM was examined in the eggs of hapuka. It has been speculated that the relatively late arrival of autologous humoral IgM may at least to some extent, be compensated by maternally derived IgM (Zapata et al., 1997). In the present study the presence of IgM in the eggs of hapuka was examined using immunoblotting and ELISA assays. The results indicated the presence of an immunoglobulin like protein in the fertilised eggs of hapuka. It appears that at $0 \mathrm{dpf}$ IgM is 
present in the eggs and slowly decreases until hatch when the IgM levels decline even further. The IgM levels appear to decline till around the time of first feeding (17 dpf or $11 \mathrm{dph}$ ), when there appears to be an increase in IgM. IgM levels appear to increase from this point onwards with higher levels recorded after $51 \mathrm{dpf}$ ( $45 \mathrm{dph}$ ). The increase in IgM levels correlates with when $\operatorname{IgM}^{+}$cells first appear in the head kidney a day later at 12 dph (Chapter 4) a few days after gene transcripts of IgM were first detected (9 dph) (Chapter 5). However, due to the lack of sample size (3), subsequent statistical analysis could not be carried out and the results validated.

The transfer of maternal IgM has been recorded in other fish species such as tilapia, sea bream and coho salmon (Yousif et al., 1995; Takemura and Takano, 1997; Picchitti et al., 2001). In tilapia, low levels of IgM were detected in the circulating blood of larvae, while high levels were found in the yolk sac, indicating that most of the IgM which is considered to be of maternal origin remained in the yolk sac. Upon complete absorption of the yolk sac there was a remarkable increase in IgM in the larval homogenate. Because the larvae had already absorbed their yolk, the increase in IgM detected in these larvae did not derive from the yolk sac. This result suggests that IgM producing cells must have started to mature and, consequently, IgM in the larval circulation increased (Takemura and Takano, 1997). Similarly, IgM levels in hapuka larvae decreased until about the time of complete yolk sac absoption (11 dph), which also coincided with the onset of exogenous feeding. After the yolk sac absorption and beginning of exogenous feeding IgM levels started to increase, which also corresponded with the maturing of IgM producing cells which were detected by IHC in the head kidney at $12 \mathrm{dph}$. It is interesting to note that in zebrafish, maternally supplied mRNAs are selectively degraded before the activation of embryonic transcription can begin. This occurs in order to transfer developmental control to the zygotic genome and a correctly timed clearance of maternal transcripts is critical for embryogenesis (Giraldez et al., 2006). Although detection of IgM mRNA in hapuka eggs was not carried out, larval transcription of IgM began on $9 \mathrm{dph}$, when levels of transferred maternal IgM appeared at their lowest. It is possible that metabolism and degradation of IgM and/or IgM transcripts in hapuka during the yolk sac absorption also signals the onset of transcription; however, further studies are needed. 
The teleost IgM tetramer generally has a molecular weight between 600 and $800 \mathrm{kDa}$ depending on fish species (Tort et al., 2003; Swain and Nayak, 2009). Western blot analysis showed that a low molecular weight Ig molecule of approximately $75 \mathrm{kDa}$ was present in hapuka eggs under non reducing conditions. Under reducing conditions the same $75 \mathrm{kDa}$ band was seen suggesting that the molecule transferred to the eggs is an already reduced form of the adult tetrameric IgM. The molecular weight of the adult IgM molecule under non reducing conditions could not be determined with the protein ladder used, although 2 bands could be seen suggesting Ig multimers (tetramers and trimers) were present. However, under reducing conditions a single molecule of approximately $75 \mathrm{kDa}$ was detected, the same size as the molecule seen in the eggs. These results would suggest that a possible halfmeric Ig is transferred to the eggs of hapuka, or possibly an already reduced heavy chain because of the low kDa.

Because monomeric isotypes (Clem and Mclean, 1975; Lobb and Clem, 1981) are seldom observed, it has long been believed that teleost immunoglobulins lack isotype diversity (Kaattari et al., 1998). It has now been discovered that a unique feature of teleost IgM, is the fact that these molecules are not secreted as uniformly disulfide bonded oligomers; but instead various redox forms exist giving rise to multiple IgM isomers (Kaattari et al., 1998). Thus although the tetrameric structure of fish Ig which is composed of four monomeric units, two identical H chains (70 kDa) and two light L chains (25 kDa) (Tort et al., 2003), different combinations of subunits may be assembled depending on the combinations of disulfide bonds and non-covalent interactions. For example, in salmonids it has been shown that the basic covalent subunit is a monomer but the final combination for the tetramer may be a fully crosslinked tetramer or combinations of monomers, dimers or trimers (Evans et al., 1998). Furthermore, the presence of halfmeric IgM forms has been demonstrated in several fish (Lobb and Clem, 1983). The approximate $75 \mathrm{kDa}$ heavy chain detected in hapuka is in accordance with other teleost fish such as the coho salmon (76 kDa) and sea bream (71 kDa) (Yousif et al, 1995; Hanif et al, 2004). Assuming the hapuka light chain has a similar molecular weight to what has been reported in other species (approximately $25 \mathrm{kDa}$ ) then the hapuka IgM tetramer could be expected to weigh approximately $800 \mathrm{kDa}$. What is interesting is the transferred Ig molecule appears to be a single heavy chain molecule, suggesting it has been reduced from the light chain prior to transfer, or was reduced after the transfer process; 
Further studies into the transfer process, or study of the light chain could shed light into this area of immunity. 


\section{Chapter 7 - Leucocyte development}

\subsection{Introduction}

The ontogeny of the immune cells and the lymphomyeloid organs that house them has been studied in several teleost species (Mulero et al., 2007b). Generally the appearance of lymphoid organs and lymphocytes is relatively early, however, the full maturation of immunological competence can develop much later (Zapata et al., 2006). Cell-mediated immunity develops slightly earlier than the humoral immune response and is very important during the larval stages (Zapata et al., 2006). Leucocytes play a role as being the key mediators of innate immune responses throughout evolution (Janeway and Medzhitov, 2002). These cells provide protection against commonly encountered pathogens through phagocytic functions, as well as specific anti-microbial enzymes and peptides (Passantino et al., 2002; Sepulcre et al., 2002).

In order to confirm the identity and likely function of different cell populations, analysis of specific characteristics of leucocytes, including enzyme components and morphology is essential (Shigdar et al., 2009). The leucocytes of fish are generally less differentiated than their mammalian counterparts, making them more difficult to distinguish from each other. Cytochemistry is the microscopic study of the chemical constituents within cells and relies on either selective binding of a stain to a particular cell component on the basis of its chemical properties or detection of enzymatic activity with specific colourimetric reagents (Hine et al., 1987). In combination with cell morphological studies, cytochemical analyses can often definitively distinguish between subsets of cells, as well as providing important functional information. This methodology has proven particularly useful to the area of hematology, where it is routinely used to delineate specific cell populations in blood samples in humans and other species (Shigdar et al., 2009). Combined with a quantitative method such as flow cytometry, it is possible to characterise the different cell types and to monitor changes in blood cell populations between juveniles and adult fish. Flow cytometry proved to be a rapid and reliable method for monitoring cell population dynamics in the blood of different fish species (Morgan et al., 1993; Esteban et al., 2000).

Aim: Due to the lack of knowledge of hapuka leucocytes the current chapter aims to identify and describe the main leucocyte populations in juvenile and adult hapuka using cytochemical 
and flow cytometry techniques. Because it is believed that fish develop their innate immune system early, it can be hypothesised that the innate cell populations of juveniles will be similar to the populations in adults.

Specific aims:

Describe the juvenile groper head kidney leucocyte populations and the peripheral blood leucocyte populations and compare them with adult hapuka leucocytes.

Study the $\operatorname{IgM}^{+} \mathrm{B}$ cells in the systemic blood and head kidney of juvenile and adult hapuka and determine if any significant differences exist.

Identify the different types of granulocytes present in hapuka by light microscopy, flow cytometry, and myeloperoxidase staining. 


\subsection{Results}

\subsubsection{Morphology of adult and juvenile hapuka leucocytes}

Percol gradients allowed the separation of the leucocytes from the head kidney and blood. The leucocyte suspensions obtained were devoid of erythrocytes. Hapuka leucocyte subpopulations were analysed by flow cytometry on the basis of their size (FSC) and granularity (SSC). Flow cytometry allowed comparison of the head kidney leucocyte populations between adult and juvenile (127 dph) hapuka (Fig. 7.1C); as well as comparison of peripheral blood leucocytes (PBL) populations between adults and juveniles (134 dph) (Fig, 7.2C). The following four populations were identified according to FSC and SSC: progenitor cells, showing variable granularity, but small size; lymphocytes, which were were small in size and showed low granularity; macrophages which showed large size but low granularity and granulocytes, which showed large size and high granularity. These results can be seen in the respective plots showing adult (Fig 7.1A) and juvenile (Fig 7.1B) head kidney populations; as well as adult (Fig 7.2A) and juvenile (Fig 7.2B) PBL populations. The flow cytometry results showed that the ratios of the granulocyte, lymphocyte, monocyte/macrophage and progenitor cell populations in the head kidney of adults were significantly different $(\mathrm{p}<0.05)$ than juvenile populations (Fig 7.1C). In particular, juveniles appeared to have a large population of progenitor cells and small population of granulocytes while the adults had the oppostite. PBL populations appeared similar (Fig 7.2C).

\subsubsection{Lymphocyte populations}

The isolated leucocytes from 117 dph old juvenile and adult head kidneys and blood were labelled with the primary antibody F06 which binds to IgM on B lymphocytes, conjugated to the secondary FITC-donkey anti mouse IgG (Fig. 7.3A and B). Results showed no significant difference $(\mathrm{p}>0.05)$ between the \% of IgM+ cells lymphocytes in juvenile and adult populations.

\subsubsection{Morphology of adult and juvenile hapuka leucocytes}

Morphological analyses indicated the adult hapuka appear to have at least 2 types of circulating granulocytes (Figure 7.4A). One type had a pale cytoplasm and multilobulated 
segmented nucleus (Figure 7.4B), typical of the heterophil granulocyte of other teleosts (Lieschke et al., 2001). The other type had an eosinophilic cytoplasm with a peripheral nonsegmented nucleus (Fig 7.4C), typical of the eosinophil granulocytes seen in other teleosts (Esteban et al., 2000). Heterophils were rare in juvenile blood smears and instead heterophil-like cells were observed which appeared immature in appearance with nonsegmented nuclei (Fig 7.5A) similar to the progranulocyte seen in the carp (Kondera, 2010) (Fig 7.5A and B), however, eosinophils were virtually absent in juveniles. Additionally macrophages were common in both adults and juveniles and were characterised by their large size and pale blue cytoplasm (Fig 7.4D and Fig 7.5D). Lymphocytes were also abundant in both adults and juveniles, observed as small cells, with a large dark staining nucleus with little cytoplasm visible. Progenitor cells were small, with variable levels of granularity and were seen in both the juveniles (Fig 7.5B) and adults; however as mentioned, numbers of progenitors were higher in juveniles.

\subsubsection{Myeloperoxidase staining of adult and juvenile hapuka leucocytes}

Histochemical staining for myeloperoxidase was performed to determine whether any hapuka leucocytes contained granules that stained positive for myeloperoxidase (MPO). Heterophils stained positive for MPO while eosinophils, macrophages and lymphocytes did not (Fig 7.5 G, H, I and J). Histochemical demonstration of MPO granules also facilitated recognition of the immature heterophil granulocyte cells in the juveniles which showed lower amounts of MPO than adults and a more diffuse staining pattern (Fig. 7.5G and H). However, histochemical staining for myeloperoxidase activity was not specific to heterophils as weak peroxidase activity was evident in other cell types (Fig 7.4F), lineage unknown. These results confirm there are $\mathrm{MPO}^{+}$leucocytes in both adults and juveniles. 

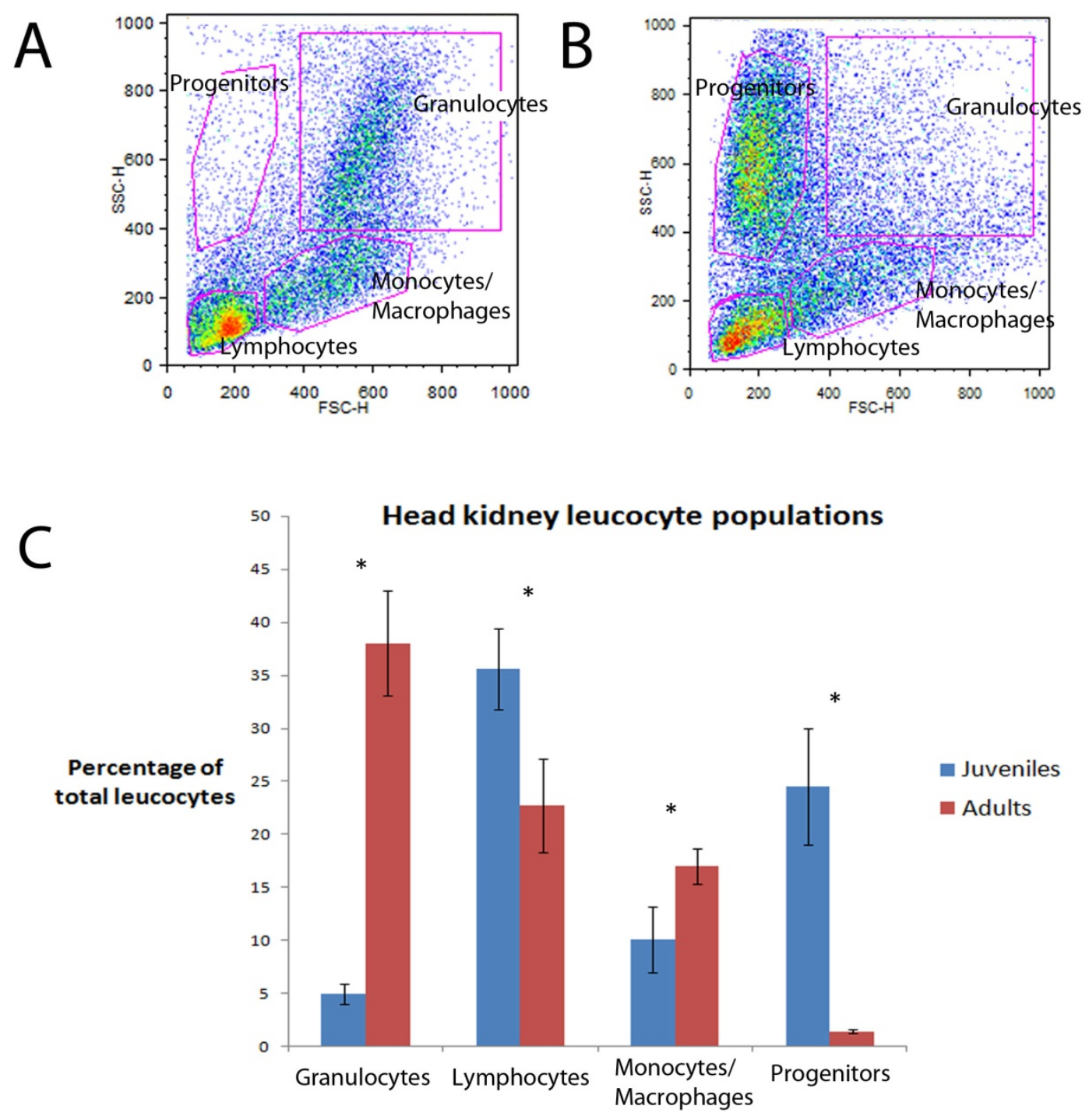

Fig. 7.1. Flow cytometric analysis of juvenile and adult head kidney leucocyte populations. Graph shows the different proportions of leucocytes amongst leucocyte populations between the juvenile and adult hapuka head kidney. Head kidneys from juvenile (127 dph) and adult hapuka were mechanically crushed through a cell strainer and the leucocytes separated using a percol gradient. (A) Adult fish scatter plot and (B) juvenile fish scatter plot showing the gates used to determine progenitors, lymphocytes, monocytes/macrophages and granulocytes. Scatter plots represent an individual, not the average. (C) Difference between adult and juvenile leucocyte populations in the head kidney shown as a percentage of total leucocytes. Adults and juveniles were compared for any significant $(*)$ difference between each relative leucocyte population ( $\mathrm{p}<0.05)$. Bars represent standard errors of the means. $(\mathrm{N}=4)$. 

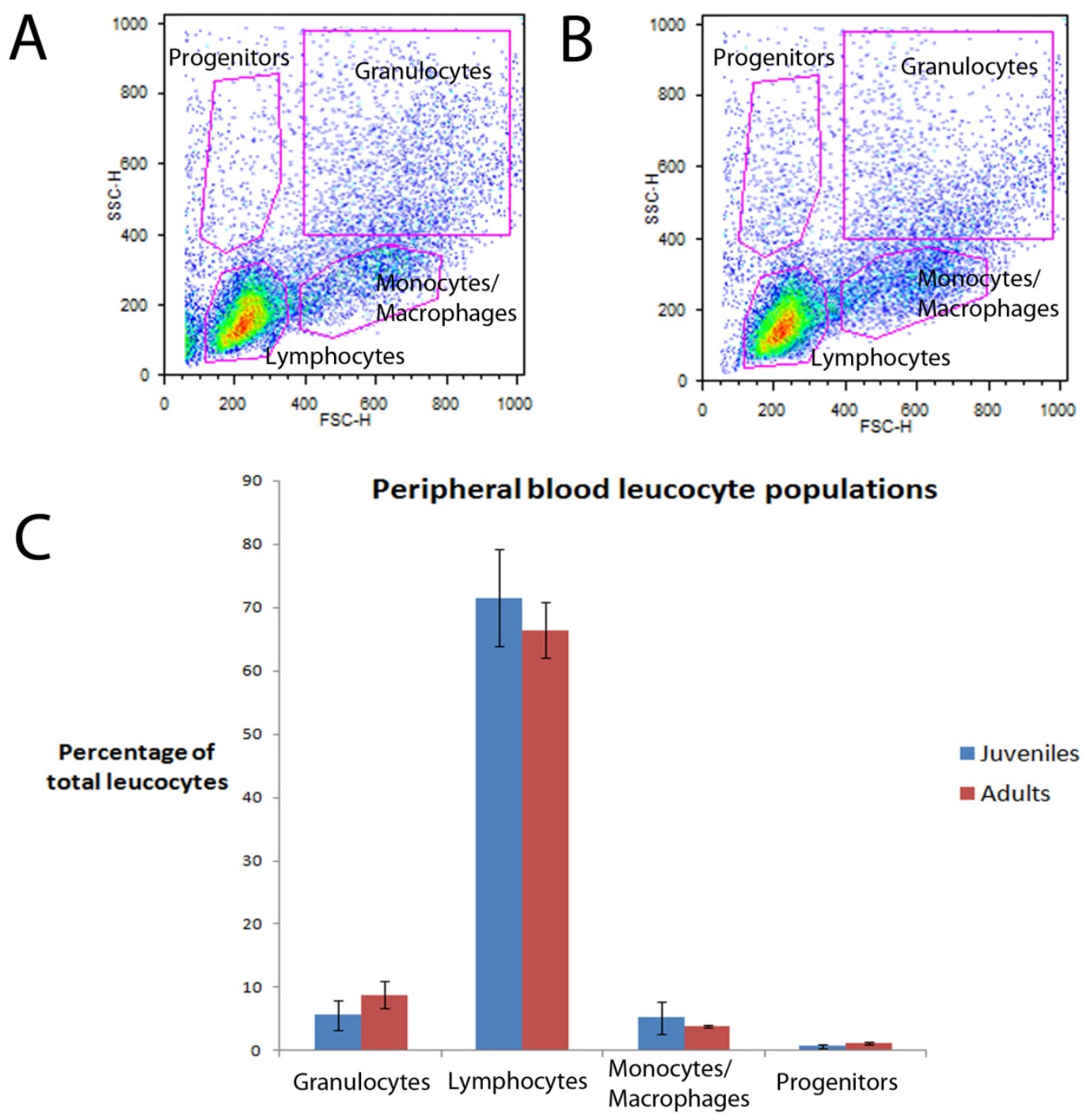

Fig. 7.2. Flow cytometric analysis of juvenile and adult peripheral blood leucocyte populations. Graph shows the different proportions of leucocytes amongst leucocyte populations between the juvenile and adult hapuka blood. Juvenile (134 dph) and adult hapuka were bled from the caudal vein using a syringe and the leucocytes separated using a percol gradient. (A) Adult fish scatter plot and (B) juvenile fish scatter plot showing the gates used to determine progenitors, lymphocytes, monocytes/macrophages and granulocytes. Scatter plots represent an individual, not the average. (C) Difference between adult and juvenile peripheral blood leucocytes populations shown as a percentage of total leucocytes. Adults and juveniles were compared for any significant $(*)$ difference between each relative leucocyte population ( $\mathrm{p}<0.05)$. Bars represent standard errors of the means. $(\mathrm{N}=4)$. 


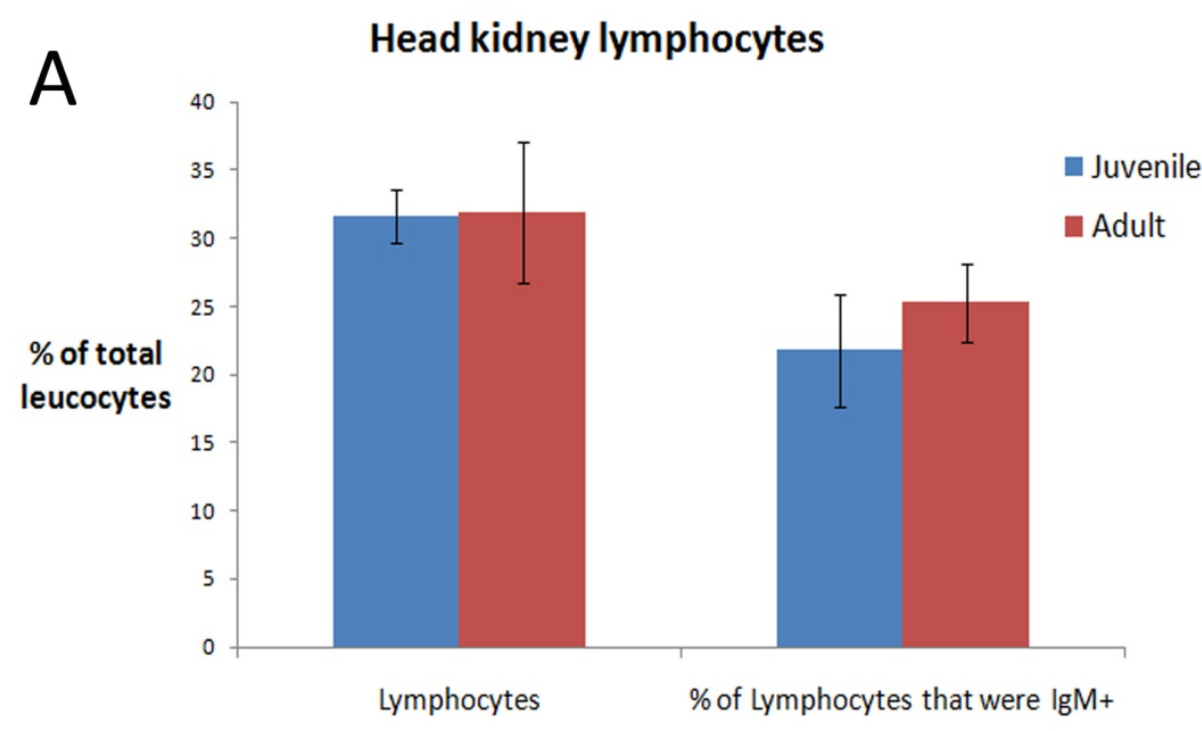

\section{Peripheral blood lymphocytes}

B

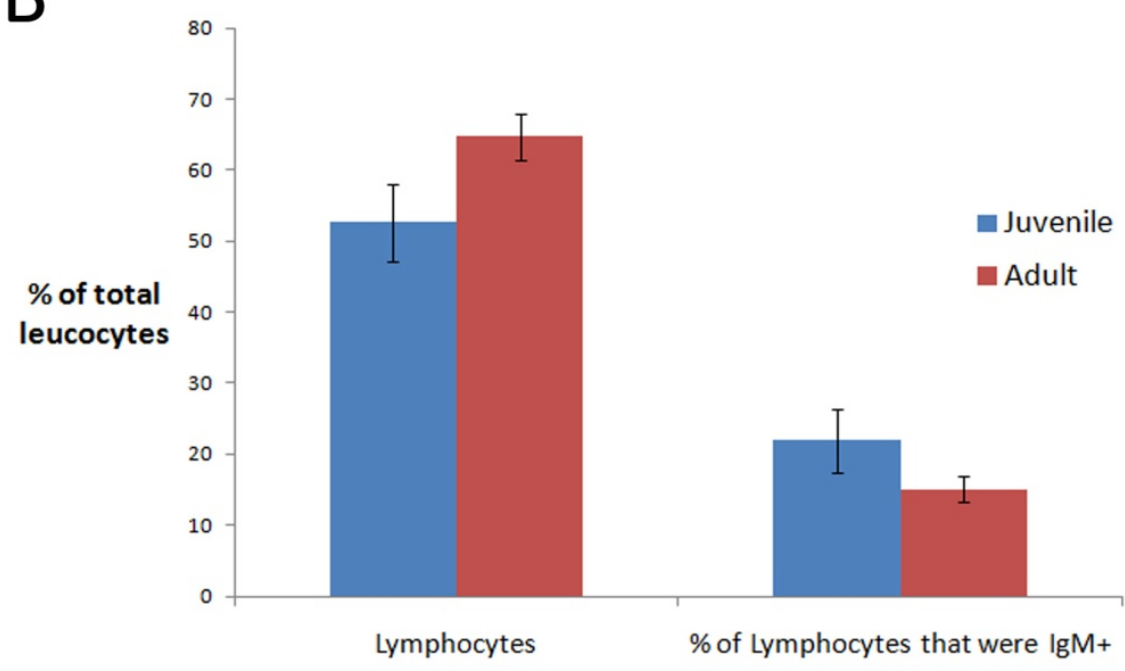

Fig. 7.3. Flow cytometric analysis of hapuka lymphocyte populations between adult and juveniles after being incubated with an IgM labelling antibody. Juvenile (117 dph) and adult hapuka were bled from the caudal vein using a syringe to collect blood, and the head kidneys mechanically crushed through a cell strainer to obtain cell suspensions. The leucocytes from blood and HK were separated from other cell types using Percoll gradients. IgM $^{+}$cells were stained using primary antibody F06 and a secondary antibody labelled with FITC. The cell suspensions were acquired by flow cytometry with 20000 events and analysed in FlowJo version 7.6.4. (A) The mean percentage of $\operatorname{IgM}^{+}$cells present in $\mathrm{HK}$ (A) and blood (B) of 
juveniles was not significantly different from that found in adult specimens $(\mathrm{p}>0.05)$. Bars represent standard errors of the means. $(\mathrm{N}=4)$. 


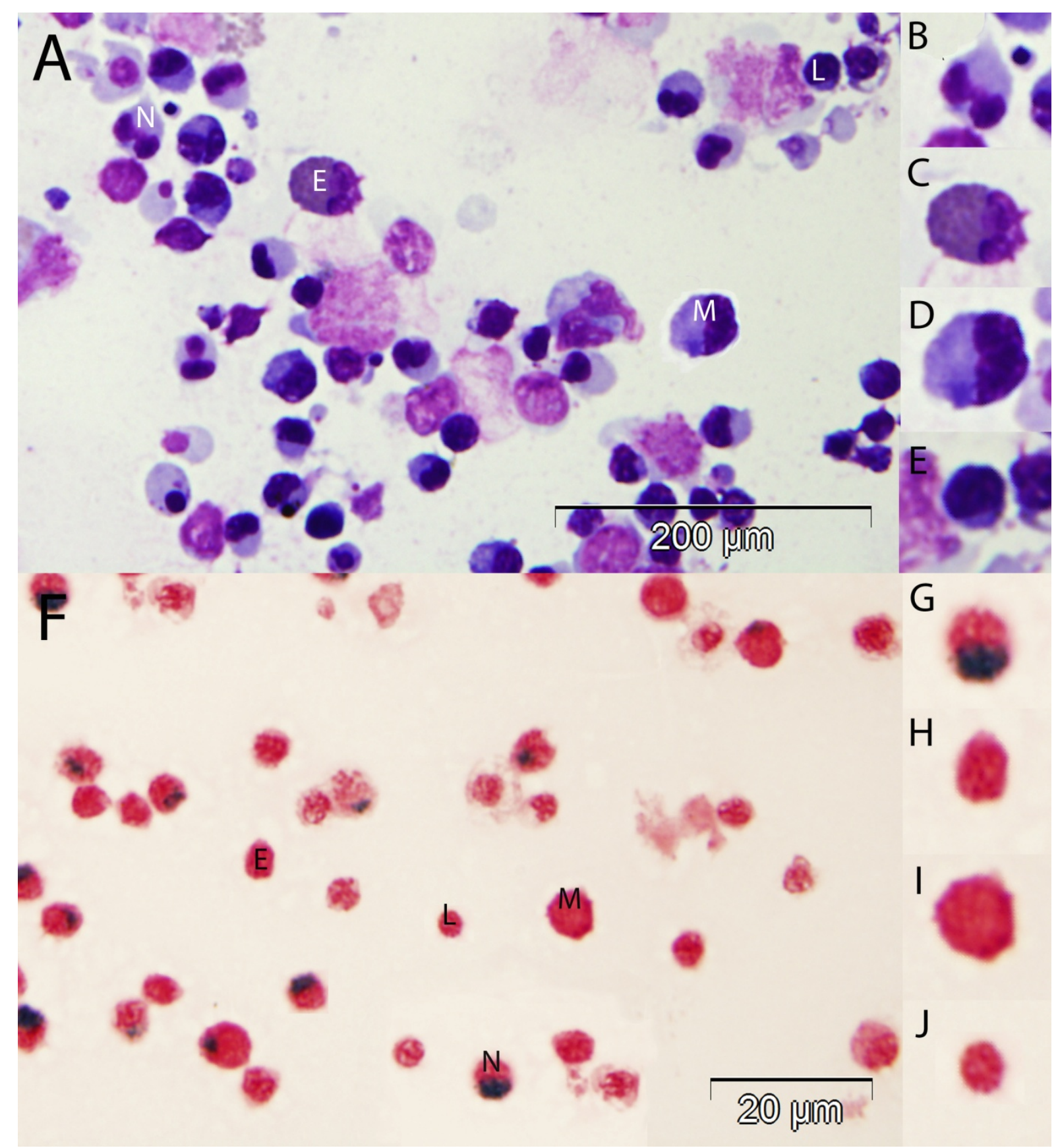

Fig. 7.4. Morphological and cytochemical appearance of adult hapuka leucocytes by light microscopy. (A) Leucocytes isolated from hapuka head kidney cytospins and stained with Giemsa-stain. (N) Neutrophil/heterophil, (E) eosinophil, (M) macrophage, (L) lymphocyte. (B) Detail of mature heterophil with multiple-lobed nucleus. (C) Detail of mature eosinophil, illustrating characteristic pink cytoplasm and peripheral nucleus. (D) Detail of mature macrophage, showing large cell size and characteristic pale blue cytoplasm. (E) Detail of mature lymphocyte, illustrating darkly stained large nucleus. (A-E) Giemsa-stained blood 
smears. (F-J) MPO stained blood smears. (F) Leucocytes isolated from adult hapuka head kidney cytospins and stained with MPO. (N) Neutrophil/heterophil, (E) eosinophil, (M) macrophage, (L) lymphocyte. (G) Detail of $\mathrm{MPO}^{+}$mature heterophil showing black-stained granules in the cytoplasm. (H) $\mathrm{MPO}^{-}$eosinophil (I) Detail of $\mathrm{MPO}^{-}$macrophage. (J) $\mathrm{MPO}^{-}$ lymphocyte. 


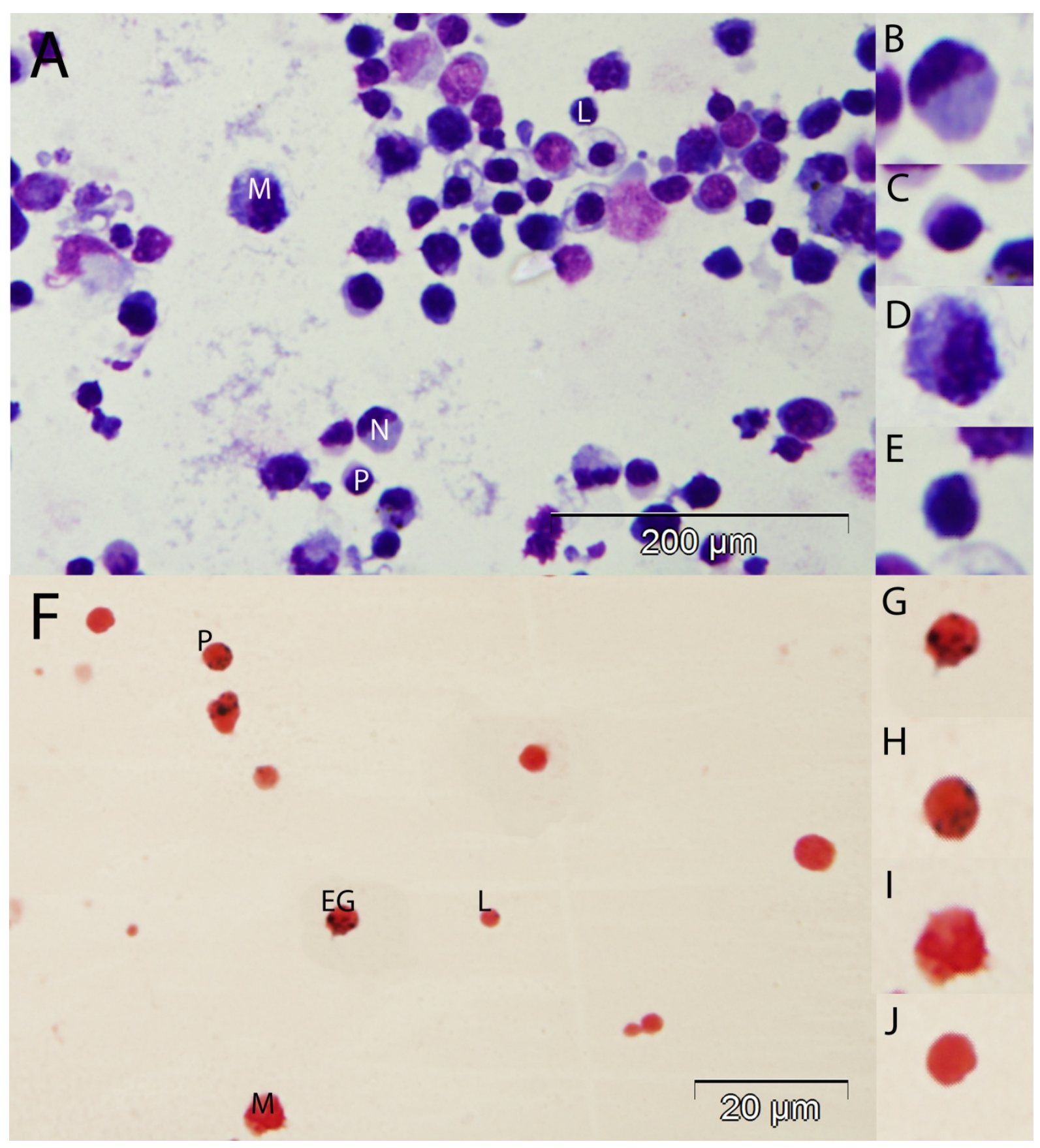

Fig. 7.5. Morphological and cytochemical appearance of juvenile hapuka leucocytes by light microscopy. (A-E) Giemsa-stained blood smears. (F-J) MPO stained blood smears. (A) Leucocytes isolated from hapuka head kidney cytospins and stained with Giemsa-stain. (B) Detail of immature heterophil with single lobed nucleus. (C) Detail of progenitor cell, showing undifferentiated nucleus and neutrophilic cytoplasm. (D) Detail of macrophage, maturity unknown, showing large cell size and characteristic pale blue cytoplasm. (E) Detail 
of lymphocyte, illustrating darkly stained large nucleus. (F) Leucocytes isolated from juvenile hapuka head kidney cytospins and stained with MPO. (G) Detail of $\mathrm{MPO}^{+}$mature heterophil showing black-stained granules in the cytoplasm. (H) MPO ${ }^{-}$Eosinophil (I) Detail of $\mathrm{MPO}^{-}$macrophage. (J) $\mathrm{MPO}^{-}$lymphocyte. Abbreviations: Neutrophil/heterophil (N), macrophage (M), eosinophilic granulocyte (EG), lymphocyte (L). 


\subsection{Discussion}

The morphology of hapuka leucocytes has not been described to date and therefore this represents the first report of their lineages and cell types. Typically, teleost fish possess two leucocyte lineages: the lymphoid and myeloid lineages. In higher vertebrates the red blood cells, the white blood cells (granular and agranular) and lymphocytes originate from a common progenitor, the stem cell, which gives rise to all the cells of the myeloid and lymphoid lineages. Our light microscopy studies found the main immune cell types described in other teleosts: granulocytes, monocyte/macrophages, lymphocytes, and plasma cells were present in hapuka head kidney and peripheral blood. By light microscopy, we identified two different types of granulocytes: heterophils (also known as neutrophilic granulocytes) and eosinophils. We have adopted the nomenclature proposed by Lieschke (zebrafish) but it is clear that some confusion exists in this field (Lieschke et al., 2001). Additionally it is important to note that these names, which refer to the staining reaction of the cells, do not infer information about the function of these cells in host defense (Ellis, 1977a).

The morphology of the hapuka heterophil was similar to that seen in other teleost species (Bielek, 1981; Esteban et al., 2000; Lieschke et al., 2001; Abdel-Aziz et al., 2010), with a neutrophilic cytoplasm and multi segmented nucleus. In juveniles, mature heterophils were uncommon and instead many heterophil-like cells were observed which appeared immature in appearance with non-segmented nuclei similar to the progranulocyte seen in the carp (Kondera, 2010). In many species, the heterophil is the most abundant granulocyte cell type (Esteban et al., 2000; Lieschke et al., 2001), whereas in others the neutrophilic progranulocyte was the most frequent granuloid cell (Kondera, 2010). In others still, the eosinophilic granulocyte is the most common granulocyte encountered (Cenini, 1984; Sepulcre et al., 2002; Abdel-Aziz et al., 2010). Using electron microscopy up to three types of granule are recorded in some teleosts such as in the mature neutrophils of sea bass (Mesenguer et al., 1991), whilst one or two granular types have been found in other teleosts (Cannon et al., 1980; Bielek, 1981). However, because electron microscopy was not employed in this study, it was not possible to characterise the nature of the hapuka heterophil granules. The hapuka heterophil granulocyte stained positive for MPO, suggesting a function analogous to that of the mammalian neutrophil. In adult common carp, heterophils showed 
respiratory burst and bactericidal activity to Aeromonas salmonicida (Bielek, 1981). Further studies may further investigate the functional features of hapuka heterophils.

In this study we compared the presence of progenitor cells in juveniles and adults by flow cytometry to characterise the maturity of juvenile leucocyte populations. In the head kidney of tilapia (Oreochromis niloticus) it was observed that granulopoietic series consisted of cells with variable shape and size at different stages of maturity from myeloblasts to mature granulocytes. Maturation of granulocytes was determined by a reduction in cell and nucleus size, with nuclear condensation and the appearance of increased amounts of secondary granules denoting mature granulocytes (Abdel-Aziz et al., 2010). Progenitor cells were detected in juvenile hapuka, morphologically appearing undifferentiated with large nuclei and neutrophilic to basophilic cytoplasm, however their size seemed variable with small and large cells observed. A great variability was observed when MPO staining was conducted, with some small cells showing several granules, others one or two. Generally speaking, progenitor heterophils were identified to be $\mathrm{MPO}^{+}$but had lower amounts of MPO staining in their cytoplasm compared to the mature heterophils seen in adults. Interestingly and in contrast to this, zebrafish and common carp mature heterophils from adults show weaker histochemical peroxidase activity than immature heterophils (Bielek, 1981; Lieschke et al., 2001). In zebrafish, even during the embryonic stage mobilization of these peroxidase-expressing cells was demonstrated to a site of acute inflammation within several hours of traumatisation (Lieschke et al., 2001). Precursor stages of the eosinophil were not discernible in juveniles or adults and no function can be given to the progenitor granulocytes of hapuka.

Eosinophilic granulocytes have been described as being absent or having not been observed in fish blood (Ferguson, 1976; Cannon et al, 1980), but common in the head kidney (Esteban et al, 2000). Also, two types of eosinophilic granulocytes have been observed in some fish (Morrow \& Pulsford, 1980). The eosinophilic granulocytes in hapuka were distinct from other cell types with their pink staining cytoplasm and peripheral non segmented nucleus. Interestingly eosinophils in adult hapuka appeared abundant in adult cytospins, however, no method was employed to distinguish eosinophils from heterophils during flow cytometry and thus determine their relative percentage. Eosinophils were abscent in the juvenile cytospins. In sea bass and zebrafish the heterophil was the most abundant granulocyte type, with a 5:1 heterophil to eosinophil ratio found in zebrafish (Lieschke et al, 2001; Esteban et al, 2000). In 
contrast, in species such as carp and tilapia, eosinophils are the most abundant granulocyte type (Cenini, 1984; Abdel-Aziz et al, 2010). Similarly, in the gilthead sea bream a fellow perciform, the eosinophils (referred to as acidophil) were the most numerous phagocytic cell type in all tissues examined (Sepulcre et al, 2002). Furthermore it has been suggested that gilthead sea bream acidophilic granulocytes are the counterpart of mammalian neutrophilic granulocytes due to their abundance as a circulating form and the staining and histochemical features of their cytoplasmic granules (Sepulcre et al, 2002). It has also been shown that infection of adult zebrafish with Pseudocapillaria tomentosa, a natural nematode pathogen of teleosts, caused marked increases in eosinophil number within the intestine, suggesting a conserved role for eosinophils in the response to helminth infection (Keir et al, 2010). The current study identifies a clear eosinophilic granulocyte cell type in hapuka, but gives no input into its possible function in the immune system.

The term monocyte/macrophage is widely used to refer to a fish blood cell type with phagocytic activity (Morrow \& Pulsford, 1980) or morphological and functional features comparable to those of monocytes from higher vertebrates (Esteban et al, 2000). Macrophages were present in hapuka juveniles and adults morphologically appearing as large cells and a pale blue cytoplasm and an eccentric bilobed nucleus similar to what is seen in other teleosts (Lopez-Ruiz et al 1992; Esteban et al, 2000; Lieschke et al, 2001). Ultrastrucural differences have been observed between monocytes and macrophages in some fish species (Lopez-Ruiz et al 1992; Bielek 1980), however, electron microscopy is needed to give a more accurate account. Lymphocytes were also observed in hapuka adult and juvenile cryospins appearing as small cells with characteristic large darkly stained nucleui which is seen in many species (Esteban et al., 2000; Kondera, 2010). Cells similar to the carp plasma cell were also observed but were rare (Kondera, 2010).

Leucocyte populations (head kidney and PBL) of adult and 127 dph juveniles were compared by FACS analysis to determine juvenile maturity. PBL leucocyte populations between adult and juveniles appeared similar and were not significantly different $(\mathrm{p}>0.05)$. Interestingly comparison of head kidney leucocyte populations between adult and juveniles appeared very different. Juveniles contained very low amounts of granulocytes but high numbers of granulocyte progenitor cells. While adult populations contained large amounts of granulocytes, but small amounts of granulocyte progenitors. Statistical analysis showed that 
each leucocyte population in the juvenile (progenitor, granulocyte, monocytes/macrophage and lymphocyte) was significantly different $(\mathrm{p}<0.05)$ than the respective adult population. These results indicate that juveniles as old as $127 \mathrm{dph}$ do not appear to have mature cell populations, especially in regards to the granulocytes. The lymphocyte populatations between adults and juveniles (134 dph) were also compared with results showing that lymphocyte populations appeared to have similar numbers of $\operatorname{IgM}^{+}$cells, with no significant difference (p $>0.05)$. In PBL populations, it is possible that thrombocytes were indistinguishable from lymphocytes in the flow cytometer data, due to both having similar cytochemical features with a low degree of granularity and complexity. However, head kidney populations do not contain significant numbers of thrombocytes, so are unaffected.

Over all this study showed the presence of heterophilic and eosinophilic granulocytes, lymphocytes, plasma cells, monocytes and monocyte/macrophages in hapuka. Using Giemsa stain, morphology was used to distinguish cell types and MPO stain allowed some characterisation of mature and immature heterophils. The use of electron microscopy would be essential in further characterisation of cell types and give a better overall description. Interestingly juvenile hapuka head kidney leucocyte populataions were significantly different from the adult hapuka head kidney leucocyte populations. It is generally expected that the fish innate immune system is robust and develops early, with the adaptive immune system developing relatively late, especially in marine teleosts (Patel et al., 2009). However, large populations of progenitors and small populations of granulocytes in hapuka juveniles suggests their innate immune system is not mature at this stage (127 dph) and therefore contrasts this belief. The results suggest that the adaptive immune system of hapuka is mature earlier than the innate immune system, which is in stark contrast to what is generally seen in teleost fish (Patel et al., 2009). Additionally, the \% of $\operatorname{IgM}^{+}$lymphocytes in juveniles and adults were not significantly different suggesting that the juvenile adaptive immune system is mature; the relatively early expression of IgM at $9 \mathrm{dph}$ and appearance of $\operatorname{IgM}^{+}$cells in the head kidney at $12 \mathrm{dph}$ further indicate this. However, $\mathrm{T}$ cell populations were not compared due to lack of antibody markers and may have offered different conclusions. 


\section{Chapter 8 - General discussion}

Due to the overfishing of the oceans, aquaculture has become the fastest growing food sector in the world and the New Zealand grouper or hapuka has been proposed as a suitable candidate for aquaculture. High mortality rates in the early larval stages are common in the aquaculture industry for many fish species (Seppola et al., 2009). These mortalities are usually due to opportunistic pathogens present naturally in the water such as bacteria, protozoa and viruses and can cause serious economic losses (Bakopoulos et al, 1997). Immunostimulation and vaccination can provide fish protection from potential pathogens. However, the effectiveness of immunostimulation and vaccination methods used on cultured fish largely depends on the level of maturity of their immune system (Mulero et al., 2007b). Yet no studies have been carried out on the hapuka immune system and so nothing is known about the timing of their immunocompetence. Therefore, this study was conducted with the main purpose of describing the ontogeny of the hapuka immune system. Additionally it is hoped that this study will shed light on several important aspects of hapuka immunity, as well as identify when hapuka larvae have achieved immunocompetence.

The development of the hapuka lymphoid organs followed the same sequence seen in other teleosts such as Atlantic cod, turbot, sea bream, sea bass and channel catfish (Jósefsson and Tatner, 1993; Padros and Crespo, 1996; Breuil et al., 1997; Schrøder et al., 1998; PetrieHanson and Ainsworth, 2001). The head kidney, the major hematopoietic organ in fish, first appeared in hapuka at $4 \mathrm{dph}$, consisting of two renal tubles, but did not appear hematopoietic or lymphopoietic until approximately $12 \mathrm{dph}$. The teleost spleen, which is thought to have roles in antigen presentation and the initiation of adaptive immune responses (Chaves-Pozo et al., 2005), was the next lymphoid organ to appear and was first observed at $16 \mathrm{dph}$. Finally, the thymus which is primarily responsible for T cell maturation (Bowden et al., 2005), was the last lymphoid organ to appear at $20 \mathrm{dph}$ and was populated by thymocytes by $50 \mathrm{dph}$. Together, information gained from the hapuka lymphoid organ ontogeny suggests the organs appear relatively mature as early as $45 \mathrm{dph}$.

The morphological maturation of lymphoid organs as well as the lymphoid cells in them indicates development and increasing maturity of the larvae, but does not necessarily correspond with the maturation of immune function (Tian et al., 2009b). Instead, the 
appearance of Ig-producing cells (IgM ${ }^{+}$cells) may better indicate the functional maturity of the immune system. The distribution of of $\operatorname{IgM}^{+}$cells in the lymphoid tissue of adult fish has been studied in many species such as turbot and carp (Koumans-Van Diepen et al., 1994; Fournier-Betz et al., 2000). However fewer studies have been concerned with the ontogeny of the B lymphocytes and their maturity.

Nevertheless, the ontogeny of B cells studied has been studied in teleost fish species such as Atlantic cod, Atlantic halibut, rainbow trout, sea bass, sea bream and mandarin fish (Breuil et al., 1997; Schrøder et al., 1998; Hanif et al., 2004; Patel et al., 2009; Tian et al., 2009b) and the timing of first appearance varies considerably between the species. In hapuka IgM ${ }^{+}$cells first appeared in the head kidney at $12 \mathrm{dph}$, followed by the spleen at $32 \mathrm{dph}$ and lastly the thymus at $50 \mathrm{dph}$. Interestingly the appearance of $\operatorname{IgM}^{+}$cells in each organ corresponded with a morphological increase in maturation of each organ. The head kidney appeared to have hematopoietic elements at $12 \mathrm{dph}$ the same day $\operatorname{IgM}^{+}$cells appeared, whereas the appearance of primitive sinusoids at $32 \mathrm{dph}$ in the spleen could be the mechanism by which $\operatorname{IgM}^{+}$cells populated this organ.

The IgM heavy chain gene encodes for the isotype determining portion of antibody in fish and the RAG1 gene encodes for the main enzyme responsible for antibody and TCR gene rearrangements. Expression of IgM was first detected at 9 dph in hapuka larvae with increased expression correlating with the growth and maturation of the head kidney. The relatively early expression of IgM in hapuka at $9 \mathrm{dph}$ also coincides with the appearance of $\operatorname{IgM}^{+}$cells in the head kidney 3 days later and suggests that B cells develop and mature in the head kidney. Interestingly, RAG1 expression was not detected in hapuka larvae before the onset of IgM expression (and TCR $\alpha$ TCR $\beta$ expression), which is possibly due to very low level quantities of RAG1 mRNA. Similarly, it is also possible the RAG1 levels stayed low in hapuka until the head kidney and thymus reached a more mature stage (50 dph) when a greater degree of cell maturation took place.

The first detection of $\operatorname{IgM}^{+}$cells does not necessarily correlate with the ability to develop an antibody response to infection. A delay has been observed between the detection of $\operatorname{IgM}^{+}$ cells and functional immunocompetence in both fresh-water and marine fish species (PetrieHanson and Ainsworth, 1999; Dos Santos et al., 2000). For example in carp it was revealed that although surface Ig positive B cells were detectable in 2 week old fish, carp were not 
able to produce plasma cells until 1 month of age (Botham and Manning, 1981). Furthermore when fish are immunised or infected prior to their ability to develop a humoral immune response, a tolerance is produced, indicated by a lack of response to later stimulation (Zapata et al., 1997; Petrie-Hanson and Ainsworth, 1999). Overall the appearance of $\operatorname{IgM}^{+}$cells in each hapuka lymphoid organ coincided with an observed morphological increase in maturity of each respective organ.

Interestingly IgZ expression was detected in hapuka larvae, first appearing $32 \mathrm{dph}$ compared to $9 \mathrm{dph}$ for IgM, and this finding indicates that hapuka possess this newly discovered Ig isotype. An IgZ EST was subsequently sequenced; however, further RACE experiments conducted to obtain the full IgZ sequence were unsuccessful. Nevertheless, a conserved domain of the hapuka IgZ showed close sequence similarity with trout IgT. Although it would be expected that the hapuka IgZ sequence would show closer similarity with a fellow perciforme, the fact that very few studies on IgZ in other teleosts have been carried out must be considered.

Studies into the ontogeny of the $\mathrm{T}$ lymphocytes in teleost fish have been limited due to the limited number of markers available (Zapata et al., 2006). Nevertheless morphological evidence combined with expression of T cell markers such as TCR $\alpha / \operatorname{TCR} \beta$ can confirm the appearance of T cells in the thymus (Willett et al., 1999; Trede et al., 2004). Generally the expression of RAG genes precedes the expression of TCR $\alpha / \mathrm{TCR} \beta$ because RAG genes are involved in the recombination process. The first expression of TCR $\beta$ in hapuka larvae occurred at $32 \mathrm{dph}$ with detectable expression of RAG1 at $50 \mathrm{dph}$. Additionally TCR $\alpha$ expression was not detected in any larval timepoint sampled. In line with these results, the thymic stroma of hapuka appeared mature at $63 \mathrm{dph}$, with many thymocytes visable, although medulla and cortex could not be distinguished; however, not all fish species develop zonation of their thymus (Press and Evensen, 1999) and so this may not reflect lack of the organs maturity. Overall, despite the different approaches used to assess maturity, the ontogeny of $\mathrm{T}$ cells remains uncertain.

The MHCII complex is expressed on professional antigen presenting cells (APCs) such as macrophages, B cells and dendritic cells and thus was used as a marker for APCs. Additionally CSF1R is an accepted marker of macrophages (Clay and Ramakrishnan, 2005) and CSF1R expression was present at $1 \mathrm{dph}$ in hapuka suggesting the presence of one or 
more types of APCs at this early stage, possibly macrophages. Because the head kidney the main hematopoietic organ was not present at this early stage any APCs present arose from a hematopoietic location preceeding the head kidney, possibly from a location similar to what is seen in zebrafish (Mathias et al., 2009). Macrophages in zebrafish were detected at a very early stage (1 dpf) and functioned in eliminating apoptotic corpses, as well as being able to phagocytose and destroy injected bacteria even during the embryonic stage (Herbomel et al., 1999).

Hapuka appear to have the typical leucocyte populations as seen in other teleosts such as heterophilic and eosinophilic granulocytes, lymphocytes, plasma cells, monocytes and monocyte/macrophages. Using Giemsa stain, morphology was used to distinguish cell types and MPO stain allowed some characterisation of mature and immature heterophils. The use of electron microscopy would be essential in further characterisation of cell types and give a better overall description. It is generally expected that the fish cellular immune system is robust and develops early, with the humoral immune system developing relatively late (Zapata et al., 2006). Using flow cytometry, our results contrasted this belief, showing that 127 dph juvenile hapuka had head kidneys with leucocyte populataions significantly different than adults; with the juveniles having a large population of progenitor cells and a small population of granulocytes suggesting their cellular immune system is immature at this stage. Additionally IgM+ cell populations between adults and 134 dph juveniles closely resembled each other suggesting the humoral immune system is mature. However, $\mathrm{T}$ cell populations were not compared due to lack of antibody markers and thus, may offer different conclusions.

The maternal transfer of immunity is of key importance in fish, supplying eggs and larvae with a limited period of possible immunity, while their own lymphoid oragans develop. Especially because fish eggs are released and embryos hatch into a pathogenically hostile environment, at a time when the embryo's immunological capacity is still extremely limited (Mulero et al., 2007b). Transfered Ig's in particular, may be of great importance for early defence against pathogens because of the relatively late appearance of autologous humoral IgM in fish juveniles (Magnadottir et al., 2005) The transfer of maternal immunity has been documented in many fish species (Takemura and Takano, 1997; Hanif et al., 2004; Ellingsen et al., 2005; Løvoll et al., 2007; Wang et al., 2008; Seppola et al., 2009; Wang and Zhang, 2010), however, functional immunity has only been tested in some. In hapuka the maternal 
transfer of complement, lysozyme and IgM were exaimed. It was found that lysozyme and IgM were transferred, while complement did not appear to be. However, only the lytic activity of complement was tested and not the presence of complement molecules. Indeed the expression of C3 mRNA in hapuka larvae was detected from 1 dph despite the lack of lytic activity in hapuka larvae up to $63 \mathrm{dph}$. Although no lytic activity was detected, C3 degradation products can still function as opsonins and anaphylatoxins. These opsonins promote phagocytosis and the expression of participating in this activity. Additionally studies have also suggested that C3 possesses an important function in organogenesis and regeneration of different organs (Mastellos and Lambris, 2002; Kimura et al., 2003).

Lysozyme is an important innate defence parameter and acts on the peptidoglycan layer of bacterial cell walls resulting in the lysis of the bacteria. The maternal transfer of lysozyme has been shown in many fish species (Yousif et al., 1991; Seppola et al., 2009; Wang and Zhang, 2010). Hapuka eggs showed lysozyme activity suggesting its maternal transfer. Lysozyme in eggs is believed to prevent vertical (mother to progeny) transmission of some bacterial pathogens; however, antibacterial function in the eggs of hapuka was not carried out. Purified lysozyme from the eggs of both coho salmon and zebrafish showed antibacterial activity against several fish pathogenic bacteria (Yousif et al., 1991; Wang and Zhang, 2010). Additionally in zebrafish it was shown that the lysozyme-mediated bacteriolysis depended on the complement, and the complement-mediated bactericidal activity can be stimulated by the lysozyme activity (Wang and Zhang, 2010); showing a synergistic role of these maternally transferred proteins. It may be possible that the lysozyme activity in hapuka was derived from the embryos themselves, in order to more accurately confirm the maternal transfer of lysozyme, gene expression studies are needed. It has already been suggested that macrophages are present early in hapuka by the expression of CSF1R and MHCII and the lysozyme activity detected may have derived from these APCs.

As well as innate factors, the transfer of the adaptive immune protein IgM was examined in the eggs of hapuka. It has been speculated that the relatively late arrival of autologous humoral IgM may be, at least to some extent be compensated by maternally derived IgM (Zapata et al, 1997). The transfer of IgM has been reported in many species (Yousif et al., 1995; Breuil et al., 1997; Takemura and Takano, 1997; Picchitti et al., 2001). Similiarily the present study demonstrated that IgM is transferred to the eggs of hapuka. The levels of IgM 
slowly decreased until around $12 \mathrm{dph}$ when levels began to increase again, signalling autologous production of IgM. Again, this finding agrees with the gene expression studies which showed the presence of IgM transcripts at 9 dph amd the IHC studies which found IgM $^{+}$cells $12 \mathrm{dph}$ in the head kidney.

Teleost IgM has been found to exist in multiple forms and tetrameric, trimeric, dimeric and even halfmeric Ig molecules have been recorded (Clem and Mclean, 1975; Lobb and Clem, 1981; Lobb and Clem, 1983). This is due to a unique feature of teleost IgM, the fact that these molecules are not secreted as uniformly disulfide bonded oligomers; but instead various redox forms exist giving rise to multiple IgM isomers (Kaattari et al., 1998). Because the reduced adult hapuka tetramer appeared to have a heavy chain size of $75 \mathrm{kDa}$, we concluded that the heavy chain transferred is also reduced. However it is unknown what, if any function can be attributed to this halfmeric form of IgM, because the antibody paratope or antigen binding site is composed of a variable region from both the heavy and light chain. Studies targeting the light chain of hapuka IgM would shed light on this aspect of maternal immunity; it is possible a monomer was originally transferred, but was reduced due to an unintended mechanism such as experimental method. Overall the transfer of maternal factors is of great importance for larval immunity, because fish are born while their immunological capacity is still extremely limited (Mulero et al., 2007b). The transfer of immune factors to the egg may represent a maternal adaptation to increase offspring viability and improve overall egg quality (Seppola et al., 2009). Even so, since no function has been attributed to the transferred factors in hapuka, further studies should investigate this important aspect.

Overall the hapuka lymphoid organs followed a developmental order similar to what is seen in other teleosts and these organs appear relatively mature by $45 \mathrm{dph}$. $\operatorname{IgM}^{+}$cells were first seen in the head kidney, followed by the spleen, MALT and thymus. The leucocytes of hapuka appear morphologically similar to those seen in other teleosts; however, no function can be attributed to the leucocytes from these studies. B cells appear to differentiate in the head kidney and IgM is expressed relatively early ( $9 \mathrm{dph}$ ). Macrophages appear to be present even earlier with CSF1R and MHCII expression from $1 \mathrm{dph}$; on the other, hand $\mathrm{T}$ cell maturity in hapuka remains uncertain. Maternal transfer of lysozyme and IgM were detected in hapuka eggs, but further studies are needed to infer their functional importance. Maturity of the lymphoid organs combined with the presence of $\operatorname{IgM}^{+}$cells within them, suggest 
hapuka larvae may be immunocompetent around 45 - $50 \mathrm{dph}$, although this is only speculative; Studies into hapuka antibody responses may offer stronger conclusions. Interestingly the head kidney leucocyte populations of hapuka juveniles show significant immaturity when compared with adults, granulocyte populations in particular. This study has uncovered important information about the ontogeny of the hapuka immune system and will help contribute to further studies. 
Table 8.1. Important ontogenic events of the hapuka immune system.

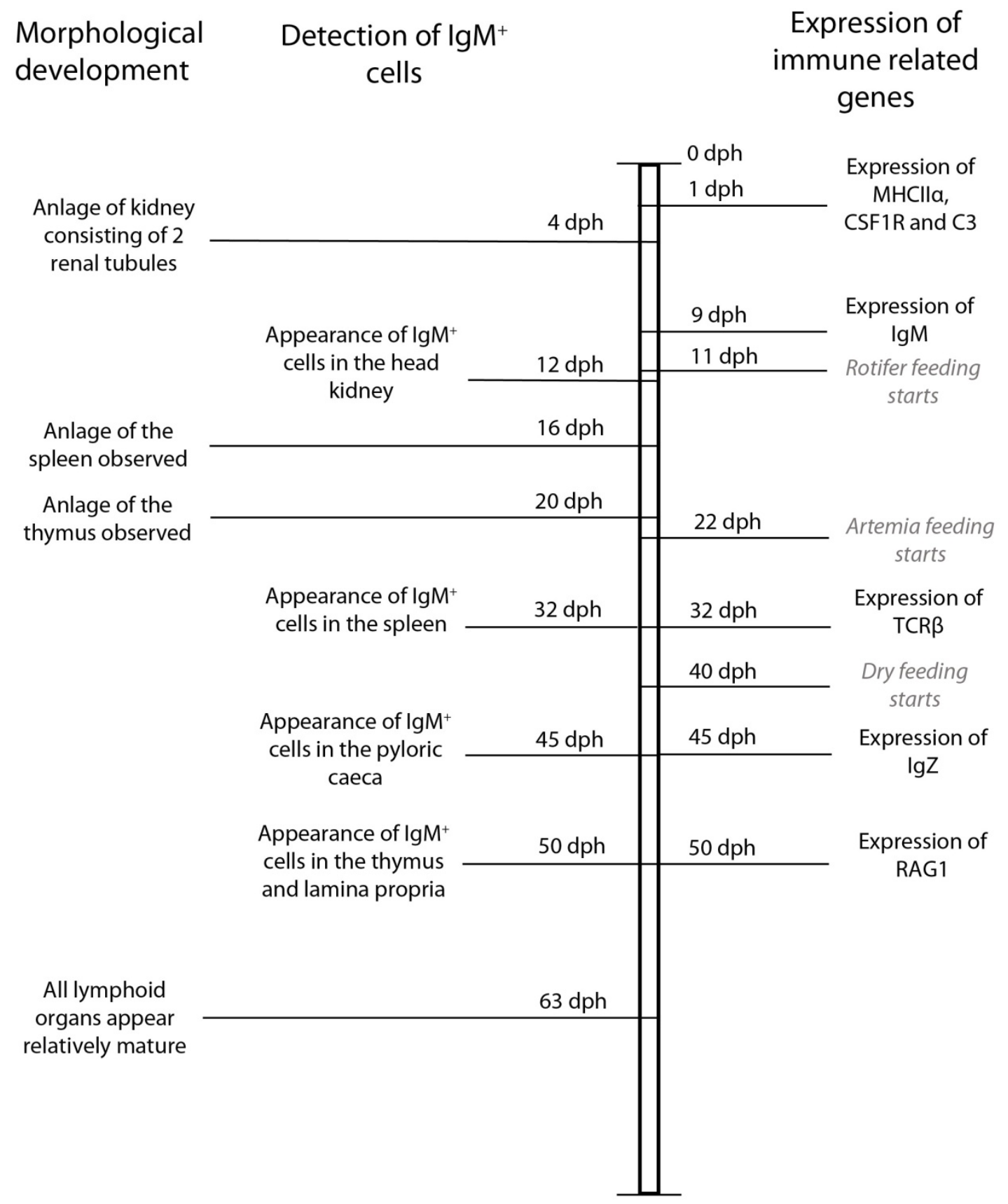




\title{
9.0 Appendix
}

\subsection{Sequence alignments}

\author{
9.1.1. $C 3$ \\ FlounderC3 - - TCCGGAGGAGGATGGGTAGGACTCAACTGTGGCTGCTGGCCTCGCTGGCCTTTGCCT 58 \\ medakac3-1 AGAGCAACGTGAGGATGAGGAGGGCTCTTCAGCTGCTGCTGGCCTCTCTGGCCTTGGTCT $6 \odot$ \\ troutc3
}

FlounderC3 CTATCGCCTCACTGGTTGATGGAGCTCCACTGAAGGTGATGTCTGCCCCGAACTTGTTGC 118 medakac3-1 CCTTGATGTCTCTCATCGATGCTGGACCGCTCAACCTGATGTCTGCCCCTAACCTGCTGC 120 troutc3

FlounderC3 GCGTAGgAACGACAGAAAACATCTTTGTGGAGTGTCAAGACTGCACAGGAGGAGACATTA 178 medakac3-1 GAGTGGGAACACCAGAAAACATTTTTGTTGAATGCCAGGACTGTAGCGGGGCGACCAAC 180 troutc3 - CTTTGTGGAATCTCAgGACCATGTAGGAGgTCCCCTGA 38 AAGTCGATATCAACGTGATGAACCATCCGACCAAGGTCAATAGGTTGGCAACCACATCTG 238 medakac3-1 CGgTCACCATCTCTGTTAAAAACCATCCAACAAAAGCTAAAACACTGGCAACCACACAAG 240 troutc3 ATGTTAAgATCATGgTGAAGAACCACCCTACACAgAgCAAAGAGCTAGCCTCTAAATCAG 98 TGACGCTTACCAGTGGGCAAAACTTCCAGGCACTTGGACAAATAAGGATCCCTGCTGGAG 298 TAACCCTAACCAATGACAATAACTTTCAAGGCTTTGGACAGATTACTATCCCACCTGGAG 300 troutc3 TGGTTCTgGATCAAGCAAACAACTTCCAGGCTATGACACAACTGGTCATCCAGAGGGGAC 158 


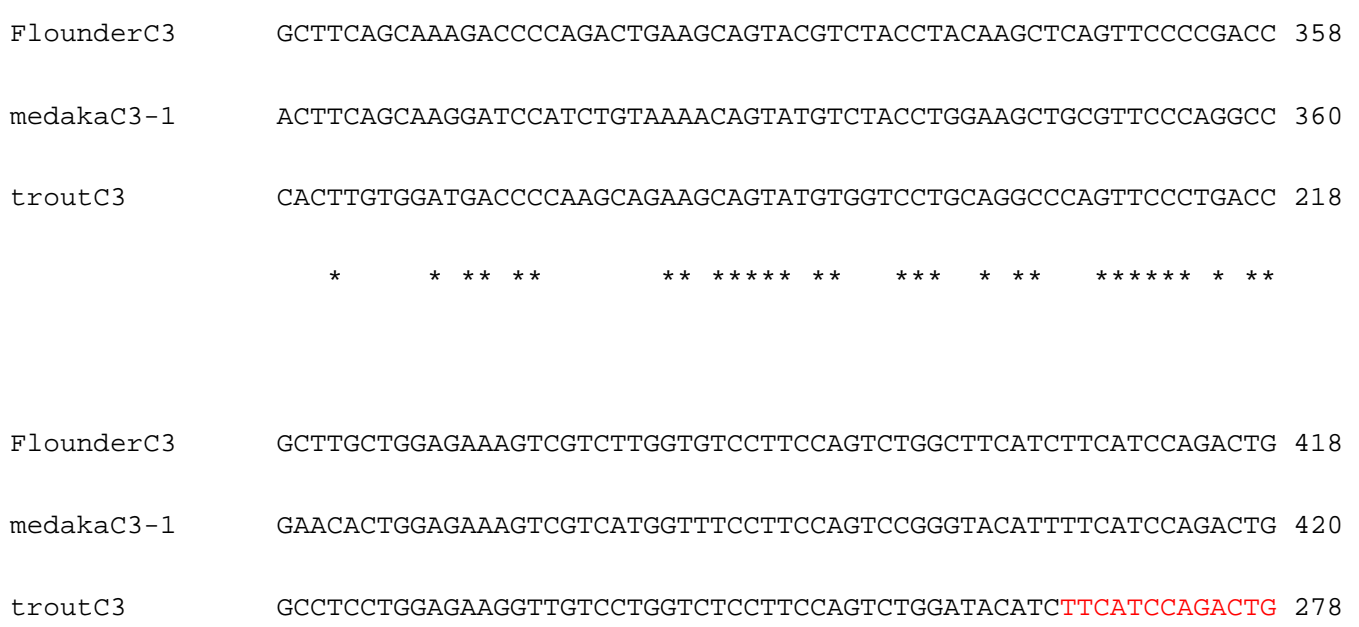


FlounderC3 TTTGGAAAGTCGTGGCTAAGTTCCACAGCAACCCACAGGAGAGCTTCTCTGCAGAGTTCG 700 medakac3-1 TTTGgAAAATGTGGCAAAGTTCCAGAGCAACCCACAGGAGAGCTTCTCTGCAAATTTCG 702 troutc3 CATGGCATGTAGTCACAAGGTTCCAGAGCACACCTCAAAAGACCTTCTCATCTGAATTTG 578 FlounderC3 AgGTCAAAGAATATGTGCTGCCCAGTTTTGAGGTGAAACTGACGTCTACAAGCCCCTTCT 760 medakac3-1 AGgTCAAAGAATATGTGCTCCCCAGCTTTGAGGTCAAGCTCTCTTCTCTGAGACCTTTTT 762 troutC3 AGGTCAAGGAGTATGTTCTGCCCAGCTTCGAGGTTAGTCTGACCCCAGCTAAAGCCTTCT 638 FlounderC3 TCTATGTGGAGAGTGAAGATCTCACCATCAACATCAAAGCTACGTATCTGTTTGGTGAAG 820 medakac3-1 TCTACGTGGACAGTGAGACTTTGGAGATTGACATTAAAGCCAGGTATCTTTTTGGACAAG 822 troutC3 TTTACGTCGACGACAATGACCTGACTGTTGACATCACTGCCAGGTATCTATACGGTAAGG 698 FlounderC3 AGGTGAGTGGCACAGCATACGTGGTATTTGGGGTTGT - - -GCTTGAGGGTGAGAAGAAAA 877 medakac3-1 AAGTGAATGGAAATGCCTATGTTGTGTTTGGGGTCAT - - -GGACCAAGGACAGAAGAAGA 879 troutc3 AAGTGACAGGGACAGGCTATGTGGTGTTTGGTGTCATCACAACAGAGAGCGAGAAAAAGA 758 GCTTCCCCAGCTCTCTTCAGAGAATATCGATCGACAATGGTATCGGGTTGGTCCAACTGA 937 GCTTCCCTGACTCTCTATCTCGAGTGCCGATTGAAAACGGAGAAGGAAAAGTAGTGTTGA 939 troutc3 GTTTCCCTGCCTCTTTGCAGAGAGTAGAGATCAAAGACGGTAAAGGAGTGGCTTGTCTGA 818 

AGAGGGAACAGATCACAAAAACCTTTCAGGATATCAATCAGCTTGTGGGCACCTCCATCT 999 AAAAGGAACACATCACACAGACTTTCCCCAAAATCCATGATCTGGTCAAACAGTCCATCT 878 TTGTTTCTGTTAGCGTGCTGACAGAAAGCGGGAGTGAGATGgTGGAGGCAGAGCTAAGAG 1059 TCGTATCAGTCAGCGTGTTAACAGAGGGTGGGGGTGAAATGGTAGAGGCAGAGAAGAGAG 938 GTATCCAGATTGTCAAATCACCCTACACCATCCACTTCAGGAAAACGCCCAAATATTTCA 1117 GCATCCAAATCGTCAAATCTCCTTACACCATCACCTTTAAAAGAACTCCAAAATATTTTA 1119 troutc3 GGATCCAGATTGTCACTTCGCCATACTCCATCCTCTTCAAGAGAACGCCCAAATACTTCA 998 AACCGGGAATGACCTTCGATATTGTGGTTGAAGTCACAAATCCAGATGAAACTCCAGCAC 1177 medakac3-1 AACCTGGAATGTCCTTTGATGTGGCGGTTGAAGTTTTAAATCCTGATGAAAGTCCAGCAG 1179 troutC3 AACCTGGCATGCCCTTTGACGTCTCTGTTTACATTACAAATCCTGACAACTCTCCAGCCA 1058 AAGGTGTTGCAGTGGTGGTGGATCCAGGTGCTGTGAAGGGTTTAACTGCAGCCAATGGCT 1237 medakac3-1 GGAACATCCCAGTGGTTGTAACTCCTGGTCCTGTAAGGGGCTTTACTGCAGCCAACGGCA 1239 troutc3 TTGGAGTGGAGGTTGAGGTGACTCCAGATCATGCTAAAGGGGTGACCAGGGCCAACGGTT 1118 TTGCAAAGCTTACAGTCAACACAATGGCTGGAGTGGCAAGACTGCCAGTCACTGCTAAGA 1297 medakac3-1 TGGCGCGGCTGACCATCAATACAGCAACACAGGATGAAAGGCTGTCAATCTCTGCAAAGA 1299 troutc3 TTGCAAAAATACCACTTAACACTGTGGCATCAGCCACAGAGCTGGTAATCACAGTGAAGA 1178 
Flounderc3

medakac3-1

troutc3

Flounderc3

medakac3-1

troutc3

Flounderc3

medakac3-1

troutc3

Flounderc3

medakac3-1

troutc3

Flounderc3

medakac3-1

troutc3

Flounderc3
CCAACGATCCTCTTATTCCACT-TGCAAGACAAGCAGAAGCCACCATGACAGCTCTCCCA 1356

CTGATGATCCAGGCATTTCCCT-TAACAGACAAGCCGAAGCCACAATGCAGGCAAACCAG 1358

CCAAGGACCCCGGCGATCCTCGGCAACAGACAGGCGGAGGC-ACCATGAAGGCTCTCCCC 1237

TATAACACTAAAAGCAACAACTACATCCACATAGGAGTGGATACAGCAGAGCTGGAATTA 1416 TACTCTACTAACAGCAAGACTTACATCCATATTGGTGTGGACACGCCTGAGGTCAAATTA 1418 TACAGAACTTCCACCAAGAACTTTCTCCATGTCGGGGTTGACTCTAATGAGCTGAAGATA 1297 ** $* * * * * * * * * * * * * * * * * * * * \quad * * * * * * *$

GGAGATAATCTAAAAGTTAACCTCAACCTAA-AAAAGCAGTCAAATCAAGACACTGACAT 1475 GGTGACAATCTGAAGGTCAACCTGAATCTTA-ACAAGCAACCAGGTGGAAACCAAGACAT 1477 GGAGACCCCATTAAGATTGATCTGAACCTGGGACCCACCACCATACC-AAACCATGACCT 1356 $* * * *$

CACATACCTGATCCTGAGCAGGGGTCAGTTGATCCAAAGTGGTCGTTACAGGACAAGAGG 1535 CACTTATCTGATCACCAGCAGgGGTCAGCTGgTGAAGTTTGGACGTTACAAAACAAGAGG 1537 TACATACATGTTCCTGAGTAGAGGTCAGCTGGTGAAAGTGGGCCGATTTAAAAGACAGGG 1416

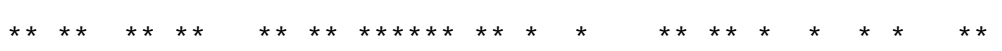
CCAAGTGCTGATTTCCCTGATAATTCCCATCACCAAAGTAATGCTGCCATCATTCCGCAT 1595 CCAAGTGCTGATCTCCCTCATAATTCCCGTTACCCAAGAGATGCTGCCATCTTTCCGGAT 1597 CAACGCGCTGGTAACACTGTCAGTGCCTGTCTCCAAGGAGCTGCTTCCGTCGTTCCGCAT 1476 $* * * * * * * * * * * \quad * * * * \quad * \quad * * * * \quad * * * * * * * * * * * * * * *$ TGTAGCCTACTACCATCTAGATGACAATGAGGTGGTGTCAGATTCCGTATGGGTGGATGT 1655 
medakac3-1

troutc3

Flounderc3

medakac3-1

troutc3

FlounderC3

medakac3-1

troutc3

FlounderC3

medakac3-1

troutc3

Flounderc3

medakac3-1

troutc3

Flounderc3

medakac3-1

troutc3
CATTGCTTTCTACCATCCCAGCGATAATGAAGTGGTGTCAGATTCAGTTTGGGTGGATGT 1657

CGTAGCGTACTACCATGTGGGAGCAGCTGACCTGGTGGCAGACTCTGTCTGGGTTGACAT 1536

CAAGGACTCCTGCATGgGCACATTGAAGCTGGAATCATCAAGACCTGCTCCGTCCTACGA 1715

TAAAGATTCATGCATGGGCTCGCTGACATTGGAGCCAAAGACCCCTGCTGCTTCCTATGA 1717

CAAGgTATCCTGCATGgGATCACTGAAAGTGACATCCACCAGGCCCAAGGCATCCTATGA 1596

$$
* * * * * * * * * * * \quad * * * \quad * * \quad * \quad * \quad * * \quad * * * * * * *
$$

GCCTCGCAAGATGTTTGGTCTGAAAGTCACCGGAGTTCCAGAGGCCATGGTGGGACTGGT 1775

GCCCCGCAAGATGTTTAGTTTAAAGGTCTCTGGAGATCCAGGTGCCACAGTGGGACTGGT 1777

GCCTCGTAGGGCTTTCAGTCTGACCATCACTGGAGACCCGGGAGCGAAAGTAGGACTGGT 1656

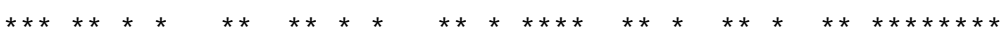

GGCAGTGGACAAAGgTGTCTACGTTCTCAATAACAAGCACCGCATCACCCAGAAAAAGgT 1835

GGCCGTAGACAAAGGTGTTTACGTCCTAAACAGCAAGCACAGACTCACGCAGAAAAAAAT 1837

GGCTGTAGACAAGGGAGTCTACGTTCTGAACAGCAAACACCGTCTCACACAGACCAAGAT 1716

GTGGGACATTATAGAGAAATACGACACAGGCTGCACACCCGGTGGAGGGAAGAACAGTAT 1895

TTGgGATGAGgTGgAGAAGTTTGACACTGgCTGCACTCCTGGTGGAGGGAAGAATGGCTT 1897

CTGGGACACCATAGAGAAGCATGATACAGGCTGTACAGCTGGAGGGgGAGCAGACAATAT 1776

GAGTGTGTTCTACGATGCCGGACTGTTGTTCGAGTCCAGTGCTGCCTCTGGGACTCCCTA 1955

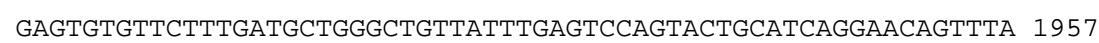

GGGGGTGTTCTACGATGCTGGTCTGGTATTTGAGACCAACACTGCTAAAGGGACTGGGAT 1836

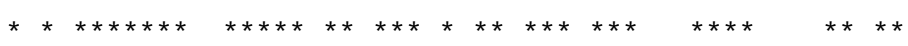




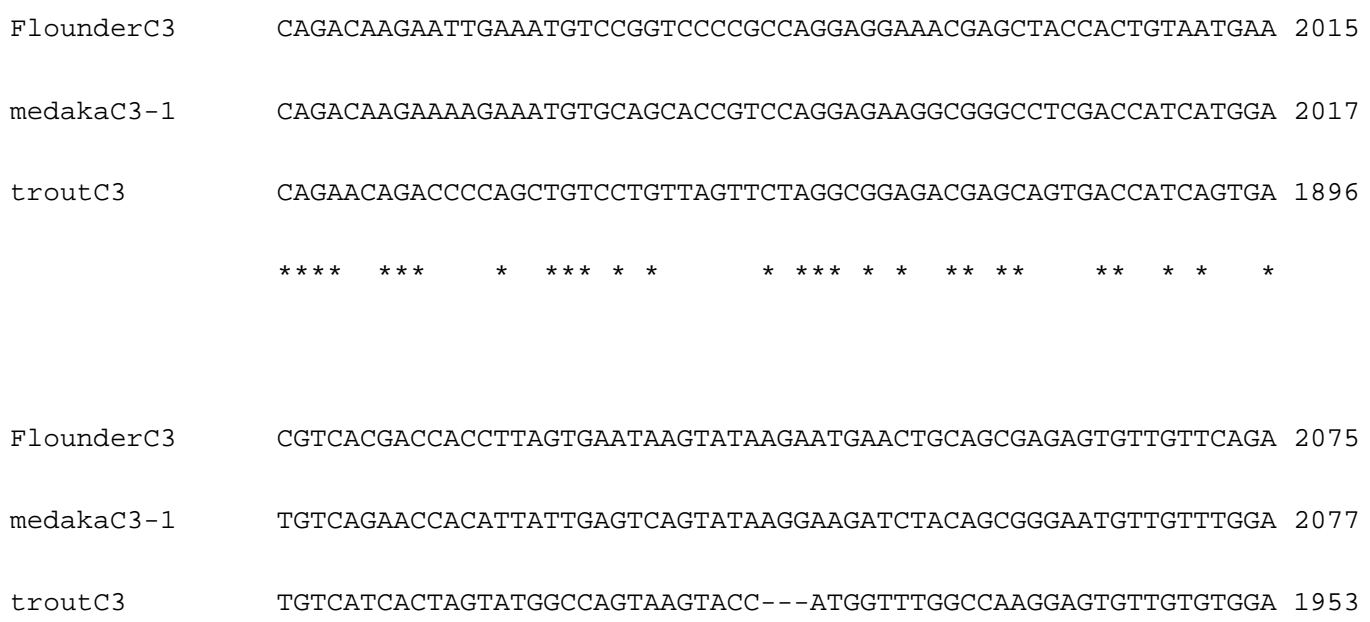


Flounderc3

medakac3-1

troutc3

Flounderc3

medakac3-1

troutc3

Flounderc3

medakac3-1

troutc3

FlounderC3

medakac3-1

troutc3

Flounderc3

medakac3-1

troutc3
GTCAGACATACAACTGCCTGCTTGCCCT - CAACAAACACCCAACTGTGAGTCCACATCAT 2362 GTCCGATATTATTTTGCCACAATGCCCC-CCAAATACACCCAACTGTGGCTCCACTTCAT 2367 GGAGGACACCAATCTTCCTGAATGCCCTGCCCAAAACAAGCA-CTGTGAGTCCACATCTG 2249 ***

TTATGAAGCCAGTTCCTTTGCAAGACTCAATAACAACCTGGCAATTCACTGGCATCAGTC 2422 CTGTGAAAAATGTTCCTCTGCAAGATTCCATCACAACCTGGGAGTTCACCGGCATCAGCC 2427 TAATAAGGAACAACTTCTTAAAGGATTCCATCACCACCTGGCAAATAACAGCCATCAGCC 2309 TGTCAAGAACCCACGGAATCTGCGTTGGAGAACCATTGGAAGTGATCGTAAGGAAGGACT 2482 TCTCAAGAACTCATGGCATCTGTGTGGGAGAGTCACTGGAGGTGATTGTTCGCAAAGACT 2487 TGTCTAAAACTCATGGCATCTGTGTGGCAGATCCGTTTGAGATGATAGTTCTAAAGGAGT 2369 ****

TCTTCATCGATCTCAGACTGCCCTACTCTGCTGTCCGgGGAGAGCAGCTAGAAATTAAGG 2542 TCTTCATAGACCTCCGGCTGCCGTACTCAGCTGTCCGCGGAGAGCAGCTGGAAGTGAAAG 2547 TCTTCATCGACCTCAAGCTGCCCTACTCAGCCGTCCGCAATGAACAGCTGGAGGTCAAAG 2429 $* * * * * * * * * * * *$
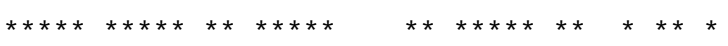

CGATCCTCCACAACTACAGCCCTGACGTTATCACAGTGCGTGTGGATCTGATTGAGGAGG $26 \odot 2$ CCATTCTACACAACTACAGGCCAGAGCTCATAACCGTTCGTATAGATCTAGCCGAAGAAA 2607 CAATCCTCCACAACTACAGCGAAGACCCCATCATTGTGCGTGTGGAGCTGATGGAGAACG 2489 

CCATGTCCACAAGATCTGTTCCCTTCATCATTATTCCCATGAAGGAGGGGACTCTTCCCA 2727 CCATGTCCACCCGGGTTGTCCCCTATGTCATCATCCCTATGAAGCTGGGCTTGCACTCCA 2609 TTGAGGTCAAAGCAGCTGTTAAAGACTCATCACTCAATGATGGAATCGTGAAGGTGCTGC 2782 TCGAGGTCAAAGCTGCTGTCAAAGACTCGTACCTGAGTGATGGAGTGAAGAAAGACCTGC 2787 TTGAGGTCAAGGCATCTGTGAAAAACTCTGGCAGCAATGACGGGGTGAAGAGGGATCTGC 2669 GGGTGGTGCCTGAAGGTGTACTGATTAAACAACCACAGATTATAACACTAGACCCCTCTA 2842 medakac3-1 GGGTGGTTCCTCCAGGAGTTCTGGTTAAAGCTATAGAATCTACAATCTTGGATCCAGCTC 2847 troutC3 GTGTTGTGGCTGAGGGAGTGCTGGTCAAGAAGGAAACCAACGTACTCCTGAACCCAGTTA 2729 AAACAGGA - - - - - GGTGAACAGGTGGAAATTCTCAACAGTAGAATCCCCAGGAAAGATA 2896 medakac3-1 ATAAGGGGAAAAACGGTGAACAAGTGGAAGTTCTGAACAGCAACATTCCCAAAAGTAATT 2907 troutc3 AACATGGT - - - - - - GGTGAGCAGACGTCACACATACCCAGTGGAGTGCCCCGAAACCA - - 2781

FlounderC3 TGGTTCCAAACACACCTACTACCACACAGATTTCTGTGACAGGGAGGGAAAACGTTGGTC 2956 medakac3-1 TTATTCCAAGCTCACCAACAAGCACTCAGATCTCATTGACAGGCCGAGAACAAGTTTCTG 2967 troutc3 -GGTGCCAAACTCTGATGCTGACACACTGATCAGTGTGACAGCTGGAGAGCAGACCAGTG 2840 
Flounderc3

medakac3-1

troutc3

Flounderc3

medakac3-1

troutc3

Flounderc3

medakac3-1

troutc3

Flounderc3

medakac3-1

troutc3

Flounderc3

medakac3-1

troutc3

Flounderc3
AACTGGTAGAGAACGCAATTAGTGGGCAATCGATGGGTACCCTGATCTACCAGCCATCAG 3016 GACTGGTGGAAAATGCCATCAGTGGAAAGTCAATGGGTACTCTGATTTATCAGCCCTCTG 3027 TGCTGGTGGAGCAGGCCATCAGTGGAGACTCTCTGGGCAGTCTGATAGTTCAGCCAGTCG 2900 GTTGCGGAGAGCAGAACATGATTCACATGACCCTGCCCGTCATTGCAGCCACGTATTTGG 3076 GTTGTGGAGAGCAGAACATGATCCACATGACCCTACCTGTCATTGCAACCATATATTTGG 3087 GGTGTGGGGAACAGAACATGATCTACATGACCCTGCCTGTCATTGCTACACACTACTTGG 2960

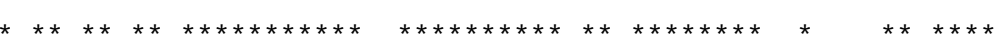
ACAAAACCAACCAGTGGGAGACTGTGGGCTTTCAGAAACGAAATGAAGCCCTCCAGCATA 3136 ACAAAACCAACCAATGGGAAGCCGTTGGCTTTCAGAAACGGGCTGAGGCCCTTCAGCACA 3147 ACAACACCAAAAAGTGGGAGGATATTGGCCTGGACAAACGGAACACAGCCATCAAGTACA 3020

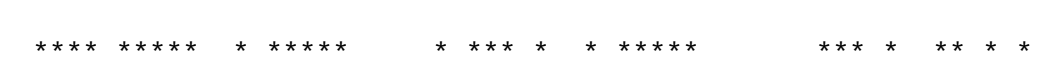

TCAAGACCGGCTACACGAACGAGCTTGCCTACCGTAAAAAAGATGGATCTTTTAGTGTGT 3196 TAAAAACAGGCTACACCAACGAACTAGCCTACCTAAAAGGCGACGGCTCTTTTGCTGTAT 3207 TCAACATTGGTTACCAACGTCAGCTGGCCTATCGTAAAGAAGATGGCTCCTATGCTGCCT 3080 $\star \star * * * * * * *$ GGGCCTCTCACGGAAGCAGCAGCTGGCTGACAGCGTACGTTGCCAAGGTGTTCGCCATGG 3256 GGGCTGATCATGGAAGCAGCTCCTGGTTAACAGCATATGTTATTAAAGTGTTTTCCATGG 3267 GGGTCAGCAGACAGAGCAGCACCTGGCTGACAGCATACGTGGTGAAGGTGTTTGCCATGT 3140 *** CTAACAGTCTGGTGGCAGTGCAGAACAACGTGATCTGTGACGCTGTTAAGTACCTGATTC 3316 
medakac3-1

troutc3

Flounderc3

medakac3-1

troutc3

FlounderC3

medakac3-1

troutc3

FlounderC3

medakac3-1

troutc3

Flounderc3

medakac3-1

troutc3

Flounderc3

medakac3-1

troutc3
CCAACAACCTGGTGGCCATCAAAAAGGAACACATTTGTGATGCTGTGAAGTTCCTGATAC 3327 CCAGTACATTAATCAGTGTTCAGGAAATGTGCTCTGTACTGCTGTCAAGTGGCTGATCC 3200 TCAACGCGCAGCAACCCGACGGCGTGTTCAAAGAAGTTGGAAGGGTGGCCCACGGAGAGA 3376 TCAGAGCTCAGCAGCCCGATGGCTTGTTCACAGAAACTGGAAAAATGTACCATGGAGAGA 3387 TGAACACACAACAGCCAGATGGCATCTTCAATGAGTTTGCTCCTGTCATTCATGCAGAGA 3260 TGATTGGTGATGTGCGCGGCACAGATTCAGAGGCCTCCATGACAGCCTTCTGCCTCATCG 3436 TGATTGGTGATGTCCGTGGCTCTGACTCTGATGCCTCTATGACAGCGTTCTGCCTCATTG 3447 TGACGgGTAACGTGAGGgGATCAGACAATGACGCCTCCATGACAGCTTTTGTTCTCATCG 3320 $* * * \quad * * * * * \quad * * * \quad * * * \quad * * * * * * * * * * * * * * * * \quad * * * * * *$ CCATGCAGGAGTCACGGACTCTATGTGCTGCGACTGTTAATAGTCTTCCAGGCAGTGTAG 3496 CCATGCAGGAGTCACGCTCGCTCTGTTCAGCCACTGTCAATACCCTGCCAGGCAGCATTG 3507 CCATGCAGGAAGCAAGCTCAGTGTGTGAGCAGTCTGTCAACAGCCTACCAGGCAGTATGG 3380 AAAAATCGgTgTTATACCTgGAGAggCGTTTgGAAAGCCTCACCAACCCATATGCTgTTG 3556 ACAAGGCAGTTGCCTACCTGgAGAAACGACTTCCCAGACTTACAAATCCTTACGCTGTTG 3567 CTAAGGCAGTAGCGTACCTCGAGAAGCGTCTGCCCCACCTGACTAACCCTTATGCTGTAG 3440 CAATAACATCGTACGCCTTGGCCAACGAAGGCAGACTGAACAAAGATGTCCTCTACAAGT 3616 CCATGACATCATATGCTCTGgCTAATGAgGGAAAACTAAACCGCGATATTCTCTACAAGT 3627 CTATGACCTCCTATGCTCTGGCCAATGCAGGGAAACTCAACAAGGAGACCCTACTGAAGT 3500 


\begin{abstract}
FlounderC3 TCGCTTCTCCAGAGCTGTCCCACTGGCCTGTACCTAAGGGTCGTGTTTACACACTGGAGG 3676 medakac3-1 TTGTTTCTCCAGAGTTGACCCACTGGCCTGTTCCTGGAAAGCACCTCTTTACCCTTGAGG 3687 troutc3 TCGCCTCTCCACAGCTGGACCACTGGCCAGTCCCTGGTGGTTACCAGTACACGCTGGAGG 3560 FlounderC3 CCACAGCTTACGCACTTCTGGCTCTGGTCAAGACCAAGGACTTTGAAAAAGCCCGACCTA 3736 medakac3-1 CCACAGCTTATGCTCTTCTGGCTTTGgTCAAGACCAAGTCTTTTGAAGATGCCAGACCTG 3747 troutc3 CCACGTCGTACGCCCTGCTTGCTCTGGTCAAGGTGAAGGCCTTCGAAGAGGCCGGCCCCA 3620
\end{abstract} FlounderC3 TTGTGAGATGGTTCAGCCAACAGCAGAAGGTGGGCGGAGGATATGGCTCAACTCAGGCTA 3796 medakaC3-1 TTGTGAGATGGTTCAACCAGCAGCAGTTTGTTGGTGGGGGTTATGGATCCACCCAGGCTA 3807 troutc3 TAGTCAGGTGGCTCAACAAGCAGAAGAAGGTGGGAGGGGGATACGGATCCACACAGTCCA 3680 FlounderC3 CCATTATAGTGTACCAGGCTGTAGCAGAGTACTGGGCCGCTGCTAAAGAACC - - AGAGT 3853 medakaC3-1 CAATAATTGTGTACCAGGCTGTAGCAGAGTACTGGGCCAATGCTCAAGAACC - - AGAGT 3864 troutc3 CCATCATGGTGTTCCAGGCTGTGGCTGAGTATTGGAGCCACGTGAAGGACCTGAAAGACT 3740 FlounderC3 ACGATCTGAATGTGGACATCTTGTTGCCAGGCAGGTCAAAGCCTGAAAAGATTGTCCTCA 3913 medakac3-1 ATGATCTGAAAGTGGATATCTTGTTGCCAGGCAAATCAAAGCCTGACAAATATGAATTCA 3924 troutc3 TTGACTTGAACATCAACCTAGAGGTGGCCGGCAGGGCATCAGTCACCAAGTGGTCCATCA 3800 FlounderC3 ACGCGGACAACAGCTATACCACAAGAACATCTAAAATCAATGATATAAACCAGGATGTGA 3973 medakac3-1 ACCGTGAAAACAGCTATGCTACAAGAACCTCTAAAATCAAAGACATAAACAAAGATATAA 3984 

AAGTGACTGCCAAAGGAACAGGAGAAGCAACAGTGACAATGGTGTCGCTGTATTATGCTC 4033 AAGTGAAGGCTACTGGATCGGGAGAAGCTGTTCTCAAAATGGTGTCCTTGTACTATGCTC $4 \odot 44$ CTGTAAAAGCCTCAGGAAATGGTGAGGCGACCTTGTCGGTGGTGACACTGTACTATGCCC 3920 TACCTCAAAAGAAGGAGAGCGACTGTCAGAAGTTCAACATGTCAGTGGAGCTTATCCCAG 4093 medakac3-1 TGCCTGAAGAAAAGGAAAGTGACTGCCAGAAGTTTGACGTGTCAGTGCAGCTGCTTCCAG 4104 troutc3 TGCCAGAGGAAAAGGACAGTGACTGTGAAAGCTTTGACCTCTCTGT-CACCCTCACTAAG 3979 AAAGG - - - - - - ATTGATGCAGATG - - AGAGTATATTTAAGCTGAAAATAGAGGTTTTA 4143 CTAAG - - - - - - AATATTGGGAATC - - AAAAGGTCTACAAGCTTCAGATAGAGGTTTTA 4154 troutc3 ATGGACAAAACAAGTCACGAGGACGCCAAGGAGTCATTTATGCTGACTATTGAGGTGTTG 4039 TATAAGGACAAGGAGCGTGATGCGACCATGTCGATCTTGGATATCGGTTTGCTGACTGGC 4203 medakac3-1 TACAAGGACAGCAATCGTGATGCCACCATGTCTATCTTAGACATCGGTTTGCAGACAGGC 4214 troutc3 TATAAGAACTCAGAGAGAGATGCGACCATGTCTATTCTGGACATCGGCTTGCTGACCGGC 4099 TTCACCCCCAACACTAATGACTTGAACTTATTGTCTAAAGGACGTGCCAGGACTCTTGCA 4263 TTCACTCCCAACTTAGATGACCTAAAAGCTCTGTCTGGAGGGCGATTTCCCCTCATTAGC 4274 troutc3 TTCATTGTGGACACAGACGATCTGAATCAGTTGTCCAAGGGGAGGGAGCGCTACATAGAG 4159 

ATTTCTCACACCCGACCAGAGGAGATCAGTTTCAGGGTCCAGCAGACCATGGAGGTGGGC 4394 GTGTCTCATAAGTTAGAAGACAGAATATCCTTTAAGATCCACAGAGTACAGGAAGTGGGA 4279

GTCTTACAGCCAGCGGCCGTTTCTGTCTATGAATATTATGACCAAACACAGTGTGTGCAG 4443 GTTCTTCAGCCTGCAGCAGTGTCTGTCTATGAATATTATGAGCAAACACCTTGTGTGAAG 4454 GTTCTTCAGCCAGCTGCCGTCTCTGTATATGAATACTACAACCAGAAGCGCTGTGTGAAG 4339

TTCTATCACCCACAGAGGAAAGCTGGACAGCTACTGAGGCTCTGCAGAAATGAGGAGTGC 4503 TTTTACCATCCAGAGAGGGAGGGAGGACAGCTGCTGAAGCTCTGCAAAGATGACGAGTGC 4514 troutC3 TTCTACCACCCACAGAGGGAGGGTGGTACTCTGAGCAGACTGTGTCTTGGAGACGTGTGC 4399 ACATGTGCTGAAGAGAACTGCAGTATGCAGAAGAAGGGCAAGATCAGCAATGATCAGCGC 4563 medakac3-1 ACATGTGCAGAAGAGAACTGCAGCATGCAGAAGAATGGTCAAATCAGCAACGATGAGCGA 4574 troutc3 ACGTGTGCGGAAGAGAGCTGCAGTATGCAGAAGAAAGGTGAG - CCAG - -ATGTCCAACGC 4456 ATAGAAAAATCTTGTGAGACTACACCGACCAGTAAAATAGATTTTGTGTACAAAGTGAGA 4623 ACATCTAAAATCTGTGAGAGCACAGAGAGCAGCAAAATTGAATATGCGTACAAAGTTCTG 4634 troutc3 ATTGACAAAGCTTGCG -GCGCGGGACTGGATTACGTTTACAAAGCCACG 4504 
Flounderc3

medakac3-1

troutc3

Flounderc3

medakac3-1

troutc3

Flounderc3

medakac3-1

troutc3

Flounderc3

medakac3-1

troutc3

Flounderc3

medakac3-1

troutc3

Flounderc3
CTGGAGGAATTCACAGACGGTGGGTCTACTGACATTTACACAATGCGGATATTGGAAGG 4683 GTGGAAGATGTTGTCCAAAAACCGTCTATAGACATCTATGCCATGCGGGTGCAGGACTCC 4694 GTGGTGGACTCGAAGCTGACCACACACACAGATACTTACACCGTGAAGATC - - -GATTTG 4561 $* * * \quad * *$ ATCAAAGAAGGAAGTTACGATGTGGCTCCTCAGGGGAAACTGCGCACATTCCTGAGTTAT 4743 ATCAAAGAAGGAAGTACAGATGTTGGCCCCAGgGGAAACTGCGGCCATTCCTCAGTTAT 4754 GTCATCAAGCCAGGTACTGACGAGGGAGTGGAGGGGAAGAATCGTGACTTCATGGGACTG 4621 *** $\quad * \quad * * * \quad * * * *$ CAACACTGCAGGGAGTCTTTAGATCTGGGCAAAGGCAAAATGTACCTCATCATGGGCACA 4803 CCCCATTGCAGAGATGCTTTGAATCTGCAGAAAGGTAAAACATACCTGATCATGGGATCA 4814 GCTTACTGTAGAGAAGCTCTGGGTCTAATGCAGGGGAAAACATACATGATTATGGGGAAG 4681 TCAAAAGATATTCACAGAG - - - - - - ATGACCAAAATGAATCGTATCATTATGTGCTTGGG 4857 TCCAGAGACATTCACAAAG - - - - - ATGAAAAACAGCTCACATATCAGTACGTCCTTGGA 4868 TCTGAAGACCTGCACAGAGTGGAGGATAAAGGACTGTTGCAGTACAAGTATGTCCTTGGA 4741 ** $\quad * * * \quad * * * * * *$ GAGAGAACCTGGATCGAGTACTGGCCCACAGAAGCTGAGTGTCAAACCGAGGAGCACAGA 4917 GAGAGAACTTGGATTGAGTATTGGCCAACAGCAGAGGAGTGTCAAGGGGATGAACACAGA 4928 GAACAGACATGGATTGAGTACTGGCCCTCACAACAAGAGTGCACATCCAGAGACTACAGA 4801 ** CCAACTTGTTTGGGCTTGCAGCAGATGgTCCAGCAGTACTTGCTCTTTGGATGTCAGCAG 4977 
medakac3-1

troutc3

Flounderc3

medakac3-1

troutc3

FlounderC3

medakac3-1

troutc3

hippoglc3

FlounderC3

medakac3-1

troutc3

hippoglc3

FlounderC3

medakac3-1

troutc3

hippoglc3

Flounderc3
GCCACATGCCTGGGCTTAGATGAGATGCTAGAGCAGTTCAGAGTGTTTGCATGTCAGCAA 4988 GAAGTCTGTCTGgGCATTGATGAGTTCATCAACCAGATCACAACCTTCGGCTGCCCAGTT 4861 TAGTGTAACTC - - - gAGAGAAAACTGTCCATTTCAAATTGGTTTTATTTTTTGCATTACC 5034 TAAAGAAA - . - . - - - GAAAAAACTTCTCCTTT - . - - TTGTTTTTTCTGGTAAAAGATG 5035 TAGTTTCTCTTCTTGCTTTGTTAATGTACATTTTTG - - TAACATTGCAATCCAGGTTGCA 4919 **

TTTGTTAT-GTAAAACTTTCTCTGCTATGAGATGTGAAGGATTTAGAGGTTACTACATGC 5093 TGTGCAGA - ATAAAATGTACCAACCTAAAAAAAAAAAAAAAAAAAAA - . - . - . - . 5082 TGCCCTGTCATAACTCATTGTAACCTAT-AGAGATTATGGAGATGAGTTTGCCCACTTGG 4978 10 TTGGTGATGTGCGCGGCACAGATTCAGAGGCCTCCATGACAGCCTTCTGCCTCATCGCCA 3439 TTGGTGATGTCCGTGGCTCTGACTCTGATGCCTCTATGACAGCGTTCTGCCTCATTGCCA 3450 CGGGTAACGTGAGGGGATCAGACAATGACGCCTCCATGACAGCTTTTGTTCTCATCGCCA 3323 $* * * * * * * * *$ TGCAGgAGTCACGgACTCTATGTGCTGCCACTGTTAGTAGTCTTCCAGGCAGTGTAGACA 70 TGCAGGAGTCACGGACTCTATGTGCTGCGACTGTTAATAGTCTTCCAGGCAGTGTAGAAA 3499 TGCAGGAGTCACGCTCGCTCTGTTCAGCCACTGTCAATACCCTGCCAGGCAGCATTGACA 3510 TGCAGGAAGCAAGCTCAGTGTGTGAGCAGTCTGTCAACAGCCTACCAGGCAGTATGGCTA 3383 $\star \star \star \star \star \star \star * ⿻ 一 𠃋 十$ $\star \star \star \star * *$ $* * * * * * * * * * * * * * \quad * * \quad *$ AAGCGgTGCAGTACCTGGAGAGGCGTTTGGACAGCCTCACCAACCCATATGCTGTTGCCA 130 AATCGgTGTTATACCTGGAGAGgCGTTTGgAAAGCCTCACCAACCCATATGCTGTTGCAA 3559 
medakac3-1

troutc3

hippoglc3

FlounderC3

medakac3-1

troutc3

hippoglc3

Flounderc3

medakac3-1

troutc3

hippoglc3

FlounderC3

medakac3-1

troutc3

hippoglc3

Flounderc3

medakac3-1

troutc3
AGGCAGTTGCCTACCTGGAGAAACGACTTCCCAGACTTACAAATCCTTACGCTGTTGCCA 3570

AGGCAGTAGCGTACCTCGAGAAGCGTCTGCCCCACCTGACTAACCCTTATGCTGTAGCTA 3443

TGACATCGTACGCCTTGGCCAACGAAGGCAAACTGAACCAAGAAGTCCTCTTCAAGTTCG 190 TAACATCGTACGCCTTGGCCAACGAAGGCAGACTGAACAAAGATGTCCTCTACAAGTTCG 3619 TGACATCATATGCTCTGGCTAATGAGgGAAAACTAAACCGCGATATTCTCTACAAGTTTG 3630 TGACCTCCTATGCTCTGgCCAATGCAGgGAAACTCAACAAGGAGACCCTACTGAAGTTCG 3503

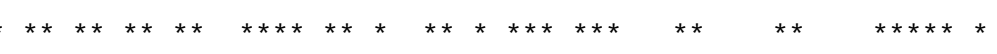
стTCTCCAGAGCTGTCCCACTgGCCGTCACCTAAgGGACGTATTTACACACTGGAGgCCA 250 CTTCTCCAGAGCTGTCCCACTGGCCTGTACCTAAGGGTCGTGTTTACACACTGGAGGCCA 3679 TTTCTCCAGAgTTGACCCACTgGCCTGTTCCTGGAAAGCACCTCTTTACCCTTGAgGCCA 3690 сСтстсСАCAGCTGGACCACTGGCCAGTCCCTGGTGGTTACCAGTACACGCTGGAGGCCA 3563 CAGCTTACGCTCTTCTgGCTCTgGTCAAgGTCGgGGCCTTCGAAGAAGCCCGACCTATTG 310 CAGCTTACGCACTTCTGGCTCTGGTCAAGACCAAGGACTTTGAAAAAGCCCGACCTATTG 3739 CAgCTTATGCTCTTCTgGCTTTGgtCAAGACCAAGTCTTTTGAAGATGCCAGACCTGTTG 3750 CGTCGTACGCCCTGCTTGCTCTGgTCAAGGTGAAGGCCTTCGAAGAGGCCGGCCCCATAG 3623

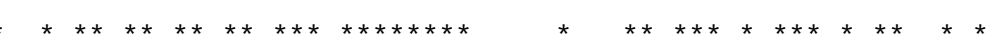

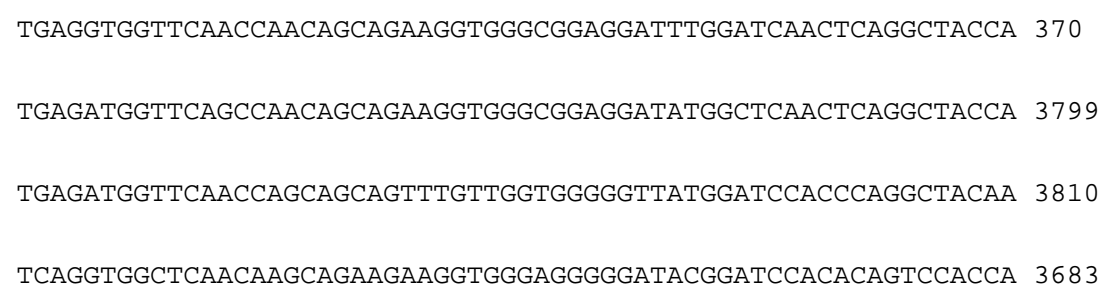

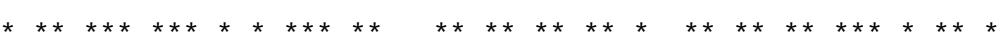




\begin{abstract}
hippoglc3 TCATAGTGTACCAGGCTGTAGCAGAGTACTGGGCCAGTGCTAAAGAACC- - -AGAATACG 427
FlounderC3 TTATAGTGTACCAGGCTGTAGCAGAGTACTGGGCCGCTGCTAAAGAACC - - AgAGTACG 3856 medakac3-1 TAATTGTGTACCAGGCTGTAGCAGAGTACTGGGCCAATGCTCAAGAACC - - AgAGTATG 3867 troutc3 TCATGGTGTTCCAGGCTGTGGCTGAGTATTGGAGCCACGTGAAGGACCTGAAAGACTTTG 3743
\end{abstract} hippoglC3 ATCTGAATGTGGATATCTTGTTGCCGGGCAGGTCAAAGCCTGAAAAGTTTATTCTGAACG 487 FlounderC3 ATCTGAATGTGGACATCTTGTTGCCAGGCAGGTCAAAGCCTGAAAAGATTGTCCTCAACG 3916 medakac3-1 ATCTGAAAGTGGATATCTTGTTGCCAGGCAAATCAAAGCCTGACAAATATGAATTCAACC 3927 troutc3 ACTTGAACATCAACCTAGAGGTGGCCGGCAGGGCATCAGTCACCAAGTGGTCCATCAACA 3803 hippoglc3 AgGAAAAGTCTATACCACAAGAACATCTAAAATCAGGGGTTAAGCCAGGATGTGAAAG 547 FlounderC3 CGGACAACAGCTATACCACAAGAACATCTAAAATCAATGATATAAACCAGGATGTGAAAG 3976 medakac3-1 GTGAAACAGCTATGCTACAAGAACCTCTAAAATCAAAGACATAAACAAAGATATAAAA 3987 troutc3 ACAAGAACCAGTTCCACACTCGTACAGACAAGGTCAACTCCATTGACAAGGACTTGACTG 3863 hippoglc3 TTACTGCCACGgGATCCGGAGAGGCAACAGTGACAATGGTTTCGCTGTATTATGCTCTAC 607 FlounderC3 TGACTGCCAAAGGAACAGGAGAAGCAACAGTGACAATGGTGTCGCTGTATTATGCTCTAC 4036 medakac3-1 TGAAGGCTACTGGATCGgGAGAAGCTGTTCTCAAAATGGTGTCCTTGTACTATGCTCTGC 4047 troutC3 TAAAGCCTCAGGAAATGGTGAGGCGACCTTGTCGGTGGTGACACTGTACTATGCCCTGC 3923 $* * * * \quad * * * \quad * * * * * \quad * \quad * * * * * * * * * * * * * * *$
hippoglc3

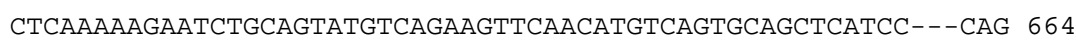
FlounderC3 CTCAAAAGAAgGAGAGCGACTGTCAGAAGTTCAACATGTCAGTGGAGCTTATCC----CAG 4093 medakac3-1 CTGAAGAAAAGGAAGTGACTGCCAGAAGTTTGACGTGTCAGTGCAGCTGCTTC - - -CAG 4104 troutc3 CAGAGGAAAAGGACAGTGACTGTGAAAGCTTTGACCTCTCTGTCACCCTCACTAAGATGG 3983 


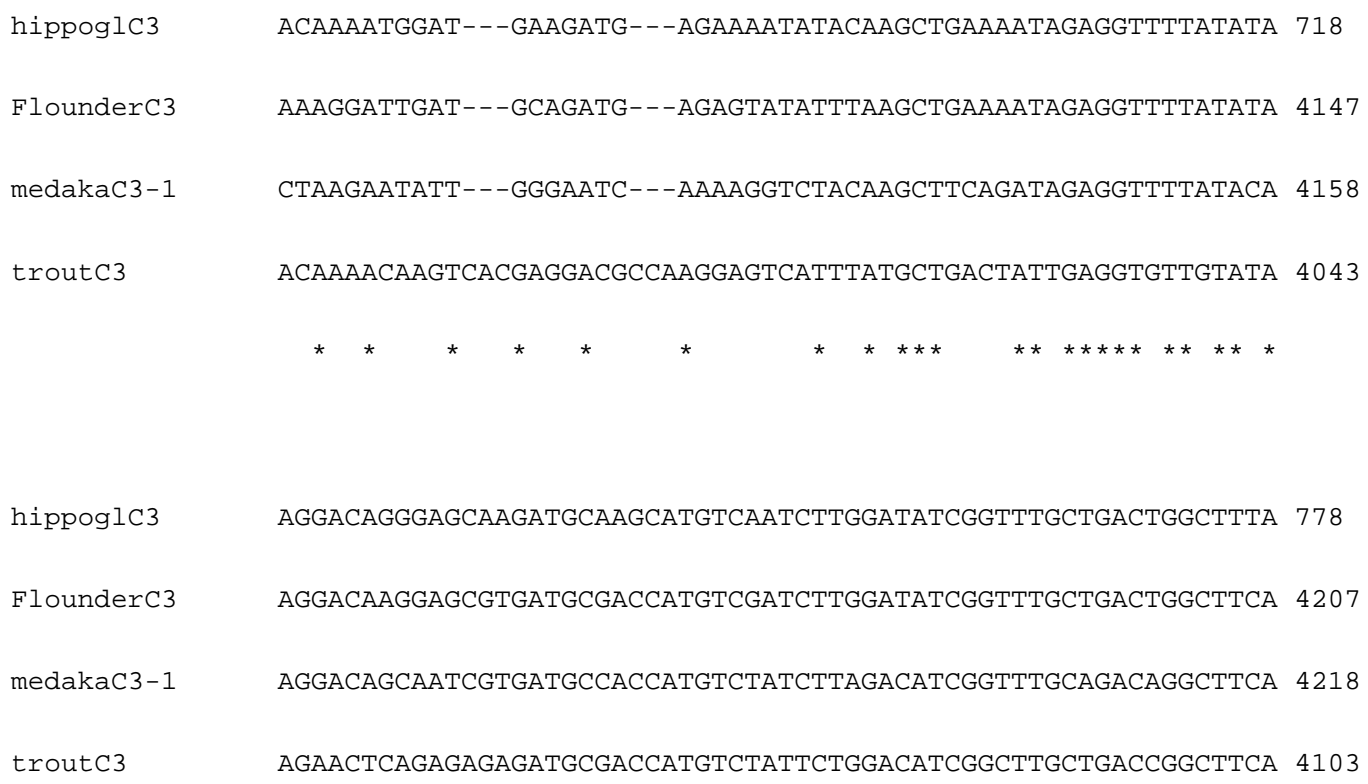


medakac3-1

troutc3

hippoglc3

FlounderC3

medakac3-1

troutc3

hippoglc3

Flounderc3

medakac3-1

troutc3

hippoglc3

FlounderC3

medakac3-1

troutc3

hippoglc3

Flounderc3

medakac3-1

troutc3

CTCACACCCGACCAGAGGAGATCAGTTTCAGGGTCCAGCAGACCATGGAGGTGGGCGTTC 4398 CTCATAAGTTAGAAGACAGAATATCCTTTAAGATCCACAGAGTACAGGAAGTGGGAGTTC 4283 TACAgCCAGCCACTGTTTCTGTCTATGAATATTATGACCAGAGACATTGTGTGAAATTCT 1018 TACAGCCAGCGGCCGTTTCTGTCTATGAATATTATGACCAAACACAGTGTGTGCAGTTCT 4447 TTCAGCCTGCAGCAgTGTCTGTCTATGAATATTATGAGCAAACACCTTGTGTGAAGTTTT 4458 TTCAGCCAGCTGCCGTCTCTGTATATGAATACTACAACCAGAAGCGCTGTGTGAAGTTCT 4343

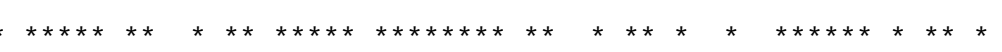
ATCATCCAGAGAGGAAAGCTGGACAGCTCATGAGGCTCTGCAGAAATGATGAGTGCACAT 1078 ATCACCCACAGAGGAAAGTGGACAGCTACTGAGGCTCTGCAGAAATGAGgAGTGCACAT 4507 ACCATCCAGAGAGGGAGGGAGGACAGCTGCTGAAGCTCTGCAAAGATGACGAGTGCACAT 4518 ACCACCCACAGAGGGAGgGTGGTACTCTGAGCAGACTGTGTCTTGGAGACGTGTGCACGT 4403 $* * * * * * * * * * * * * * * * * * * * \quad * * * * * * * * * *$ GTGCCGAAGAGAACTGCAGTATGCAGAAGAAGGGCAAGATCAGCAATGATCTGCGCACAG 1138 GTGCTGAAGAGAACTGCAGTATGCAGAAGAAGGGCAAGATCAGCAATGATCAGCGCATAG 4567 GTGCAGAAGAGAACTGCAGCATGCAGAAGAATGgTCAAATCAGCAACGATGAGCGAACAT 4578 GTGCGGAAGAGAGCTGCAGTATGCAGAAGAAAGGTGAG - CCAG - -ATGTCCAACGCATTG 4460

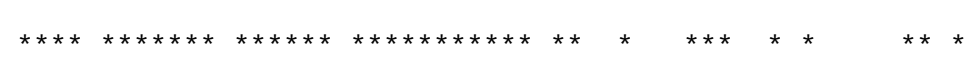
AAAAATCTTGTGAGACTACTCCTACCAGCAAAATTGATTTTGTGTACAAAGTGAGACTGG 1198 AAAAATCTTGTGAGACTACACCGACCAGTAAAATAGATTTTGTGTACAAAGTGAGACTGG 4627 CTAAAATCTGTGAGAGCACAGAGAGCAGCAAAATTGAATATGCGTACAAAGTTCTGGTGG 4638 ACAAAGCTTGCGG - - - - - - - - CGCGgGACTGGATTACGTTTACAAAGCCACGgTGG 4508 


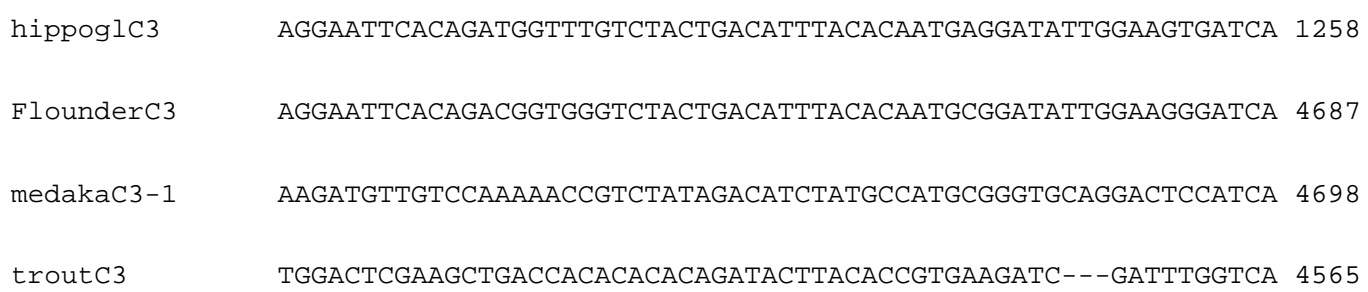




\subsection{2. $C S F-1$}

CSF -1

$\mathrm{Sb}$

Rbt ATAGgGACAGAAGAGAGACAGGGTTGGAGGAACTTTACTCGCTCCCGGATGGTGAATCCA 60 Zfffs1R

$\mathrm{Sb}$

Rbt CAGAGCTCTGTGGGATCAGAGGCATACCACTGAGCTGAAGAAATCTACAGACACAATAAC 120 Zfffs1R -------GCTTTCAAGCTGAAATGAGAATCTGTACTGAAGGAGTGAAAGATCAGTCTATA 53

$\mathrm{Sb}$

Rbt

Zfcfs1R

$\mathrm{Sb}$

Rbt

Zfffs1R
CCTACCTCACTCTGCTGATGGGGATCGTGGCCTCTGCTGCTTCAGTGGAATGGAGGCGTC 67

TGTACCTGGCCTTCCTTCTGGGGATCCTGCCCACTGCAGCTCAAG---AATGGCGACGTC 231 TCGCGCTCTTATTCCTCATTGGGATCCTGCTTGGTCAAGTTCAGG---GTTGGTCTGAAC 170 
CGGTGATCAAGTTCAACTCTAAGGCGGTGGTGAGTGCGGAGGTGGTGGTCAGTCCCGGGA 127

Rbt CTGTGATCAAGCTAAACTCAGAGGTCGTGGTTGGGTCTGAAGTAGTACTGAACCCTGGCA 291

Zfffs1R CGCGGATCAGACTGAGCTCTGGTGCTCTAGCCGGCACAGATGTGATCCTGGAATCCGGAT 230

ССTCTCTGGATCTTAAGTGCGAGGGCGACAGGCCCGTAAACTGGCAGCCAAGGCTAGCCA 187

$\mathrm{Rbt}$ CCCCATTGGTCCTGAGGTGTGAGGGGGATGGGCCAGTCAACTGGCTGACCCGGTTGTCCA 351

Zfcfs1R CTCCTCTTCAGCTGGTCTGTGAGGGCGACGGTCCAGTGACGTTTCTTCCCCGTCTGGCCA 290

$\mathrm{Sb}$

$\mathrm{Rbt}$

Zfcfs1R

$\mathrm{Sb}$

Rbt

Zfcfs1R

$\mathrm{Rbt}$

Zfffs1R

$\mathrm{Sb}$

Rbt
AACACAGACGCTTCGTTTCTAAGGCCAACGGGAACGTCCGCACCTTTAAGGTGGAACGTC 247 AACACAAGAGCTTAATCTCCAAGGGCAATGGGAGAGTCAGAACCTTCAAGGTGGACCGCC 411 AACACAAGCGCTACATTTCCAAAGAAGTGGGGAAAATACGCAGTTTCCGCGTGGAAAAGA 350

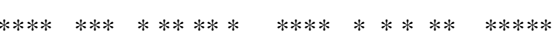

CCACTGCAGAATTCACTGGAACATACAGATGTTATTACACTGCCATGCCGCAGCAACGTC 307 CCTCTGCAGAACACACTGGGACATATAAATGTGAATATACCAGTGTGA-ACGTCAAGGTT 470 CAACGGTGGACTTCACAGGAACATACAAGTGCGTCTATATGAATGGAA-------ATGAT 403<smiles></smiles>

----AACTGATCTCCTCAGTGCATGTGTATATAAAAGATCCAAACCGTGTGTTCTGGACC 363 CGGGACTTGTTCTCTACGGTGCACGTGTATGTGAAAGACCCAGACAGCCTGTTTTGGACC 530 TCAAACTTGTCGTCTTCGGTTCATGTGTTTGTCCGGGACTCTCGAGTTCTCTTTGTTTCT 463 $* * * \quad * * * * * * * * * * * * * \quad * * * \quad * * * \quad *$ AGCAGCACGTCCTTGCGTGTGGTGAGGAAGGAAGGTGAGGACTACCTGCTGCCCTGCCTG 423 AGCAGCGCGTCCCTGCGTGTGGTGAGGAAGGAGGGGGAGGACCACCTGCTCCCCTGCCTG 590 

CTGACCGACCCAGAGGCCACAGACTTGGGGCTCCGCATGGACAACTGTACCTTCGTGCCC 650

Zfffs1R CTGACCGACCCGGAGGCCACAGACTTCACATTTCGCATGGACAACGGTTCAGCAGCGCCC 583

$\mathrm{Sb}$

$\mathrm{Rbt}$ Zfcfs1R

$\mathrm{Sb}$

Rbt Zfcfs1R

$\mathrm{Sb}$

Rbt Zfcfs1R

$\mathrm{Sb}$

Rbt Zfcfs1R

CCGGGGATGAACTTCACAGTTTACCGGCACCGTGGTATTCTCATCCACAGCCTCCACCCG 543 CCAGGGATGAACTACACAGCAGACCCCCGCAGAGGCATTCTCATCCGCAACCTCCATCCC 710 TACGGCATGAACATCACCTACGACCCCAGAAAAGGTGTCCTGATCCGCAACGTTCATCCT 643 $* * * * * * * * * * * \quad * * * \quad * * * * * * * * * * * * * * * * *$

AGCTTCAACGCTGACTACGTCTGCACAGCCAGGGTCAACGGAGTGGAGAAGACGTCCAAG 603 AGCTACAATGCTGACTATGTCTGCAGCGCCAAACTCCACGGGGTGGAGAGGACTTCCAAG 770 GGATTTAACGCAGACTACATTTGCTGCGCTAGAATCGGAGGTGCAGAGAAAGTGTCAAAG 703 $* * * * * * * * * * * * * * * \quad * * * \quad * * \quad * * * * * * * \quad * * * * *$

GCCTTTTCCATCAACGTCATTCAGAAGCTTCGCTTCCCTCCATACGTCTTCTTGGAGACA 663 ACTTTCAACCTCAACATCATCCAAAGGCTGCGTTTCCCACCTTATGTATTCCTGGAAAAG 830 ATATTCTCGATAAACATCATTCAAAGGTTACGTTTTCCACCGTATGTGTACCTGAAGAGG 763 $* * \quad * * * * * * * * * * * * * * * * * * * * * * * * * * * * * * *$

GATGAATATGTGCGCATTGTTGGAGAGGAGCTCAAGATTCGCTGCACCACGCACAACCCC 723 GATGAGTATGTTCATATCGTGGGCGAGAAGCTGAGCATCCACTGCACCACACACAACCCC 890 AACGAGTATGTAAAACTGGTTGGGGAGAGACTTCAGATCAGCTGTACGACAAATAATCCA 823 
Rbt Zfcfs1R

Sb

Rbt

Zfcfs1R

Sb

Rbt

Zfcfs1R

$\mathrm{Sb}$

Rbt

Zfcfs1R

$\mathrm{Sb}$

Rbt

Zfcfs1R

AACTTCAACTACAACGTCACCTGGAAATACACCACCAAGTCGAGAGTGATAGTAGAGGAG 783 AACTTCAACTATAATGTCACGTGGAATTACAGCTCCAAAAAGAGATTTACAATAGAGCAG 950 AACTTTTACTACAACGTCACATGGACACACTCCTCAAGAATGCTGCCCAAAGCAGAGGAG 883 AAGGTTCGCTCCAGTGGAGAGAACCGCCTTGACATAACGAGCATCCTGACCATCTCGGCT 843 AAAGTCCAATCAGTTGACAGTAACCGTCTGGACATTGAAAGCATCCTGACCATCCCTGTA 1010 AAA--TCAA-CAATGGAGGGCGACCGTTTAGCCATCGAGAGCATCCTGACCATCCCGTCT 940 $* *$ GTGGAGCTTGCAGACACAGGAAACCTTTCCTGCATTGGCACAAATGAAGCAGGGGTGAAC 903 GTGGACCAGTCAGACACAGGCAACATTACCTGCATCGGCACCAACGAGGCTGGAGTCAAC 1070 GTCCAGCTGTCGCACACTGGGAACATCACCTGTACGGGTCAGAACGAAGCCGGGGCTAAC 1000 $* * * * * * * * * * * * * * * * * * * * * * \quad * * * * * * * * * * * *$

AGTTCAACGACATACCTGCTGGTTGTAGATAAGCCCTACATCAGGCTGTTGCCCCAGTTG 963 AAATCTACCACCTCCCTGATAGTTGTAGAGGAGGCCTACATCCGTCTTTCTCCCCAGCTG 1130 AGCTCCACCACACAGCTGCTGGTCGTAGAGGAGCCGTACATTCGACTGTCGCCAAAGCTC 1060 $* * * * * * *$ TCCССTAAACTGGCCCACCAGGGCCTTTCGGTGGAGGTGAACGAGGGAGAAGATCTGGAG 1023 TCCTCCAAGCTGGCTCACCAGGGCCTGTCCATTGACGTGAACGAGGGGGAAGACCTGAAA 1190 TCTTCTAAACTCACACACCGCGGTCTGTCCATCGAGGTGAGCGAAGGAGACGATGTGGAT 1120 $* * * * * * * * * * * * * * * * * * * * * * * * * * * * * * * * * * * * *$

CTCAGTGTGCTCATCGAAGCGTACCCCCACATCATCGAGCACAGATGGTACACCCCAACA 1083 CTCAGTGTCCTGATCGAGGCGTACCCTCAGATCATAGGCCAGCACTGGGCCACCCCTACA 1250 CTCGGGGTTTTGATCGAAGCGTATCCTCCTCTGACTTCACACAAGTGGGAGACGCCCACA 1180 


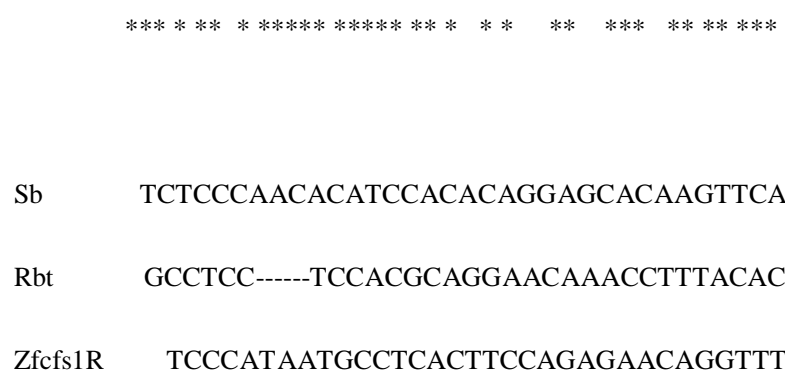

$\mathrm{Sb}$

$\mathrm{Rbt}$

Zfffs1R

$\mathrm{Sb}$

Rbt

Zfcfs1R

$\mathrm{Sb}$

Rbt

Zfcfs1R

$\mathrm{Sb}$

Rbt

Zfcfs1R

$\mathrm{Sb}$

Rbt

Zfcfs1R

$\mathrm{Sb}$

CTGCAGATGGCGATCCСтCTCCAGGCTCCCACGGTGGAGGTGCAGAGGGAGGAGTACGGG 1443 
Rbt

Zfffs1R

Rbt

Zfcfs1R

$\mathrm{Sb}$

$\mathrm{Rbt}$

Zfcfs1R

$\mathrm{Sb}$

Rbt

Zfcfs1R

$\mathrm{Sb}$

Rbt

Zfcfs1R

$\mathrm{Sb}$

Rbt

Zfffs1R

CTCCAGATGCCTGCTCCTCTCTTGGCCCAAACAGTCGAGGTCCAGAGGGAGGAGTATGGA 1604 CTGCAG---------CCGATCCAGACGCAGACAGTGGAGTTCCAGAAGGAAAGTTTCGGG 1531 $* * * * *$

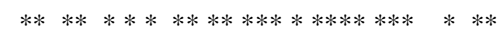

GCTGTGGAGGTGGAGAGCGTCCTCACCGTCGGGCCGTCCAGCCGGCGGATGACGGTGGAG 1503 GTGGTCGGGGTCCAGAGCGTCCTGACAATGGAACCGTCCAGCCATAGGTTGACCGTGGAG 1664 GCTGTCGGTGTGGAAAGCGTCCTGACCGTGGGCC---CCAACCGCAGGATGACCGTCGTC 1588 $* * * * * * * * * * * * * * * * * * * * \quad * * * * * \quad * * * * * * * * *$
TGCGTGGCCTTCAACCTCGTCGGAGTCAGCAGCGACACCTTTGCCATGGAGGTTTCCGAC 1563 TGTGTCGCCTTCAACCTAGTCGGAGTCGGTAAAGACACCTTCGCCATGGACGTTTCCAAT 1724 TGTGTGGCCTTTAACCTGGTCGGTCAAGGCAGTGACACCTTCTCCATGGAGGTCTCTGAT 1648 $* * * * * * * * * * * * * * * * * * *$

AAACTCTTCACTTCTACCTTGACTGGCGCAGCAGGCATTCTGGCCATCCTCCTCGTGCTT 1623 ATAATGTTCACCTCCACTCTATTGGGAGCAGCTGGTGTGCTGGCCСTTCTCCTCCTGCTA 1784 CAAATCTTCACCAGTGCCATGTGCGGCTCGACGGTGGCGATGGTGGTGCTCGGGCTGCTG 1708 $* * * * * * \quad * * \quad * * * * * \quad * * * \quad * * * * \quad * * * *$

CTGGTTTTCCTGCTTTATAAATATAAACAGAAACCCAGGTATGAGATCCGCTGGAAGATC 1683 CTCATGGTCCTGCTCTACAAGTACAAACAGAAACCGAGATATGAGATCCGGTGGAAGATC 1844 CTTATCTTCATGATCTACAAGTATAAACAGAAGCCCAGATATGAGATCCGCTGGAAAATC 1768 $* * * * * * * * * * * * * * * * * * * * * * * * * * * * * * * * * * * * * * * * * * * * * *$ ATTGAGGCAAGAGATGGAAACAACTACACGTTCATCGACCCCACTCAGCTGCCCTACAAT 1743 ATCCAGGCCAGTGAAGGAAACAACTACACCTTTATCGACCCAACTCAGATGCCGTACAAT 1904 ATCGAAGCCACAAATGGAAACAACTACACCTTCATCGACCCCACACAGCTGCCGTACAAC 1828 $* * * * * * \quad * * * * * * * * * * * * * * * * * * * * * * * * * * * * * * * * * * * * * * * * *$ 
GAGAAGTGGGAGTTCCCAAGAGACAAGCTGAAGCTAGGAAAGATCCTGGGTGCGGGAGCT 1803

Rbt GAGAAGTGGGAgtTTCCCAGGGACAAGCTCAAGCTAGGAAAGATCCTAGGAGCCGGGGCC 1964

Zfffs1R GAGAAATGGGAGTTTCCTCGAGACAAACTCAAACTCGGGAAGACTCTTGGTGCTGGTGCG 1888

TTCGGAAAGGTTGTAGAGGCCACAGCTTATGGTCTGGGAGAGGAGAAGGGAAATGCGATG 1863

$\mathrm{Rbt}$ TTTGGGAAGGTGGTGGAGGCCACAGCCTATGGTCTGGGGGAGGACGAC---AACGCGATG 2021

Zfffs1R

TTTGGGAAGGTGGTGGAGGCCACAGCTTACGGTCTGGGCAAAGAGGAC---AACATCACA 1945

$\mathrm{Sb}$

CGCGTTGCTGTGAAAATGTTAAAAGCCAGCGCTCATTCAGATGAGAGGGAAGCTCTGATG 1923

Rbt

CGAGTGGCTGTAAAGATGCTCAAAGCCAGGGCCCACTCAGATGAGAGAGAGGCTTTGATG 2081

Zfcfs1R CGAGTGGCTGTGAAAATGCTCAAAGCCAGTGCTCATCCTGATGAACGTGAGGCTCTGATG 2005

$\mathrm{Sb}$

Rbt

Zfcfs1R

$\mathrm{Sb}$

Rbt

Zfcfs1R

$\mathrm{Sb}$

$\mathrm{Rbt}$
TCTGAACTGAAGATCCTGAGCCACCTGGGACACCACAAGAACATTGTCAATCTTCTGGGA 1983 TCAGAACTGAAGATTCTGAGTCACCTGGGACAGCACAAGAACATTGTCAACCTCCTGGGA 2141 TCTGAGCTGAAGATCCTCAGTCACCTCGGCCAGCATAAGAACATCGTCAACCTGCTGGGT 2065 $* * * * * * * * * * * * * * * * * * * * * * * * * * * * * * * * * * * * * * * * * * * * * * * * *$

GCCTGCACCTATGGAGGACCGGTGCTTGTAATCACAGAATACTGCAGCCTCGGCGACCTC 2043 GCCTGCACTCAGGCGGGACCTGTACTGGTGATCACTGAGTACTGTAGTCATGGCGACCTT 2201 GCCTGCACACATGGAGGGCCTGTGCTGGTCATCACGGAGTACTGTTGTCATGGCGACCTG 2125

CTGAACTTCCTTCGCCAGAAGGCAGAGACCTTTGTGAACTTTGTTATGAACATGCCCGAC 2103 CTGAACTTCCTGCGACACAAGCAGGAGACCTTCCTGAACTTTGTCATGAACATACCAGCG 2261 
Rbt

Zfcfs1R

$\mathrm{Sb}$

Rbt

Zfcfs1R

$\mathrm{Sb}$

Rbt

Zfcfs1R

$\mathrm{Sb}$

Rbt

Zfcfs1R

$\mathrm{Sb}$

Rbt

Zfcfs1R

ATTGTGGAGAACTCTAATGACTACAAGAACATCTGCAATCAGAAACACTTCATTAGAAGT 2163 GTACCAGAGGAGACCAGTGACTACAAGAACCTCTGTGAAGGGAAACAGTTCATCAGAAGT 2321 TTTCCAGAACCCATGACGGATTATAAGAACGTCAGCACCGAGCGAATGTTTGTCAGGAGT 2245 $* \quad * * \quad * * * * * * * * * * * * * * \quad * * \quad * * * * * * * *$

GACAGTGGGATCTCCAGTACGTCCTTGAGCAGCTACTTGGAGATGAGGCCTAGTCAGCTG 2223

GACAGTGGGATCTCCAGTGTGTGTTCTGACAGCTACCTGGAGATGAGGCCTGGTCCCCAG 2381 GACAGTGGGATTTCCAGCACATGCTCTGATCACTATCTGGACATGAGACCAGTCACATCC 2305 $* * * * * * * * * * * * * * * * \quad * * \quad * * * * * * * * * * * * * * *$

CCAAATATAGAATCСTCTCAAGACCCTGTCTGCGAGGAGACTG---CTGACT---GGCCG 2277 CC---TGTCAACTCCTCTCTGGACTCTGTGTGTGAGGATGGTGGGCCGGACTCGTGGCCG 2438 AGACCAACAAACTCAGCTCTGGATTCTTCGTCGGAGTGTCAGG---AGGACTCGTGGCCG 2362 $* * * * * * * * \quad * * \quad * * * * \quad * \quad * * * * \quad * * * * *$

CTGGACATCGATGACTTGCTGCGGTTTTCCTTTCAAGTGGCTCAGGGCCTGGACTTTCTG 2337 TTGGACATGGAGGACCTGCTGAGATTCTCCTACCAGGTGGCTCAGGGCCTGGACTTCCTT 2498 CTGGACATGGATGATTTACTCAGATTCTCCTCTCAGGTGGCGCAGGGACTGGACTTCCTC 2422 GCTGCTAAAAATTGTATTCACAGAGACATCGCTGCCAGGAATGTCCTGTTGACTGATCAC 2397 GCAGCCAAGAACTGTATTCACCGGGACGTGGCAGCTCGGAACGTCCTCCTGACAGACCTC 2558 GCTGCTAAAAATTGCATCCACCGAGACGTGGCGGCCAGAAACGTTCTGCTCACCAACAGC 2482 
Rbt

Zfcfs1R

$\mathrm{Sb}$

Rbt

Zfcfs1R

$\mathrm{Sb}$

Rbt

Zfffs1R

$\mathrm{Sb}$

Rbt

Zfcfs1R

AGAGTGGCCAAGATTTGTGACTTTGGTCTGGCACGTGACGTCATGAATGACTCCAACTAC 2457 CATGTGGCTAAGATCTGTGACTTCGGCCTGGCACGTGACATCATGAATGACTCCAACTAT 2618 CGAGTGGCCAAAATCTGTGACTTCGGACTGGCTCGAGACATCATGAACGACTCCAACTAC 2542 GTGGTGAAGGGCAACGCTCGTCTGCCGGTGAAGTGGATGGCTCCAGAGAGCATCTTTGAC 2517 GTGGTGAAGGGCAATGCGCGTCTGCCAGTGAAGTGGATGGCTCCAGAGAGTATCTTTGAC 2678 GTAGTCAAAGGAAACGCTCGTCTCCCAGTGAAGTGGATGGCTCCAGAGAGCATTTTCGAG 2602

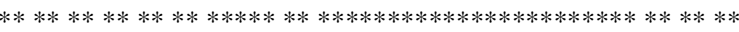

TGTGTCTACACCGTCCAGAGTGACGTCTGGTCCTATGGCATCCTCCTGTGGGAGATCTTC 2577 TGTCTCTACACTGTCCAGAGTGACGTCTGGTCCTATGGGATCCTGCTATGGGAGATCTTC 2738 TGTGTTTATACGGTTCAGAGTGACGTCTGGTCTTACGGGATCATGCTGTGGGAGATTTTC 2662

TCTTTAGGCAAGAGCCCGTACCCCAGCATGGCTGTGGACTCCAGGTTCTACAAGATGGTG 2637 TCTCTAGGAAAGAGTCCCTACCCCAGTATCCTGGTGGATACTAAATTCTATAACATGATC 2798 TCACTGGGAAAGAGTCCGTATCCAAACATCCTGGTGGACTCAAAGTTTTACAAAATGATC 2722 $* * * * *+2 \cdot(2)$ AAGCGTGGCTACCAGATGTCCCAACCAGACTTTGCTCCCCCCGAGATCTACACGATCATG 2697 AAGTGTGGTTATCAGATGTCTCGGCCAGACTTTGCACCTCCAGAGATGTATACAATCATG 2858 AAGTGTGGCTATCAGATGTCCAGACCTGACTTCGCTCCTCCAGAGATGTACACGATCATG 2782 $* * * * * * * * * * * * * * * * *$ AAGATGTGCTGGAATCTGGAGCCGACAGAGCGGCCGACGTTCAGCAAGATCACTCAGATG 2757 AAAATGTGCTGGAATCTGGAGCCAACAGAGCGACCGACCTTCAGCAAGATCAGCCAGCTG 2918 AAAATGTGCTGGAACCTGGACGCCGCTGAGAGACCCACATTCAGCAAGATCAGCCAGATG 2842 


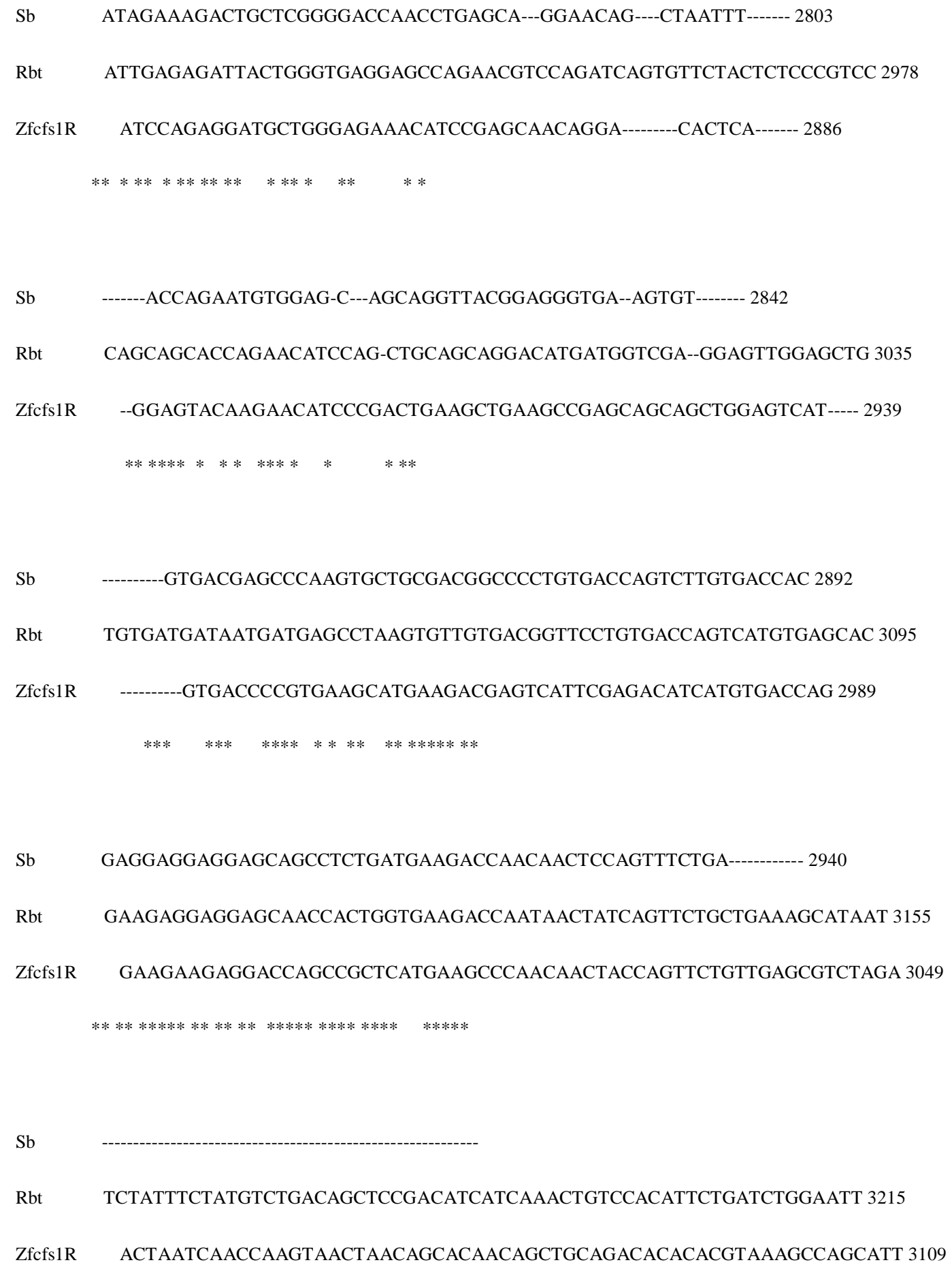

Rbt ATtGAGAGATTACTGGGTGAGGAGCCAGAACGTCCAGATCAGTGTTCTACTCTCCCGTCC 2978

Zfcfs1R ATCCAGAGGATGCTGGGAGAAACATCCGAGCAACAGGA---------CACTCA------- 2886

$\mathrm{Sb}$

Rbt

Zfcfs1R

$\mathrm{Sb}$

Rbt

Zfcfs1R

$\mathrm{Sb}$

GAGGAGGAGGAGCAGCCTCTGATGAAGACCAACAACTCCAGTTTCTGA

GAAGAGGAGGAGCAACCACTGGTGAAGACCAATAACTATCAGTTCTGCTGAAAGCATAAT 3155

Zfcfs1R

$\mathrm{Sb}$

Rbt

Zfcfs1R

-------ACCAGAATGTGGAG-C---AGCAGGTTACGGAGGGTGA--AGTGT-------- 2842

CAGCAGCACCAGAACATCCAG-CTGCAGCAGGACATGATGGTCGA--GGAGTTGGAGCTG 3035 --GGAGTACAAGAACATCCCGACTGAAGCTGAAGCCGAGCAGCAGCTGGAGTCAT----- 2939

---------GTGACGAGCCCAAGTGCTGCGACGGCCCCTGTGACCAGTCTTGTGACCAC 2892 TGTGATGATAATGATGAGCCTAAGTGTTGTGACGGTTCCTGTGACCAGTCATGTGAGCAC 3095 ---------GTGACCCCGTGAAGCATGAAGACGAGTCATTCGAGACATCATGTGACCAG 2989

GAAGAAGAGGACCAGCCGCTCATGAAGCCCAACAACTACCAGTTCTGTTGAGCGTCTAGA 3049

TCTATTTCTATGTCTGACAGCTCCGACATCATCAAACTGTCCACATTCTGATCTGGAATT 3215 ACTAATCAACCAAGTAACTAACAGCACAACAGCTGCAGACACACACGTAAAGCCAGCATT 3109

$\mathrm{Sb}$ 
Zfcfs1R TGTTCTGTCTGTCCTCGTATACACTCACTGGGTGATTTCAC-----ATGCTGGTTCTGGG 3164

$\mathrm{Sb}$

Rbt

Zfcfs1R

$\mathrm{Sb}$

Rbt

Zfcfs1R

Rbt

Zfcfs1R

Rbt

Zfcfs1R
AAATGGAATTGTGATATTTTGTTAAT-GCATTGAAAATCAGTTTTTAGGCCTGTTTTACA 3334

TGAT-------TTATATCTCGTAAACAGTCCTGAAGAAGTCTTTTCAACTCTAGTATTCC 3217

CTGTATACAGACAGGAGGCTGCGAGAGTCATGTCATGTGACTTGTTATATCCCATGACAA 3394

TTGTTTTCCAGTACAAATATCTAAATGT--TCTCAAATCAAGAGATATTTACTTTAATGA 3275

GTTTTGGAAAAACAAAGGCGGGAATGAATCTAATCACAGATAGTGCCTTAGATGTGTAAT 3454

GTC-----AAAGCAATTCATGAAATCTTATTTTAATAGGAAGTATCTTAACATTTTACA 3329

TAGTATATATAATGCCTTATTTTACATGAATTACTCTTCTTTGTTGTTTTGGAGATT--- 3511

CAAGAAGTCTCGTCTTTTTTATTTCATGTATTTTCTGACACCATCGGCTTGAATTTTCCA 3389

$\mathrm{Sb}$

Rbt

-АTСTTTTAAATCTATGCACCAAAGATGCATCTACCCTGAC-AGAACAGATTGTGTTGCT 3569

Zfcfs1R

GATTAATTAAGGTAACACTTTCATTAAGTACCAATTTCCACTATTAACTAATGCCTTATT 3449 
$\mathrm{Sb}$

$\mathrm{Rbt}$ TGGTGAGGATTTATCTATTATTTGAGGGAAATGGGAACGAATGCTGGTGGTGTTTGAATT 3689

$\mathrm{Sb}$

$\mathrm{Rbt}$ GACATTTGTCGGCGGGTTCACTTTCACATTGTAGCTACCTTTTCTCAACATGCTATGCAG 3749

Zfcfs1R AATAGGAAAAAT $-3581$

$\mathrm{Sb}$

$\mathrm{Rbt}$ CAGCAAGGCAGTAGCAAACAATGCAATTGTATAATTTCTGCTACAGTATATTTGAGTTTT 3809 Zfffs1R

$\mathrm{Sb}$

Rbt TTTATTCGTATGATGGCTTAGTTTGATGCTGGACGTAATAACATGAGATGCAATTTAACT 3869 Zfffs1R

$\mathrm{Sb}$

Rbt GGGGACCACATTCCATGTATTGTCCCTCAGCCTAAACATGCTGCATGAAATGCATTGAAA 3929 
Zfffs1R

$\mathrm{Sb}$

$\mathrm{Rbt}$

TGGATTTTGAGACGCTATTTACATCAATGAAAGCATGTGTATTGTTTAAAAAAAAATCTC 3989

Zfffs1R

$\mathrm{Sb}$

Rbt

TAGCCATAGTTGTTTTGTATGACAGTCACAATATGACAGAATCACGCAGCTGTCTAAAAG 4049

Zfffs1R

$\mathrm{Sb}$

Rbt GCACAAGATTTTAGTTGTGCGTTAACCAATATTACTTCAGACTCGGCCAGTCGACATATA 4109

Zfcfs1R

$\mathrm{Sb}$

Rbt GCCTATATGCTATATGCTACAGTAGGGAATGAAAGGCAGATAAAACTGTACAAGGAAATC 4169 Zfffs1R

$\mathrm{Sb}$

Rbt TGTGGATCACAGTATTGACAACACAAAGGCTTTGTTTTTGATTGATTCAATCGATTCTTT 4229 Zfcfs1R 
Rbt ATTTCTGTAACACTCAATATTTTGATGTTCATTCATTCGTCACTTCATCATTTTTGGGGG 4289 Zfcfs1R

$\mathrm{Sb}$

Rbt GTCAATTATGCTGTAAAAATGTTGATTCATTGTATTGAATGTAGAATTCAGCTAATACTG 4349 Zfffs1R

$\mathrm{Sb}$

Rbt CCTACTGTAATTATGATGATTGCAGATACAAGCTCTACGTCAAAGTGAAAAGCTATATGT 4409 Zfffs1R

$\mathrm{Sb}$

Rbt CAGCTGTAAATCAGAATTGTTGTAAGACATTTACTCGAATTGTCAGCAGCTATTCTGAAC 4469 Zfffs1R

$\mathrm{Sb}$

Rbt ACTGAGTTGAAAGGAGAGAAAACTATGAGCTTTTTATTAAAGGGAAATTTTAAAAAATAA 4529 Zfffs1R

$\mathrm{Sb}$

Rbt $\quad$ AAGAAAAAAAAAAAA 4544

Zfcfs1R 


\subsubsection{IgM}

Siniperca GCCTTGACGGACTTCATTCAGTACCCTCCAGTACAGAAAGGCAACGTTTATACGGGAATC 540

IgMFW ---------TTTCATTCAGTACCCACCAGTACAGAAAGGCAACGTTTATACGGGAGTC 49

Siniperca AGTCAAATCCAAGTGAGGAGACAGGACTGGGACGCCAGGGAGTCTTTCCAATGTGCCGTG 600 IgMFW AGTCAAATCCGAGTGAGGAGACAGGACTGGGACGCAAGGGAGACTTTCCAATGTGCCGTG 109 Siniperca ACACATCCAGCAGGAAATGAACAGGCTGATTTCATAAAACCAAAGGTGACTTATGTGCTG 660 IgMFW ACACATCCAGCGGGAAATGCACAGGGTGATATCATCCCGACAAAGGTGATTTAT--ACCC 167 $* * * * * * * * * * * * * * * * * * * * * * * * * * * * * * * \quad * * * * * * * * * * * * * \quad *$

Siniperca CCAACTGAACTTAAAGTGTTGGCCTCCTCTGGAGAGGAACAAGAGGCTTCCTTCTCCTGC 720 IgMFW CCTACT----CTATAGTGT-GGCCTCCTCTGATGAGGAA-ACCGAGCTTCCTTCTCCTGC 221 Siniperca TTtGCCAGAgATTTTCACCAAAAGATTATGAGATCAAATGGCTGAAAAATGAAGCTGAA 780 IgMFW TTTGACATA--TTTTTCCCAAGAG--TATGAG--TCAATGGATGAAGAGGAA---TGAA 272 Siniperca ATCCCCAACAAAATATATGAGATCAAAATGCCTCTTGAGCAAAGAAAGGACAAGAAT-GG 839 IgMFW ATCCCCAACAAATAACA----ATCCC--CACCTTCTGAG---AAAAAGGACGAAAATTGG 323 Siniperca AACTACACTGTACAGTGCAGCAAGTTTCCTCACGGTACCGACCAGTGAGTGGACTGTTG- 898 IgMFW AACTAAAGC---CAGTG------ATTTCGTTGAGTTAAGGGGAAG-GTGAAAACGGATAC 373 
Siniperca ACACTAAGTTTACATGTGAGTTTGAGGGGAAAGGTGAAAAAGGTGCAACATTCATGAATT 958 IgMFW ATTCTGAATTCTC-TGTGACCTCAACCTTCTGATTGATGA------------------ 412

IgMRV GATTTATAACTTG 13

CCAACTGAACTTAAAGTGTTGGCCTCCTCTGGAGAGGAACAAGAGGCTTCCTTCTCCTGC 720

IgMRV CCTACT---CTTAGAGTGTTGGCCTCCTCTGATGAGGAAACCGAGGCTTCCTTCTCCTGC 70

Siniperca TTTGCCAGAGATTTTTCACCAAAAGATTATGAGATCAAATGGCTGAAAAATGAAGCTGAA 780 IgMRV TTTGCCAAAGATTTTTCACCAAACGAGTATGAGTTCAAATG-CTGAAGAATGAAGTGGAA 129

IgMRV ATCCCCAACAAAATACACGAGATCAAAACACCTTCTGAGGAAAGAAAGGACGAGAATGGA 189

Siniperca ACTACACTGTACAGTGCAGCAAGTTTCCTCACGGTACCGACCAGTGAGTGGACTGTTGAC 900 IgMRV ACTAAACTGTACAGTGCAGCAAGTTTTCTCATGGTACCGTCCAGTGAGTGGACTCACAAC 249 
Siniperca ACTAAGTTTACATGTGAGTTTGAGGGGAAAGGTGAAAAAGGTGCAACATTCATGAATTCA 960

IgMRV ACTAAGTTTACATGTGAgTTTAAGGGGAAGGGTGAAAACGGTGATACATTCGTGAATTCA 309

Siniperca TCAGTGACCTACAAACATACAACTCCTGGCAAC---------TGTGAAGTAGATGTGGAC 1011

IgMRV TCTGTGACCTACAGACCTTCAGATTGTGATGATGTAGGATGTCCTGAAGCAGATGTG-AC 368

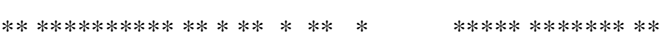

Siniperca ATAAAGATCACTGGCCCCACGTTGGCGGACATGTTTTTAAACAGAAAAGGAACTATAGTA 1071

IgMRV ATAAAGATCACAGGCCCCACAATGGAGGACATGTTTTTATACAAAAAAGGAAAGATAGTA 428

Siniperca TGTCAAGTCAAGgTAAACGAGCCATATGTCGGAAGGATTTTGTGGGAGGACGAGAAAGGA 1131

IgMRV TGTCGAGTCCAGGTAAAC-AACCATCTGTCGAGAAGATTTCGTGGGAGGACCAGCATGGA 487

Siniperca AACGAAATGGCTGGTGCCTCGAAGACCTTCAATGA------TAAAGGCACATTTAGCCTT 1185

IgMRV AACGAAATGGCTGATGCCTCCATGACCCCCCCTAAAGGAAGTAAAGGCCAATTCAGCCTT 547

Siniperca CCACTTGAAATCACGTATGACGAATGGAGCAAGGGGATAAAGCGCTACTGCGTTGTTGAA 1245

IgMRV CCACTTGAAATCAC-TATGACGAATGGAGCAAGGGGATAAAGC-CTACTGCATTGTTGAA 605

Siniperca CATGAAAATTTGATTGAACCACTTAAGGAACTCTATGAAAGGAGTTTCGGAGGACAGACT 1305

IgMRV CATGGAGACTGGCTTGAACCACTTAAGAAACAATATGAAAGGAAGATCGGAGAACAGACT 665 
IgMRV CAGCGTCCTTCAGTGTTTATGCTGCCTCCAGTAGAACATACTAGAAAAGAAATGGTGACC 725

IgMRV CCTGACTTGCTATGTGAAAGACTTCTTCCCTCAGGAAGTTTTTGTGTCTTGGCTTGTTGA 785

Siniperca TGACGAgGAAGCAGACTCAAAATACAAGTTCTATACCACAAACCCCGTAGAGAGCAATGG 1484

IgMRV TGACGAGGAAGCAGACTCAAAATACGAGT-CCATACCACAAACCGAGAAT--------- 834

IgMFW ----------TTTCATTCAGTACCCACCAGTACAGAAAGGCAACGTTTATACGGGAGTC 49

IgMFW AGTCAAATCCGAGTGAGGAGACAGGACTGGGACGCAAGGGAGACTTTCCAATGTGCCGTG 109

IgMFW ACACATCCAGCGGGAAATGCACAGGGTGATATCATCCCGACAAAGGTGATTTAT--ACCC 167 $* * * * * * * * * * * * * * * * * * * * * * * * * * * * * * \pi \quad * * * * * * * * * * * * * \quad *$

IgMRV CCTACT---CTTAGAGTGTTGGCCTCCTCTGATGAGGAAACCGAGGCTTCCTTCTCCTGC 225

IgMRV TTTGCCAAAGATTTTTCACCAAACGAGTATGAGTTCAAATG-CTGAAGAATGAAGTGGAA 284

IgMRV ATCCCCAACAAAATACACGAGATCAAAACACCTTCTGAGGAAAGAAAGGACGAGAATGGA 344 
IgMRV ACTAAGTTTACATGTGAGTTTAAGGGGAAGGGTGAAAACGGTGATACATTCGTGAATTCA 464 IgMRV TCTGTGACCTACAGACCTTCAGATTGTGATGATGTAGGATGTCCTGAAGCAGATGTG-AC 523 $* * * * * * * * * * * * * * * * * * * * * \quad * \quad * * * * * * * * * * * * * *$

IgMRV ATAAAGATCACAGGCCCCACAATGGAGGACATGTTTTTATACAAAAAAGGAAAGATAGTA 583 $* * * * * * * * * * * * * * * * * * * * * * * * * * * * * * * * * * * * * * * * * * * * * * * * * * * * *$

IgMRV TGTCGAGTCCAGGTAAAC-AACCATCTGTCGAGAAGATTTCGTGGGAGGACCAGCATGGA 642 $* * * * * * * * * * * * * * * * * * * * * * * * * * * * * * * * * * * * * * * * * * * * * * * * *$

IgMRV AACGAAATGGCTGATGCCTCCATGACCCCCCCTAAAGGAAGTAAAGGCCAATTCAGCCTT 702 IgMRV CCACTTGAAATCAC-TATGACGAATGGAGCAAGGGGATAAAGC-CTACTGCATTGTTGAA 760 IgMRV CATGGAGACTGGCTTGAACCACTTAAGAAACAATATGAAAGGAAGATCGGAGAACAGACT 820 $* * * * * * * * * * * * * * * * * * * * * * * * * * * * * * * * * * * \quad * * * * * * * * * * * * *$ IgMRV CAGCGTCCTTCAGTGTTTATGCTGCCTCCAGTAGAACATACTAGAAAAGAAATGGTGACC 880 
IgMRV CCTGACTTGCTATGTGAAAGACTTCTTCCCTCAGGAAGTTTTTGTGTCTTGGCTTGTTGA 960 IgMRV TGACGAGGAAGCAGACTCAAAATACGAGT-CCATACCACAAACCGAGAAT--------- 1100

\subsubsection{IgM sequenced}

Siniperca GCCTTGACGGACTTCATTCAGTACCCTCCAGTACAGAAAGGCAACGTTTATACGGGAATC 540

IgMFW ---------TTTCATTCAGTACCCACCAGTACAGAAAGGCAACGTTTATACGGGAGTC 49

Siniperca AgTCAAATCCAAGTGAGGAGACAGGACTGGGACGCCAGGGAGTCTTTCCAATGTGCCGTG 600 IgMFW AGTCAAATCCGAGTGAGGAGACAGGACTGGGACGCAAGGGAGACTTTCCAATGTGCCGTG 109 Siniperca ACACATCCAGCAGGAAATGAACAGGCTGATTTCATAAAACCAAAGGTGACTTATGTGCTG 660 IgMFW ACACATCCAGCGGGAAATGCACAGGGTGATATCATCCCGACAAAGGTGATTTAT--ACCC 167 Siniperca CCAACTGAACTTAAAGTGTTGGCCTCCTCTGGAGAGGAACAAGAGGCTTCCTTCTCCTGC 720 IgMFW CCTACT----CTATAGTGT-GGCCTCCTCTGATGAGGAA-ACCGAGCTTCCTTCTCCTGC 221 Siniperca TTtGCCAGAGATTTTTCACCAAAAGATTATGAGATCAAATGGCTGAAAAATGAAGCTGAA 780 IgMFW TTTGACATA--TTTTTCCCAAGAG--TATGAG--TCAATGGATGAAGAGGAA---TGAA 272 
IgMFW ATCCCCAACAAATAACA----ATCCC--CACCTTCTGAG---AAAAAGGACGAAAATTGG 323

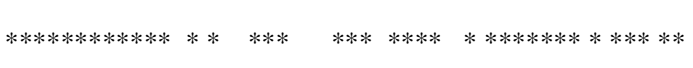

Siniperca AACTACACTGTACAGTGCAGCAAGTTTCCTCACGGTACCGACCAGTGAGTGGACTGTTG- 898

IgMFW AACTAAAGC---CAGTG------ATTTCGTTGAGTTAAGGGGAAG-GTGAAAACGGATAC 373

Siniperca ACACTAAGTTTACATGTGAGTTTGAGGGGAAAGGTGAAAAAGGTGCAACATTCATGAATT 958

IgMFW ATTCTGAATTCTC-TGTGACCTCAACCTTCTGATTGATGA----------------- 412

Siniperca CATCAgTGACCTACAAACATACAACTCCTGGCAACTGTGAAGTAGATGTGGACATAAAGA 1018

Siniperca ACACATCCAGCAGGAAATGAACAGGCTGATTTCATAAAACCAAAGGTGACTTATGTGCTG 660

IgMRV - -

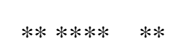

Siniperca CCAACTGAACTTAAAGTGTTGGCCTCCTCTGGAGAGGAACAAGAGGCTTCCTTCTCCTGC 720

IgMRV CCTACT---CTTAGAGTGTTGGCCTCCTCTGATGAGGAAACCGAGGCTTCCTTCTCCTGC 70

Siniperca TTTGCCAgAgATTTTTCACCAAAAGATTATGAGATCAAATGGCTGAAAAATGAAGCTGAA 780

IgMRV TTTGCCAAAGATTTTTCACCAAACGAGTATGAGTTCAAATG-CTGAAGAATGAAGTGGAA 129

Siniperca ATCCCCAACAAAATATATGAGATCAAAATGCCTCTTGAGCAAAGAAAGGACAAGAATGGA 840

IgMRV ATCCCCAACAAAATACACGAGATCAAAACACCTTCTGAGGAAAGAAAGGACGAGAATGGA 189 
Siniperca ACTACACTGTACAGTGCAGCAAGTTTCCTCACGGTACCGACCAGTGAGTGGACTGTTGAC 900 IgMRV ACTAAACTGTACAGTGCAGCAAGTTTTCTCATGGTACCGTCCAGTGAGTGGACTCACAAC 249 $* * * * * * * * * * * * * * * * * * * * * * * * * * * * * * * * * * * * * * * * * * * * * * * * * * * * \quad * *$

Siniperca ACTAAGTTTACATGTGAGTTTGAGGGGAAAGGTGAAAAAGGTGCAACATTCATGAATTCA 960 IgMRV ACTAAGTTTACATGTGAGTTTAAGGGGAAGGGTGAAAACGGTGATACATTCGTGAATTCA 309 Siniperca TCAGTGACCTACAAACATACAACTCCTGGCAAC---------TGTGAAGTAGATGTGGAC 1011 IgMRV TCTGTGACCTACAGACCTTCAGATTGTGATGATGTAGGATGTCCTGAAGCAGATGTG-AC 368 $* * * * * * * * * * * * * * * * * * * * * \quad * * * * * * * * * * * * * *$

Siniperca ATAAAGATCACTGGCCCCACGTTGGCGGACATGTTTTTAAACAGAAAAGGAACTATAGTA 1071 IgMRV ATAAAGATCACAGGCCCCACAATGGAGGACATGTTTTTATACAAAAAAGGAAAGATAGTA 428 $* * * * * * * * * * * * * * * * * * * * * * * * * * * * * * * * * * * * * * * * * * * * * * * * * * * * * * *$

Siniperca TGTCAAGTCAAGGTAAACGAGCCATATGTCGGAAGGATTTTGTGGGAGGACGAGAAAGGA 1131 IgMRV TGTCGAGTCCAGGTAAAC-AACCATCTGTCGAGAAGATTTCGTGGGAGGACCAGCATGGA 487 Siniperca AACGAAATGGCTGGTGCCTCGAAGACCTTCAATGA------TAAAGGCACATTTAGCCTT 1185 IgMRV AACGAAATGGCTGATGCCTCCATGACCCCCCCTAAAGGAAGTAAAGGCCAATTCAGCCTT 547 $* * * * * * * * * * * * * * * * * * * * * * * * * * * * \quad * * * * * * * * * * * * * * * * *$

Siniperca CCACTTGAAATCACGTATGACGAATGGAGCAAGGGGATAAAGCGCTACTGCGTTGTTGAA 1245 IgMRV CCACTTGAAATCAC-TATGACGAATGGAGCAAGGGGATAAAGC-CTACTGCATTGTTGAA 605 
Siniperca CATGAAAATTTGATTGAACCACTTAAGGAACTCTATGAAAGGAGTTTCGGAGGACAGACT 1305 IgMRV CATGGAGACTGGCTTGAACCACTTAAGAAACAATATGAAAGGAAGATCGGAGAACAGACT 665

IgMRV CAGCGTCCTTCAGTGTTTATGCTGCCTCCAGTAGAACATACTAGAAAAGAAATGGTGACC 725 CCTGACTTGCTATGTGAAAGACTTCTTCCCTCAGGAAGTTTTTGTGTCTTGGCTTGTTGA 785

IgMFW AGTCAAATCCGAGTGAGGAGACAGGACTGGGACGCAAGGGAGACTTTCCAATGTGCCGTG 109 $* * * * * * * * * * * * * * * * * * * * * * * * * * * * * * * * * * * * * * * * * * * * * * * * * * * * * * * * * * * *$

IgMFW ACACATCCAGCGGGAAATGCACAGGGTGATATCATCCCGACAAAGGTGATTTAT--ACCC 167 $* * * * * * * * * * * * * * * * * * * * * * * * * * * * * * * * \quad * * * * * * * * * * * * * * \quad *$ IgMRV CCTACT---CTTAGAGTGTTGGCCTCCTCTGATGAGGAAACCGAGGCTTCCTTCTCCTGC 225 IgMRV TTTGCCAAAGATTTTCACCAAACGAGTATGAGTTCAAATG-CTGAAGAATGAAGTGGAA 284 


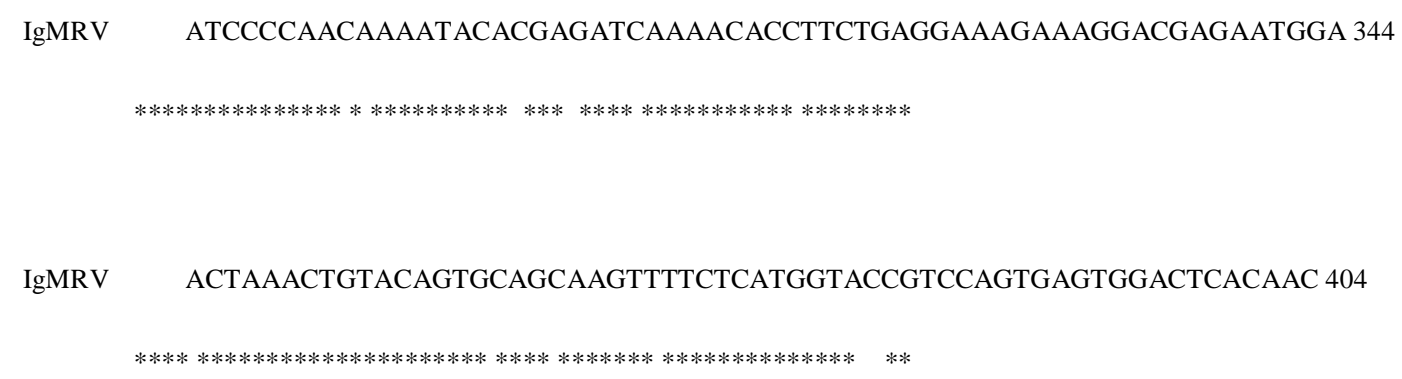



1100

\subsubsection{IgZ - original alignment}

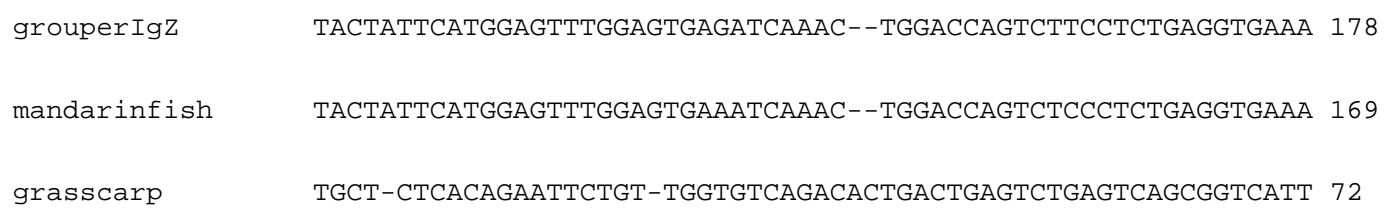


grasscarp

grouperIgZ

mandarinfish

grasscarp

grouperIgz

mandarinfish

grasscarp

grouperIgZ

mandarinfish

grasscarp

grouperIgz

mandarinfish

grasscarp

grouperIgZ

mandarinfish

grasscarp
TATGATGGTGGTTATATATCCTACTCTCAGTCTGTTCAGGGACGGTTCACCATCTCCAGA 249

GATG - TGCCCAGCAGCACTCAGTACCTCGAGGTCAAGAGCCTGACAGCAGAAGATTCTGC 417 GATG-TGTCCAGCAGCACTCAGTACCTCGAGGTCAAGAGCCTGACAGCAGAAGATTCTGC 408 GACAACAGCAAGAAACAGAT-GTATCTGCAGATGAATAATATGAAGAATGAAGACACTGC 308 **

TGTTTACTTCTGTGCTCGGT- - - - - - CGGCTGGGCAGCTTTCGACTACTGGGGCCG 468 TGTTTACTTCTGTGCTCGGTATATGGGCTCCGACGGTTTATATTTCGACTACTGGGGTCG 468 TGTATATTATTGTGCAAGACTGG - - - - - - GGGCTGGGGCGTACTTCGACTACTGGGGGAA 362 $* * * * * * * * * * * \quad *$

GGGGACTGCGGTCACAGTATATTCAC - - AAACAACTGCGGCCCCGGCTCTGTTTCCTTT 525 TGGGACTGAAGTCACAGTATCTTCAG - - TAACAGTTGCATCACCGACTCTGTTCCCTTT 525 AGGAACCAAAGTCACCGTTTCCTCAGCTGAACCATCTCCGCCGAAGTCAATCTTCGGCCT 422 GGTTCAGTGTAAGTCTGGGACTGCAGGTACAGTCACTGTTGGCTGTATTGCACAAGACTT 585 GGTTCAGTGCAACTCTGGGCCTGCAGATAAAATCACTGTTGGTTGTCTTGCACGCGACTT 585 GTCTCAGTGTTCTTCTGATTCTG - AGTTCC - -TCACCATCGGCTGCGTGTCAAGAGGTTT 479 CTTCCCAGAGAG - - - TCTCACTTTCCAGTGGACCGATGCCAGCGGGACCACGCAGACT - - 640 CTACCCAAAGAG - - - TCTTACTTTCCAGTGGACCAATTCCAGTGGGACCGCCCTGACT - - 640 CTCCCCCGCGGACTTTCTTACTTTCAAATGGACGGATCCCGCTAAGAAAGAGGTGACTGA 539 
grouperIgZ

mandarinfish

grasscarp

grouperIgZ

mandarinfish

grasscarp

grouperIgZ

mandarinfish

grasscarp

grouperIgz

mandarinfish

grasscarp

grouperIgZ

mandarinfish

grasscarp

grouper IgZ

mandarinfish

grasscarp

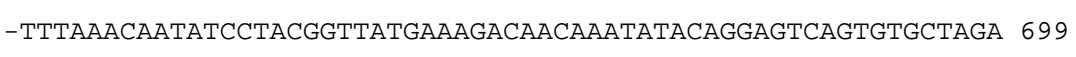
- TCtgAGAATTATCCTCCAGCTGAGAAAAACAACAAATATACAGGAGTCAGTTTGGTCCA 699 TTTCGTGCAGTATCCAGCGTTCGgGAGTGAAGGAGACTATACCAAAATCAGCCATCTGCG 599 TGTGTCAAAGTCTGCCTGGGATTCAAGGAGGAGTTTTAGTTGCTCAGTGACTCACCCTGG 759 AgTATCCAAATCTGACTGgGATTCAAGGAAGTCTTTCAAATGTTCAGTACATCATAACGg 759 TGTGAAAAAAGCGACTGGAATCCTCAAACCTCTTACACATGTGAAGCTTCAAATTCGAA 659 **

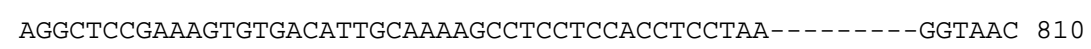
ATCTACCCACGATCTACAAGTGCACAAGCCTATTCC - - TCCAAA - - - - - - AGTGAC 807 AgACAAAAAAGAAGTTATTATACCTCGACCAGCCTCACCGCCAGATCAGCCTGCAACTGT 719 *

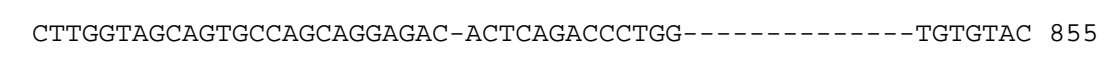

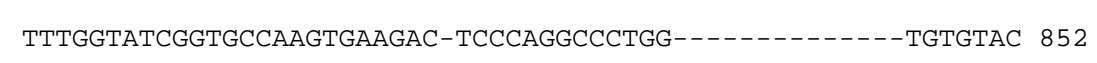
CTACTTAACAGTACCTACACAAAAGGATTTAGAAACTGGAACAGCAACCTTCTTGTGTTT 779 * ******* *** ***** * **** GATTGAGGATCTTCCCT-CAAATCAATTG - -TCAGTCAAATGGAAAAAGGATGATAACTC 912 GATTGAGGACGGTCGCAGTGGAACACTTGACTCATTTAAGTGGAAAAAGATGGCGCAGA 912 AgCCCAGCAGTTTTCACCTAAAACATAT - - -TCGTTTAAGTGGTTTAAgGATGAAACGCA 836

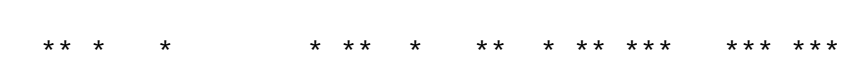

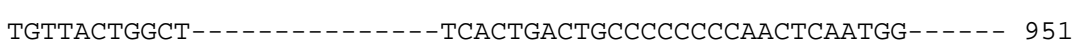

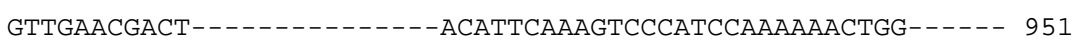 GTTGACAAAGTTGACACATTCGATAAACACCTATGACGCAAGTGAGAAGAATGGCTCAGT 896 


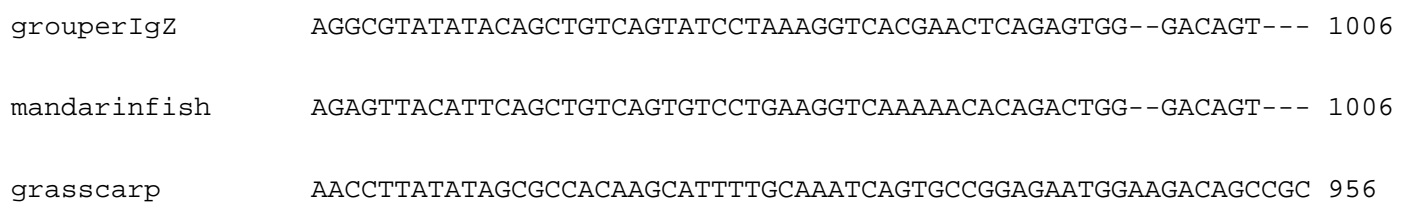


mandarinfish grasscarp

grouperIgZ

mandarinfish

grasscarp

grouper IgZ

mandarinfish

grasscarp

grouper IgZ

mandarinfish

grasscarp

grouper IgZ

mandarinfish

grasscarp

grouperIgZ

mandarinfish

grasscarp
TGAAACAACAAAGTCTGTTGATGGTCAGCGCATCAAAACCAGCACGATGACTCGTAGTCG 1290

ACGTTTCTCAGGACAATTCA - - - - CAGAATATTAAAATCCACAAATTCATAGTTGATAC 1250

CACTGATTGGCAGAGTATCAACAAAGTGCGGTGTTCTGCCATAAGAGACAATATGACACC 1332 CACTGAGTGGCAGAGAGTCAACAAAGTGCGCTGTTCTGCCATTAGAGACGA- -TGACACC 1348 AAATAAATGGTTTGATGGTGAAACTGTCACCTGC - - ACCATCAACGACG - - -GACACA 1303 AGTTATTCAGGAACTGACCATCCAGAAAGGAGATGGGAGTGATCCAAAAGTGACAGTCCA 1392 C-TTATTCAAGATCTGACTGTCCACAAAGGAGATGGGCGTGAGCCAAAAGTGACAGTCCA 1407 - - TCAAGCAgGAAATCCATTGTAATAAAgGAGATGAAAAGACACCCAATGTTACCATTTA 1361 CATTCTCCCATTGGAGGACATCGACAAAGCAGCTCAGGGGTCAGAGGTCACTCTGGTGTG 1452 CGTCCTCACAGAGGAGGACATCAACAAAGGAGCT - . - - - - GAGGTCACTCTGGTGTG 1458 CAGACCT - . - - GATAGTAACAACGACACAAATC - . - - - ATGTCTCTCTGGTGTG 1406 TCTGGTCTCCAGTCGTGCGCAGCAGGATTACTACATCGCCTGGAGAG - - - - - AAG - 1502 TCTGGTCTCCAGTCCTGTGCTGCAGGATTACTACATCGCCTGGTCAG - - - - - - AAG - 1508 TGAGGTCACAAGCCCTAAACTTGGCGATGTCTATATCATGTGGAAAGTGAGAGAAAAGCC 1466

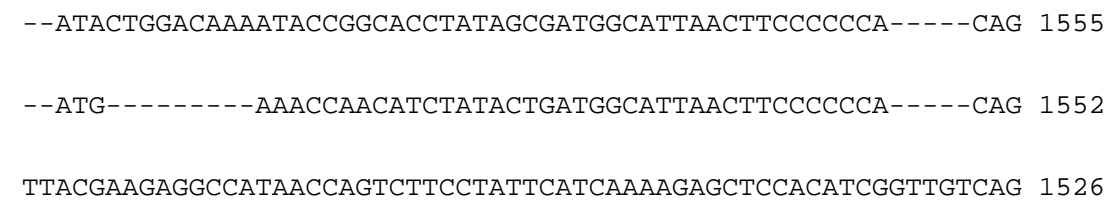
* 


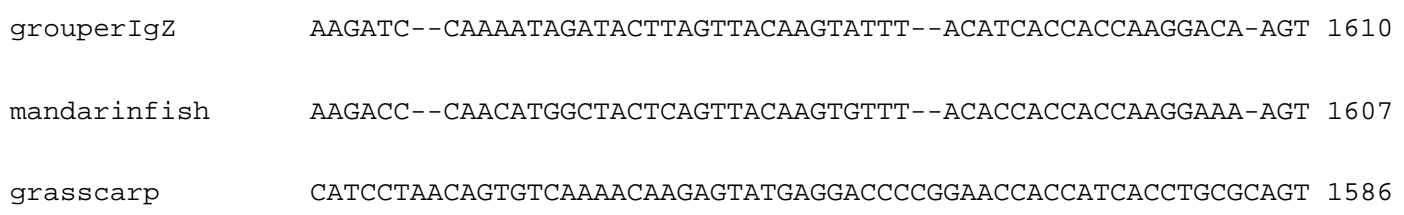


TGT - - - - CACACTGTCGAACAGCTTGAGAAGTGT - - - - - - GCTG - - - TTTCTAAT 1911

mandarinfish TGT - - - - CACATTGTCTAACAGCTTGGGAAGTGT - - - - - - GCTGACTGTTTCAAAT 1942 grasscarp TATATGCACACATTTTTGAAGATATTGACAAATATATACTCAATGTTCACACTCATCAAT 1939

\subsubsection{Obtained IgZ sequence for hapuka}

grouperIgZ

mandarinfish

p. oxy

grouperIgZ

mandarinfish

p. oxy

grouper IgZ

mandarinfish

p. oxy

grouperIgZ

mandarinfish

p. oxy
GAACTACAGTGTTTATCACAGAATGGAAAATACAGTTATCTGGAGTTTGTTATTTGTAGT 120 GAACTACAGTGTTTATCACAGAATGGAAAATACAGTTATCTGGAGTTTGTTCTTTGTAGT 111

TACTATTCATG - GAGTTTGGAGTGAGATCAAACTGGACCAGTCTTCCTCTGAGGTGAAAA 179

TACTATTCATG - GAGTTTGGAGTGAAATCAAACTGGACCAGTCTCCCTCTGAGGTGAAAA 170 AGCTATTTAGgTGACACTATAGAATACTCAAGCTTGCATGCCTGCAGgTCGACTCTAGAG 67 GACCTGGAGAGACAGTGAAGATGTCATGTATCATTTCTGGTTTTGACATGACAGACTACA 239 GACCTGGAGAGACGgTGAAGATGTCATGTATCATATCTGGTTATAGCATGACAAGCTACA 230 GATCCCCGGGTACCGAGCTCGAATT - CGCCCTATAGTGAGTCGTATTACAATTCACT - - G 124 ATATTCACTGGATACGACAGAGGCCAGGGAATGCTCTGGAGTGGATTGGGTGGATGAACA 299 GTATTCACTGGATACGACAGAGGCCAGGGAGAGCTCTGGAGTGGATTGGGTGGATGAACA 290 GCCGTCGTTTTACAACGTCGTGACT - GGGAAAACCCTGGCGTTACCCAACTTAATCGCCT 183 
grouperIgz

mandarinfish

p.oxy

grouper IgZ

mandarinfish

p.oxy

grouperIgZ

mandarinfish

p.oxy

grouperIgZ

mandarinfish

p.oxy

grouperIgZ

mandarinfish

p.oxy

grouper IgZ

mandarinfish
CA-GGCACAAACTCTGCTAGCTATGGCAGTTCCTTTCAAAGTCGTTTCATCATGACTGAA 358 CA-GGCTCAAACTCTGCTAGCTATGCCAGCTCCTTTCAAAGCCGTTTCATCATGACTGAA 349 TGCAGCACATCCCCCTTTCGCCA-GCTGGCGTAATAGCGAAGAGGCCCGCACCGATCGCC 242

GATGTGCCCAGCAGCAC - - TCAGTACCTCGAGgTCAAGAGCCTGACAGCAGAAGATTCTG 416 GATGTGTCCAGCAGCAC - - TCAGTACCTCGAGGTCAAGAGCCTGACAGCAGAAGATTCTG 407 CTTCCCAACAGTTGCGCAGCCTGAATGGCGAATGGACGCGCCCTGTAGCGGCGCATTAAG 302 CTGTTTACTTCTGTGCTCGGT - - - - - - - - CGGCTGGGCCAGCTTTCGACTACTGGGGCC 467 CTGTTTACTTCTGTGCTCGGTATATGGGCTCCGACGGTTTATATTTCGACTACTGGGGTC 467 C - - GCGGCGGGTGTGGTGGTTAC - - - GCGCAGCGTGACCG - - CTACACTTGCCAGCGCC 354 GGGG - GACTGCGG - TCACAGTATATTCACAAACAACTGCGGCCCCGGCTCTGTTTCCTTT 525 GTGG - GACTGAAG - TCACAGTATCTTCAGTAACAGTTGCATCACCGACTCTGTTCCCTTT 525 CTAGCGCCCGCTCCTTTCGCTTTCTTCCCTTCCTTTCTCGCCACGTTCGCCGGCTTTCCC 414

GGTTCAG - TGTAAGTCTGGGACTGCAGGTACAGTCACTGTTGGCTGTATTGCACAAGACT 584 GGTTCAG - TGCAACTCTGGGCCTGCAGATAAAATCACTGTTGGTTGTCTTGCACGCGACT 584 CGTCAAGCTCTAAATCGGGGGCTCCCTTTAGGGTTCCGATTTAGTGCTTT--ACGGCACC 472 TCTTCCCAGAGAGTCTCACTTTC - -CAGTGGACCGATGCCAGCGGGACCACGCAGACTTT 642 TCTACCCAAAGAGTCTTACTTTC - - CAGTGGACCAATTCCAGTGGGACCGCCCTGACTTC 642 


$$
\text { p. oxy }
$$

grouperIgZ

mandarinfish

p.oxy

grouperIgz

mandarinfish

p.oxy

grouperIgZ

mandarinfish

p.oxy

grouperIgZ

mandarinfish

p.oxy

grouperIgZ

mandarinfish

p.oxy

TCGACCCCAAAAAACTTGATTAGGGTGATGGTTCACGTAGTGGGCCATCGCCCTGATAGA 532

TAAACAATATCCTACGGTTATGAAAGACAACAAAT - ---ATACAGGAGTCAGTGTGCTAG 698 TGAGAATTATCCTCCAGCTGAGAAAAACAACAAAT - - - -ATACAGGAGTCAGTTTGGTCC 698 CGGTTTTTCGCCCTTTGACGTTGGAGTCCACGTTCTTTAATAGTGGACTCTTGTTCCAAA 592

ATGTGTCAAAGTCTGCCTGgGATTCAAGGAGGAGTTTTAGTTGCTCAGTGACTCACCCTG 758 AAGTATCCAAATCTGACTGGGATTCAAGGAAGTCTTTCAAATGTTCAGTACATCATAACG 758 CTGGAACAACACTCAACCCTATCTCGGTCTATTCTTTTGAWTWAMAAGGGATTTTTGCCG 652 GAGGCT-CCGAAAGTGTGACATTGCAAAAGCCTCCTCCACCTCCTAAGGTAACCTTGGTA 817 GATCTA-CCCACGATCTACAAGTGCACAAGCCTATTCC - - -TCCAAAAGTGACTTTGGTA 814 ATTTCRGCCTAYTGGTTAAAAATGAGCTGATTT 685 GCAGTGCCAGCAGGAGACACTCAGACCCTGGTGTGTACGATTGAGGATCTTCCCTCAAAT 877 TCGGTGCCAAGTGAAGACTCCCAGGC $\ldots$ CAATTGTCAGTCAAATGGAAAAAGGATGATAACTCTGTTACTGGCTTCACTGACTGCCCC 937 


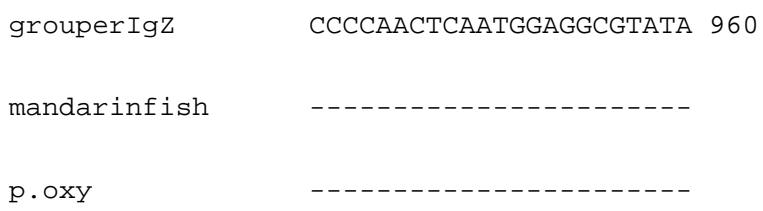

\subsubsection{IgZ - Third alignment}

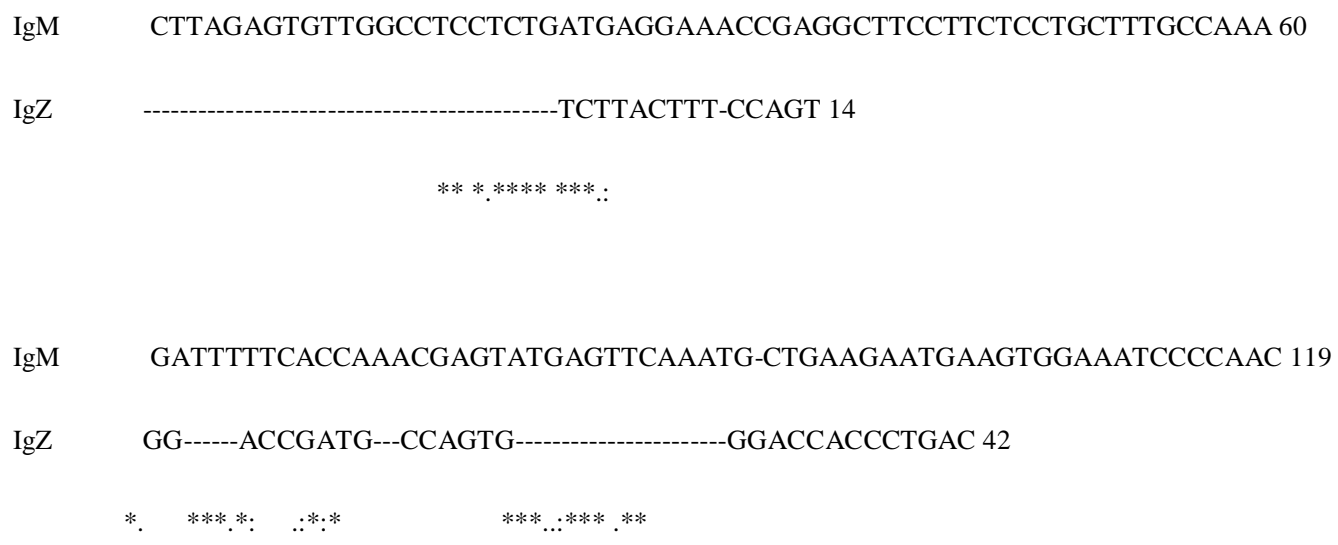


ACAGGCCCCACAATGGAGGACATGTTTTTATACAAAAAAGGAAAGATAGTTGTCGAGTCC 418

IgZ -----CCTACAAARGTG-ACTT-TGCTATCGGTGCC 225 AGGTAAAC-AACCATCTGTCGAGAAGATTTCGTGGGAGGACCAGCATGGAAACGAAATGG 477 $\operatorname{Ig} Z$ AAGTGAAGGCACCCAG-GCCCTGGTGTGTACGATTGAGGACGG--------TCGCAATG- 275 *.**.**.***.: **:*.:*: ***: ******. : :**.****

$\operatorname{IgM}$ CTGATGCCTCCATGACCCСCCCTAAAGGAAGTAAAGGCCAATTCAGCCTTCCACTTGAAA 537 $\operatorname{IgZ}$ -----GAACACTTGACTCATTTAAGTGGAA--AAAG $-304$

$$
*_{. .}^{*}{\text {.:***** * } .::^{*}: * * * * * * * *}^{*}
$$

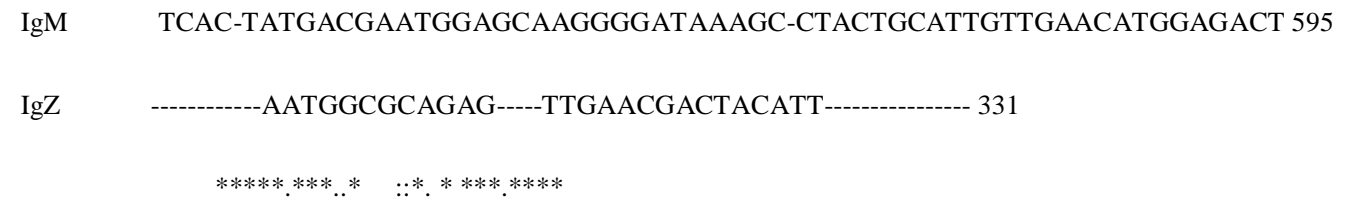




\title{
9.1.8. RAG1
}

RAG1Sp -------TTCCTGGATTCACCAGTTTGAATGGCAGCCAGCTCTCAAGAATGTGTCTACA 53

RAG1Lm GAGCTTCTTCCTGGTTTCATCAGTTTGAATGGCAGCCAGCTCTAAAGAATGTGTCTACA 88

RAG1Stegpar GAGCTTCTCCCCGGCTTCCACCAGTTTGAATGGCAGCCGGCTCTCAAGAAYGTGTCTGCA 88

RAG1latris GAGCTTCTCCCCGGCTTTCACCAGTTTGAATGGCAGCCAGCTCTCAAAAATGTGTCTACA 600

RAG1Sp TCTTGCAATGTCGGCATTATTAATGAACTCTCTGGATGGGCTTCCTCTGTGGATGACGCC 113

RAG1Lm TCTTGCAATGTCGGCATTATTAATGGGCTCTCTGGATACGCTTCCTCTGTGGATGACTCT 148

RAG1Stegpar TCTTGCAACGTCGGCATTATTAACGGGCTCTCTGGATGGGCTTCCTCGGTGGATGACTCC 148 RAG1latris TCGTGCAACATTGGCATCATTAATGGGCTCTCTGGACGGGCTCCCTCGGTGGATGACGTT 660

\begin{abstract}
RAG1Sp CCGGCTGACACCATCACTCGACGGTTTCGCTATGATGTGGCACTGGTGTCAGCATTAAAG 173 RAG1Lm CCTGCTGACACCATCACTCGGCGGTATCGCTATGATGTGGCACTGGTGTCAGCATTAAAA 208 RAG1Stegpar CYGGCTGACACAATCACTCGGCGCTTTCGCTATGATGTGGCACTGGTGTCGGCGTTAAAG 208 RAG1latris CCAGCTGACACCGTCACTCGGCGGTTTCGCTATGATGTGGCACTGGTGTCAGCATTAAAA 720
\end{abstract}

RAG1Sp GATCTGGAGGAGGACATCATGGAGGGGCTGAGAGAGAGTGGGCTGGAAGACAGTGCTTGC 233 RAG1Lm GATCTGGARGAGGACATCATGGAGGGGCTGAGAGAGAGCGGGCTGGAAGACAGTGCTTGC 268 RAG1Stegpar GATCTGGAGGAGGACATCATGGACGGGCTGAGAGAGAGTGGGATGGAAGACAGCGCTTGC 268 RAG1latris GATCTGGAGGAGGACATCATGGAGGGGCTGAGAGAGAGTGGGATGGAAGACAGCGCTTGC 780 


\begin{abstract}
RAG1Sp ACCTCAGGCTTCAATGTCATGATCAAGGAATCTTGTGATGGCATGGGTGATGTCAGCGAA 293 RAG1Lm ACCTCAGGCTTCAGTGTCATGATCAAGGAATCTTGTGACGGCATGGGCGATGTCAGCGAA 328 RAG1Stegpar ACCTCAGGCTTTAGCGTCATGATCAAGGAATGTTGTGATGGTATGGGCGATGTCAGCGAG 328 RAG1latris ACCTCGGGCTTCAGTGTCATGATCAAGGAAGCTTGCGATGGCATGGGCGACGTCAGCGAG 840
\end{abstract}

RAG1Sp AAGCATGGTGGAGGACCAGTCGTTCCCGAGAAGGCAGTACGTTTCTCTTTCACTGTTATG 353 RAG1Lm AAGCATGGTGGCGGACCAGTTGTTCCTGAGAAGGCTGTACGTTTCTCTTTCACTGTTATG 388 RAG1Stegpar AAGCACGGCGGAGGACCTGTTGTTCCCGAGAAGGCGGTGCGCTTCTCTTTCACCGTCATG 388 RAG1latris AAGCACGGCGGCGGACCAGCTGTTCCTGAGAAGGCTGTACGTTTTTCTTTCACTGTTATG 900
RAG1Sp TCTGTATCTGTCCTGGCAGAAAATGAgGAGGAAGAGGTTACCATTTTCACTGAGCCAAAG 413
RAG1Lm TCTGTATCTATTCTGGCAGAAAAGGAAAAGGAAGAGGTTACTATTTTTACCGAGCCAAAG 448 RAG1Stegpar TCTGTCTCTGTCCTCGCAGAYGAGGAGGAGGAGGAGGTTACCATYTTCACTGAGCCAAAA 448 RAG1latris TCTGTCTCTGTCCAGGCAGACGATGAGGAGGAAGCGGTTACCATCTTCACCGAGCCAAAG 960
RAG1Sp
CCAAACTCAGAACTGTCCTGTAAGCCACTTTGCCTGACATTTGTGGATGAGTCAGACCAT 473
RAG1Lm
CCAAACTCAGAACTGTCCTGTAAGCCTCTTTGCCTGACATTTGTGGACGAGTCAGACCAT 508
RAG1Stegpar
CCAAACTCAGAGCTGTCCTGCAAGCCСCTCTGCCTGATGTTCGTGGATGAGTCAGACCAY 508
RAG1latris
CCCAACTCAGAACTGTCCTGTAAGCCCCTGTGCCTGACGTTC $-1002$

\title{
9.1.9. $T C R \alpha$
}

\section{$\operatorname{cod}$}

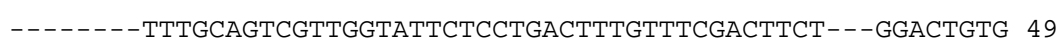

sb AGgACACAATAATGATGACAGCTGGTCTGATCACACTCTCTGCAGCTCT---GCTCTGCA 66

rbt AACAGTGAGTCAACATGATCAGAATTCTTATCTCCATCACCATGGGTTACAGAGCCTGG 120 
TGATATTTC - AGCCATCCCATCCCATAATACTT - - CAGGAAAACAC - - - CCAGGCGGAGA 103 TTATAGGTCTAATCGATGGGAGTGATGTCACT - - - CAGACTCCCCT - - - GCTGTGGATGA 120 CTGCAGGTT - - - ССTCTCCGAGTAATCAGgTTCACCAGGGACCTGCAGACCTGTACAAGA 177 TTAAATGTCAA - - - - CACGATGA - CGACAATCTCA - - - - - - ATGTCATGTTATG - - 146 TGGAGgGTCAGTCTgCCACGATGAACTGCAGTCACACTAAGGGCACGTCATATTACGAGA 180 ACCAGgGAGAGTTGgCTAAGATGg - -AGTGTTCACA-TAGTATATCAACCTATAATGTCA 234 - GTACCAGCGAAGACCACAG - - -AGCAACAATTTGAGTCTAATAGGCT - -ACAGCTACTA $20 \odot$ TgTACTgGTACAGACAgCTgCCTgGACAgAggATGAAgGAGATAGTTTTCACAACT - CAA 239 TCCTCTgGTACAAGCAATCCAACTACAGAGAATTGGTGTTTTTAGGATACAT-GCAATTG 293 TGGCAACGACCCCAACTACGAAGAAGTGTTCAAA - - - GATCAATTTGAGATGACGATGGA 257 AGTCCCCCACATCAA-TATGAAAGTGgCTTCAGCACTGAGAAATTTCCAGCAACGAAGAA 298 AAAACTGGATTTCC - - - - TGAGgTTGGATTTGATATAGAAGGA - - - - - GATGCTAATGCA 344 GAGCAAACTGAAAGGAGCGCTGGTACGTCGAAAGGCAGAGGCA-AACGACTCTGGGGAGT 316 AGATGCTCTGACTGGATCTTTGACA-GTGGAGAGGCTGCTGCTCAATGACAGTGGAGTAT 357 GGTGGTACCAGCA - - - - CCTTAACC - ATCAAACAACTAACTCCAAATAGCAGTGCTGTGT 399 ATTTCTGCGCTGCCCGCACGCCCCTCAGGGGTTCGTCTGGAAACGAGGCCTACTTTGGAA 376 

ATTTCTGTGCTGT - - - - GACCAGTGGTGGT - - - AACACAGAAGCTCACTTTGGTG 405 ATTACTGTGCTGCTACCGGGACAAAAAACTAT - - - - - - AATCCTGCATTCTTTGGAG 450 AAGGGACTAAACTCACGGTCCTGGAACCGGGGTGTATCGTCTCCCCGCCCACGGTGGTGG 436 GAGGAACAAAGTTAACTGTTTTAGGTAAAGACGATAAAATTACCCCACCAACAGTGAAAG 465 CGGGAACCAAACTGACTGTTCTGGATCCAAACATCAAAGTCACTGAACCCACAGTGAAAG 510 TCCTGCCGCCCTCTGAGAAGGAGTGCCGGGACCGG - - - - - AAGGAGCAGCTGAAGAAGA 490 TGCTTGAACCGTCAGAAAAGGAGTGCCGAAACAAGgTAGAAAAAGAAAAAAGGAAGAAGA 525 TCCTAGCACCCTCCGCTAAGGAGTGTGAAGATAGA - - - - AACAAGAAGAAGAAGAAGA 564 * * CCCTGGTGTGCGTGGCGTCAGGCTTCTACCCGGACCACGTCGGCGTGTCCTGGACTGTGA 550 CGTTGCTTTGTGTGATCAGCAGATTCTACCCAGACCATGTCAATGTGACCTGGAAGATCA 585 CCCTAGTGTGTGTAGCCACCCGCTTCTACCCCGACCACGTCACGGTCTTCTGGCAAGTCA 624 ACGGCCAGTCGGTCATTAAGGGCGTGGCCAGTGACCACCCCGCCCTGCGTGTGGACGACA 610 ATAATGAGGAAATGTCTAAGGGTGTGGCGACGGACAACATGCCCGCACAGCCGAACGATG 645 ACAATGTCAACAGAACTGAAGGTGCCGGGACCGACAACAGGGCCTTGTGGGATAAAGATG 684 AA - - - - - TACCAGATCACCAGCCGGCTCCGGGTGGAGGCCCGGGAGTGGTACACAGAGG 664 GAAAGTTTTACAAAATCACCAGCAGGCTGAAGGTCGACGCCAACAAATGGTTCGATCCCG 705 GT - - - TTATACAGTATCACCAGCAGACTGAGAGTCCCAGCCAATGAATGGCACAAACCAG 741 


\subsubsection{0. $T C R \beta$}

cod

$\mathrm{sb}$

rbt

$\operatorname{cod}$
GCACCATCTTCACCTGCAATGTCAGCTTCTTCAACGGGAATGACACCATCTACACCTCGG 724 AGAATGAATTCAAGTGCATTGCCAGCTTCTTCAATGGGACAGGAACGACATACCATGAAA 765 AGAACAGATTCACCTGCATTGTCAGCTTTTACGATGGGACTGACAATATAAGAGTGACTA 801 CCGAGGTTTATGGGGGCGGTGATGTCAGATGGATCAAGACGGAACCAGACGGCGAGACCA 784 ACGGAACT - - - AGAGGCATAGAAGCTCCA - - - - - AAGACAGGACAAAACA-TAACAACA 815 ATGACACC - - - ATTAGTGGAGATCTCCAA- - GGTCAAAGTGGGG-GAGAGA-TAACGACA 854 GAGAGGAATTCGTTAAGGTCACCCAGACGGCCAAACTGTCCTACATCGTAATGATCGTCA 844 GAGGCGTATTTG - - AAGAGAAGTCAGACCGCCAAGCTCTCCTACGGCGTTTTAATCATCA 873 GATTACTATGTG - -AAGAGCACCCAGACTGCCAAGCTGGCCTACAGCATCTTCATCGCTA 912 AGAACATCGTCTACGGAGTCTTTGTCACGATACTGGCCTGGAAACT - -CGGTCTC - - - GG 899 AGGGCTGCGTCTACGGCGCCTTCGTGATGTTTCTGGTGTGGAAGCTTCCGGGTTC - - -AT 930 AGAGTACCTTCTATGGCCTGGTCGTCATGGTTATGATTTGGAAGTTCCAGGGCTCCTCAG 972 * $\quad * * * * * * \quad * * * * * * * * \quad * * * * * * * * * *$ AgGACACAATAATGATGACAGCTGGTCTGATCACACTCTCTGCAGCTCT - - -GCTCTGCA 66 AACAgTGAgTCAACATGATCAGAATTCTTATCTCCATCACCATGGGTTACAGAGCCTGGg 120 TGATATTTC - AGCCATCCCATCCCATAATACTT - - CAGGAAAACAC - - CCAGGCGGAGA 103 195 
$s b$

rbt

cod

$\mathrm{sb}$

rbt

cod

sb

rbt

cod

sb

rbt

cod

sb

rbt

cod

sb

TTATAGGTCTAATCGATGGGAGTGATGTCACT - - - CAGACTCCCCT - - - GCTGTGGATGA 120

CTGCAGGTT - - - ССTCTCCGAGTAATCAGgTTCACCAGGGACCTGCAGACCTGTACAAGA 177

TTAAATGTCAA - - - - CACGATGA-CGACAATCTCA - - - - - - - ATGTCATGTTATG - - - 146 TGGAGGGTCAGTCTGCCACGATGAACTGCAGTCACACTAAGGGCACGTCATATTACGAGA 180 ACCAGGGAGAGTTGGCTAAGATGG - -AGTGTTCACA-TAGTATATCAACCTATAATGTCA 234
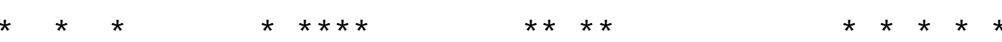

- gTACCAGCGAAGACCACAg - - - AgCAACAATTTGAGTCTAATAGGCT - - ACAGCTACTA 200 TGTACTGGTACAGACAGCTGCCTGGACAGAGGATGAAGGAGATAGTTTTCACAACT-CAA 239 TCCTCTgGTACAAGCAATCCAACTACAGAGAATTGGTGTTTTTAGGATACAT-GCAATTG 293 TGGCAACGACCCCAACTACGAAGAAGTGTTCAAA - - GATCAATTTGAGATGACGATGGA 257 AGTCCCCCACATCAA-TATGAAAGTGGCTTCAGCACTGAGAAATTTCCAGCAACGAAGAA 298 AAAACTGGATTTCC - - - TGAGGTTGGATTTGATATAGAAGGA - - - - GATGCTAATGCA 344 GAGCAAACTGAAAGGAGCGCTGGTACGTCGAAAGGCAGAGGCA-AACGACTCTGGGGAGT 316 AGATGCTCTGACTGGATCTTTGACA-GTGGAGAGGCTGCTGCTCAATGACAGTGGAGTAT 357 GGTGGTACCAGCA - - - CCTTAACC-ATCAAACAACTAACTCCAAATAGCAGTGCTGTGT 399 ATTTCTGCGCTGCCCGCACGCCCCTCAGGGGTTCGTCTGGAAACGAGGCCTACTTTGGAA 376 ATTTCTGTGCTGT - - - - - GACCAGTGGTGGT - - - - -AACACAGAAGCTCACTTTGGTG 405 
rbt

$\operatorname{cod}$

$\mathrm{sb}$

rbt

$\operatorname{cod}$

$\mathrm{sb}$

rbt

$\operatorname{cod}$

sb

rbt

$\operatorname{cod}$

sb

rbt

$\operatorname{cod}$

$\mathrm{sb}$

rbt
ATTACTGTGCTGCTACCGGGACAAAAAACTAT

-AATCCTGCATTCTTTGGAG 450

AAGGGACTAAACTCACGGTCCTGGAACCGGGGTGTATCGTCTCCCCGCCCACGGTGGTGG 436 GAGGAACAAAGTTAACTGTTTTAGGTAAAGACGATAAAATTACCCCACCAACAGTGAAAG 465 CGGGAACCAAACTGACTGTTCTGGATCCAAACATCAAAGTCACTGAACCCACAGTGAAAG 510

TCCTGCCGCCCTCTGAGAAGGAGTGCCGGGACCGG - - . - - AAGGAGCAGCTGAAGAAGA 490 TGCTTGAACCGTCAGAAAAGGAGTGCCGAAACAAGGTAGAAAAAGAAAAAAGGAAGAAGA 525 TCCTAGCACCCTCCGCTAAGGAGTGTGAAGATAGA - . - - - AACAAGAAGAAGAAGAAGA 564 CCCTGGTGTGCGTGGCGTCAGGCTTCTACCCGGACCACGTCGGCGTGTCCTGGACTGTGA 550 CGTTGCTTTGTGTGATCAGCAGATTCTACCCAGACCATGTCAATGTGACCTGGAAGATCA 585 CCCTAGTGTGTGTAGCCACCCGCTTCTACCCCGACCACGTCACGGTCTTCTGGCAAGTCA 624 ACGGCCAGTCGGTCATTAAGGGCGTGGCCAGTGACCACCCCGCCCTGCGTGTGGACGACA 610 ATAATGAGGAAATGTCTAAGGGTGTGGCGACGGACAACATGCCCGCACAGCCGAACGATG 645 ACAATGTCAACAGAACTGAAGGTGCCGGGACCGACAACAGGGCCTTGTGGGATAAAGATG 684 AA - - - - TACCAGATCACCAGCCGGCTCCGGGTGGAGGCCCGGGAGTGGTACACAGAGG 664 GAAAGTTTTACAAAATCACCAGCAGGCTGAAGGTCGACGCCAACAAATGGTTCGATCCCG 705 GT - - -TTATACAGTATCACCAGCAGACTGAGAGTCCCAGCCAATGAATGGCACAAACCAG 741 
cod

sb

rbt

$\operatorname{cod}$

sb

rbt

cod

$\mathrm{sb}$

$r b t$

cod

$s b$

rbt

rbt

sebastes

sb

GCACCATCTTCACCTGCAATGTCAGCTTCTTCAACGGGAATGACACCATCTACACCTCGG 724 AGAATGAATTCAAGTGCATTGCCAGCTTCTTCAATGGGACAGGAACGACATACCATGAAA 765 AgAACAGATTCACCTGCATTGTCAGCTTTTACGATGGGACTGACAATATAAGAGTGACTA 801

CCGAGGTTTATGGGGGCGgTGATGTCAGATGGATCAAGACGGAACCAGACGGCGAGACCA 784 ACGGAACT - - - AGAGGCATAGAAGCTCCA - - - - - AAGACAGGACAAAACA-TAACAACA 815 ATGACACC - - -ATTAGTGGAGATCTCCAA- - GGTCAAAGTGGGG-GAGAGA-TAACGACA 854 GAGAGGAATTCGTTAAGGTCACCCAGACGGCCAAACTGTCCTACATCGTAATGATCGTCA 844 GAGGCGTATTTG - - AAGAGAAGTCAGACCGCCAAGCTCTCCTACGGCGTTTTAATCATCA 873 GATTACTATGTG - - AAGAGCACCCAGACTGCCAAGCTGGCCTACAGCATCTTCATCGCTA 912

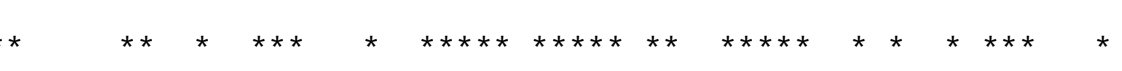
AgAACATCGTCTACGgAGTCTTTGTCACGATACTGGCCTGGAAACT - -CGGTCTC - - - GG 899 AGGGCTGCGTCTACGGCGCCTTCGTGATGTTTCTGGTGTGGAAGCTTCCGGGTTC - - - AT 930 AGAGTACCTTCTATGGCCTGGTCGTCATGGTTATGATTTGGAAGTTCCAGGGCTCCTCAG 972

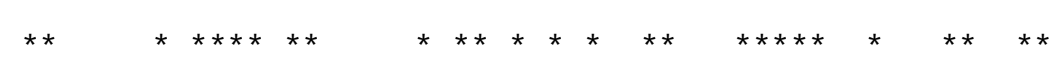

AACAGTGAGTCAA--CATGATCAGAATTCTTATCTCCATCACCATGGGTTACAGAGCCTG 118 AGTCATGAAACACGTCCTGATCATCACTGGCCTCTGCTTCACCTTTAACATCATA--CTG 69 AGCTCAGGACACAATAATGATGACAGCTGGTCTGATCACACTCTCTGCAGCTCTGCTCTG 64 
$r b t$

sebastes

sb

rbt

sebastes

$\mathrm{sb}$

$r b t$

sebastes

$\mathrm{sb}$

rbt

sebastes

$\mathrm{sb}$

rbt

sebastes

$\mathrm{sb}$

rbt
GGCTGCAGGTTCCTCTCCGAGTAATCAGGTTCACCAGGGACCTGCAGACCTGTACAAGAA 178

GTCT-CAGGTTCCTCACTCAGTGACAAAGTCGACCAGGCTCCAACTGATATATACGGAAA 128 CATTATAGgTCTAATCGATGgGAGTGATGTCACTCAGACTCCC-CTGCTGTGGATGATGG 123 CCAGGGAGAGTTGGCTAAGATGGAGTGT - - TCACATAGTATATCAACC-TATAATGTCAT 235 ACAAGGAGAAACAGCTGAAATCACCTGC - - TCACATAAAATAGACAAC - TACAACCGAAT 185 - - AGgGTCAGTCTGCCACGATGAACTGCAGTCACACTAAGGGCACGTCATATTACGAGAT 181

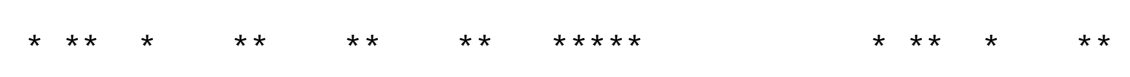

CCTCTGGTACAAGCAATCCAACT-ACAGAGAATTGGTGTTTTTAGGATACATGCAATTGA 294 ССTCTGGTACAAGCAATTAA - - - ACAGAAACCTACAGTTCCTGGGATATCTGAATATAA 241 GTACTGGTACAGACAGCTGCCTGGACAGAGGA-TGAAGGAGATAGTTTTCACAACTCAAA 240 AAACTGGATTTCC - - - TGAGGTTGGATTTGAT- - - - - ATAGAAGGAGATGCTAATGCAG 345 ACAAGGGTTATCC - - - TGAAGATGGAGTGGATGTGACCATAGACGGGGATGCAAACAAAG 298 GTCCCCCACATCAATATGAAAGTGGCTTCAGCACTGAGAAATTTCCAGCAACGAAGAAAG $30 \odot$ GTGGT - - - ACCAGCACCTTAACCATCAAACAACTAACTCCAAATAGCAGTGCTGTGTATT 402 GCCGG - - - AACTGCACATTAACAATTAACAGTCTCAGTGTGAGCAGCAGTGCAGTTTACT 355 ATGCTCTGACTGGATCTTTGACAGTGGAGAGGCTGCTGCTCAATGACAGTGGAGTATATT 360 ACTGTGCTGCTAC - - CGGGACAAAAAACTA - - - - TAATCCTGCATTCTTTGGAGCGG 453 
sebastes

sb

rbt

sebastes

sb

rbt

sebastes

$s b$

rbt

sebastes

$s b$

rbt

sebastes

$\mathrm{sb}$

rbt

sebastes
TCTGTGCTGCTAGTTACGGGACAGGGGGCCCCCAGACTGAACCTGCTTACTTTGGAAAAG 415 TCTGTGCTGTGAC - - - CAGTGGTGGTAACAC - - - - - - AGAAGCTCACTTTGGTGGAG 408

GAACCAAACTGACTGTTCTGGATCCAAACATCAAAGTCACTGAACCCACA - - - GTGAAAG 510 GAACCAAACTCACCGTTTTAGAAACAGATCGAACAGTCACCCCACCAACAAAGGTAAAAA 475 GAACAAAGTTAACTGTTTTAGGTAAAGACGATAAAATTACCCCACCAACA - - - GTGAAAG 465

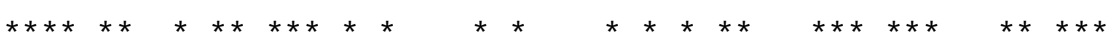

TCCTAGCACCCTCCGCTAAgGAgTgTGAAGATAG - - -AAA- - - CAAGAAGAAGAAGAAGA 564 TATTTCCACCTTCAgCAAAgGAgTgCAgAAACAA- - -AAAgGACGATATAAgGAAGAAGA 532 TgCTTGAACCGTCAgAAAAgGAgtgCCGAAACAAgGtAGAAAAAGAAAAAGgAAGAAGA 525 CCCTAGTGTGTGTAGCCACCCGCTTCTACCCCGACCACGTCACGGTCTTCTGGCAAGTCA 624 CCCTCGTCTGTGTGGCTTCCGGTTTCTACCCCGACCATGTTAGCGTCTCCTGGGAAAAAA 592 CGTTGCTTTGTGTGATCAGCAGATTCTACCCAGACCATGTCAATGTGACCTGGAAGATCA 585 ACAATGTCAACAGAACTGAAGGTGCCG - - - - GGACCGACAACAG - - - - - GGCCTTGTG - 673 ACGGTAAAGTGGTTCCGGATAGCGAGGCAAAGGATAGACAGGAGAAGTATGGCGTGGCGA 652 ATAATGAgGAAATGTCTAAGGGTGTGGC - - - -gACGGACAACAT- - - - - gCCCGCACAG 635 *

- GGATA - - - - - - AAGATGGT - - - - - TTATACAGTATCACCAGCAGACTGAGAGTCC 717 CGGACAGCGCTGCCAAGAGgGTCGgGGAGTTCTACAGAATCACCAGCAGACTGAGAGTTC 712 
$\mathrm{sb}$

rbt

sebastes

$\mathrm{sb}$

rbt

sebastes

$\mathrm{sb}$

rbt

sebastes

$\mathrm{sb}$

$r b t$

sebastes

$\mathrm{sb}$
CCGA - - - - - ACGATGGA - - AAGTTTTACAAAATCACCAGCAGGCTGAAGGTCG 681 CAgCCAATGAATGgCACAAACCAGAGAACAGATTCACCTGCATTGTCAGCTTTTACGATG 777 CTGCTGCACATTACAACACACCCGGCAACACTTTCACATGCATCGTCAGCTTCTATAACG 772 ACGCCAACAAATGGTTCGATCCCGAGAATGAATTCAAGTGCATTGCCAGCTTCTTCAATG 741 GGACTGACAATATAAGAGTGACTAATGACACCATTAGTGGAGATCTCCAAGGTC - - - AAA 834 GAAC - - ACAAAAT - - - - GTCCTTCGTCATGCTTCCATTGATAGTATTAAAGGTG - - - AAT 823 GGACAGGAACGAC - - - - ATACCATGAAAACGGAACTAGAGGCATAGAAGCTCCAAAGA 795 GTGGGGGAGAGATAACGACAGATTACTATGTGAAGAGCACCCAGACTGCCAAGCTGGCCT 894 CAGAGGGAGGCATGACCAGAGAGAAGTATTTGAAGCACACACAAAGTGCCAAACTYTCGT 883 CAGGACAAAACATAACAACAGAGGCGTATTTGAAGAGAAGTCAGACCGCCAAGCTCTCCT 855 ACAGCATCTTCATCGCTAAGAGTACCTTCTATGGCCTGGTCGTCATGGTTATGATTTGGA 954 ACGGCGTCCTCATCGTGAAGAGCTGCATCTACGGAGCCTTCATTGGGTTTTTGGTGTGGA 943 ACGGCGTTTTAATCATCAAGGGCTGCGTCTACGGCGCCTTCGTGATGTTTCTGGTGTGGA 915 
seabass

sebastes

fugu

seabass

sebastes

fugu

seabass

sebastes

fugu

seabass

sebastes

fugu

seabass

sebastes

fugu

AACCAGGTCTCAGCGTCACCGGGCCGACG - - - GTCACGCTGCTG 41 TGTGTGGCTTCCGGTTTCTACCCCGACCATGTTAGCGTCTCCTGGGAAAAAAACGGTAAA $60 \odot$ TGCGTGGCCAGCGGATTCTACCCGGACCACGTGAGCGTGTCCTGGGAGGTCAACGGGCAA 161

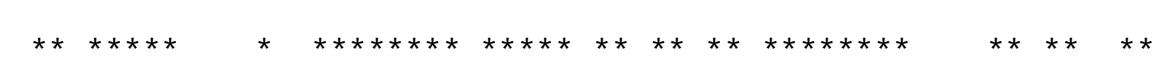

AATGTCACTAATGGTGTGGCGACGGAC - - - - - GAAGCTGCCCAGC-TGATGCCGGAAAA - 215 GTGGTTCCGGATAGCGAGGCAAAGGATAGACAGGAGAAGTATGGCGTGGCGACGGACAGC $66 \odot$ AAGGTGACGGACGGCGTGGCGACGGAC - - - - -GGCGCCGCCCTGC - - - GGCCCGAGGG - 211 
GACTGGGAAAACTCAGATAATGAATTCAAGTGCATTGTCAATTTCTTCAATAAAACCCAT 318 CATTACAACACACCCGGCAACACTTTCACATGCATCGTCAGCTTCTATAACGGAACACAA 780 GACTGGTTCCGTCCAGACTCCGACTTCACCTGCATTATCAGCTTCTTTAACGGAACCAGC 314 ACTGTCCCTTACACAGATTCAATCTATGGTGAAGCTGTGACAACAGCAAATGTCATGACA 378 AATGTCCTTCGTCATGCTTCCATTGATAGTATTAAAGGTGAATCAGAGGGAGGCATGACC 840 ACAGAGCTGTACAGCGCTTCGCTCCAGGGCGAAGCTGCCGCGGCCACAGAGGTGATGAGC 374 AgAGAGAAATATGTGAAGATCACACAGgCTGCCAAACTCACATACAGTGTTTTCATCGCC 438 AGAGAGAAGTATTTGAAGCACACACAAAGTGCCAAACTYTCGTACGGCGTCCTCATCGTG 900 AGAGAGACCTATCTGAGGATCACGCAGGCCGCCAAGCTCTCCTACGGCGTTTTCATCCTC 434 AAGAGCTGCATTTACGgGGCCTTTGTGGTGTTTCTGGTGTGGAAGCTTCAGGGTTCAAAG 498 AAGAGCTGCATCTACGGAGCCTTCATTGGGTTTTTGGTGTGGAAGCTTCAGGGTTCAAGT 960 AAGAGCGTCGTCTACGGGGCCTTCGTGATCTTTCTGGCCTGGAAGCTGCAGG - - - TAGGT 491 GGAAAGCAGAACTACTGAGAGCTGAGGCCAAATCTATTCTAGGAGATCTAGAAGAAGATG 558 GGAAAACACAACAACTAGGCGCCGA - - - - - - - ATCCTGGGAGATG-AGTTCATCTTC 1009

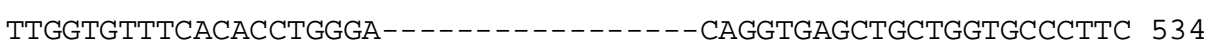


sebastes

fugu

\subsubsection{MHCII}

nilet

$\mathrm{sb}$

rbt

$z f$

nilet

$s b$

rbt

$z f$

nilet

$\mathrm{sb}$

rbt

$z f$

nilet

$\mathrm{sb}$

rbt

$z f$
TGTAACTCTGTAAATATTATATGATAAAAGAGCTGCGTTAGGTTTCTTCTAAAACTGCAT 1069

CTGTGGTCTGACTACTCTCACGGTTCTGGCTGCTCC - -TGTTTCTATTGCAGGGTTGGAC 592

AAGCTTTTGTCAGTAGAAAGAAATTAAAATGCCAAGAAACAGATGTGTCATACTGAGTGG $6 \odot$

- TCA-GAGAC - - - - 8

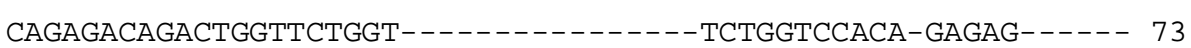

TCAGTATCGGC -

GGTTCTGA-ATGTCT

25

TAAATTCTGATTGgCTGAggtgATTCTGAgGCAGTTATATGGCTCACAAGAGATAGTTAG 120

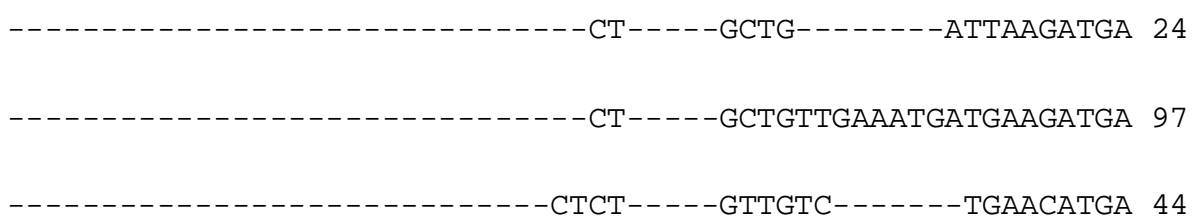

AgCTAGTAAAACTTAATTTGTAGTGTATGTTCTTCTTGGCTCTCAGAAAGATGGAGgTGT 180

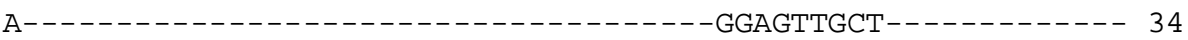

T. 120

A

ATGTGTTCATCCTAACTCTTAGTGTGTTTGTTTCTTCAGAGGTTAATGGTAATCGTATTT 240 
nilet

$\mathrm{sb}$

rbt

$z f$

nilet

$\mathrm{sb}$

rbt

$z f$

nilet

$\mathrm{sb}$

rbt

$z f$

nilet

$\mathrm{sb}$

rbt

zf

- CCTCTTC - - - - - - - СTCTCC

TGTGTTC-T 55

GT - - - - - - CCTCGTC

- СTCTCC

-TGTGTCC-T 143

GT - - - - - CCTCATC

CTCTGC

-TGTCAGG-T 81

TTTTAATTACTTCATCTCTAATTTTACTTTTTGCTGCATTTGTCTTGCAGTTGTGTTCAT 300

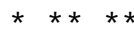

CT - - - - - - GTGTCTCT

GCTGA -

TGGTCAAC 78

CT - - - - - - GTGTCTCA

GCTGA

-AGTTCTTC 166

GT

GACAA -

-AgTtCTGC 104

CTCATAGACGATGTCTTTTGACACTTGACATGGATGATATTTTATCTGTTTCAGTTGTAC $36 \odot$

ATACTGACATCAATATCGTTGGCTGTTCTGACTTTGATGGAGAAGTCATGTATGGACTGG 138 ATCAGGACATTGCTGTCGTTGGCTGTTCAGCCTCTGATGGAGAGATGGTGTACGGTCTGG 226 ATACTGATATATATATTAATGGATGCAGTGATTCAGATGGAGTGGATATGTATGGACTGG 164 ATGAGGATATTGTTATGGACGGATGCTCAGATACAGAGAAAGAGTATATATCTGTTCTTG 420 ATGGTGAAGAGAAGTGGTACGCAGACTTTAACAAACACATCGGAGTGTACCCTCAGCCTC 198 ATGGTGAAGTGATGTGGTACGCAGACTTCAAGAACAAGAAAGGAGTCTACCCTGTTCCTG 286 ATGgTGAAGAGTTGTGGTACGCAGACTTCAACAAAAAGGAGGGAGTGGTGGCTCTGCCTC 224 ATGGAGAgGAAATGTACCATACAGACTTCAGTGGAAAACGGGGAGAGATGACATTGCCTG 480 
nilet

sb

$r b t$

$z f$

nilet

sb

rbt

$z f$

nilet

$\mathrm{sb}$

rbt

$z f$

nilet

sb

rbt

$z f$

nilet

$\mathrm{sb}$

CTTTTGTTGTTAACCCTTTCCACTACCAGGAAGGAACTTATGAAGGCGCTGTGACAAATG 258 ACTTTGTAGgGA - - - - - TTCGCTACCAgGAAgGAGCTTATCAACAAGCTGAgGCTAATC $34 \odot$ CGTTTGCAGATCAGA - - TTTCCTTCCCTGGATA - - - TTATGAACAGGCTGTAGGTAATC 278 ACTTTGCAGATC - - - CTTTTACCTATCCTGGTA - - CTTATGAGCAGAGTCTTGCTGATT 534 TACAGGTCTGCCAAAATGCTCTGAAGATTGTTCGTGAAGCGATGAAG - - - - - - - - - 305 TACAgATCTGCAAAACAAACCTGGATATAGTTCGTCAAGCCTACAAG - - - - - - - - - - 387

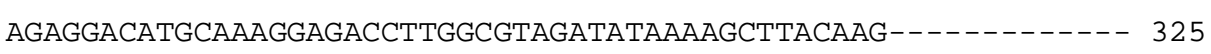
ATGAAACATGCAAACATAACTTAGATGTTGCCGCCAAGgCCTACAAATCACCTTTAgAGA 594

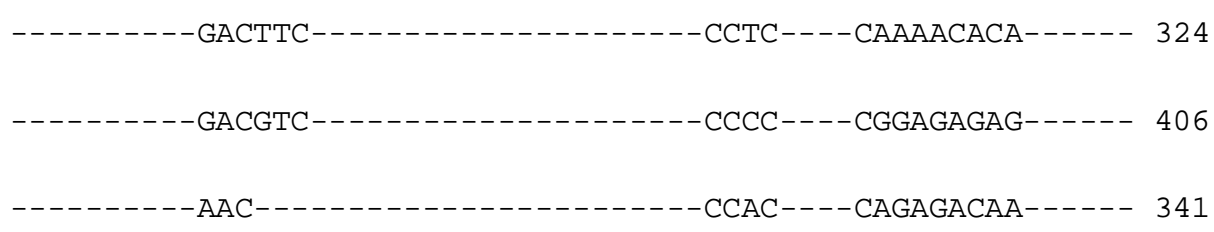
AATTGgGTGAGACTTTATACTTAGTTTTATGgTACTGCTTCTTTACAAAGTGTAAGTATA 654 **
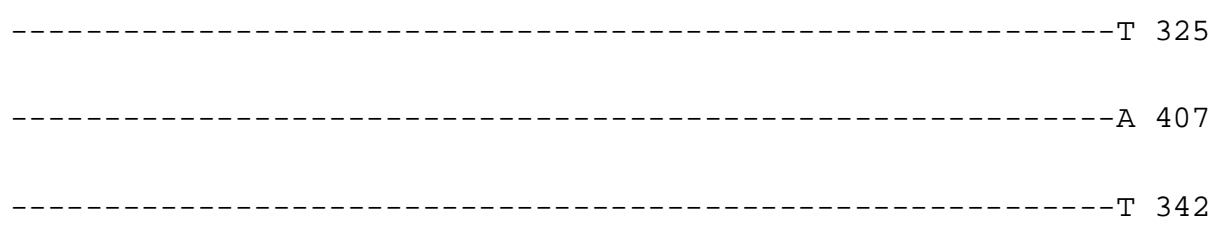

TTAAATCGAGTCATATAAATCCAAATGTTTAAGCAAAGGCAGTTATTTTTTGATCTACCT 714 TGCTCCTTC - - - - - AGCTGTGA - - - TGATCTACACCAGAGATGAGGTGGAGTTTG 372 TGCTCССTC - - - - - - CAGTCCGG - - - TGATCTACCCCAGAGACGAGGTGGAGCTGG 454 
rbt

$z f$

nilet

$\mathrm{sb}$

rbt

$z f$

nilet

$\mathrm{sb}$

rbt

$z f$

nilet

$\mathrm{sb}$

rbt

$z f$

nilet

$\mathrm{sb}$

$\mathrm{rbt}$

$z f$
AGACCCTCCT - - - - - CACAGCAG - - - C-ATCTACCCCAGGGATGACGTGGAACTGG 389 TGCTTCTTTTTTTAGATCCACCTCAGACTTCAATCTATTCAAGGGATGATGTGCAGCCAG 774 GAGTCCAGAACATTCTGATCTGTCATGTGACTGGTTTCTATCCTGCTCCTGTCAATGTCT 432 AAGTGAAGAACATCCTGATCTGTCATGTGACTGGTTTCTATCCTGCTCCTGTGAAGTTCT 514 GGGTGGAGAACACCCTCATCTGCCACGTCAGTGGGTTCTTCCCTTCACCTGTCAGAGTCA 449 ATATTGAAAATAAGCTCATCTGTCATGTGACTGGTTTCTTCCCTCCACCTGTCAGAGTCT 834 CCTGGACCAAGAATGGACAGAAAGTCACTGAAGGATCTAGCATCAAT-GTTCCCTACATC 491 CCTGGACCAAGAACGGAAAGAACGTGACTGAAGGAACCAGCGTCAAC-GTTCCCTACATG 573 GGTGGACCAGGAACGATCAGAATGTAACTGAGGGAGGGCGTATCAGC-ACCCCCTACCCC 508 CCTGGACAAAGAACAACGAGATTGTGACAGAGGGGATGAGTGTAAGCCAGTATCGAC-CA 893

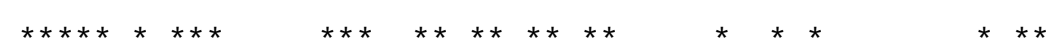
AACAAAGATGGTTCCTTCAAACAGACATCCAGACTGGACTTCACCCCACAGCTGGGAGAC 551 AATAAAGACGGAACCTACAACCAGTTCTCCAAACTGGACTTCACCCCCCAACAAGGAGAC 633 AACACTGATGTCACCTTCAACCAGTTCTCCAGTCTGAGCTTCACCCCAGAGGAGGGAGAC 568 AATAACGATGGCACATATAACATTTTCTCTACTCTAAGATTCACTCCTGTGGAAGGAGAC 953 $\star * \quad * * \quad * \quad * \quad * \quad *$ ATGTACAGCTGTACAgTGGAACATGTGTCCCTGACTGAACCACTAACCAAGATCTATGAT 611 TTCTACAGCTGTTCAGTGTCCCATCCAGCCCTGAAGGACCCACTGACCAGGATCTGGGAT 693 ATCTATGGCTGTACTGTGGAGCACAAGGCCCTTACTGAGCCCCTGACACGGATCTGGGAA 628 ATTTACAGCTGCAGTGTGAACCACAAAACCCTTGAACAGCCTCAAACTAAAGCATGGGGT 1013 
nilet

$\mathrm{sb}$

rbt

$z f$

nilet

$\mathrm{sb}$

rbt

$z f$

nilet

$\mathrm{sb}$

rbt

$z f$

nilet

$\mathrm{sb}$

rbt

$z f$
GTGGATTCATCTGGTCAGTCTGATCCAAGTGTTGGCCCCGCAGCGTTCTGTGGAGTGGGT 671

GTGGA - - - - - - GAAGACTCTG - - CCCGGTGTTGGACCTGCAGTGTTCTGTGGACTGGGT 744 CCTGA - - - - - - GGTGAGCCAG - - CCCAGTGTGGGCCCTGCTGTGTTCTGTGGTGTGGGT 679 - - - GA - - - - - - GATTATTTTT - - - - - TTGTTG - - - TTATATTGTTACAT - - - - - - AT 1047 CTGACTGTGGGTCTGCTCGGTGTGGCTGCTGGAACCTTCTTCCTCATCAAAGGAAACGAG 731 CTGACTGTGGGTCTGCTCGGTGTGGCTGCTGGAACCTTCTTCCTCATCAAAGGAAACGAG $8 \odot 4$ CTGACTCTGG CC - - TTGTAATTCTGTACAAAATAATTG - - - - ACATTGTG - - - GACAAAGTAAACAAC 1096 * $\quad$ *

TGCAGCTGATTGGCTTACAATGATGATGTCATCACGGTTCTGT 774 TGCAGATGATTGGTCGgGGCTGATGATGTCACCTCTGTTCTCTTTGATAACTTTCCTTCA 864 TAC - - - - - - TGG - - - - - TAACGAAAACAACACCATTT 1122 TCTTGTATCAATAAACTCCTGAACACTGTGTTGATCTGATTCCTGCTGAACTGTCACTGA 924 AATGAACTAATAATCAGTGTG ACTGT 800 AAAAATGAATAATC - - TGTG GT 1142 
nilet

$\mathrm{sb}$

rbt

$z f$

nilet

$\mathrm{sb}$

rbt

$z f$

nilet

$\mathrm{sb}$

rbt

zf

nilet

$\mathrm{sb}$

rbt

zf

nilet

$\mathrm{sb}$
TTAGTGTTTGTGTGCATAGTT -CACCTGTT---AATG 843 TCAGTGTGTGTGTGTGTGGCCTGTGTTGGACAGTGACATCATCAGCACCTCCTCCAGGTG 1044

CCATTGCACAT - TACATAATTATAAATG AGCTTTT---- ATG 1179

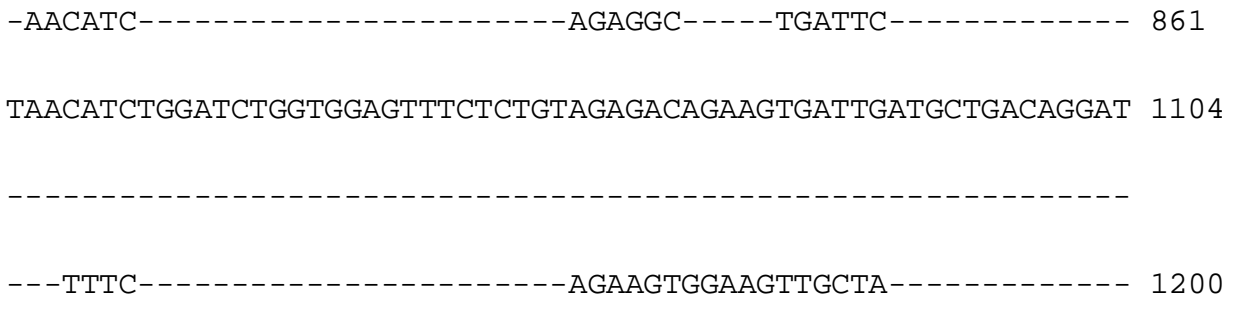

GAGACCATGATCCTGATTTAAAGACGAGGAGACAAAGTCAAGTGTGTGTTGATGCTGAGC 1164 TGCCCAG TGTTGGTCCAG - - - 1218 
rbt

zf

nilet

sb

rbt

zf

nilet

$\mathrm{sb}$

rbt

zf

nilet

$\mathrm{sb}$

rbt

zf

nilet

sb

rbt

zf
- - - GCTGTT - CT - - - - - GTCTGTGATCA - - - TACGTTAATAAAGTTTAACTCTGGAAT 970

CCTGCCGTCACTTATAGAATCCGTCATCAGCCTCATGTGGTTCTGATCCGACTCCTGAAT 1284

- - - - CTGTTTTCT - - - - GGGGCTGCTGGGAGT - - - - TGCTGCTGGAACGTTTTTCCTCA - 1284

TCAAAGCGAACCCAAGCTTCCTG-

-ACCA- - . - - CAGCGTCTGC - 1007

CAGTAACTGATCTAAACTCCCTGTTAGTTTCTCGTTGCACCAACCGGGTCGACGTCTGCT 1344

TAAAAGGAAAC - - - AACTGCA -

-ATTAAAAAAAATGGCATTAAA- 1323

CTTAAACTCAGACGGGTCACTTTTCATTCTGCGTCCCAGCTGACACCGGGTCATACCGGG 1404

TTCCTCT - - - - GGAC

1036

TTCTTCTCACTGAGACCGGCAGAAGTTCAGACTGGGTTTAGTTCTGTTGGTGCAACAGGA 1464

- TCCTTGAA - - AAAC - 
nilet

$\mathrm{sb}$

rbt

$z f$

nilet

$\mathrm{sb}$

rbt

$z f$

nilet

$\mathrm{sb}$

rbt

$z f$

nilet

$\mathrm{sb}$

rbt

$z f$
TCTCTTCCTG -

CCA -

TAAAAAC 1056

TCCATTCTATAGTCTTTTCCTAACTCTGACCAGCTGAGCAGTCAGAACCGGTCTAAAGAC 1524 - АTACTTTCTCT-

-TGAAAAC 1375

AAAGGAG

ATCA - - ATTTGAAATC - -AT 1079

CCGTTGTAGCTGATGGAGCGACTGCAGGTTTAATCCTCCATCACTGATCTGACCTCTGAC 1584

ATGTT - - - - TAAAAGAG -

-TTT- - - АTCTTGC 1398

TT

TTCTGTCTGAACAGAACCAGTGATGAAACATCTGTGAACTGGTCCAGTGAAACTCCCAGA 1644

TTT

-AAAATGAAAGAT

1417

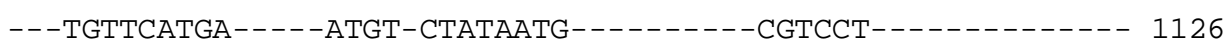

TGTTGCTGATGATTCTGATGTGCTGTAATGTTTGTGAAGACGTTATGTTGAACATCGTGT 1704

- - - - GCATATAA - - - - AT - - - - - TAAA-

1431 
rbt

zf

rbt

$z f$

$\mathrm{sb}$

rbt

zf

\subsection{Sequences}

\subsubsection{IgM sequence}

Forward Frame 1:

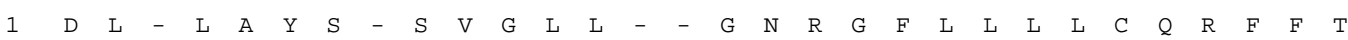
1 GATTTATAACTTGCCTACTCTTAGAGTGTTGGCCTCCTCTGATGAGGAAACCGAGGCTTCCTTCTCCTGCTTTGCCAAAGATTTTTCACC
$\begin{array}{llllllllllllllllllllllllllllllll}31 & K & R & V & - & V & Q & M & L & K & N & E & V & E & I & P & N & K & I & H & E & I & K & T & P & S & E & E & R & K & D\end{array}$
91 AAACGAGTATGAGTTCAAATGCTGAAGAATGAAGTGGAAATCCCCAACAAAATACACGAGATCAAAACACCTTCTGAGGAAAGAAAGGAC 


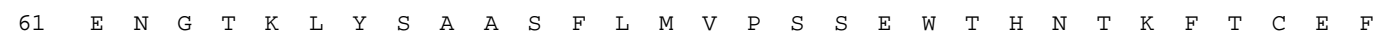

181 GAGAATGGAACTAAACTGTACAGTGCAGCAAGTTTTCTCATGGTACCGTCCAGTGAGTGGACTCACAACACTAAGTTTACATGTGAGTTT

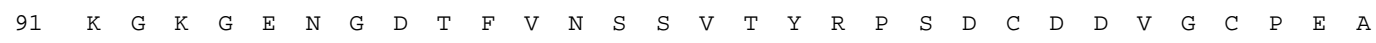

271 AAGGGGAAGgGTGAAAACGgTGATACATTCGTGAATTCATCTGTGACCTACAGACCTTCAGATTGTGATGATGTAGGATGTCCTGAAGCA

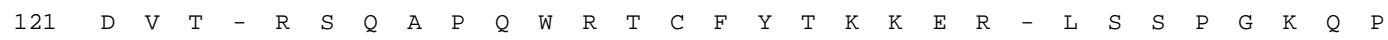

361 GATGTGACATAAAGATCACAGGCCCCACAATGGAGGACATGTTTTTATACAAAAAAGGAAAGATAGTTGTCGAGTCCAGGTAAACAACCA

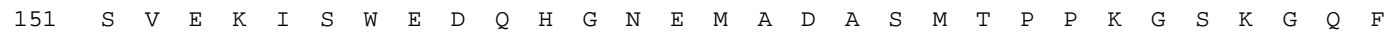

451 TCTgtCGAGAAGATTTCGTGgGAgGACCAGCATGGAAACGAAATGGCTGATGCCTCCATGACCCCCCCTAAAGGAAGTAAAGGCCAATTC

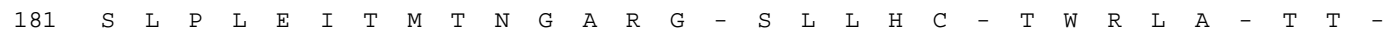

541 AgCCTTCCACTTGAAATCACTATGACGAATGGAGCAAGgGGATAAAGCCTACTGCATTGTTGAACATGGAGACTGGCTTGAACCACTTAA

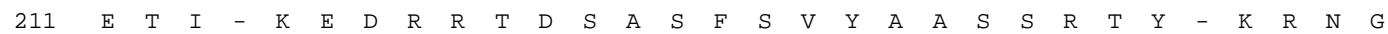

631 GAAACAATATGAAAgGAAGATCGgAGAACAGACTCAgCGTCCTTCAGTGTTTATGCTGCCTCCAGTAGAACATACTAGAAAAGAAATGGT

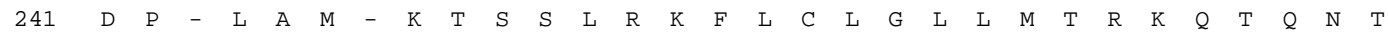

721 GACCCCTGACTTGCTATgTGAAAGACTTCTTCCCTCAGGAAGTTTTTGTGTCTTGGCTTGTTGATGACGAGgAAGCAGACTCAAAATACG

$\begin{array}{lllllllll}271 & S & P & Y & H & K & P & R\end{array}$

811 AgtCCATACCACAAACCGAGAAT

\subsubsection{IgZ sequence}

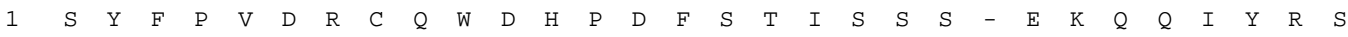

1 TCTTACTTTCCAGTgGACCGATGCCAGTGgGACCACCCTGACTTCAgTACAATATCCTCCAGCTgAgAAAAACAACAAATATACAGGAGT

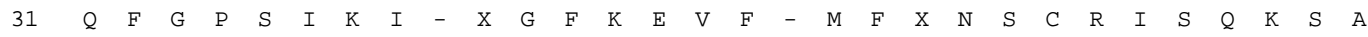




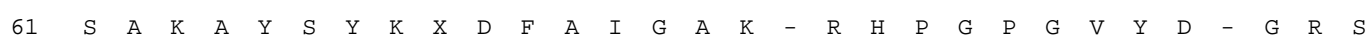

181 AgTGCAAAAGCCTATTCCTACAAANGTGACTTTGCTATCGGTGCCAAGTGAAGGCACCCAGGCCCTGGTGTGTACGATTGAGGACGGTCG

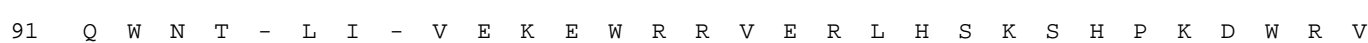

271 CAATGGAACACTTGACTCATTTAAGTGGAAAAAGAATGGCGCAGAGTTGAACGACTACATTCAAAGTCCCATCCAAAAGATTGGAGAGTT

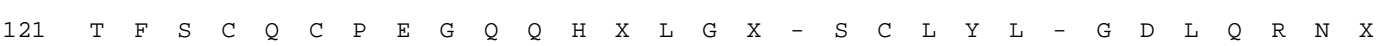

361 ACATTCAGCTGTCAGTGTCCTGAAGgTCAGCAACACANACTGGGACANTAAAGCTGTTTATACCTGTGAGGTGATTTACAGAGGAACANA

151 I $\quad-\quad X \quad X \quad G \quad L \quad X \quad S \quad S \quad X$

451 ATATAANAANAAGGCCTCNAAAGCTCCNAT

\subsection{3. $M H C I I \alpha$}

Forward Frame 1:

$\begin{array}{llllllllllllllllllllllllllllllllll}1 & N & Q & Q & I & C & K & D & N & L & K & V & D & L & Q & A & Y & K & N & P & P & L & Q & L & D & P & P & S & S & P & M\end{array}$

1 AATCAACAGATCTGCAAAGATAACCTGAAAGTGGATCTCCAGGCCTATAAGAACCCTCCTCTACAGCTCGATCCTCCTTCCAGTCCGATG

$\begin{array}{lllllllllllllllllllllllllllllllllllll}31 & \mathrm{I} & \mathrm{Y} & \mathrm{P} & \mathrm{R} & \mathrm{D} & \mathrm{D} & \mathrm{V} & \mathrm{E} & \mathrm{L} & \mathrm{E} & \mathrm{Q} & \mathrm{Q} & \mathrm{N} & \mathrm{H} & \mathrm{L} & \mathrm{I} & \mathrm{C} & \mathrm{H} & \mathrm{V} & \mathrm{T} & \mathrm{G} & \mathrm{F} & \mathrm{Y} & \mathrm{P} & \mathrm{A} & \mathrm{P} & \mathrm{V} & \mathrm{K} & \mathrm{I} & \mathrm{Y}\end{array}$

91 ATCTACCCCAGAGACGACGTGGAGCTGGAACAGCAGAACCACCTCATCTGTCATGTGACCGGTTTCTATCCTGCTCCTGTAAAGATCTAC

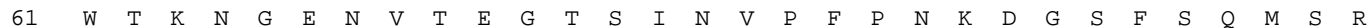

181 TGGACGAAGAACGGAGAGAACGTGACCGAAGGAACCAGCATCAATGTTCCCTTCCCCAACAAAGACGgTTCCTTCAGCCAGATGTCCAGA

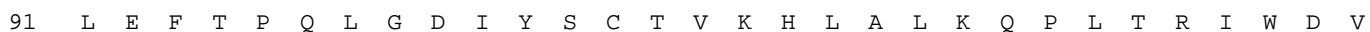

271 CTGGAGTTCACCCCACAGCTGGGAGACATTTACAGCTGTACAGTGAAACATCTGGCCCTGAAGCAACCACTGACCAGAATCTGGGATGTG

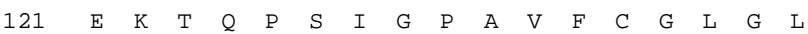

361

GAGAAGACTCAGCCCAGTATTGGACCTGCAGTGTTTTGTGGACTGGGTCT 


\subsection{Complement photos}

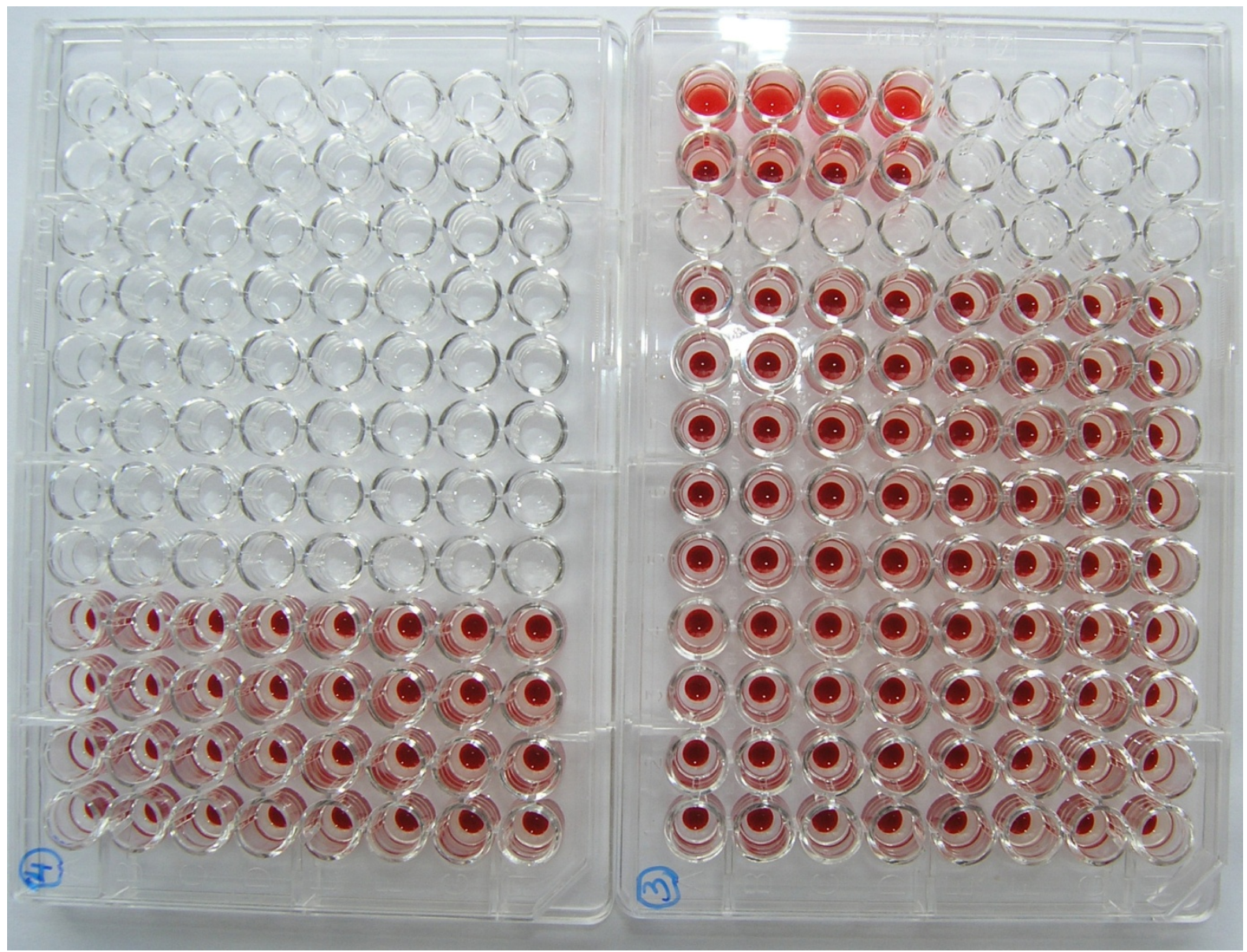




\subsection{Leucocyte Statistical data}

\begin{tabular}{|c|c|c|c|c|c|}
\hline Head kidney & & & & & \\
\hline juveniles & & & & & \\
\hline 127 dph & & & & & \\
\hline Sample & Granulocytes, & Lymphocytes & monocytes,Fr & Progenitors,Fre & eq. of Parent \\
\hline 1: control1.01 & $1 \quad 1.73$ & 28.4 & 0.777 & 42.1 & \\
\hline 2: control1.01 & 1.48 & 20.9 & 0.43 & 44.3 & \\
\hline 3: control2.01 & 8.53 & 41.4 & 5.45 & 28.8 & \\
\hline 4: control3.01 & 5.39 & 29 & 14.6 & 22.1 & \\
\hline 5: control4.01 & 7.31 & 38.5 & 22 & 7.2 & \\
\hline 6: control5.01 & 4.82 & 40.8 & 15.3 & 15.5 & \\
\hline 7: control6.01 & 5.51 & 50.5 & 12.4 & 11.5 & \\
\hline Mean & 4.97 & 35.6 & 10.1 & 24.5 & \\
\hline StdDev & 2.62 & 10 & 8.13 & 14.6 & \\
\hline STdERROR & 0.99183984 & 3.78775327 & 3.07149062 & 5.51046623 & \\
\hline Adults & granulocytes, & lymphocyte, F & monocytes, Fr & progenitors,Fre & eq. of Parent \\
\hline 1: HKadult1.( & $\quad 27.1$ & 34.2 & 16.6 & 1.86 & \\
\hline 2: HKadult2.( & 28.4 & 33.2 & 17.1 & 2.03 & \\
\hline 3: HKadult3.1 & 38.1 & 18.2 & 23.7 & 1.11 & \\
\hline 5: HK2.002 & 53.9 & 6.68 & 22 & 0.55 & \\
\hline 6: HK3.003 & 31.5 & 27.2 & 14.6 & 1.62 & \\
\hline 7: HK4.004 & 58.6 & 8.19 & 10.4 & 1.44 & \\
\hline 8: HK5.005 & 28.5 & 31.6 & 14.6 & 1.45 & \\
\hline Mean & 38.0142857 & 22.7528571 & 17 & 1.43714286 & \\
\hline StdDev & 12.7 & 10.9 & 4.26 & 0.457 & \\
\hline StdERROR & 4.92962032 & 4.44375148 & 1.72612972 & 0.18631405 & \\
\hline & $p=0.00043$ & $p=0.04802$ & $p=0.08172$ & $p=0.00577$ & \\
\hline PBL & & & & & \\
\hline juveniles & & & & & \\
\hline $134 \mathrm{dph}$ & & & & & \\
\hline Sample & granulocytes, & Lymphocytes & Monocytes,Frı & Progenitors,Fre & eq. of Parent \\
\hline 1: juvenile1P & 2.85 & 81.5 & 2.04 & 0.61 & \\
\hline 2: juvenile2P & 10.4 & 56.4 & 10.4 & 1.3 & \\
\hline 3: juvenile3P & 3.75 & 76.7 & 3.18 & 0.401 & \\
\hline Mean & 5.67 & 71.5 & 5.21 & 0.77 & \\
\hline StdDev & 4.12 & 13.3 & 4.53 & 0.47 & \\
\hline $\begin{array}{l}\text { StdERROR } \\
\text { adults }\end{array}$ & 2.38088452 & 7.69249273 & 2.61743725 & 0.27161881 & \\
\hline Sample & granulocytes, & lymphocyte,F & monocytes, $\operatorname{Fr}$ & progenitors,Fre & eq. of Parent \\
\hline 1: PBLadult1. & 6.59 & 70.6 & 3.66 & 1.23 & \\
\hline 2: PBLadult2. & 7 & 71.1 & 4.17 & 1.41 & \\
\hline 3: PBLadult3. & 13 & 57.6 & 3.57 & 0.959 & \\
\hline Mean & 8.86 & 66.4 & 3.8 & 1.2 & \\
\hline StdDev & 3.59 & 7.65 & 0.324 & 0.227 & \\
\hline StdERROR & 2.07171695 & 4.41902453 & 0.18681542 & 0.13107292 & \\
\hline & $p=0.36943$ & $p=0.60342$ & $p=0.64508$ & $p=0.25321$ & \\
\hline
\end{tabular}




\begin{tabular}{|c|c|c|}
\hline $\begin{array}{l}\text { head kidney } \\
\text { Adults }\end{array}$ & & \\
\hline Sample I & Iymphocyte,F I & ymphocyte/IgM+,Freq. of Parent \\
\hline 1: HKadult1.( & $\quad 37.9$ & 21.5 \\
\hline 2: HKadult2.( & 36.3 & 23.5 \\
\hline 3: HKadult3.( & 21.5 & 30.9 \\
\hline Mean & 31.9 & 25.3 \\
\hline StdDev & 9.04 & 4.95 \\
\hline STERROR & 5.2204725 & 2.8589042 \\
\hline head kidney & & \\
\hline Juvenile & & \\
\hline Sample I & lymphocyte, F I & ymphocyte/IgM+,Freq. of Parent \\
\hline 1: HKjuvenile & 31.8 & 18.9 \\
\hline 2: HKjuvenile & 34.8 & 16.6 \\
\hline 3: HKjuvenile & 28.1 & 30 \\
\hline Mean & 31.6 & 21.8 \\
\hline StdDev & 3.36 & 7.17 \\
\hline STERROR & $\begin{array}{c}1.9376389 \\
p=0.95665\end{array}$ & $\begin{array}{r}4.1369608 \\
=0.53292 \\
\end{array}$ \\
\hline PBL & & \\
\hline Adults & lymphoryte F I & vmnhoryte/IaM+ Freo of Darent \\
\hline 1: PBLadult1. & $\begin{array}{r}66.2 \\
66.2\end{array}$ & $\begin{array}{c}17.1 \\
17.4 \text {, }\end{array}$ \\
\hline 2: PBLadult2. & 69.4 & 16.9 \\
\hline 3: PBLadult3. & 58.6 & 11.3 \\
\hline Mean & 64.7 & 15.1 \\
\hline StdDev & 5.55 & 3.29 \\
\hline STDERROR & 3.2027766 & 1.900877 \\
\hline PBL & & \\
\hline Juveniles & & \\
\hline Sample I & lymphocyte, F I & ymphocyte/IgM+,Freq. of Parent \\
\hline 1: PBLjuvenil & $\quad 41.7$ & 26.7 \\
\hline 2: PBLjuvenilı & 57.1 & 12.8 \\
\hline 3: PBLjuvenil & 59.1 & 26.2 \\
\hline Mean & 52.6 & 21.9 \\
\hline StdDev & 9.52 & 7.88 \\
\hline STDERROR & $\begin{array}{c}5.4970699 \\
p=0.1471\end{array}$ & $\begin{array}{r}4.5522888 \\
=0.27197\end{array}$ \\
\hline
\end{tabular}


Abdel-Aziz, E. H., Abdu, S. B., Ali Tel, S. and Fouad, H. F. (2010). Haemopoiesis in the head kidney of tilapia, Oreochromis niloticus (Teleostei: Cichlidae): a morphological (optical and ultrastructural) study. Fish physiology and biochemistry 36(3): 323-336.

Abelli, L., Picchietti, S., Romano, N., Mastrolia, L. and Scapigliati, G. (1996). Immunocytochemical detection of thymocyte antigenic determinants in developing lymphoid organs of sea bass Dicentrarchus labrax (L.). Fish \& shellfish immunology 6: 493-505.

Abelli, L., Picchietti, S., Romano, N., Mastrolia, L. and Scapigliati, G. (1997). Immunohistochemistry of gut-associated lymphoid tissue of the sea bass Dicentrarchus labrax (L.). Fish \& shellfish immunology 7: 235-245.

Afonso, A., Ellis, A. E. and Silva, M. T. (1997). The leucocyte population of the unstimulated peritoneal cavity of rainbow trout (Oncorhynchus mykiss). Fish \& shellfish immunology 7: 335-348.

Agius, C. (1980). Phylogenetic development of melano-macrophage centres in fish. Journal of Zoology 191: 11-31.

Agius, C. and Roberts, R. J. (2003). Melano-macrophage centres and their role in fish pathology. Journal of Fish Diseases 26: 499-509.

Akmirza, A. and Tepecik, R. E. (2007). Seasonal variation in some haematological parameters in naturally infected and uninfected roach (Rutilus rutilus) with Cryptobia tincae. Journal of Applied Biological Sciences 1(3): 61-65.

Al-Adhami, M. A. and Kunz, Y. W. (1976). Haemopoietic centres in the developing angelfish, Pterophyllum scalare, (Cuvier and Valenciennes). Development Genes and Evolution 179(4): 393-401.

Anstee, D. J., Holt, P. H. and Pardoe, G. I. (1973). Agglutinins from fish ova defining blood groups B and P. Vox Sanguinis 25: 347-360.

Aparicio, S., Chapman, J., Stupka, E., Putnam, N., Chia, J., Dehal, P., Christoffels, A., Rash, S., Hoon, S., Smit, A., Gelpke, M. D. S., Roach, J., Oh, T., Ho, I. Y., Wong, M., Detter, C., Verhoef, F., Predki, P., Tay, A., Lucas, S., et al. (2002). Whole-Genome Shotgun Assembly and Analysis of the Genome of Fugu rubripes. Science 297(5585): 1301-1310. 
Bakopoulos, V., Peric, Z., Rodger, H., Adams, A. and Richards, R. H. (1997). First report of fish Pasteurellosis from Malta. Journal of Aquatic Animal Health 9: 26-33.

Balcazar, J. L., de Blas, I., Ruiz-Zarzuela, I., Cunningham, D., Vendrell, D. and Muzquiz, J. L. (2006). The role of probiotics in aquaculture. Veterinary microbiology 114(3-4): 173-186.

Beentjes, M. P. and Francis, M. P. (1999). Movement of hapuka \{Polyprion oxygeneios) determined from tagging studies. New Zealand Journal of Marine and Freshwater Research 33: $1-12$.

Bengtén, E., Leanderson, T. and Pilström, L. (1991). Immunoglobulin heavy chain cDNA from the Teleost Atlantic cod (Gadus morhua L.): nucleotide sequences of secretory and membrane form show an unusual splicing pattern. European Journal of Immunology 21: 3027-3033.

Bengtén, E., Quiniou, S., Hikima, J., Waldbieser, G., Warr, G. W., Miller, N. W. and Wilson, M. (2006). Structure of the catfish IGH locus: analysis of the region including the single functional IGHM gene. Immunogenetics 58(10): 831-844.

Bielek, E. (1981). Developmental stages and localization of peroxidatic activity in the leucocytes of three teleost species (Cyprinus carpio L.: Tinca tinca L.; Salmo gairdneri Richardson). Cell and tissue research 220: 163-180.

Bisbal, G. A. and Bengtson, D. S. (1995). Development of the digestive tract in larval summer flounder. Journal of Fish Biology 47: 277-291.

Bjorkman, P. J., Saper, M. A., Samraoui, B., Bennett, W. S., Strominger, J. L. and Wiley, D. C. (1987). The foreign antigen binding site and $\mathrm{T}$ cell recognition regions of class $\mathrm{I}$ histocompatibility antigens. Nature 329: 512-518.

Blaxter, J. H. S. (1988). Pattern and variety in development. Fish physiology XI. The physiology of developing fish. Part A. Eggs and larvae. New York, Academic Press: 1-58.

Blazer, V. S. (1992). Nutrition and disease resistance in fish. Annual Review of Fish Disease 1: 309-323. 
Bly, J. E. and Clem, L. W. (1991). Temperature-mediated processes in teleost immunity: in vitro immunosuppression induced by in vivo low temperature in channel cat fish. Veterinary immunology and immunopathology 28: 365-377.

Boes, M. (2000). Role of natural and immune IgM antibodies in immune responses. Molecular immunology 37: 114-119.

Bondad-Reantaso, M. G., Subasinghe, R. P., Arthur, J. R., Ogawa, K., Chinabut, S., Adlard, R., Tan, Z. and Shariff, M. (2005). Disease and health management in Asian aquaculture. Veterinary parasitology 132(3-4): 249-272.

Boshra, H., Li, J. and Sunyer, J. O. (2006). Recent advances on the complement system of teleost fish. Fish \& shellfish immunology 20(2): 239-262.

Botham, J. W. and Manning, M. J. (1981). The histogenesis of the lymphoid organs in the carp Cyprinus carpio L and the ontogenetic development of allograft reactivity. Journal of Fish Biology 19: 403-414.

Bowden, T. J., Cook, P. and Rombout, J. H. (2005). Development and function of the thymus in teleosts. Fish \& shellfish immunology 19(5): 413-427.

Brattgjerd, S. and Evensen, O. (1996). A sequential light microscopic and ultrastructural study on the uptake and handling of Vibrio salmonicida inthe head kidney phagocytes of experimentally infected Atlantic salmon, Salmo salar L. Veterinary Pathology 33: 55-65.

Breuil, G., Vassiloglou, B., Pepin, J. F. and Romestand, B. (1997). Ontogeny of IgM-bearing cells and changes in the immunoglobulin M-like protein level (IgM) during larval stages in sea bass (Dicentrarchus labrax). Fish \& shellfish immunology 7: 29-43.

Bromage, E. S., Kaattari, I. M., Zwollo, P. and Kaattari, S. L. (2004). Plasmablast and Plasma Cell Production and Distribution in Trout Immune Tissues. The Journal of Immunology 173: 7317-7323.

Brown, J. H., Jardetzky, T. S., Gorga, J. C., Stern, L. J., Urban, R. G., Strominger, J. L. and Wiley, D. C. (1993). Three-dimensional structure of human class II histocompatibility antigen HLA-DRl. Nature 364: 33-39. 
Buonocore, F., Randelli, E., Casani, D., Costantini, S., Facchiano, A., Scapigliati, G. and Stet, R. J. (2007). Molecular cloning, differential expression and 3D structural analysis of the MHC class-II beta chain from sea bass (Dicentrarchus labrax L.). Fish \& shellfish immunology 23(4): 853-866.

Cannon, M. S., Mollenhauer, H. H., Eurell, T. E., Lewis, D. H., Cannon, A. M. and Tompkins, C. H. (1980). An ultrastructural study of the leucocytes of the channel catfish, Ictalurus punctatus. Journal of Morphology 164: 1-23.

Castillo, A., Razquin, B. E., Lopez-Fierro, P., Alvarez, F., Zapata, A. and Villena, A. J. (1990). Enzyme- and immuno-histochemical study of the thymic stroma in the rainbow trout, Salmo gairdneri, Richardson. Thymus 15: 153-166.

Castillo, A., Sanchez, C., Dominguez, J., Kaattari, S. L. and Villena, A. J. (1993). Ontogeny of IgM and IgM-bearing cells in rainbow trout. Developmental \& Comparative Immunology 17: 419-424.

Castro, R., Bernard, D., Lefranc, M. P., Six, A., Benmansour, A. and Boudinot, P. (2010). T cell diversity and TcR repertoires in teleost fish. Fish \& shellfish immunology.

Cecchini, S., Terova, G., Caricato, G. and Saroglia, M. (2000). Lysosome activity in embryos and larvae of sea bass (Dicentrarchus labrax L.), spawned by broodstocks fed with vitamin C enriched diets. The European Association of Fish Pathologists 20: 120-124.

Cenini, P. (1984). The ultrastructure of leucocytes in carp (Cyprinus carpio). Journal of Zoology 204: 509-520.

Cerda-Reverter, J. M., Zanuy, S., Carrillo, M. and Madrid, J. A. (1998). Time-course studies on plasma glucose, insulin, and cortisol in sea bass (Dicentrarchus labrax) held under different photoperiodic regimes. Physiology and Behavior 64(3): 245-250.

Chantanachookhin, C., Seikai, T. and Tanaka, M. (1991). Comparative study of the ontogeny of the lymphoid organs in three species of marine fish. Aquaculture 99: 143-155.

Chaves-Pozo, E., Munoz, P., Lopez-Munoz, A., Pelegrin, P., Garcia Ayala, A., Mulero, V. and Meseguer, J. (2005). Early innate immune response and redistribution of inflammatory 
cells in the bony fish gilthead seabream experimentally infected with Vibrio anguillarum. Cell and tissue research 320(1): 61-68.

Chilmonczyk, S. (1992). The thymus in fish: development and possible function in the immune response. Annual Review of Fish Disease 2: 181-200.

Clay, H., Davis, J. M., Beery, D., Huttenlocher, A., Lyons, S. E. and Ramakrishnan, L. (2007). Dichotomous role of the macrophage in early Mycobacterium marinum infection of the zebrafish. Cell Host and Microbe 2(1): 29-39.

Clay, H. and Ramakrishnan, L. (2005). Multiplex fluorescent in situ hybridization in zebrafish embryos using tyramide signal amplification. Zebrafish 2(2): 105-111.

Clem, L. W. and Mclean, W. E. (1975). Phylogeny of immunoglobulin structure and function. VII. Monomeric and tetrameric immunoglobulins of the margate, a marine teleost. Immunology 29: 791-799.

Corripio-Miyar, Y., Bird, S., Treasurer, J. W. and Secombes, C. J. (2007). RAG-1 and IgM genes, markers for early development of the immune system in the gadoid haddock, Melanogrammus aeglefinus, L. Fish \& shellfish immunology 23(1): 71-85.

Dale, D. C., Boxer, L. and Liles, W. C. (2008). The phagocytes: neutrophils and monocytes. Blood 112(4): 935-945.

Danilova, N., Bussmann, J., Jekosch, K. and Steiner, L. A. (2005). The immunoglobulin heavy-chain locus in zebrafish: identification and expression of a previously unknown isotype, immunoglobulin Z. Nature Immunology 6(3): 295-302.

Danilova, N., Hohman, V. S., Sacher, F., Ota, T., Willett, C. E. and Steiner, L. A. (2004). T cells and the thymus in developing zebrafish. Developmental and comparative immunology 28(7-8): 755-767.

Danilova, N. and Steiner, L. A. (2002). B cells develop in the zebrafish pancreas. PNAS 99: 13711-13716. 
Dannevig, B. H., Lauve, A., Press, C. M. and Landsverk, T. (1994). Receptor-mediated endocytosis and phagocytosis by rainbow trout head kidney sinusoidal cells. Fish \& shellfish immunology 4: 3-18.

Das, A. B. and Ratha, B. K. (1996). Physiological adaptive mechanisms of catfish (Siluroidei) to environmental changes. Aquatic Living Resources 9: 135-143.

Demers, N. E. and Bayne, C. J. (1997). The immediate effects of stress on hormones and plasma lysozyme in rainbow trout. Developmental \& Comparative Immunology 21(3): 63-73.

Demers, N. E., Jolles, J. and Jolles, P. (1988). The immediate effects of stress on hormones and plasma lysozyme in rainbow trout. European Journal of Immunology 173(269-273).

Dos Santos, N. M., Romano, N., de Sousa, M., Ellis, A. E. and Rombout, J. H. (2000). Ontogeny of $\mathrm{B}$ and $\mathrm{T}$ cells in sea bass (Dicentrarchus labrax, L.). Fish \& shellfish immunology 10(7): 583-596.

Ellingsen, T., Strand, C., Monsen, E., Bogwald, J. and Dalmo, R. A. (2005). The ontogeny of complement component C3 in the spotted wolffish (Anarhichas minor Olafsen). Fish \& shellfish immunology 18(5): 351-358.

Ellis, A. E. (1977a). The leucocytes of fish: A review. Journal of Fish Biology 11: 453-491.

Ellis, A. E. (1977b). Ontogeny of the immune response in Salmo salar. Histogenesis of the lymphoid organs and appearance of membrane immunoglobulin and mixed leucocyte reactivity. Developmental Immunobiology: 225-231.

Ellis, A. E. (1998). Ontogeny of the immune system. Handbook of vertebrate immunology. Pastore, P. P., Griebel, P., Bazin, H. and Govaerts, A. USA, Academic Press: 25-30.

Ellis, A. E. (1999). Immunity to bacteria in fish. Fish \& shellfish immunology 9: 291-308.

Espenes, A., Press, C. M., Dannevig, B. H. and Landsverk, T. (1995). Investigation of the structural and functional features of splenic ellipsoids in rainbow trout (Oncorhynchus mykiss). Cell and tissue research 279: 469-474.

Esteban, M. A., Munoz, J. and Meseguer, J. (2000). Blood Cells of Sea Bass (Dicentrarchus labrax L.). Flow Cytometric and Microscopic Studies. The anatomical record 258: 80-89. 
Evans, D. A., Klemer, J. V. and Kaattari, S. L. (1998). Heuristic models of the intermonometric disulfide bonding process in teleost IgM. Journal of Theoretical Biology 195: 505-524.

Evans, D. H. (1998). The physiology of fishes. Boca Raton, CRC Press.

Falk-Petersen, I. and Hansen, T. K. (2003). Early ontogeny of the spotted wolffish (Anarhichas minor Olafsen). Aquaculture Research 34: 1059-1067.

Falk-Petersen, I. B. (2005). Comparative organ differentiation during early life stages of marine fish. Fish \& shellfish immunology 19(5): 397-412.

Fänge, R. (1986). Lymphoid organs in sturgeons (Acipenseridae). Veterinary immunology and immunopathology 12: 153-161.

Fänge, R., Lundblad, G. and Lind, J. (1976). Lysozyme and chitinase in blood and lymphomyeloid tissues of marine fish. Marine Biology 36: 277-282.

Fänge, R. and Nilsson, S. (1985). The fish spleen: structure and function. Experimentia 41: 152-158.

Ferguson, H. W. (1976). The relationship between ellipsoids and melano-macrophage centres in the spleen of turbot (Scophthalmus maximus). Journal of Comparative Pathology 86: 377380.

Fischer, U., Dijkstra, J. M., Kollner, B., Kiryu, I., Koppang, E. O., Hordvik, I., Sawamoto, Y. and Ototake, M. (2005). The ontogeny of MHC class I expression in rainbow trout (Oncorhynchus mykiss). Fish \& shellfish immunology 18(1): 49-60.

Fishelson, L. (1995). Cytological and morphological ontogenesis and involution of the thymus in cichlid fishes (Cichlidae, Teleostei). Journal of morphology 223: 175-190.

Fixe, P. and Praloran, V. (1997). Macrophage colony-stimulating-factor (M-CSF or CSF-1) and its receptor: structure-function relationships. European Cytokine Network 8: 125-136.

Flajnik, M. F. and Kasahara, M. (2010). Origin and evolution of the adaptive immune system: genetic events and selective pressures. Nature Reviews Genetics 11: 47-59. 
Fletcher, T. C. and Grant, P. T. (1969). Immunoglobulins in the serum and mucus of the plaice (Pleuronectes platessa). Biochemical Journal 115(5): 65.

Fournier-Betz, V., Quentel, C., Lamour, F. and LeVen, A. (2000). Immunocytochemical detection of Ig-positive cells in blood, lymphoid organs and the gut associated lymphoid tissue of the turbot (Scophthalmus maximus). Fish \& shellfish immunology 10(2): 187-202.

Frank, K. T., Petrie, B., Choi, J. S. and Leggett, W. C. (2005). Trophic cascades in a formerly cod-dominated ecosystem. Science 308: 1621-1623.

Galloway, J. L. and Zon, L. I. (2003). Ontogeny of hematopoiesis: examining the emergence of hematopoietic cells in the vertebrate embryo. Current Topics in Developmental Biology 53: 139-158.

Gambon-Deza, F., Sanchez-Espinel, C. and Magadan-Mompo, S. (2010). Presence of an unique IgT on the IGH locus in three-spined stickleback fish (Gasterosteus aculeatus) and the very recent generation of a repertoire of VH genes. Developmental \& Comparative Immunology 34: 114-122.

Garcia-Hernandez, M. P., Lozano, M. T., Elbal, M. T. and Agullerio, B. (2001). Development of the digestive tract of sea bass (Dicentrarchus labrax L.). Light and electron microscopic studies. Anatomy and embryology 204: 39-57.

Giraldez, A. J., Mishima, Y., Rihel, J., Grocock, R. J., Van Dongen, S., Inoue, K., Enright, A. J. and Schier, A. F. (2006). Zebrafish MiR-430 promotes deadenylation and clearance of maternal mRNAs. Science 312(5770): 75-79.

Glynn, A. A. (1969). The complement lysozyme sequence in immune bacteriolysis. Immunology 16: 463-471.

Gordon, S. (2007). The macrophage: past, present and future. European Journal of Immunology 37(1): 9-17.

Grindstaff, J. L., Brodie, E. D., III and Ketterson, E. D. (2003). Immune function across generations: integrating mechanism and evolutionary process in maternal antibody transmission. Proceedings of the Royal Society 270: 2309-2319. 
Hamlin, H. J., Herbing, I. H. V. and Kling, L. J. (2000). Histological and morphological evaluations of the digestive tract and associated organs of haddock through post-hatching ontogeny. Journal of Fish Biology 57: 716-732.

Hanif, A., Bakopoulos, V. and Dimitriadis, G. J. (2004). Maternal transfer of humoral specific and non-specific immune parameters to sea bream (Sparus aurata) larvae. Fish \& shellfish immunology 17(5): 411-435.

Hanif, A., Bakopoulos, V., Leonardos, I. and Dimitriadis, G. J. (2005). The effect of sea bream (Sparus aurata) broodstock and larval vaccination on the susceptibility by Photobacterium damsel subsp. piscicida and on the humoral immune parameters. Fish \& shellfish immunology 19: 345-361.

Hanington, P. C., Hitchen, S. J., Beamish, L. A. and Belosevic, M. (2009a). Macrophage colony stimulating factor (CSF-1) is a central growth factor of goldfish macrophages. Fish \& shellfish immunology 26: 1-9.

Hanington, P. C., Tam, J., Katzenback, B. A., Hitchen, S. J., Barreda, D. R. and Belosevic, M. (2009b). Development of macrophages of cyprinid fish. Developmental and comparative immunology 33(4): 411-429.

Hansen, J. D., Landis, E. D. and Phillips, R. B. (2005). Discovery of a unique Ig heavy-chain isotype (IgT) in rainbow trout: implications for a distinctive B cell developmental pathway in teleost fish. PNAS 102(19): 6919-6924.

Hansen, J. D. and Zapata, A. G. (1998). Lymphocyte development in fish and amphibians. Immunological Reviews 166: 199-220.

Herbomel, P., Thisse, B. and Thisse, C. (1999). Ontogeny and behaviour of early macrophages in the zebrafish embryo. Development 126: 3735-3745.

Herraez, M. P. and Zapata, A. G. (1986). Structure and function of the melanomacrophage centres of the goldfish Carassius auratus. Veterinary immunology and immunopathology 12: 117-126.

Hine, P. M., Wain, J. M. and Boustead, N. C. (1987). The leucocyte enzyme cytochemistry of fish. New Zealand Fisheries Research Bulletin 28: 1-74. 
Hoehne-Reitan, K. and Kjørsvik, E. (2004). Functional development of the liver and exocrine pancreas. American Fisheries Society 40: 9-36.

Hordvik, I., Voie, A. M., Glette, J., Male, R. and Endresen, C. (1992). Cloning and sequence analysis of two isotypic IgM heavy chain genes from Atlantic salmon, Salmo salar L. European Journal of Immunology 22: 2957-2962.

Houde, E. D. (1993). Differences between marine and freshwater fish larvae: implications for recruitment. Journal of Marine Science 51(1): 91-97.

Howell, B. R., Day, O. J., Ellis, T. and Baynes, S. M. (1998). Early life stages of farmed fish. Biology of farmed fish. Black, K. D. and Pickering, A. England: Sheffield, Academic Press: 27-66.

Huttenhuis, H. B. T., Grou, C. P. O., Taverne-Thiele, A. J., Taverne, N. and Rombout, J. H. W. M. (2006). Carp (Cyprinus carpio L.) innate immune factors are present before hatching. Fish \& shellfish immunology 20(4): 586-596.

Inami, M., Taverne-Thiele, A. J., Schrøder, M. B., Viswanath, K. and Rombout, J. H. W. M. (2009). Immunological differences in intestine and rectum of Atlantic cod (Gadus morhua L.). Fish \& shellfish immunology 26: 751-759.

Iuchi, I. and Yamamoto, M. (1983). Erythropoiesis in the Developing Rainbow Trout, Salmo gairdneri irideus: Histochemical and lmmunochemical Detection of Erythropoietic Organs. The Journal of Experimental Zoology 226: 409-417.

Jaillon, O., Aury, J., Brunet, F., Petit, J., Stange-Thomann, N., Mauceli, E., Bouneau, L., Fischer, C., Ozouf-Costaz, C., Bernot, A., Nicaud, S., Jaffe, D., Fisher, S., Lutfalla, G., Dossat, C., Segurens, B., Dasilva, C., Salanoubat, M., Levy, M., Boudet, N., et al. (2004). Genome duplication in the teleost fish Tetraodon nigroviridis reveals the early vertebrate protokaryotype. Nature 431: 946-957.

Janeway, C. A. and Medzhitov, R. (2002). Innate immune recognition. Annual Review of Immunology 20: 197-216. 
Joosten, P. H. M., Aviles-Trigueros, M., Sorgeloos, P. and Rombout, J. H. W. M. (1995). Oral vaccination of juvenile carp (cyprinus carpio) and gilthead seabream (Sparus Aurata) with bioencapsulated Vibrio anguillarum bacteria. Fish \& shellfish immunology 5: 289-299.

Jósefsson, S. and Tatner, M. F. (1993). Histogenesis of the lymphoid organs in sea bream (Sparus aurata L.). Fish \& Shellfish Immunology 3: 35-49.

Kaattari, S., Evans, D. and Klemer, J. (1998). Varied redox forms of teleost IgM: an alternative to isotypic diversity? Immunological Reviews 166: 133-142.

Kanlis, G., Suzuki, Y., Tauchi, M., Numata, T., Shirojo, Y. and Kawano, K. (1995). Immunoglobulin concentration and specific antibody activity in oocytes and eggs of immunized red sea bream. Fisheries Science 61: 791-795.

Kato, K., Ishimaru, K., Sawada, Y., Mutsuro, J., Miyashita, S., Murata, O. and Kumai, H. (2004). Ontogeny of digestive and immune system organs of larval and juvenile kelp grouper Epinephelus bruneus reared in the laboratory. Fisheries Science 70: 1061-1069.

Kentouri, M., Leon, L., Tort, L. and Divanach, P. (1994). Experimental methodology in aquaculture: Modification of the feeding rate of the gilthead sea bream (Sparus aurata) at a self-feeder after weighing. Aquaculture 119: 191-200.

Kimura, Y., Madhavan, M., Call, M. K., Santiago, W., Tsonis, P. A. and Lambris, J. D. (2003). Expression of complement 3 and complement 5 in newt limb and lens regeneration. Journal of Immunology 170: 2331-2339.

Kjørsvik, E., Pittman, K. and Pavlov, D. (2004). From fertilization to the end of metamorphosis-functional development. Culture of cold-water marine fish. Moksness, E., Kjørsvik, E. and Olsen, Y. Oxford, Blackwell Publishing 204-269.

Kondera, E. (2010). Haematopoiesis in the head kidney of common carp (Cyprinus carpio L.): a morphological study. Fish physiology and biochemistry.

Koumans-Van Diepen, J. C. E., Taverne-Thiele, J. J., Van Rens, B. T. T. M. and Rombout, J. H. W. M. (1994). Immunocytochemical and flow cytometric analysis of B-cells and plasma cells in carp (Cyprinus carpio L.): an ontogenetic study. Fish \& shellfish immunology 4: 1928. 
Kuroda, N., Naruse, K., Shima, A., Nonaka, M., Sasaki, M. and Nonaka, M. (2000). Molecular cloning and linkage analysis of complement C3 and C4 genes of the Japanese medaka fish. Immunogenetics 51: 117-128.

Lam, S., Cahu, C. L., Gong, Z., Lam, T. J. and Sin, Y. M. (2004). Development and maturation of the immune system in zebrafish, Danio rerio: a gene expression profiling, in situ hybridization and immunological study. Developmental \& Comparative Immunology 28(1): 9-28.

Lambert, J. G. D., Bosman, G. I. C. G. M., Van Den Hurk, R. and Van Oordt, P. G. W. J. (1978). Annual cycle of plasma estradiol-17b in the female trout Salmo gairdneri. Annales de Biollogie Animale Biochimie Biophysique 18: 923-927.

Lange, S., Bambir, S., Dodds, A. W. and Magnadottir, B. (2004a). An immunohistochemical study on complement component C3 in juvenile Atlantic halibut (Hippoglossus hippoglossus L.). Developmental and comparative immunology 28(6): 593-601.

Lange, S., Bambir, S., Dodds, A. W. and Magnadottir, B. (2004b). The ontogeny of complement component C3 in Atlantic cod (Gadus morhua L.)—an immunohistochemical study. Fish \& shellfish immunology 16: 359-367.

Li, J., Barreda, D. R., Zhang, Y. A., Boshra, H., Gelman, A. E., Lapatra, S., Tort, L. and Sunyer, J. O. (2006). B lymphocytes from early vertebrates have potent phagocytic and microbicidal abilities. Nature Immunology 7: 1116-1124.

Lieschke, G. J., Oates, A. C., Crowhurst, M. O., Ward, A. C. and Layton, J. E. (2001). Morphologic and functional characterization of granulocytes and macrophages in embryonic and adult zebrafish. Blood 98(10): 3087-3096.

Liu, Y., Zhang, S., Jiang, G., Yang, D., Lian, J. and Yang, Y. (2004). The development of the lymphoid organs of flounder, Paralichthys olivaceus, from hatching to 13 months. Fish \& shellfish immunology 16(5): 621-632.

Lobb, C. J. and Clem, L. W. (1981). Phylogeny of immunoglobulin structure and function X. Humoral immunoglobulin of the sheepshead, Archosargus probatocephalus. Developmental \& Comparative Immunology 5: 272-282. 
Lobb, C. J. and Clem, W. (1983). Distinctive subpopulations of catfish serum antibody and immunoglobulins. Molecular immunology 20: 811-818.

Lopez-Ruiz, A., Esteban, M. A. and Meseguer, J. (1992). Blood Cells of the Gilthead Seabream (Sparus aurata L.): Light and Electron Microscopic Studies. The anatomical record 234: 161-171.

Løvoll, M., Johnsen, H., Boshra, H., Bogwald, J., Sunyer, J. O. and Dalmo, R. A. (2007). The ontogeny and extrahepatic expression of complement factor C3 in Atlantic salmon (Salmo salar). Fish \& shellfish immunology 23(3): 542-552.

Løvoll, M., Kilvik, T., Boshra, H., Bogwald, J., Sunyer, J. O. and Dalmo, R. A. (2006). Maternal transfer of complement components C3-1, C3-3, C3-4, C4, C5, C7, Bf, and Df to offspring in rainbow trout (Oncorhynchus mykiss). Immunogenetics 58: 168-179.

Magnadottir, B. (2006). Innate immunity of fish (overview). Fish \& shellfish immunology 20(2): 137-151.

Magnadottir, B., Lange, S., Gudmundsdottir, S., Bogwald, J. and Dalmo, R. A. (2005). Ontogeny of humoral immune parameters in fish. Fish \& shellfish immunology 19(5): 429439.

Marchanlonis, J. J., Jensen, I. and Schulter, S. F. (2002). Structural, antigenic and evolutionary analyses of immunoglobulins and $\mathrm{T}$ cell receptors. Journal Of Molecular Recognition 15: 260-271.

Margulies, D. H. and McCluskey, J. (2003). The major histocompatibility complex and its encoded proteins. Fundamental Immunology. Paul, W. E. New York, Lippincott-Raven: 571612.

Martensson, I., Almqvist, N., Grimsholm, O. and Bernardi, A. I. (2010). The pre-B cell receptor checkpoint. FEBS Letters 584(12): 2572-2579.

Mastellos, D. and Lambris, J. D. (2002). Complement: more than a 'guard' against invading pathogens? Trends in Immunology 23: 485-491. 
Mathias, J. R., Dodd, M. E., Walters, K. B., Yoo, S. K., Ranheim, E. A. and Huttenlocher, A. (2009). Characterization of zebrafish larval inflammatory macrophages. Developmental and comparative immunology 33(11): 1212-1217.

Mazur, C. F. and Iwama, G. K. (1993). Handling and crowding stress reduces the number of plaque-forming cells in Atlantic salmon. Journal of Aquatic Animal Health 5: 98-101.

Meijer, A. H., Van der Sar, A. M., Cunha, C., Lamers, G. E., Laplante, M. A., Kikuta, H., Bitter, W., Becker, T. S. and Spaink, H. P. (2008). Identification and real-time imaging of a myc-expressing neutrophil population involved in inflammation and mycobacterial granuloma formation in zebrafish. Developmental \& Comparative Immunology 32(1): 36-49.

Meseguer, J., Lopez-Ruiz, A. and Garcia Ayala, A. (1995). Reticulo-endothelial stroma of the head-kidney from the seawater teleost gilthead seabream (Sparus aurata L): an ultrastructural and cytochemical study. Anatomical Record 241: 303-309.

Mesenguer, J., Esteban, M. A. and Agullerio, B. (1991). Stromal cells, macrophages and lymphoid cells in the head kidney of sea bass Dicentrarchus labrax L. Archives of Histology and Cytology 54: 229-309.

Morgan, B. P., Marchbank, K. J., Longhi, M. P., Harris, C. L. and Gallimore, A. M. (2005). Complement: central to innate immunity and bridging to adaptive responses. Immunological Letters 97: 171-179.

Morgan, J. A. W., Pottinger, T. G. and Rippon, P. (1993). Evaluation of flow cytometry as a method for quantification of circulating blood cell populations in salmonid fish. Journal of Fish Biology 42(1): 131-141.

Morrison, M. (1993). Histology of the Atlantic cod, Gadus morhua: an atlas. Part 4. Eleutheroembryo and larva. Ottawa, National Research Council of Canada, Department of Fisheries and Oceans: 496.

Morrison, R. N. and Nowak, B. F. (2002). The Antibody Response of Teleost Fish. Seminars in Avian and Exotic Pet Medicine 11(1): 46-54.

Mosser, D. M. and Edwards, J. P. (2008). Exploring the full spectrum of macrophage activation. Nature Reviews Immunology 8(12): 958-969. 
Moulana, M., Evenhuis, J., Albertino, M., Godwin, U., Kountikov, E. I., Stuge, T. B., Wilson, M., Bengten, E., Miller, N. W. and McConnell, T. J. (2008). Characterization of antichannel catfish MHC class IIbeta monoclonal antibodies. Veterinary immunology and immunopathology 126(1-2): 120-130.

Mulero, I., Chaves-Pozo, E., Garcia-Alcazar, A., Meseguer, J., Mulero, V. and Garcia Ayala, A. (2007a). Distribution of the professional phagocytic granulocytes of the bony fish gilthead seabream (Sparus aurata L.) during the ontogeny of lymphomyeloid organs and pathogen entry sites. Developmental and comparative immunology 31(10): 1024-1033.

Mulero, I., Garciaayala, A., Meseguer, J. and Mulero, V. (2007b). Maternal transfer of immunity and ontogeny of autologous immunocompetence of fish: A minireview. Aquaculture 268(1-4): 244-250.

Murray, C. K. and Fletcher, T. C. (1976). The immunohistochemical localization of lysozyme in plaice (Pleuronectes platessa) tissue. Journal of Fish Biology 9: 329-334.

Nakao, M., Mutsuro, J., Obo, R., Fujiki, K., Nonaka, M. and Yano, T. (2000). Molecular cloning and protein analysis of divergent forms of the complement component C3 from a bony fish, the common carp (Cyprinus carpio): presence of variants lacking the catalytic histidine. European Journal of Immunology 30: 858-866.

Nonaka, M. and Smith, S. L. (2000). Complement system of bony and cartilaginous fish. Fish \& shellfish immunology 10(3): 215-228.

Øvergård, A. C., Fiksdal, I. U., Nerland, A. H. and Patel, S. (2011). Expression of T-cell markers during Atlantic halibut (Hippoglossus hippoglossus L.) ontogenesis. Developmental and comparative immunology 35(2): 203-213.

Padros, F. and Crespo, S. (1996). Ontogeny of the lymphoid organs in the turbot Scophthalmus maximus: a light and electron microscope study. Aquaculture 144: 1-16.

Parichy, D. M., Ransom, D. G., Paw, B., Zon, L. I. and Johnson, S. L. (2000). An orthologue of the kit related gene fms is required for development of neural crest-derived xanthophores and a subpopulation of adult melanocytes in the zebrafish, Danio rerio. Development 127(14): 3031-3044. 
Passantino, L., Tafaro, A., Altamura, M., Arena, R., Passantino, G. F. and Jirillo, E. (2002). Morphologycal and cytochemical characterization and phagocytic activities of head kidney macrophages from rainbow trout (Salmo gairdneri Richardson). Immunopharmacology and Immunotoxicology 24(4): 679-691.

Patel, S., Sorhus, E., Fiksdal, I. U., Espedal, P. G., Bergh, O., Rodseth, O. M., Morton, H. C. and Nerland, A. H. (2009). Ontogeny of lymphoid organs and development of IgM-bearing cells in Atlantic halibut (Hippoglossus hippoglossus L.). Fish \& shellfish immunology 26(3): 385-395.

Person-Le Ruyet, J., Mahe, K., Le Bayon, N. and Le Delliu, H. (2004). Effects of temperature on growth and metabolism in a Mediterranean population of European sea bass, Dicentrarchus labrax. Aquaculture 237: 269-280.

Petrie-Hanson, L. and Ainsworth, A. J. (1999). Humoral immune responses of channel catfish (Ictalurus punctatus) fry and fingerlings exposed to Edwardsiella ictaluri. Fish \& shellfish immunology 9: 579-589.

Petrie-Hanson, L. and Ainsworth, A. J. (2001). Ontogeny of channel catfish lymphoid organs. Veterinary immunology and immunopathology 81: 113-127.

Picchietti, S., Abelli, L., Buonocore, F., Randelli, E., Fausto, A. M., Scapigliati, G. and Mazzini, M. (2006). Immunoglobulin protein and gene transcripts in sea bream (Sparus aurata L.) oocytes. Fish \& shellfish immunology 20(3): 398-404.

Picchietti, S., Guerra, L., Buonocore, F., Randelli, E., Fausto, A. M. and Abelli, L. (2009). Lymphocyte differentiation in sea bass thymus: CD4 and CD8-alpha gene expression studies. Fish \& shellfish immunology 27(1): 50-56.

Picchietti, S., Taddei, A. R., Scapigliati, G., Buonocore, F., Fausto, A. M., Romano, N., Mazzini, M., Mastrolia, L. and Abelli, L. (2004). Immunoglobulin protein and gene transcripts in ovarian follicles throughout oogenesis in the teleost Dicentrarchus labrax. Cell and tissue research 315: 259-270.

Picchitti, S., Scapigliati, G., Fanelli, M., Barbato, F., Canese, S., Mastrolla, L., Mazzini, M. and Abelli, L. (2001). Sex-related variations of serum immunoglobulins during reproduction 
in gilthead sea bream and evidence for a transfer from the female to the eggs. Journal of Fish Biology 59(6): 1503-1511.

Pickering, A. D. and Stewart, A. (1984). Acclimation of the interrenal tissue of the brown trout Salmo trutta L. to chronic crowding stress. Journal of Fish Biology 24: 731-740.

Press, С. M. and Evensen, Ø. (1999). The morphology of the immune system in teleost fishes. Fish \& shellfish immunology 9: 309-318.

Press, C. M., Evensen, O., Reitan, L. J. and Landsverk, T. (1996). Retention of furunculosis vaccine components in Atlantic salmon Salmo salar L., following different routes of administration. Journal of Fish Disease 19: 215-224.

Press, M., Dannevig, B. H. and Landsverk, T. (1994). Immune and enzyme histochemical phenotypes of lymphoid and nonlymphoid cells within the spleen and head kidney of Atlantic salmon (Salmo salar L.). Fish \& shellfish immunology 4: 79-93.

Razquin, B. E., Castillo, A., Lopez-Fierro, F., Alvarez, A., Zapata, A. and Villena, A. J. (1990). Ontogeny of IgM-producing cells in the lymphoid organs of rainbow trout, Salmo gairdneri Richardson: an immuno- and enzyme-histochemical study. Journal of Fish Biology 26(2): 150-173.

Roberts, C. D. (1996). Hapuka and bass: the mystery of the missing juveniles. Seafood New Zealand 4(1): 17-21.

Roca, F. J., Sepulcre, M. A., Lopez-Castejon, G., Meseguer, J. and Mulero, V. (2006). The colony-stimulating factor-1 receptor is a specific marker of macrophages from the bony fish gilthead seabream. Molecular immunology 43(9): 1418-1423.

Rodrigues, P. N. S., Hermsen, T. T., Rombout, J. H. W. M., Egberts, E. and Stet, R. J. M. (1995). Detection of MHC class II transcripts in lymphoid tissues of the common carp (Cyprinus carpio L.). Developmental \& Comparative Immunology 19(6): 483-496.

Rombout, J. H., Abelli, L., Picchietti, S., Scapigliati, G. and Kiron, V. (2010). Teleost intestinal immunology. Fish \& shellfish immunology. 
Rombout, J. H., Huttenhuis, H. B., Picchietti, S. and Scapigliati, G. (2005). Phylogeny and ontogeny of fish leucocytes. Fish \& shellfish immunology 19(5): 441-455.

Rombout, J. H., Taverne-Thiele, A. J. and Villena, M. I. (1993). The gut associated lymphoid tissue (GALT) of carp (Cyprinus carpio L.): an immunocytochemical analysis. Developmental \& Comparative Immunology 17: 55-66.

Rombout, J. H. W. M., Blok, L. J., Lamers, C. H. J. and Egberts, E. (1986). Immunization of carp (Cyprinus carpio) with a Vibrio anguillarum bacterin: indications for a common mucosal immune system. Developmental \& Comparative Immunology 10: 341-351.

Rotllant, J., Pavlidis, M., Kentouri, M., Abad, M. E. and Tort, L. (1997). Non-specific immune responses in the red porgy Pagrus pagrus after crowding stress. Aquaculture 156: 279-290.

Ryo, S., Wijdeven, R. H., Tyagi, A., Hermsen, T., Kono, T., Karunasagar, I., Rombout, J. H., Sakai, M., Verburg-van Kemenade, B. M. and Savan, R. (2010). Common carp have two subclasses of bonyfish specific antibody IgZ showing differential expression in response to infection. Developmental and comparative immunology 34(11): 1183-1190.

Salinas, I., Zhang, Y. A. and Sunyer, J. O. (2011). Mucosal immunoglobulins and B cells of Teleost fish. Developmental \& Comparative Immunology: In press.

Santamaria, C. A., Marin de Mateo, M., Traveset, R., Sala, R., Grau, A., Pastor, E., Sarasquete, C. and Crespo, S. (2004). Larval organogenesis in common dentex, Dentex dentex L. (Sparidae); Histological and histochemical aspects. Aquaculture 237: 207-228.

Sarasquete, C., Polo, A. and Yufera, M. (1995). Histology and histochemistry of the development of the digestive system of larval gilthead seabream, Sparus aurata L. Aquaculture 130: 79-92.

Savan, R., Aman, A., Sato, K., Yamaguchi, R. and Sakai, M. (2005). Discovery of a new class of immunoglobulin heavy chain from fugu. European Journal of Immunology 35(11): 3320-3331.

Scapigliati, G., Romano, N., Buonocore, F., Picchietti, S., Baldassini, M. R., Prugnoli, D., Galice, A., Meloni, S., Secombes, C. J., Mazzini, M. and Abelli, L. (2002). The immune 
system of sea bass, Dicentrarchus labrax, reared in aquaculture. Developmental \& Comparative Immunology 26: 151-160.

Schirone, R. C. and Gross, L. (1968). Effect of Temperature on Early Embryological Development of the Zebra Fish, Brachydmio rerio. Journal of Experimental Zoology 169(1): 43-52.

Schroder, H. W. and Cavacini, L. (2010). Structure and function of immunoglobulins. Clinical Immunology 125(2): 41-52.

Schrøder, M. B., Villena, A. J. and Jorgensen, T. O. (1998). Ontogeny of lymphoid organs and immunoglobulin producing cells in the Atlantic cod (Gadus morhua L.). Developmental \& Comparative Immunology 22(5/6): 507-517.

Secombes, C. J. (1996). The nonspecific immune system: cellular defences. The Fish Immune System: Organism, Pathogen and Environment Iwama, G. and Nakanishi, I. G. San Diego, Academic Press: 63-103.

Seppola, M., Johnsen, H., Mennen, S., Myrnes, B. and Tveiten, H. (2009). Maternal transfer and transcriptional onset of immune genes during ontogenesis in Atlantic cod. Developmental and comparative immunology 33(11): 1205-1211.

Sepulcre, M. P., Pelegrin, P., Mulero, V. and Meseguer, J. (2002). Characterisation of gilthead seabream acidophilic granulocytes by a monoclonal antibody unequivocally points to their involvement in fish phagocytic response. Cell and tissue research 308(1): 97-102.

Shigdar, S., Harford, A. and Ward, A. C. (2009). Cytochemical characterisation of the leucocytes and thrombocytes from Murray cod (Maccullochella peelii peelii, Mitchell). Fish \& shellfish immunology 26(5): 731-736.

Sin, Y. M., Ling, K. H. and Lam, T. J. (1994). Passive transfer of protective immunity against ichthyophthiriasis from vaccinated mother to fry in tilapias, Oreochromis aureus. Aquaculture 120: 229-237.

Slierendecht, W. J., Jesen, L. B., Horlyck, V. and Koch, C. (1999). Genetic polymorphism of complement component C3 in rainbow trout (Oncorhynchus mykiss) and resistance to viral haemorrhagic septicaemia. Fish \& shellfish immunology 3: 199-206. 
Sumpter, J. P. (1997). Environmental control of fish reproduction: a different perspective. Fish physiology and biochemistry 17: 25-31.

Sunyer, J. O. and Lambris, J. D. (1998). Evolution and diversity of the complement system in poikilothermic vertebrates. Immunological Reviews 166: 39-57.

Sunyer, J. O. and Tort, L. (1995). Natural haemolytic and bactericidal activities of sea bream Sparus aurata serum are effected by the Alternative Complement Pathway. Veterinary immunology and immunopathology 45: 333-345.

Sunyer, J. O., Tort, L. and Lambris, J. D. (1997). Diversity of the third form of complement, C3, in fish: functional characterization of five forms of C3 in the diploid fish Sparus aurata. Biochemical Journal 326: 877-881.

Sunyer, J. O., Zardakis, I. K., Sahu, A. and Lambris, J. D. (1996). Multiple forms of complement C3 in trout that differ in binding to complement activators. Biochemical Journal 93: 8546-8551.

Swain, P., Dash, S., Sahoo, P. K., Routray, P., Sahoo, S. K., Gupta, S. D., Meher, P. K. and Sarangi, N. (2007). Non specific immune parameters of brood Indian major carp, Labeo rohita and their seasonal variations. Fish \& shellfish immunology 22: 38-43.

Swain, P. and Nayak, S. K. (2009). Role of maternally derived immunity in fish. Fish \& shellfish immunology 27(2): 89-99.

Tadiso, T. M., Lie, K. K. and Hordvik, I. (2011). Molecular cloning of IgT from Atlantic salmon, and analysis of the relative expression of tau, mu, and delta in different tissues. Veterinary immunology and immunopathology 139: 17-26.

Takemura, A. and Takano, K. (1997). Transfer of maternally-derived immunoglobulin (IgM) to larvae in tilapia, Oreochromis mossambicus. Fish \& shellfish immunology 7: 355-363.

Tian, J., Sun, B., Luo, Y., Zhang, Y. and Nie, P. (2009a). Distribution of IgM, IgD and IgZ in mandarin fish, Siniperca chuatsi lymphoid tissues and their transcriptional changes after Flavobacterium columnare stimulation. Aquaculture 288(1-2): 14-21. 
Tian, J. Y., Xie, H. X., Zhang, Y. A., Xu, Z., Yao, W. J. and Nie, P. (2009b). Ontogeny of IgM-producing cells in the mandarin fish Siniperca chuatsi identified by in situ hybridisation. Veterinary immunology and immunopathology 132(2-4): 146-152.

Tort, L., Balasch, J. C. and Mackenzie, S. (2003). Fish immune system. A crossroads between innate and adaptive responses. Immunologia 22(3): 277-286.

Trede, N. S., Langenau, D. M., Traver, D., Look, A. T. and Zon, L. I. (2004). The use of zebrafish to understand immunity. Immunology 20: 367-379.

Van der Salma, A. L., Martinez, M., Flika, G. and Bonga, S. E. W. (2004). Effects of husbandry conditions on the skin colour and stress response of red porgy, Pagrus pagrus. Aquaculture 241: 371-386.

Venkatesh, B., Kirkness, E. F., Loh, Y., Halpern, A. L., Lee, A. P., Johnson, J., Dandona, N., Viswanathan, L. D., Tay, A., Venter, C., Strausberg, R. L. and Brenner, S. (2007). Survey Sequencing and Comparative Analysis of the Elephant Shark (Callorhinchus milii) Genome. PLoS Biology 5(4): 932-944.

Wakefield, C. B., Newman, S. J. and Molony, B. W. (2010). Age-based demography and reproduction of hapuka, Polyprion oxygeneios, from the south coast of Western Australia: implications for management. Journal of Marine Science 67: 1164-1174.

Wang, Z. and Zhang, S. (2010). The role of lysozyme and complement in the antibacterial activity of zebrafish (Danio rerio) egg cytosol. Fish \& shellfish immunology 29(5): 773-777.

Wang, Z., Zhang, S., Wang, G. and An, Y. (2008). Complement activity in the egg cytosol of zebrafish Danio rerio: evidence for the defense role of maternal complement components. Plos One 3(1): 1463.

Whyte, S. K. (2007). The innate immune response of finfish--a review of current knowledge. Fish \& shellfish immunology 23(6): 1127-1151.

Willett, C. E., Cortes, A., Zuasti, A. and Zapata, A. G. (1999). Early Hematopoiesis and Developing Lymphoid Organs in the Zebrafish. Developmental Dynamics 214: 323-336. 
Williams, T. D. (1994). Intraspecific variation in egg size and egg composition: effects on offspring fitness. Biological Reviews 68: 35-59.

Wilson, M. R. and Warr, G. W. (1992). Fish immunoglobulins and the genes that encode them. Annual Review of Fish Disease 2: 201-221.

Yano, T. (1996). The nonspecific immune system: Humoral defence. The Fish Immune System: Organism, Pathogen and Environment. Iwama, G. and Nakanishi, T. San Diego, Academic Press: 105-157.

Yousif, A. N., Albright, L. J. and Evelyn, T. P. T. (1991). Occurrence of lysozyme in the eggs of coho salmon Oncorhynchus kisutch. Diseases of Aquatic Organisms 10: 45-49.

Yousif, A. N., Albright, L. J. and Evelyn, T. P. T. (1994). In vitro evidence for the antibacterial role of lysozyme in salmonid eggs. Diseases of Aquatic Organisms 19: 15-19.

Yousif, A. N., Albright, L. J. and Evelyn, T. P. T. (1995). Immunological evidence for the presence of an IgM-like immunoglobulin in the eggs of coho salmon Oncorhynchus kisutch. Diseases of Aquatic Organisms 23: 109-114.

Yufera, M. and Darias, M. (2007). The onset of exogenous feeding in marine fish larvae. Aquaculture 268(1-4): 53-63.

Yuko, O. and Flajnik, M. (2006). IgD, like IgM, is a primordial immunoglobulin class perpetuated in most jawed vertebrates. PNAS 103(28): 10723-10728.

Zambonio-Infante, J. L., Gisbert, E., Sarasquete, C., Navarro, I., Gutierrez, J. and Cahu, C. L. (2008). Feeding and digestive functions of fishes

Zapata, A. (1979). Ultrastructural study of the teleost fish kidney. Developmental \& Comparative Immunology 3: 55-65.

Zapata, A., Diez, B., Cejalvo, T., Gutierrez-de Frias, C. and Cortes, A. (2006). Ontogeny of the immune system of fish. Fish \& shellfish immunology 20(2): 126-136.

Zapata, A. G., Torroba, M., Varas, A. and Jimenez, E. (1997). Immunity in fish larvae. Developments in Biological Standardization 90: 23-32. 
Zhang, Y. A., Salinas, I., Li, J., Parra, D., Bjork, S. and Xu, Z. (2010). IgT, a primitive immunoglobulin class specialized in mucosal immunity. Nature Immunology 11: 827-835.

Zhang, Y. A., Salinas, I. and Oriol Sunyer, J. (2011). Recent findings on the structure and function of teleost IgT. Fish \& shellfish immunology. 